\title{
Economic Effects of Hypothetical Reductions in Tree Growth in the Northeastern and Southeastern United States
}

\author{
J. M. Callaway \\ R. F. Darwin \\ R. J. Nesse
}

August 1986

Prepared for

the U.S. Environmental Protection Agency

under a Related Services Agreement

with the U.S. Department of Energy

Contract DE-AC06-76RLO 1830

Pacific Northwest Laboratory

Operated for the U.S. Department of Energy

by Battelle Memorial Institute 
Although the research described in this article has been funded wholly or in part by the United States Environmental Protection Agency (EPA), it has not been subjected to EPA review and therefore does not necessarily reflect the views of EPA and no official endorsement should be inferred.

\title{
DISCLAIMER
}

This report was prepared as an account of work sponsored by an agency of the United States Government. Neither the United States Government nor any agency thereof, nor any of their employees, makes any warranty, express or implied, or assumes any legal liability or responsibility for the accuracy, completeness, or usefulness of any information, apparatus, product, or process disclosed, or represents that its use would not infringe privately owned rights. Reference herein to any specific commercial product, process, or service by trade name, trademark, manufacturer, or otherwise, does not necessarily constitute or imply its endorsement, recommendation, or favoring by the United States Government or any agency thereof. The views and opinions of authors expressed herein do not necessarily state or reflect those of the United States Government or any agency thereof.

\author{
PACIFIC NORTHWEST LABORATORY \\ operated by \\ BATTELLE \\ for the \\ UNITED STATES DEPARTMENT OF ENERGY \\ under Contract DE-AC06-76RLO 1830
}

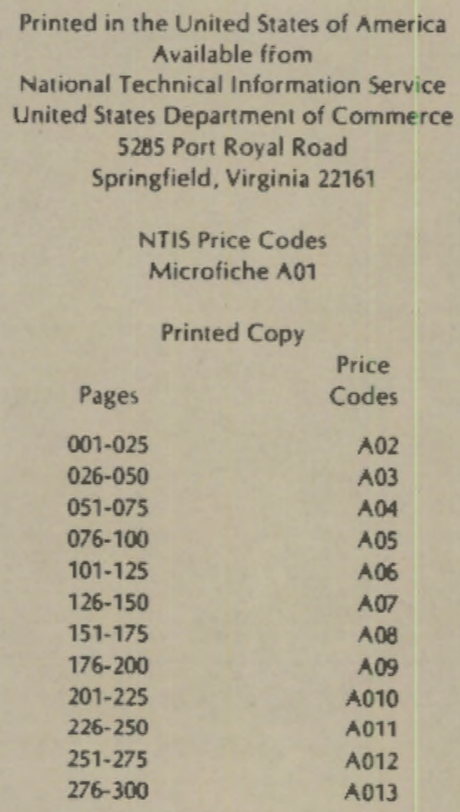


ECONOMIC EFFECTS OF HYPOTHETICAL REDUCTIONS IN TREE GROWTH IN THE NORTHEASTERN AND SOUTHEASTERN UNITEO STATES
J. M. Call away
R. F. Darwin
R. J. Nesse

August 1986

Prepared for the U.S. Environmental Protection Agency under a Related Services Agreement with the U.S. Department of Energy under Contract DE-ACD6-76RL0 1830 


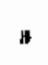


INTRODUCTION

This research was conducted by the Pacific Northwest Laboratory (PNL) for the Office of Research and Development (ORD) within the U.S. Environmental Protection Agency (EPA) as a part of the National Acid Precipitation Assessment Program (NAPAP). It was undertaken primarily to assist NAPAP in developing and implementing a capability to assess the economic damages caused by acid deposition and other pollutants and the economic benefits of controlling the pollutants. Specifically, the objectives of this research are:

- To review and critically evaluate economic methods and models for assessing the economic impacts of acid deposition-induced changes in forest productivity

- To scope and assess the sensitivity of the potential economic impacts of changes in forest productivity

- To provide information and recommendations that will enhance Federal efforts to assess the economic impacts of acid deposition and to determine the benefits of alternative acid deposition mitigation and control strategies.

\section{METHODS REVIEW}

A conceptual framework was developed for understanding and valuing the economic impacts of acid deposition-induced changes in forest productivity in markets for hardwood and softwood stumpage and the products made from this stumpage. Although the framework focuses on valuing the economic impacts of acid deposition, it could be used for any factor that causes changes in forest productivity. The scope of potential economic impacts due to changes in forest productivity was characterized. Based on this analysis, key methodological features were identified--features which would contribute substantially to providing accurate estimates of the economic damages caused by changes in forest productivity. These features served as the basis for identifying and critically evaluating existing models. The models selected to estimate the economic 
effects of changes in forest productivity were the Timber Assessment Market Models (TAMM), which are physically linked to the inventory projection model, Timber Resource Assessment System (TRAS). Both TAMM and TRAS are used by the U.S. Forest Service for their assessments of timber inventories, prices and harvests.

TAMM consists of two models, TAMMSOFT and TAMMHARD, that are economic models of the softwood and hardwood stumpage and primary forest product markets in the United States. Both models provide regional estimates of market prices, production and consumption, for lumber and/or plywood. Product and stumpage markets in each region are linked together. The stumpage supply in the modeis reflect the harvest response of private owners to changes in stumpage prices and inventories. Hardwood and softwood inventory volumes are supplied to both models directly from TRAS. The projected harvest levels are used in TRAS to update the softwood inventories in each region. The outputs of the market models include information about the size and distribution of well-accepted measures of economic welfare (consumers' and producers' surpluses) in regiona? stumpage and product markets.

\section{ANALYSIS OF ECONOMIC IMPACTS}

No empirical relationships between variations in wet and dry deposition and recently-observed episodes of forest dieback or decline have been established. Therefore, the quantitative analysis contained in this report makes no claim to estimate the economic effects of acid deposition. It is designed to show, instead, that the models could be usen for acid deposition assessments and the range of economic effects that could occur due to a wide range of slowdowns in tree growth, regardless of the source of those slowdowns.

The range of economic impacts considered in this report include:

1) changes in regional hardwood and softwood timber inventories; 2) changes in prices, production and consumption in regional markets for hardwood and softwood stumpage, lumber and plywood; and 3 ) estimates of regional economic damages. For brevity, only the analysis of the economic damages due to hypothetical reductions in tree growth is presented in this sumary. 
This analysis was performed as follows. First, base case economic values (economic surplus) in all markets was established by running the TAMM-TRAS system of models for the period 1976-2030. Total economic surplus in the U.S. forest sector was calculated annually from 1985 to 2030 as the sum of the economic surpluses of timber owners, plywood and lumber producers and consumers of lumber and plywood in all regions, plus the market value of the timber inventory remaining in 2030. Next, the radial growth rates in TRAS used to calculate the average annual grown increments for both hardwoods and softwoods were reduced simultaneously in the Northeast and Southeast by 10,15 and $20 \%$ to reflect hypothetical decreases in tree growth. The system of models was then rerun using this information and the new economic surplus values were recorded and aggregated. Finally, the annual value of the economic damages for each hypothetical growth reduction was calculated as the difference between the total surplus values, with and without the growth change. The present value of these damages for the period 1985-2030 was calculated and annualized (i.e., levelized) using a $10 \%$ discount rate.

Table ES.1 presents preliminary estimates for the present (discounted) value of total surplus changes in selected years for the three reduced growth cases. This table also shows the estimated present value of damages accumulated over the period 1985-2030 along with the corresponding annualized value of damages. The next to last row of Table ES.l gives the cumulative present value of the damages between 1985 and 2030 which ranged from $\$ 3.4$ to a little more than $\$ 5.0$ billion depending on the severity of the hypothetical growth reduction. The corresponding annualized values for the three cases are roughly $\$ 342, \$ 447$ and $\$ 510 \mathrm{million}$.

The distributional impacts of the assumed growth reductions are difficult to present in compact, tabular form. In general, timber owners as a group benefit from radial growth reductions, while consumers (and to a lesser extent producers) of primary wood products experience welfare losses due to the higher prices of stumpage and wood products. However, timber owners in the Southeast suffer economic damages due to all growth slowdowns. In addition, producers in that region are hurt considerably more by these changes in growth than producers in the Northeast, who actually experience slight benefits. This 
TABLE ES.1. Commercjal Forests: Estimated Annual Changes in the Present Value ${ }^{(a)}$ of Economic Surplus Due to Hypothetical Reductions in Radial Growth for Selected Years (Millions of 1984 Dollars)

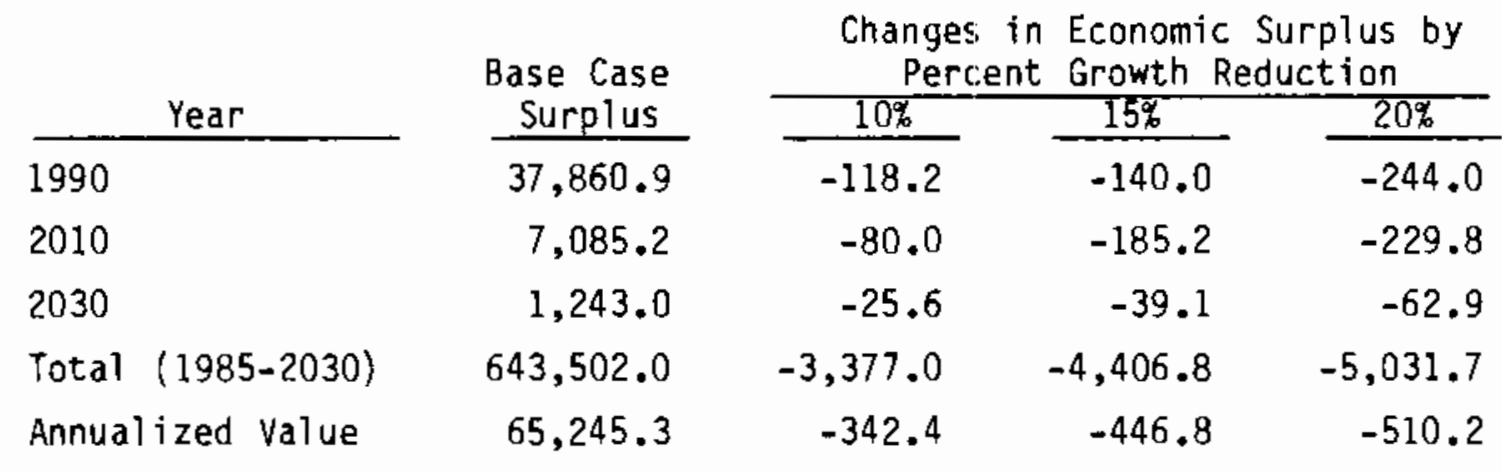

(a) Base year is 1985 ; discount rate is $10 \%$.

suggests a relative (but not absolute) improvement in the competitive position of the Northeast over the Southeast due to decreased tree growth in both regions. 


\section{CONTENTS}

EXECUTIVE SUMMARY $\ldots \ldots \ldots \ldots \ldots \ldots \ldots \ldots \ldots \ldots \ldots \ldots \ldots \ldots \ldots \ldots \ldots \ldots \ldots \ldots \ldots \ldots \ldots \ldots$

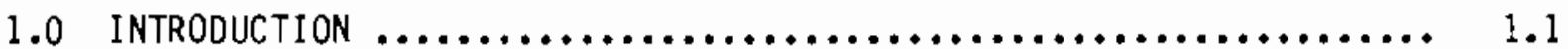

1.1 ACID DEPOSITION PHENOMENON $\ldots \ldots \ldots \ldots \ldots \ldots \ldots \ldots \ldots \ldots \ldots \ldots \ldots \ldots \ldots$

1.2 LEGISLATIVE AND ADMINISTRATIVE BACKGROUND $\ldots \ldots \ldots \ldots \ldots \ldots \ldots . . . . .$.

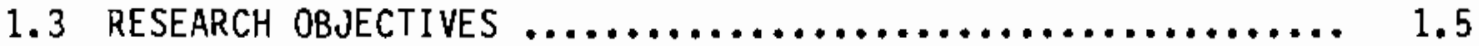

1.3.1 Organization of the Report ................... 1.5

2.0 CONCLUSIONS AND RECDMMENDATIONS $\ldots \ldots \ldots \ldots \ldots \ldots \ldots \ldots \ldots \ldots \ldots \ldots \ldots \ldots \ldots$

2.1 CONCLUSIONS $\ldots \ldots \ldots \ldots \ldots \ldots \ldots \ldots \ldots \ldots \ldots \ldots \ldots \ldots \ldots \ldots \ldots \ldots \ldots$

2.1.1 Effects of Acid Deposition on Forest

Productivity .............................. 2.1

2.1.2 Methods for Assessing the Economic Impacts

of Acid Deposition .......................... 2.2

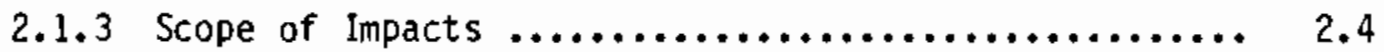

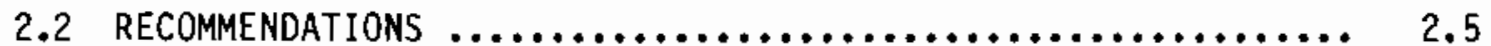

2.2.1 Methodology Improvements ................... 2.6

2.2 .2 Improved Simulations $\ldots \ldots \ldots \ldots \ldots \ldots \ldots \ldots \ldots \ldots \ldots \ldots . . \ldots \ldots$

3.0 THE ECONOMIC IMPACTS DF ACID DEPOSITION ON

COMMERCIAL TIMBER RESOURCES: AN OVERVIEW ................ 3.1

3.1 EVIDENCE OF GROWTH SLOWDOWNS IN THE EASTERN U.S. ......... 3.1

3.2 TRANSLATING ENVIRONMENTAL IMPACTS INTO ECONOMIC

DAMAGES: A CONCEPTUAL FRAMEWORK .................. 3.4

3.2 .1 Measuring Damages ......................... 3.4

3.2.2 Acid Deposition and the Economics of

Timber Management .......................... 3.8

3.2.3 Linkages to Other Markets and Regions ............ 3.15

3.3 IDENTIFICATION OF IMPORTANT METHODOLOGICAL FEATURES $\ldots \ldots \ldots . \quad 3.20$

4.0 ANALYSIS OF MARXET MODELS $\ldots \ldots \ldots \ldots \ldots \ldots \ldots \ldots \ldots \ldots \ldots \ldots \ldots \ldots \ldots \ldots \ldots \ldots$ 
4.1 OVERVIEW OF MaRKET MODELS $\ldots \ldots \ldots \ldots \ldots \ldots \ldots \ldots \ldots \ldots \ldots, 4.1$

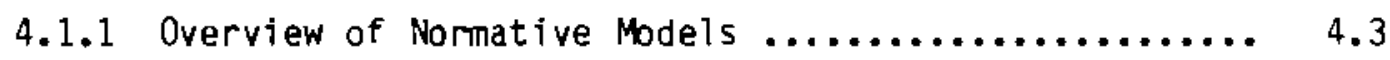

4.1.2 Overview of Econometric Models $\ldots \ldots \ldots \ldots \ldots \ldots \ldots .6 .6$

4.2 NORMATIVE MODELS $\ldots \ldots \ldots \ldots \ldots \ldots \ldots \ldots \ldots \ldots \ldots \ldots \ldots \ldots \ldots, 4.8$

4.2.1 Long-Run Timber Supply Projection Methodology ....... 4.10

4.2.2 Timber Resource Economic Estimation System ........ 4.13

4.2.3 Supply Potential Optimal Control Model ............ 4.16

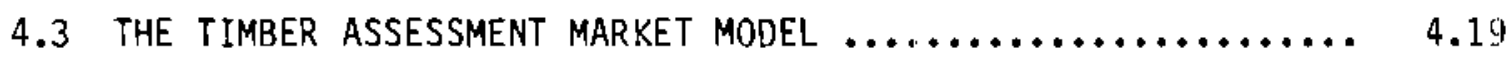

4.3.1 Model Overview $. . . \ldots \ldots \ldots \ldots \ldots \ldots \ldots \ldots \ldots \ldots \ldots, 4 . \ldots \ldots$

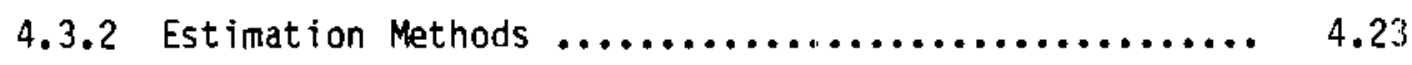

4.3.3 Model Structure $\ldots \ldots \ldots \ldots \ldots \ldots \ldots \ldots \ldots \ldots \ldots \ldots, 4.27$

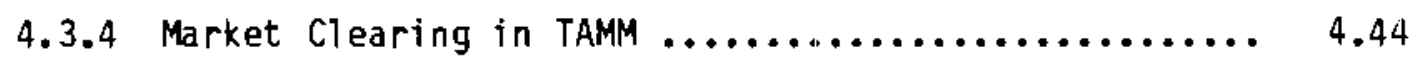

4.3.5 Model Interaction in TAMM $\ldots \ldots \ldots \ldots \ldots \ldots \ldots \ldots . . .6 .47$

4.3.6 Summary of Inputs and Outputs $\ldots \ldots \ldots \ldots \ldots \ldots \ldots . . .4 .48$

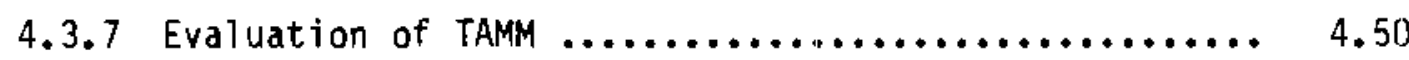

5.0 INVENTORY PROJECTION MODELS $\ldots \ldots \ldots \ldots \ldots \ldots \ldots \ldots \ldots \ldots \ldots \ldots, 5.1$

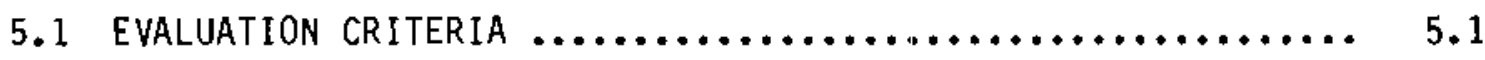

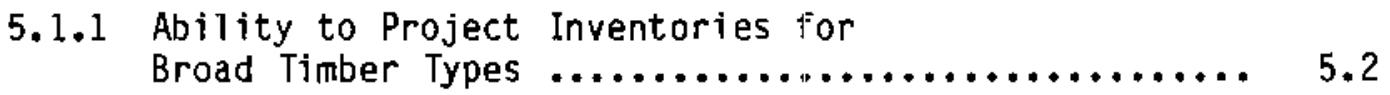

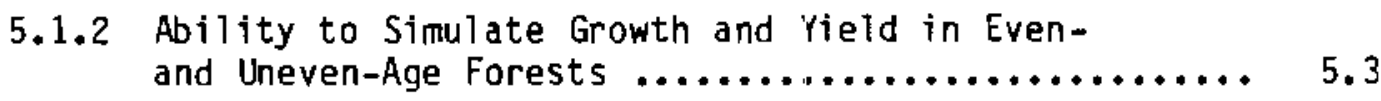

5.1.3 Ability to Simulate Management $\ldots \ldots \ldots \ldots \ldots \ldots \ldots . .6 .3$

5.1 .4 Ability to Perform Repeated Projections at
Reasonable Cost ............................... 5.4

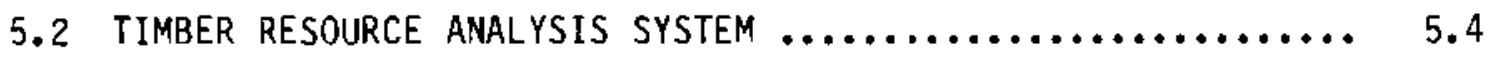

5.2.1 Application of Evaluation Criteria $\ldots \ldots \ldots \ldots \ldots \ldots .6 .8$

5.3 STANO AND TREE EVALUATION AND MOOELING SYSTEM $\ldots \ldots \ldots \ldots \ldots . . .1$. 
5.3.1 Application of Evaluation Criteria .............. 5.18

5.4 TIMBER RESOURCE INVENTORY MODEL $\ldots \ldots \ldots \ldots \ldots \ldots \ldots \ldots \ldots \ldots \ldots \ldots \ldots \ldots \ldots$

5.4.1 Application of Criteria $\ldots \ldots \ldots \ldots \ldots \ldots \ldots \ldots \ldots \ldots, 5.27$

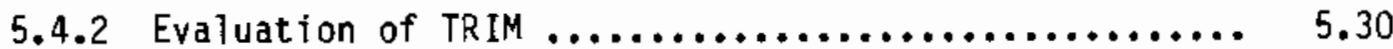

6.0 SIMULATIONS $\ldots \ldots \ldots \ldots \ldots \ldots \ldots \ldots \ldots \ldots \ldots \ldots \ldots \ldots \ldots \ldots \ldots, 6.1$

6.1 THE BASE CASE $\ldots \ldots \ldots \ldots \ldots \ldots \ldots \ldots \ldots \ldots \ldots \ldots \ldots \ldots \ldots \ldots, 6.1$

6.2 REDUCED GROWTH CASES $\ldots \ldots \ldots \ldots \ldots \ldots \ldots \ldots \ldots \ldots \ldots \ldots \ldots \ldots, 6.4$

6.3 alternative, base Case scenarios $\ldots \ldots \ldots \ldots \ldots \ldots \ldots \ldots \ldots .6 .10$

6.3 .1 Low Housing Starts $\ldots \ldots \ldots \ldots \ldots \ldots \ldots \ldots \ldots \ldots \ldots, 6.11$

6.3.2 Increased Processing Efficiency ............... 6.12

6.3.3 Reduced Timberland Acreage...$\ldots \ldots \ldots \ldots \ldots \ldots \ldots .6 .6 .13$

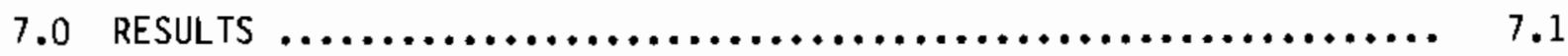

7.1 IMPACTS ON GROWING STOCK INVENTORIES $\ldots \ldots \ldots \ldots \ldots \ldots \ldots \ldots . \ldots .1$

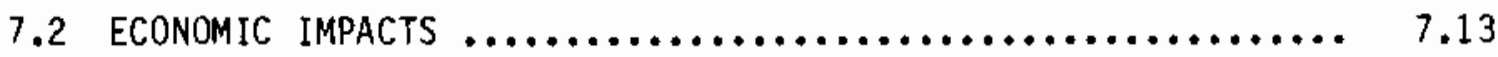

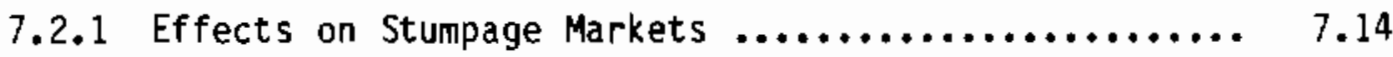

7.2.2 Effects on Product Markets .................... 7.20

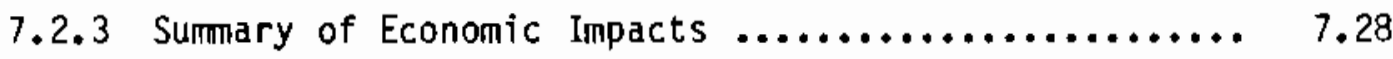

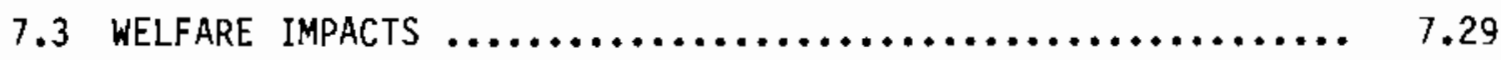

7.3.1 Overview of Welfare Measures $\ldots \ldots \ldots \ldots \ldots \ldots \ldots \ldots .7 .30$

7.3.2 Results of Welfare Analys is $\ldots \ldots \ldots \ldots \ldots \ldots \ldots \ldots, 7.34$

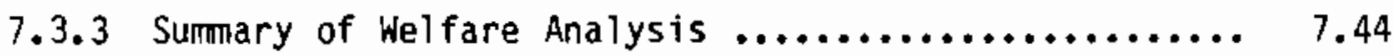

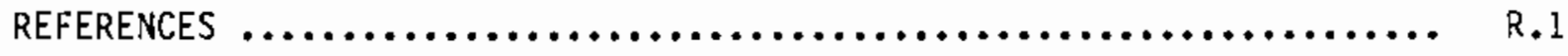

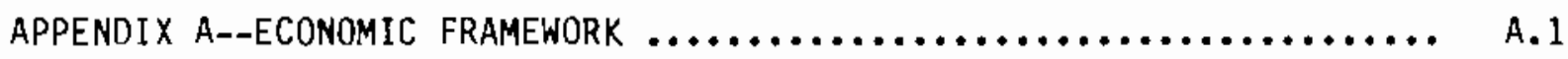

APPENDIX B--TECHNICAL ADJUSTMENTS TO TAMM $\ldots \ldots \ldots \ldots \ldots \ldots \ldots \ldots \ldots$ B. 1

APPENDIX C--SIMULATED ECONOMIC IMPACTS OF VARIOUS POLLUTION

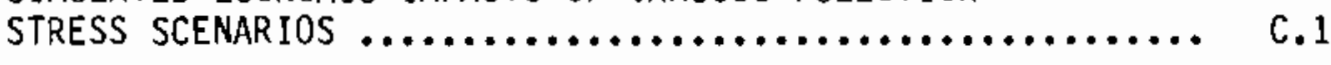




\section{FIGURES}

3.1 Price and Output Determination in a Market for a Good ......... 3.7

3.2 Market Supply Curve for Hypothetical Stumpage Market ......... 3.12

3.3 Measurement of Economic Damages Due to Acid Deposition ......... 3.14

3.4 Hypothetical Impacts of Acid Deposition on Interregional

Trade ............................................. 3.18

3.5 Schematic Diagram of Hypothetical Effects of Acid Deposition on Stumpage and Produce Markets in Two Regions ............... 3.20

4.1 Graphic Depiction of Market Model Structure in TAMM .......... 4.22

4.2 Softwood Lumber and Plywood Demand Regions in TAMM ........... 4.28

4.3 Softwood Product and Stumpage Supply Regions in TAMM ......... 4.32

5.1 Graphic Representation of the Q Method for

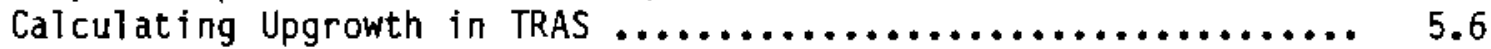

5.2 STEMS Management Guide for the Mixed Swamp Conifer Cover Type ........................................ 5.16

7.1 Changes in Privately Owned Growing Stock Inventories Due to Hypothetical Reductions in Radial Growth in the Northeast and Southeast: 1990-2030 Forecasts of the Combined Softwood and Hardwood Stock 


\section{TABLES}

ES.1 Commercial Forests: Estimated Annual Changes in the Present Value of Economic Surplus Due to Hypothetical Reductions in Radial Growth for Selected Years ........................ vi

6.1 Population, Gross National Product, and per Capita Disposal Income in the United States for 1977, with Projections to 2030

6.2 Housing Starts and Comercial Timberland Acreage in the

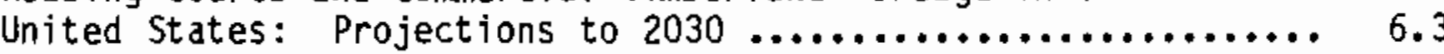

6.3 Pulp Consumption in the United States for 1980, with Projections to 2030

6.4 Hypothetical Reductions of Average Annual Radial Growth Rates Used to Simulate the Physical Effects of Pollution ............ 6.5

6.5 Product Margins for Softwood Lumber in the Northeast and North Central Regions: Decade Projections, 1990 to 2030

6.6 Product Margins for Softwood Lumber in the Northeast and North Central Regions, when the Production of Softwood Lumber and Plywood is Adjusted: Decade Projections, 1990 to 2030 .........

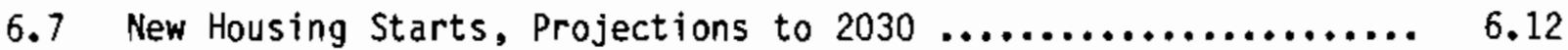

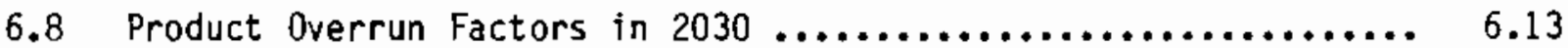

6.9 Private Commercial Timberland in the Un ited States, Projections to 2030

6.10 Private Commercial Timberland in the United States by Region, 2030 Projections

7.1 Changes in Growing Stock Inventories Due to Hypothetical Reductions in Radial Growth in the Northeast and Southeast: 2030 Forecasts

7.2 Impacts of a $15 \%$ Growth Reduction in the Northeast Region on Growing Stock Inventories: 2030 Projections

7.3 Impacts of a $15 \%$ Growth Reduction in the Southeast Region on Growing Stock Inventories: 2030 Projections

7.4 Impacts of Reducing the Growth of Only Hardwood or Only Softwood Species in the Northeast and Southeast Regions on Growing Stock Inventories: 2030 Projections 
7.5 The Inventory Effects of Adjusting Northern Softwood Lumber and PTywood Production when Timber Growth in the Northeast is Reduced by 15\%: 2030 Projections ........... 7.9

7.6 The Inventory Effects of Adjusting Norther Softwood Lumber and Plywood Production when Timber Growth in the Northeast and Southeast is Reduced by 15\%: 2030 Projections ........... 7.10

7.7 Impacts of Lower Housing Starts, Greater Efficiency, and Faster Conversion of Timberland on Growing

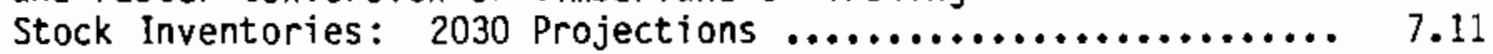

7.8 Impacts of Growth Reductions in the Northeast and Southeast on Harvests: 2030 Projections .................. 7.15

7.9 Impacts of Hypothetical Growth Reductions in the Northeast and Southeast on Stumpage Prices: 2030 Projections .......... 7.16

7.10 Harvest Impacts of Adjusting Northern Softwood Lumber and Plywood Production when Timber Growth in the Northeast and Southeast is Reduced by 15\%: 2030 Projections ........... 7.18

7.11 Stumpage Price Impacts of Adjusting Northern Softwood Lumber and Plywood Production when Timber Erowth in the Northeast and Southeast is Reduced by 15\%:

2030 Projections

7.12 Impacts of Lower Housing Starts, Greater Efficiency, and Faster Conversion of Timberland on Harvests:

2030 Projections

7.13 Impacts of Lower Housing Starts, Greater Efficiency, and Faster Conversion of Timberland on Stumpage Prices: 2030 Projections

7.14 Impacts of Growth Reductions in the Northeast and Southeast Regions on U.S. Lumber Supplies:

2030 Projections

7.15 Impacts of Hypothetical Growth Reductions in the Northeast and Southeast Regions on Softwood Lumber Prices:

2030 Projections

7.16 Impacts of Lower Housing Starts, Greater Efficiency, and Faster Conversion of Timberland on U.S. Lumber Supplies: 2030 Projections

7.17 Impacts of Lower Housing Starts, Greater Efficiency, and Faster Conversion of Timberland on Softwood Lumber Prices: 2030 Projections 
7.18 Impacts of Hypothetical 10\%, 15\%, and 20\% Growth Reductions in the Northeast and Southeast Regions on Lumber Consumption and Wholesale Price Indices: 2030 Projections ............... 7.26

7.19 Impacts of Lower Housing Starts, Greater Efficiency, and Faster Conversion of Timberland on Lumber Consumption and Wholesale Price Indices: 2030 Projections

7.20 Effects on U.S. Lumber Supply of Adjusting Northern Softwood Lumber and Plywood Production when Timber Growth in the Northeast and Southeast is Reduced

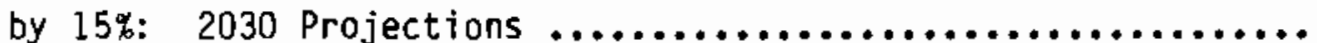

7.21 Effects on Softwood Lumber Prices of Adjusting Northern Lumber and Plywood Production when Timber Growth in the Northeast and Southeast is Reduced by 15\%: 2030 Projections

7.22 Effects on Lumber Consumption and Wholesale Price Indices of Adjusting Northern Softwood Lumber and Plywood Production when Timber Growth in the Northeast and Southeast is

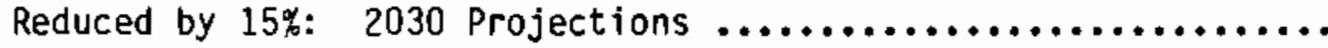

7.23 Welfare Measures Used to Quantify Changes in the Economic Well-Being of Various Economic Agents in the United States ..... 7.32

7.24 Impacts of $15 \%$ Growth Reductions in the Northeast and Southeast Regions on Pulp Production: 2030 Projections ....... 7.33

7.25 Changes in the Present Value of Cumulative Short-Run Economic Surplus in the United States Due to Hypothetical Reductions in Radial Growth in

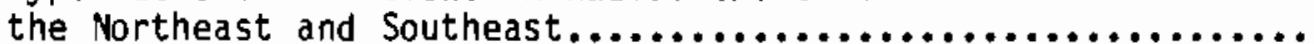

7.26 Changes in the Present Value of Cumulative Short-Run Consumers' Surplus and Economic Profit in Lumber and Plywood Markets and Producers' Surplus in Stumpage Markets Due to Hypothetical Reductions in Radial Growth in the Northeast and Southeast

7.27 Regional Changes in the Present value of Cumulative Short-Run Consumers' Surplus in Lumber and Plywood Markets when Timber Growth in the Northeast and Southeast is Reduced by $15 \%$ and Production of Softwood Lumber and Plywood in the Northeast and North Central Regions is Increased by $25 \%$ 
7.28 Regional Changes in the Present Value of Cumulative Short-Run Producers' Surplus and Economic Frofit in Lumber and Plywood Markets when Timber Growth in the Northeast and Southeast is Reduced by $15 \%$ and Production of Softwood Lumber and Plywood in the Northeast and North Central Regions is

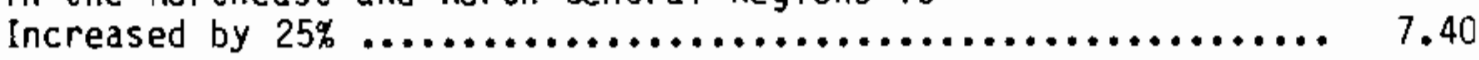

7.29 Changes in the Present Value of Cumulative Short-Run Producers' Surplus in Stumpage Markets and of the Inventory Remaining in 2030 when Timber Growth in the Northeast and Southeast is Reduced by $1.5 \%$ and Production of Softwood Lumber and Plywood in the Northeast and North Central Regions is Increased by $25 \%, \ldots . . .7 \quad 7.42$ 


\subsection{INTRODUCTION}

This research was performed by the Pacific Northwest Laboratory (PNL) for the Office of Research and Development (ORD) within the U.S. Environmental Protection Agency (EPA) as a part of the National Acid Precipitation Assessment Program (NAPAP). It was undertaken primarily to assist NAPAP in developing and implementing a capability to assess the economic damages caused by acid deposition and other air pollutants and the economic benefits of controlling these airborne pollutants. Although the discussion in this report mainly focuses on acid deposition, the models and results could be applied to other agents that might affect forest productivity.

\subsection{ACID DEPOSITION PHENOMENON}

Although acid deposition is comonly referred to as "acid rain," the term actually encompasses both the wet and dry deposition of acidic substances. That is, acid deposition can take the form of rain, snow, or other "wet" precipitation, or it can be deposited as dustfall, impacted fine particulate aerosols, or by adsorption and absorption of gases. The acidity of such deposition is determined by a complex mixture of partially or completely disassociated acidic and alkaline substances.

Acid deposition is a global phenomenon, traceable to both natural sources (such as volcanic emission, biological activities and natural combustion) and man-made atmospheric poliutants. While a number of atmospheric chemicals have been identified as precursors to acid deposition, sulfur dioxide $\left(\mathrm{SO}_{2}\right)$ and the oxides of nitrogen $\left(\mathrm{NO}_{\mathrm{x}}\right)$ are the principal substances linked with the phenomenon. On a global basis, about half of the sulfur in the atmosphere is attributed to natural sources (ITFAP 1982a). However, in those areas where acid deposition has aroused the most concern (such as the northeastern United States), man-made sources--pollutants associated with high levels of industrial activity--are considered to be the dominant cause (ITFAP 1982a). While scientists have been able to discern, to some extent, whether the sources are natural or man made in a given receptor region, opinion varies as to the relative contribution of close and distant sources of the precursors of acid 
deposition. Research to provide a better understanding of pollutant transport and transformation, and of the relationship between pollution concentrations at a source and those found in the receptor regions as acid deposition, is an important component of the federal program.

The complex atmospheric transport and cloud processes responsible for the transfer of atmospheric pollutants to the ground as acid deposition are not well understood. Compounding this uncertainty is the lack, until recently, of long-term monitoring networks that utilize comparable measurement techniques to document trends in precipitation acidity. It has, therefore, been difficult to establish the degree to which ecological damage has occurred as a result of acid deposition, or to establish the relationship between varying levels of local or long-range pollutants and subsequent acidic depositions in susceptible regions.

The best documented acid deposition effects at this time are those to aquatic ecosystems, particularly for lakes in Canada and Scandinavia. It is suspected that lakes in the Adirondack Mountains in New England and the upper midwest are showing stress from increased acidity and that numerous watersheds in other regions are probably vulnerable (ITFAP 1982b). Although aquatic ecosystems can often accommodate some rate of gradual acidification, dramatic damage (e.g., fish kills) has been noted in bodies of water where spring melting of acid-containing snow and ice causes major and rapid changes in the acidity and other properties of the receiving waters. Aquatic life is also damaged as a resuit of impaired reproductive capability due to increased ievels of toxic metal ions (especiatly aluminum) released from the soil by acid precipitation (ITFAP 1982b).

Much less is known about the deleterious effects of acid deposition on crops, forests, and soils. Some laboratory and field studies indicate that damage can occur from excessive acid deposition, although little effect is noted from ambient conditions. It has also been nypothesized, however, that acid deposition may have a beneficial effect on plants by increasing sulfur and nitrogen in soils that are deficient in those nutrients, thereby stimulating growth. 
Acid deposition may also affect materials and cultural resources. For example, structural materials, coatings, automobiles, electronic equipment, monuments, and stone structure are possibly vulnerable to acidified precipitation, soils, and surface or ground waters. However, atmospheric oxidants, corrosive gases, and particulate pollutants can also contribute to accelerated degradation of materials (ITFAP 1982b), and the specific potential for damage attributable to acid deposition is, again, not yet clear.

Finally, acid deposition may have indirect effects on human health. It is possible that the presence of acidified water in public water systems could lead to an increase in dissolved heavy-metals ions llead, copper, mercury, cadmium, etc.) in drinking water; long-term exposure to such water could lead to toxicity effects. However, these effects are usually mitigated in municipal water systems. Indirect effects could also occur via the human food chain. Both fish and plants that are taken from regions of high acid deposition show higher levels of heavy metals than those collected in unaffected areas (ITFAP 1982b). However, there is little evidence to suggest that such effects have occurred in North America.

\subsection{LEGISLATIVE AND ADMINISTRATIVE BACKGROUND}

In response to concerns about the actual and potential impacts of acid deposition on the environment, Congress passed, and the President signed into law, the Acid Precipitation Act of 1980 (Title VII of The Energy Security Act P.L. 96-294). This Act created NAPAP and established the Interagency Task Force on Acid Precipitation (ITFAP) to develop and implement a long-term comprehensive national research program within the framework of NAPAP. Planning for NAPAP commenced in the fall of 1980 and a final plan was completed, after extensive public review, in the summer of 1982 . This was supplemented by a more detailed Operating Research Plan (NAPAP 1984) published two years later.

The primary goal of NAPAP, set forth in the final plan (NAPAP 1984), is

"to develop and progressively improve an objective information base on the causes and effects of acid deposition and its effective management." An important aspect of this goal involves organizing the available scientific information about the causes and physical effects of acid deposition into a framework 
suitable for addressing policy questions. To do this, the plan calls for the execution of several assessments, the first schedsled for 1985, to evaluate the causes, effects, and damages resulting from acid deposition, along with policy

alternatives to reduce these damages.

As planned, the broad scope of these assessments will include the following activities:

1. Assess and integrate the current scientific knowledge and uncertainty about the degree, location, and significance of the adverse and beneficial effects which could result in North America from deposition of acidic and acidifying materials, including their economic significance.

2. Assess and integrate the scientific knowledge about the composition and distribution of acid deposition in North American, the source/receptor relationships, atmospheric composition, and emission patterns.

3. Formulate a range of emission control and receptor mitigation strategies for comparative analysis.

4. Apply the available data and analytical tools to the comparison and optimization of the strategy alternatives on the basis of costbenefit and cost-effectiveness criteria and examine the uncertainties associated with the results.

5. Identify the research that could reduce the physical, biological, and economic uncertainties that constrain the policy analysis process. Responsibility for conducting these activities has been assigned to an Assessments Task Group (Task Group I) within ITFAP. The U.S. Environmental Protection Agency (EPA) has been assigned the responsibility for coordinating the efforts of Task Group 1. The research reported in this document was undertaken as a part of Task Group I's assessment research. It represents a first step in evaluating and implementing methods to assess the economic impacts and determine the value of the damages caused by acid deposition in the United States. 


\subsection{RESEARCH OBJECTIVES}

The research reported in this document is intended to satisfy the following objectives:

- To review and critically evaluate economic methods and models for assessing the economic impacts of acid deposition on stumpage and primary forest product markets in the U.S. economy.

- To assess the potential economic impacts of acid deposition on stumpage and primary forest product markets in the U.S., including estimates of the economic damages caused by hypothetical reductions in tree growth rates for the 1985 Assessment.

- To provide information and recommendations which will enhance NAPAP's efforts to assess the economic impacts of acid deposition and to determine the benefits of alternative acid deposition, mitigation, and control strategies.

\subsubsection{Organization of the Report}

This report is divided into seven major sections. Following this Introduction, Section 2.0 contains the major conclusions and recommendations that have emerged from this research. The conclusions and recommendations contained in this section are generally related to 1 ) characterizing the potential economic impacts of acid deposition on stumpage and primary forest product markets in the U.S. and 2) developing better information about the effects of acid deposition on forest productivity and better economic models to assess the economic impacts of these physical effects.

Section 3.0 has three basic objectives. The first is to provide a brief overview of the evidence for growth slowdowns in eastern forests. As we state in that section, there is little evidence linking the slowdowns to acid deposition. The second is to provide a conceptual framework for understanding and valuing the impact of changes in forest productivity on buyers and sellers in markets for hardwood and sof twood stumpage and the primary products made from this stumpage. Finally, Section 3.0 identifies the major features of an 
appropriate methodology for estimating the potential economic damages of acid deposition in these markets, consistent with the conceptual framework previously set forth.

The next two major sections of the report represent an analysis of different models and methods for assessing the potential economic impacts of acid deposition-induced changes in forest productivity. Specifically, Section 4.0 critically reviews different types of economic models of stumpage and primary wood products markets. Much of this analysis is focused on the Timber Assessment Market Models (TAMM), developed for the U.S. Forest Service by Adams and Haynes (1980), which were used in this research to estimate the economic damages associated with hypothetical reductions in annual tree growth rates. Section 5.0 presents a critical evaluation of several different inventory projection models. This type of model is needed to simulate the potential effects of acid deposition on the physical inventory of trees over time and to interact with an economic market model for accounting purposes.

Section 6.0 and 7.0 contain the quantitative portions of the research. Section 6.0 describes the simulation cases that were developed to estimate the potential economic impacts of acid deposition on stumpage and primary wood product markets in the U.S. Section 7.0 reports the results of these simulations. It focuses on the effects of hypothetical reductions in annual tree growth rates in the northeastern and southeastern United States on 1) inventory levels, 2) harvest levels and stumpage prices, 3) the production and prices of lumber and plywoor, and 4) on the value of the economic damages to buyers and sellers in both stumpage and selected primary wood product markets.

The report also contains three appendices. Appendix A presents the mathematical exposition for the economic framework contained in Section 3 . Appendix $B$ presents information about changes that were made to the TAMM models to facilitate the analysis in Section 7.0. Finally, Appendix C contains more detailed results of the simulations than those displayed in Section 7.0 . 


\subsection{CONCLUSIONS AND RECOMMENDATIONS}

The purpose of this research was to assist NAPAP to develop and implement a capability to assess the economic damages caused by acid deposition and other air pollutants and the economic benefits of controlling these pollutants. In that general framework, the specific objectives of this research were:

- To review and critically evaluate economic methods and models for assessing the economic impacts of acid deposition on stumpage and primary forest product markets in the U.S. economy.

- To scope and assess the sensitivity potential economic impacts of acid deposition on stumpage and primary forest product markets in the U.S.

- To provide information and recommendations that will enhance Federal efforts to assess the economic impacts of acid deposition and to determine the benefits of alternative acid deposition mitigation and control strategies.

\subsection{CONCLUSIONS}

The major conclusions of this report generally fall into three separate categories. The first set of conclusions relates to the availability of information about the effects of changes in acid deposition levels on forest productivity and the implications of this for economic assessments of the consequences of acid deposition. The second set of conclusions relates to the selection of appropriate models for simulating the effects of changes in forest productivity on buyers and sellers in stumpage and primary wood product markets in the United States. The final set of conclusions is based on our analysis of the simulated economic impacts of hypothetical reductions in annual three growth rates in the northeastern and southeastern United States.

\subsubsection{Effects of Acid Deposition on Forest Productivity}

Analysis of the physical effects of acid deposition on tree growth and stand structure is still in the stage of basic hypothesis development. A number of hypotheses about the direct and indirect effects of acid deposition on 
tree growth and stand structure have been developed and subjected to limited testing in laboratory and greenhouse experiments. Research has identified a number of alternative mechanisms through which acid deposition might affect tree growth. However, it has not been possible to establish scientifically whether acid deposition is partially or completely responsible for recently observed decreases in tree growth in the United States, although this possibility cannot be ruled out.

In view of the lack of scientific evidence linking increases in acid deposition levels to changes in forest productivity, it would be wrong to assume that one can accurately project the effects of acid deposition or acid deposition controls on stumpage and forest product markets in the United States. However, it would be incorrect to assume that economic analysis has nothing to contribute to acid deposition-related research at this time. Specifically, economic research can provide four different types of contributions to the current NAPAP research effort. These include:

- characterizing the potential scope of the economic impacts of acid deposition

- identifying the methodological capabilities and model features that will be required to assess the economic impacts of acid deposition

- evaluating existing methods and models to adequately satisfy the methodological problems that must be imposed by acid deposition phenomena

- using existing models, on a preliminary basis, to assess the sensitivity of the simulated economic impacts of acid deposition to different assumptions about the nature of the potential physical effects of acid deposition on tree growth and stand structure.

\subsubsection{Methods for Assessing the Economic Impacts of Acid Deposition}

If the physical effects of acid deposition on forest productivity are relatively small, then it may be appropriate to approximate the annual value of the resulting economic damages by multiplying the projected annual change in timber inventories by the appropriate stumpage price values. This method is referred to broadly in the literature as the damage function approach. On the 
other hand, if the changes in forest productivity are large enough to induce measurable price and quantity changes in stumpage markets, the damage function approach will not provide a good approximation of the true value of the economic damages. The most important reasons for this are, first, that the damage function approach does not account for damages to buyers and sellers of processed wood products and, second, that it ignores substitutions which individuals and firms can make in their consumption and production decisions in response to market price changes to mitigate (or take advantage of) the effects of changes in forest productivity.

Generally speaking, these limitations can be overcome by basing measures of economic damages on accepted economic principles and by using mathematical models of supply and demand relationships in appropriate markets, not only to characterize the behavior of consumers and producers, but also to generate the information required to measure economic damages in the form of changes in consumer and producer well-being (consumer and producer surplus). In the current case, one can identify five, more specific, features which should ideally be built into a methodology used to evaluate the economic impacts associated with acid deposition-induced changes in forest productivity. These features include:

- A forest inventory model that is not only capable of simulating regeneration, growth and mortality of hardwoods and softwoods on a regional basis, but can also interact directly with a forest sector economic model to simulate the effects of harvesting on inventory size and composition.

- Stumpage supply curves which will be responsive to acid depositioninduced changes in the size and composition (i.e., age and species) of the forest inventory, as well as to changes in expected future prices.

- An economic model that captures the different market likages from stumpage markets to primary wood product markets.

- The capability to simulate the effects of interregional trade on expanding the consequences of acid deposition to other regions. 
- The capability to value the damages of acid deposition and the benefits of control policies using accepted measures of well-being (consumer and producer surplus) in multiple markets.

The only existing system of economic models to contain all of these features (at the time this research was performed) was the Timber Assessment Market Models (TAMM) (Adans and Haynes 1980; Lange 1983). This system of models is physically linked to an inventory projection model, the Timber Resource Analysis System, or TRAS (Larson and Goforth 1970, 1974). Both of these models have been used, extensively, by the U.S. Forest Service to asses's the timber supply situation in the United States. The Forest Service is in the process of reviewing and testing a replacement model for TRAS, known as TRIM (Timber Resource Inventory Model). While TRIM was found to be a superior model to TRAS on technical grounds, it has not yet been fully tested with TAMM. Until TRIM is made fully operational with TAMM; we concluded that the TAMM-TRAS combination of models represented the best availaole methods for evaluating the potential economic impacts associated with acid deposition.

\subsubsection{Scope of Impacts}

We used a modified version of the TAMM-TRAS system of models to simulate the economic impacts due to hypothetical changes in forest productivity in the northeastern and southeastern United States. These productivity changes were represented in TRAS by a uniform reduction of 10,15, or $20 \%$ to all of the radial growth rates for hardwood and softwood species in the growing stock inventories of the two target regions. The results and detailed analysis of these simulations are presented in Section 7.0. Based on this analysis two major conclusions emerge about the potential economic impacts due to acid deposition-induced changes in forest productivity.

- The Economic Impacts of Reduced Tree Growth May Not Be Isolated To Regions where These Reductions Occur. Our analysis generaliy showed that reduced tree growth in one region resulted in lower growing stock inventories, higher stumpage prices and lower harvests, higher lumber and plywood prices and reduced lumber and plywood production in the target region. However, because of interregional trade in 
lumber and plywood these impacts spilled over into other regions. Specifically, higher Tumber and plywood prices in national and U.S.Canadian markets led to increased lumber and plywood production, larger harvests and higher stumpage prices, and increased exports for reduced imports) of lumber and plywood to (or from) regions directly affected by reduced by tree growth.

- Decreases In Tree Growth Rates Can Cause Economic Damages, But These Damages May Not Be Evenly Distributed. Our analysis showed that simulated reductions in annual tree growth rates in the northeastern and southeastern United States resulted in decreases in the aggregate economic welfare of econoric agents in stumpage and primary forest product markets in these regions. However, since reduced tree growth in these regions increased the demand for lumber, plywood and stumpage in other regions, aggregate economic welfare in regions, not directly influenced by reduced tree growth, actual increased. Damages were also unevenly distributed across economic agents. In particular, our analysis showed that simulated reductions in tree growth rates in the northeast and southeast generally resulted in decreases in the economic welfare of lumber and plywood buyers throughout the country. On the other hand, timber owners and lumber and plywood producers generally benefited from reduced tree growth at the direct expense of the huyers of these products.

Taken together, these two conclusions highlight the potential for changes in forest productivity to influence not only the levels of economic activity in stumpage and wood product markets, but also the distribution of economic activity and income among regions and economic agents.

\subsection{RECOMMENDATIONS}

The recommendations associated with this research generally fall into two broad categories. The first set of recommendations is related to improving upon the existing capability for evaluating the potential economic impacts of 
increases in acid deposition levels. The second category includes recommendations to broaden the scope of productivity changes which are subject to analysis.

\subsubsection{Methodology Improvements}

As previously stated, the quantitative analysis of the effects of reduced tree growth on stumpage and primary wood products markets in the U.S. was conducted using the TAMM economic model and the TRAS inventory projection model. The major strengths of the TAMM-TRAS system of models are related to its abi:ity to provide information about possible future trends in production, consurption and market prices in many different regiona? product and stumpage markets, for both hardwoods and softwoods on a regional basis. The TAMM-TRAS system was designed, originally, to fulfill such a purpose--to provide long-range projections of forest product markets as called for by the Forest and Rangeland Renewable Resource Planning Act (RPA). The models generally function well in this role. However, there are several modifications which could be made to the system of models that would improve the existing capability to evaluate the economic impacts of acid deposition-induced changes in forest productivity. Specifically, we recommend that the following actions be taken:

- Investigate the feasibility of making the supply of softwood lumber and plywood in the Northeast and North Central supply regions responsive to both product and stumpage prices.

- Investigate the feasibility of integrating the short-and long-run demands for pulpwood in an explicit spatial equilibrium framework.

- Investigate the feasibility of making the technical efficiencies associated with converting stumpage into primary wood products responsive to both product and stumpage prices

- Replace the TRAS inventory model with TRIM once this model has been properly validated and tested by the U.S. Forest Service and the appropriate data bases are made availabie. 


\subsubsection{Improved Simulations}

For the purposes of this research, the quantitative analysis of the economic impact of changes in forest productivity focused only on changes in radial growth rates in the Northeast and Southeast timber supply regions. The physical effects focus was purposely kept narrow due in part to the lack of information about the effects of acid deposition on forest productivity, and also because of a desire not to generate more information than could be efficiently analyzed in the early stages of the assessment program. Specifically, we recommend that the following action be taken:

- Develop a plan for obtaining regional estimates of the existing and future effects of acid deposition or air pollution on forest productivity. This requires extrapolating the results from numerous site specific studies to larger geographic regions.

- Consistent with this plan, continue to simulate and investigate the effects of forest growth slowdowns, adding new geographic areas and new effects, such as changes in mortality as evidenced by the forest effect research. 


\subsection{THE ECONOMIC IMPACTS OF ACID DEPOSITION ON COMMERCIAL TIMBER RESOURCES: AN OVERVIEW}

This section of the report has three basic objectives. These include:

- providing a brief overview of the evidence of growth slowdowns in the Eastern U.S.

- providing a conceptual framework for understanding and valuing the impact of physical changes on buyers and sellers in markets for hardwood and softwood stumpage and the primary products made from this stumpage.

- identifying the major features of a methodology for estimating the potential economic damages of acid deposition or other air pollutants on timber resources that is consistent with the conceptual framework described above.

\subsection{EVIDENCE OF GROWTH SLDWDOWNS IN THE EASTERN U.S.}

The section describes the evidence for concern about possible slowdowns in forest growth or productivity in the Eastern United States. A number of studies indicate that the radial growth rates of both high and low elevation trees have declined from previous years. The task of observing and estimating any forest growth slowdowns is complex because such slowdowns often exist for a number of natural reasons such as climate, insects, fungi, and other pathogens. These investigations have not been able to pinpoint a cause although a number of factors including acid deposition and other pollutants have been suggested. Therefore, we do not attempt to attribute our estimates of the economic damages of the reduced growth to acid deposition.

Red spruce decline in high elevation was first reported by siccama et al. (1982) in the Green Mountains of Vermont. Evidence included a decrease in the basal area growth rate and density of 50\% between 1965 and 1980 and the presence of visible symptoms such as needle loss. The reduced growth was found in all observed age classes. Similar evidence of red spruce decline, including increase mortality, has been observed in other areas of the high elevation 
northeastern and southeastern forests (Bruck 1984) with the symptoms seeming to increase with elevation. The association between growth slowdowns and high elevation is important because air pollution concentrations and deposition tend to increase with elevation. In addition to the studies of growth slowdowns in high elevation forests, growth slowdowns have been detected in low elevation forests (Johnson et al. 1980). However, the conclusions in these studies are based on changes in tree ring growth, which is generally regarded as less certain than the visible symptoms observed in high elevation spruce.

Another source of evidence that Eastern forests may be experiencing a reduction in growth rates is the periodic analysis of timber inventories in the Southeastern United States conducted by the Forest Service's Southeastern Forest Experiment Station. The most recent FIA analysis indicates that the annual growth rates of softwood timber have declined over a fairly large geographic area compared to the previous FIA analysis (Sheffield et al. 1985). For example, the radial growth of yellow pines in the Piedmont Region and mountains of Georgia was 20- 30\% less between 1972 and 1982 than between 1961 and 1972 (Sheffield et al. 1985, p. 1). Further investigations indicate that radial growth rates of most yellow pines under 16 inches in diameter declined by between 30 and $50 \%$ throughout the Piedmont, Mountain, and Coast Plain Regions of the Southeast (Sheffield et al., p. 1-2).

A number of causes have been proposed for the growth rate reductions in the Southeast. Sheffield et al. (1985) list and discuss the following:

- Atmospheric deposition

- Aging of stands

- Increased stand density

- Increased hardwood competition

- Drought

- Lower water tables

- Changes in land use

- Diseases

- Multiple effects 
It is not possible, at present, to determine which of the above potential effects might have caused the changes in growth rates. The hypothes is that acid deposition, one of several candidates, caused the growth slowdowns can not be accepted or rejected with present scientific information. For what reason, we do not attempt to link our analysis to acid deposition. Our model and analysis is more general; the changes in growth rates are hypothetical and could be due to any cause. However, our results presented in Chapter 7.0 are based on growth reductions that are consistent with those reported by the U.S. Forest Service FIA (Sheffield et al. 1985).

In spite of the difficuties in determining the cause of the growth rate slowdowns, a number of fairly general conclusions can be drawn from the previous studies about the type of information that may be needed to accurately assess the economic impacts of the growth slowdowns. In general, the available evidence suggests that the magnitude of the growth slowdown depends on 1) the type of species; 2) the trees' age or stage of development; 3 ) environmental conditions at the site especially related to soil, climate, elevation and other site-specific characteristics; and 4) the species composition of the affected stands and forests. While there are several inventory projection models (to be discussed in Section 5.0) that have the technical capability to take most of the above factors into account, the scientific evidence about the physical impacts of acid deposition or air pollution on tree growth and stand structure is not yet available. Put more simply: we possess the technical capability to simulate the economic consequences in great detail of a physical phenomena that scientists do not fully understand.

In view of the above problem, it would be wrong to assume that one can accurately project the effects of acid deposition or acid deposition controls on stumpage and forest product markets in the United States. However, it would also be incorrect to assume that economic analysis has nothing to contribute to acid deposition-related research at this time. Specifically, economic research can provide four different types of contributions to the current NAPAP research effort. These include:

- characterizing the potential scope of the economic impacts of acid deposition 
- identifying the methodological capabilities and model features that will be required to assess the economic impacts of acid deposition

- evaluating existing methods and models to adequately satisfy the methodological problems that must be imposed by acid deposition phenomena

- using existing models, on a preliminary basis, to assess the sensitivity of the simulated economic impacts of acid deposition to different assumptions about the nature of the potential physical effects of acid deposition on tree growth and stand structure.

\subsection{TRANSLATING ENVIRONMENTAL IMPACTS INTO ECONOMIC DAMAGES: A CONCEPTUAL FRAMEWORK}

Section 3.1 identified the various pathways through which scientists believe that acid deposition may influence forest productivity. This section of the report provides a conceptual framework for characterizing the different types of economic impacts that could occur as a result of changes in forest productivity and for understanding how changes in forest productivity can be evaluated in monetary units (e.g. dollars) based on induced changes in the behavior of buyers and sellers in markets for hardwood and softwood stumpage and the primary products made from this stumpage. Accordingiy, Section 3.2.1 identifies in general terms the appropriate measures to use in valuing the effects of my changes in forest productivity which may be caused by acid deposition. Section 3.2.2 outlines a conceptual framework for understanding how changes in forest productivity can influence the behavior of buyers and sellers of hardwood and softwood stumpage in regions directly affected by acid deposition. Section 3.2.3, in turn, shows how these impacts can spread into markets for products that are made from stumpage and, perhaps more interestingly, into stumpage and wood product markets in regions where no changes in forest productivity are experienced.

\subsubsection{Measuring Damages}

Two different approaches can be used to evaluate the economic damages of acid deposition (Smith 1982). The first is the so-called damage function 
approach. This technique uses dose-response functions to translate changes in acid deposition into physical damages. Physical damages are then multiplied by a unit economic value, such as a market price, to obtain a measure of economic damages.

For example, if the effects of acid deposition on the annual growth increments for different size trees of a particular species in a given location were known, the impact of this effect on the total inventory volume for that species could be calculated on an annual basis. The projected annual change in the inventory could then be multiplied by a projected stumpage price value for each year of the projected life of the current inventory to obtain annual estimates of the future damages of acid deposition to the subject species. Discounting these values at an appropriate measure for the opportunity cost of capital and then summing these values for each year in the projection period would provide a measure of the present value of the damages caused by acid deposition to the species in question. Repeating these steps for all commercially-important species on all acres of commercial timberland would result in an estimate of the present value of the aggregate damages of current levels of acid deposition in commercial timberland.

There are a number of shortcomings associated with applying the above approach, or variants of it, to measure the economic value of the damages caused by current levels of acid deposition. First, the damage function approach can sometimes be used to approximate the economic losses of producers of goods and services and, in some cases, the economic damages suffered by owners of natural resources, such as timberland. However, this approach does not capture the effects which acid deposition may have, indirectiy, on firms which process stumpage into Iumber, plywood, paper and a large number of other products or on the consumers who purchase goods and services that contain wood products. Damages to intermediate firms and consumers can only be ignored if the physical effects of acid deposition are so small or so isolated that they do not affect stumpage prices. Thus, a second problen with the damage function approach is that it implicitly fails to take into account possible changes in the prices of resources at risk as a result of acid deposition-induced reductions in the supplies of these resources. A third problem is that it ignores 
substitutions which individuals and firms can make in their consumption and production decisions due to changes in prices. Generally speaking, extremely unrealistic assumptions have to be made about the preferences of individuals, the technology of firms, and the structure of the markets being analyzed for the damage function approach to yield damage measures which are consistent with economic theory.

A second approach overcomes these shortcomings by using mathematical representations (models) of supply and demand curves in appropriate markets to characterize the behavior of consumers and producers. Information about the direction and magnitude of environmental impacts is generally used in conjunction with this approach to shift the relevant supply or demand curves in affected markets to simulate the behavioral responses of consumers and producers. Appropriate damage measures can then be evaluated from these simulatad shifts in supply and demand curves.

The basis for the latter approach is illustrated in Figure 3.1 which characterizes price (P) and output (0) detemination in a market for a hypothetical good, given market demand and supply curves (D), and (S) for the good. The demand curve shows the quantity of the aggregate market good that purchasers choose to take from the market, per unit time, for each aggregate product price. The market supply curve indicates the the maximum output, per unit time, that producers in the market are willing to supply at each product price. The market supply curve is sometimes called the marginal cost curve because each point on the curve represents the marginal cost (increase in total cost) measured along the vertical axis that corresponds to a given output on the horizontal axis. Market equilibrium occurs at the point of intersection between the market supply and demand curves, where Q units of aggregate output are supplied in the market at price $P$, which also corresponds to the marginal production cost.

The welfare of consumers (e.g. buyers of Q) can be approximated (Willig 1976) by the area underneath the market demand curve and above the price line, 


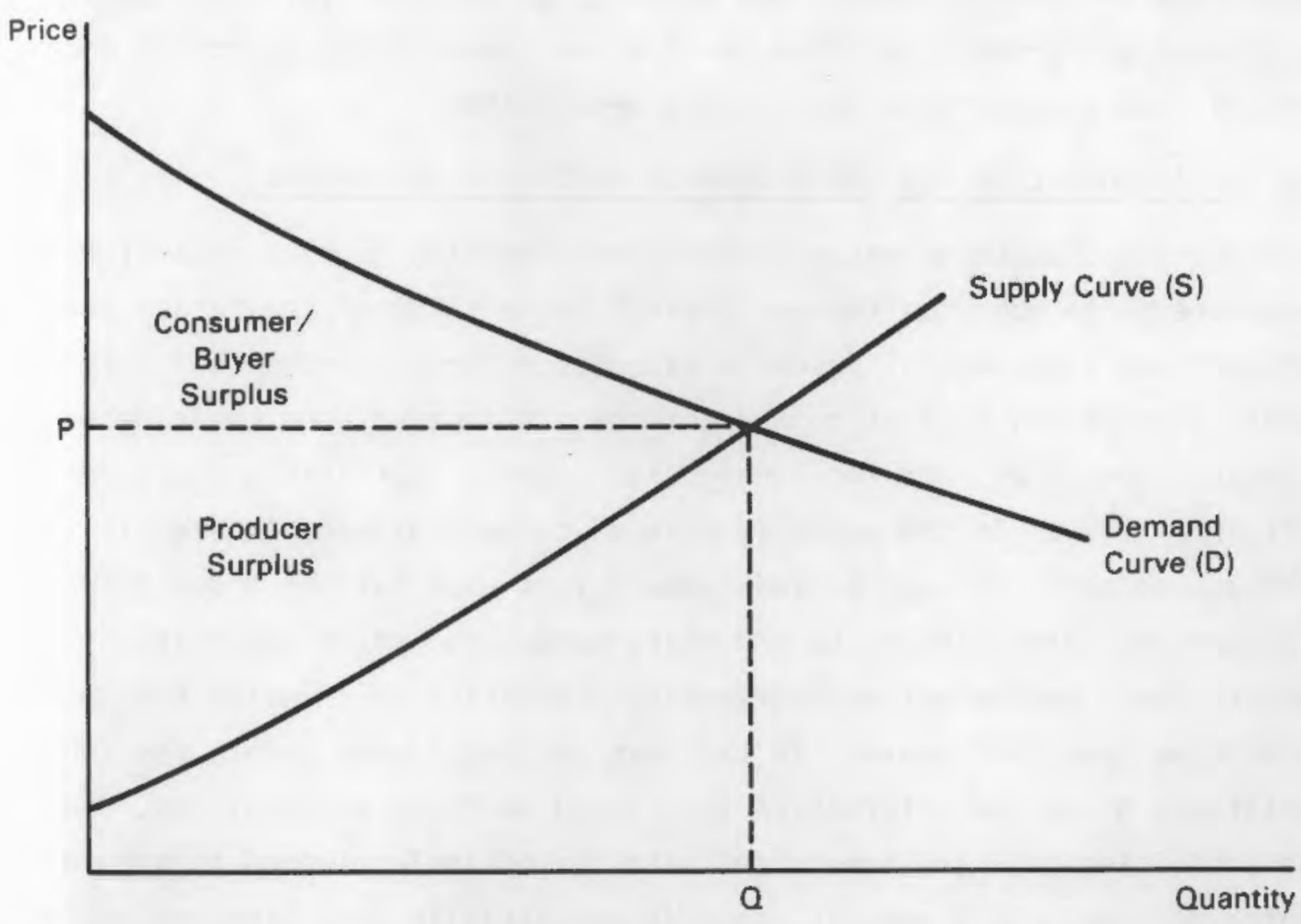

FIGURE 3.1. Price and Output Determination in a Market for a Good

drawn horizontally from $P$. This area, known as consumer surplus, is conventionally defined as the difference between the maximum amount of money individuals are willing to pay for a good rather than do without it and the amount actually paid. Producer surplus measures the welfare of firms in the market (e.g. producers of $Q$ ). It is given by the area above the market supply curve and below the price line. This area is equal to the difference between the amount received by firms from the sale of $Q$ less the minimum cost of producing Q. The total welfare derived from the production and consumption of $Q$ in the market is approximated by the sum of these two areas.

The concepts of consumers and producer surplus, as illustrated in Figure 3.1, provide the theoretical basis for translating environmental impacts from a variety of sources, including (potentially) acid deposition, into dollar terms. In the next section, we will show how these concepts can be used to value the effects of acid deposition-induced shifts in the market supply curve 
for stumpage on stumpage owners and buyers. In Section 7.0 , these concepts will be applied formally to value the damages caused by hypothetical decreases in annual tree growth rates due to acid deposition.

\subsubsection{Acid Deposition and the Economics of Timber Management}

A basic postulate of natural resources economics is that natural resource owners attempt to maximize the net present value (NPV) of the future stream of income derived from natural resource extraction (or some other suitably defined economic objective), subject to the constraints imposed upon their behavior by the natural, physical, and regulatory environments (Hotelling, 1931; Peterson and Fisher, 1977). In the specific case of timber resource owners, it is common to assume that, in each period, owners form expectations about future timber prices and harvesting costs and that, based upon these expectations, they undertake those management and harvesting activities which solve the optimization problem described above. In the next period, timber owners revise their expectations given new information and, based on these expectations, undertake those activities that are consistent with the optimal solution to the revised planning problem. This process proceeds sequentially over time, with timber owners continually revising their expectations, determining new optimal harvesting and management plans, and taking actions that are congruent with these plans.

The Planning Problem of the Individual Timber Owner

It is important to take a closer look at this process in some detail to gain a better insight about the way in which acid deposition may affect the current and future behavior of timber owners. For these purposes, the planning process can best be illustrated by a relatively simple problem which focuses on the decision of when to harvest all of the trees on an even-aged, single species stand of timber. Given a) the economic objective of maximizing NPV, and b) a growth function which relates the volume of harvestable timber to tree age, the timber owner must determine the optimal rotation lengths over time which will generate the highest NPV. This problem is virtually identical to the classical rotation problem associated with the nineteenth century German forester Faustmann (Samuelson, 1976), with one exception. The Faustmann problem assumes constant future prices at current-period levels, which results in a 
unique rotation length for all rotations. Here, we relax that assumption so that rotation length may vary over time. The mathematics of this problem are presented, in full, in Section A.1 of Appendix A.

Associated with this problem is a set of mathematical relationships (first-order conditions) that defines the rules the timber owner must follow in each period if he is to achieve his objective. These first-order conditions are expressed in terms of the relationship between marginal benefits and marginal costs and can be explained as follows: Over an increment of time, the value of the standing timber, if it is not harvested, will increase by an amount equal to the net price of stumpage (the price of stumpage minus marginal harvesting costs) times the amount of timber growth that occurred during that time increment. This is discounted back to the present to determine the time rate of change in stumpage value, more commonly referred to as the opportunity cost of stumpage. This discounted opportunity cost represents the cost of holding timber, uncut, for an increment of time. One can also view this opportunity cost as the benefits derived from not harvesting the timber and allowing it to grow, instead. Alternatively, the timber owner can harvest his trees and plant new trees to be harvested in a later period and so on. If he decides to harvest his trees, rather than allow them to grow, he can invest this money at some interest rate, $r$. He can also expect to receive added benefits from the interest he earns on timber sales from successive rotations in the future.

Efficient production (i.e., maximizing NPV) calls for the timber owner to equate the discounted interest earned from current and future harvests, at each harvest, with the discounted opportunity cost associated with holding the timber in its current state. When this rule is followed, holding timber off the market will no longer benefit the timber owner, since the opportunity cost of holding timber will be greater than the marginal benefits to be gained from harvesting the timber. The overriding importance of this rule from the standpoint of natural resource economics is that the opportunity cost of timber, which must be counted in addition to the periodic marginal cost, plays a fundamentally important role in determining efficient production within stumpage markets. 
The Effect of Acid Deposition on Individual Planning Decisions

In order to examine the way in which acid deposition may affect the behavior of individual timber owners, one is forced to make assumptions about the relationship between tree growth and acid deposition levels. At present, no such dose response functions are available for commercially important tree species (or any other species for that matter). In the absence of this information, one is forced to make assumptions about this relationship which are general enough to include a broad range of potential impacts. For the purposes of this analysis, we assume that, other things being equal, tree growth is determined by tree age and by the age-specific level of acid deposition that is present at a particular age. The level of acid deposition present in a given period can then be linked to tree age hy assuming that acid deposition levels change monotonically with time. These assumptions make it possible to express the growth functions contained within the optimal rotation problem in terms of the rotation ages of current and past harvests. This characterization of the dose response function is perfectly general in the sense that it can be tailored to fit any set of assumptions or observations regarding both the agespecific impacts of acid deposition on tree growth, by species, and the direction and rate of change of acid deposition over time.

The characterization of the dose response function used here is described in greater detail in Section A.3 of Appendix A. This appendix also examines the impact of changes in acid deposition levels over time on optimal rotation lengths given the assumptions that a) the effect of increasing the level of acid deposition on tree growth is negative, and b) acid deposition is increasing over time. Under these assumptions, it is shown that the primary effects of acid deposition are to decrease the opportunity cost associated with holding timber and to reduce the benefits from harvesting timber, as well. The former effect occurs because any delay in harvesting the first rotation increases the levels of acid deposition to which future generations of trees may be exposed. This reduces the economic incentive to delay harvesting. The second effect is due, strictly, to the assumed negative (or at least not positive) effect of acid deposition on tree growth at all ages. Holding rotation length 
constant, reduced growth will lead to smaller earnings if the timber is harvested and the receipts are invested. Because these two effects are in opposite directions, the effect of an increase in acid deposition on rotation length cannot be determined a priori. However, given the above assumptions regarding the effects of acid deposition or tree growth, harvest volumes will decrease as acid deposition increases.

\section{Derivation of the Market Supply Curve for Stumpage}

The analysis presented above applies specifically to the harvest scheduling and harvesting behavior of individual timber owners holding fixed amounts of land. However, the analysis can be couched in the more familiar terms of individual owner and market supply curves without a great deal of difficulty. In Section A.2 of Appendix A, we show how the stumpage supply curve for an individual timber owner can be "built up" from the optimal rotation problem using the method described by $\operatorname{Vaux}(1954,1969)$ and Hyde $(1979,1980)$. The individual supply curves can then be summed horizontally (e.g., aggregating stumpage quantities for each price level) to generate a market supply curve, as shown in Figure 3.2.

The market supply curve for stumpage is represented by the line S. Each point on this curve represents the amount of timber (on the horizontal axis) that will be harvested at the corresponding price (on the vertical axis). The curve $\hat{S}$, on the other hand, represents the marginal harvesting cost associated with each level of stumpage. The vertical distance between the two curves $(\lambda)$ represents the opportunity cost associated with the corresponding level of harvest (on the horizontal axis). In this case, the opportunity cost of timber retains its familiar meaning. It is, simply, the value of the timber growth that is forgone as a result of harvesting the last unit of timber ( 0 ) today rather than allowing it to grow for another period. Efficient production is defined by the points along the true supply curve for stumpage ( $S$ ) and not $\hat{S}$, which fails to take into account the impact of current decisions on future harvests due to holding costs.

The market supply curve for stumpage, when derived by the method described in Appendix A, contains an extraordinarily rich amount of information about the composition of supply. This is because each point on the supply curve can, in 


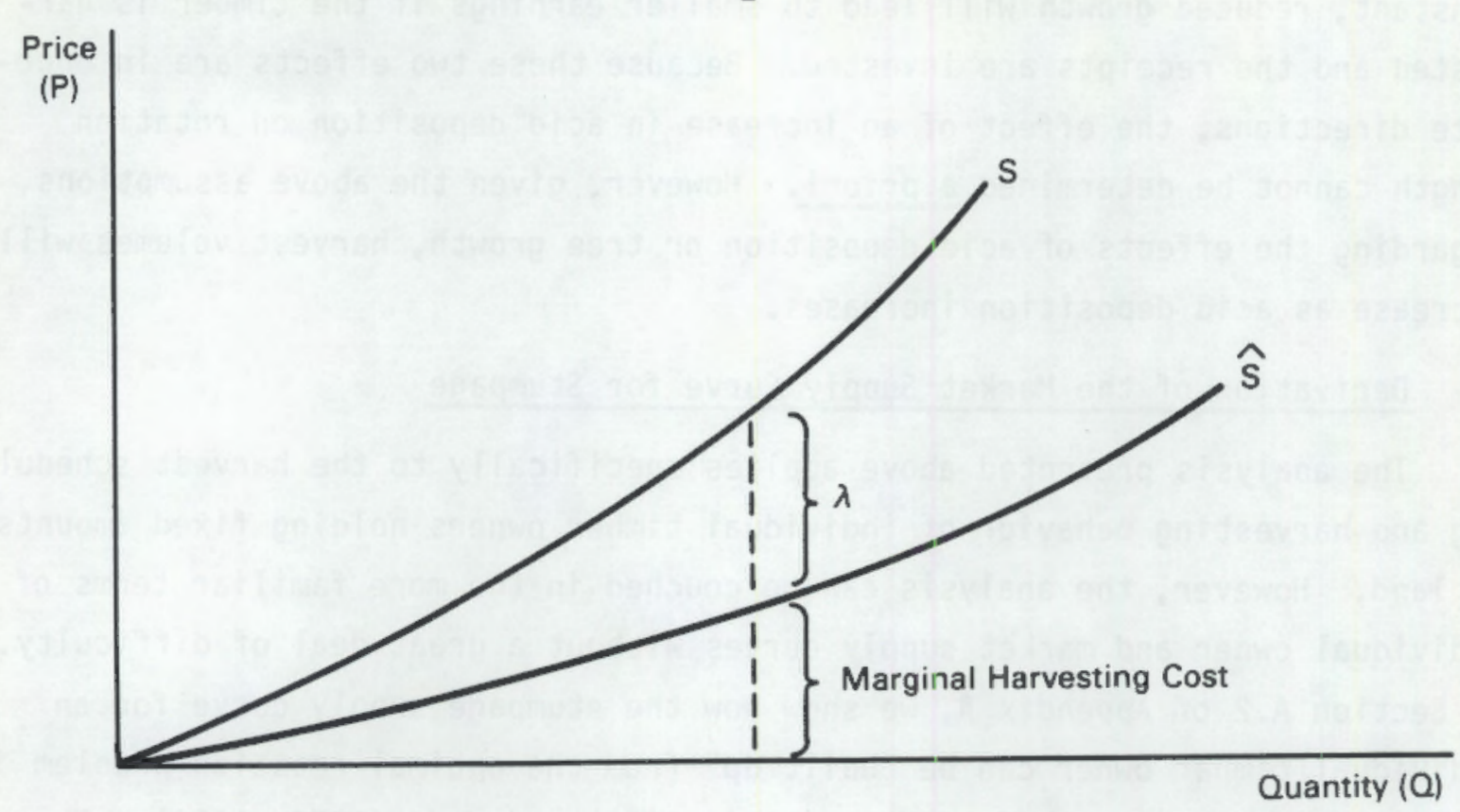

FIGURE 3.2. Market Supply Curve for Hypothetical Stumpage Market

theory, be decomposed into specific acres of trees, by species, by individual owners and owner groups, by site class, by age, etc. At low prices, the oldest trees of the slowest growing species on the best quality of land will be harvested. The marginal harvesting and opportunity cost of these trees will be relatively low. As one moves up the market supply curve, younger, more vigorously growing trees on poorer classes of land will be harvested. Finally, only very high prices will justify the harvesting of the smallest trees on the poorest quality of land, owing to the large harvesting and opportunity costs associated with cutting these trees.

Unlike conventional, static supply curves, the market supply curve for a renewable resource like timber is linked explicitly to both past and expected market behavior. Past harvests are reflected in changes in the composition of stumpage that can be supplied at current prices. For example, if future timber 
supplies are expected to decline for some reason, this will produce an incentive to conserve current timber resources for future use. Consequently, the market supply curve in the current period will be shifted further to the left (i.e., inward) than would otherwise be the case. Very low prices in previous periods would mean that more timber would be available for the current period harvest at existing prices than would otherwise be the case, implying a shift to the right in the supply curve for the current period. The market supply curve in the current period is also influenced by changes in future price expectations. To the extent that future prices are expected to increase, current harvests will decrease and more timber will be available for harvesting in future periods than would otherwise be the case. A decline in expected future prices would have the opposite impact and shift the supply curve for the period to the right.

Given the characteristics of the market supply curve for stumpage described above, one is now in a position to speculate about the effects of acid deposition on stumpage supply. If acid deposition reduces tree growth over time, timber owners will anticipate a reduction in future inventories. This will effectively increase the opportunity cost of stumpage since current growth will be worth more in the future due to lower supplies. Independent of any effects on marginal harvesting costs, this will cause the market supply curve to shift to the left over time, meaning that market prices will have to be higher to call forth a given level of stumpage supply in the market than would be true in the absence of acid deposition. If the demand for stumpage is not affected by acid deposition, then expected future prices will increase and timber owners will also be forced to harvest more and more timber earlier on poorer quality lands, which have higher marginal harvesting costs.

Effects of Acid Deposition on Stumpage Market Equilibrium

These effects are illustrated in Figure 3.3. The curve OS represents the market supply curve for stumpage in the absence of acid deposition. Given the market demand curve stumpage, the market clears at point $M$ where $Q$ units of stumpage are supplied at a market price of $P$. At this equilibrium, consumer welfare (surplus) can be valued by the area DMP, while the producer surplus received by timber owners from the sale of stumpage can be valued by the area 


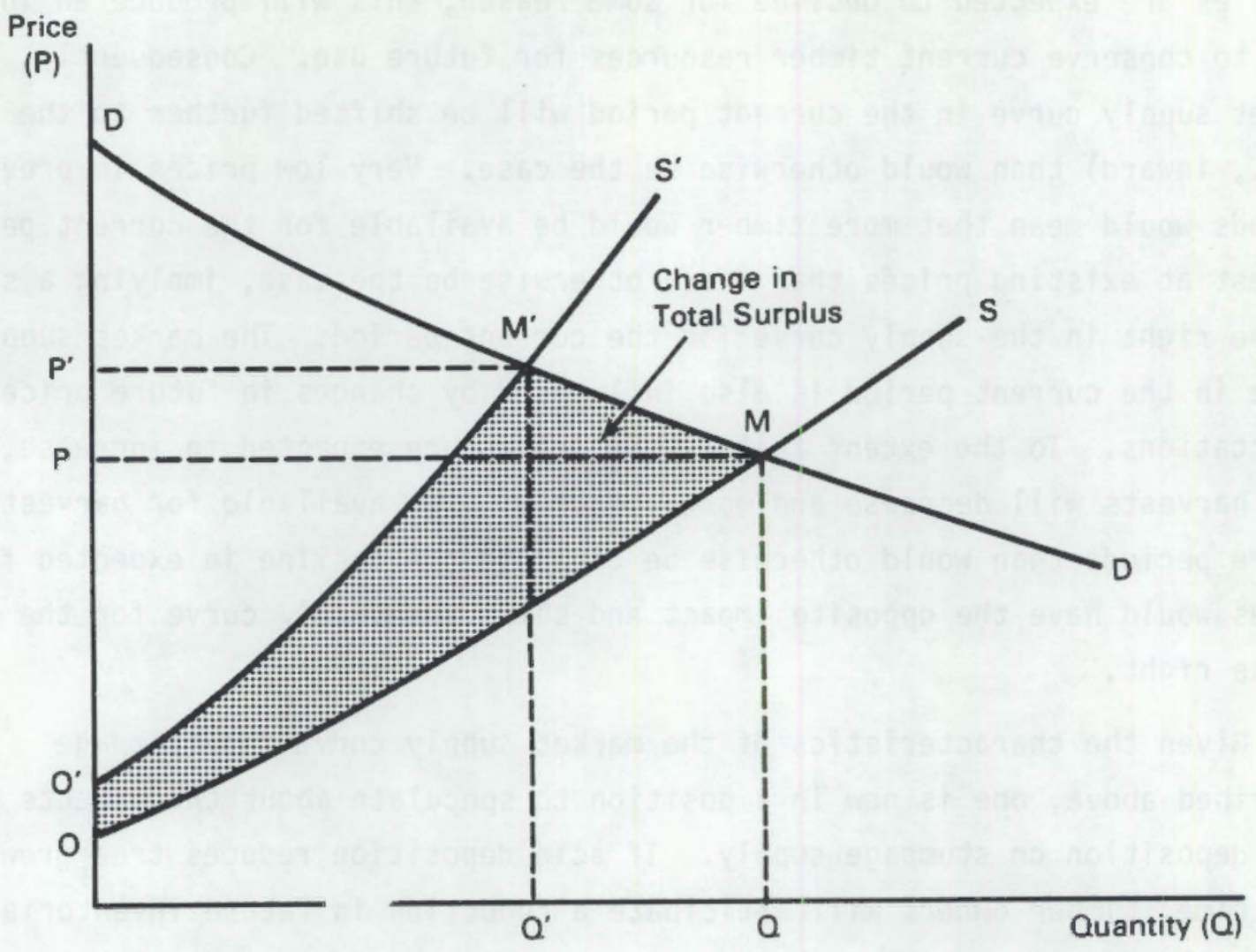

FIGURE 3.3. Measurement of Economic Damages Due to Acid Deposition

OMP. The market supply curve for stumpage, given the history of decreased tree growth due to acid deposition, is shown by the supply curve 0'S'. Given the same demands, the stumpage market now clears at $M^{\prime}$ where $Q^{\prime}$ units of stumpage are supplied at a market price of $P^{\prime}$. Consumer surplus is now equal to the area $D M^{\prime} P$ ' while the profit received by timber owners from the sale of stumpage is equal to the area $0^{\prime} M^{\prime} P^{\prime}$. Thus, the total loss in the sum of producer and consumer welfare between the two states is the shaded area OMM' $Q$ '.

The magnitude and the timing of the shift in the market supply curve for stumpage that might be caused by acid deposition will depend very much on the size and the composition of the inventory base in previous periods. If the forest inventory is very large relative to demand, and if it is composed of a large proportion of mature trees, the market supply curve may not be greatly affected by acid deposition for quite some period of time, and welfare loss experienced by consumer and producers would be relatively small. The reason 
for this is that, given these supply conditions, producers would have little incentive to harvest smaller trees on poorer quality sites due to the very high marginal harvesting and opportunity costs associated with harvesting these trees. In regions that face different supply conditions, the effects of acid deposition may be felt more quickly due to the need to harvest the al ready small stock of young trees at faster and faster rates.

Summary

The results of the preceding analysis with specific reference to the effects of acid deposition in stumpage markets can be summarized as follows:

- If acid deposition decreases forest productivity over time, one can expect that decreases in forest productivity will, over time, lead to a) higher stumpage prices, b) smaller harvests, and c) reductions in the level of aggregate welfare generated within stumpage markets than would otherwise be the case.

- The magnitude of the above impacts will depend, on a region-by-region basis, upon the size of existing timber inventories relative to demand and upon the age and site class distribution of these inventories.

\subsubsection{Linkages to Other Markets and Regions}

The impacts of acid deposition on stumpage markets can be transmitted to other markets and to other regions, even through economic agents in these markets or others may not be directly influenced by the effects of acid deposition on the productivity of commercial timberland. Impacts can be transmitted between markets due to the flow of raw materials through the inter-industry structure of the U.S. economy. Impacts can be transmitted between regions as a result of interregional trade in either stumpage or the forward products made from wood, such as lumber, plywood, pulp, etc.

Impacts on Other Markets

Impacts on other markets can be distinguished, first of all, based on the direction in which they travel through the inter-industry linkage structure of the economy. Impacts that are transmitted from stumpage markets back through 
factor and input markets can be identified in terms of background linkage effects. Impacts that are transmitted from stumpage markets through the demand for stumpage into primary and secondary wood product markets can be identified in terms of forward linkage effects.

In the above context, backward linkage effects include primarily the effects which acid deposition-induced changes in stumpages prices could have on the markets which supply labor, equipment, and other goods and services for harvesting timber. For example, if acid deposition increases the price of stumpage as suggested above, then this would influence the demand for labor to harvest this stumpage. With less stumpage to harvest, less labor would be required to perform these operations. If the effect was wide-spread enough, one could expect a decrease in the wage rate of forest workers, followed by a reduction in the number of hours supplied by these workers.

Forward linkage effects include the effects which acid deposition-induced changes in stumpage prices could have on the markets which use stumpage as a raw or processed material. For example, an increase in the price of stumpage would mean higher raw material prices to lumber yards, pulp and paper plants, furniture manufacturers, etc. Higher raw material prices would, in turn, lower the amount demanded by these industries, but it would also lead to higher prices for the consumers of lumber, paper and furniture. How this would affect the welfare of firms, as measured by changes in their producer surplus, would depend on how much of the increased wood cost would be passed along to consumers in the form of higher prices. Consumers, on the other hand, would experience reductions in their welfare, as measured by changes in consumer surpluses, whenever the prices of the wood products they consume moved upward as an indirect result of acid deposition.

Of the two types of linkages effects mentioned above, those due to forward linkages are relatively more important. This is due to the fact that backward linkages are less important to industries which extract natural resources from the earth than forward linkages. In the case of the forest products sector of the IJ.S. economy, this can be seen by the relatively small amount of income that is generated by industries that are associated with harvesting timber as opposed to those industries which process and finish this timber. 


\section{Impacts on Other Regions}

In the United States, acid deposition is a regional phenomenon that varies in magnitude across regions. However, this does not necessarily mean that economic impacts of acid deposition are confined to the same regions in which this phenomenon occurs physically. In fact, it is easy to show that, whenever there is trade in wood products between two regions, the potential exists for the imports of acid deposition to "spil1 over" from regions where acid deposition is physically damaging trees to regions where it is not.

This type of spillover effect is illustrated in Figure 3.4. This figure depicts the market for, say, lumber in two regions--A, on the left, and $B$, on the right. The initial supply and demand curves for lumber in $A$ are illustrated by the lines $\mathrm{D}_{\mathrm{a}} \mathrm{D}_{\mathrm{a}}$ and $0 \mathrm{~S}_{\mathrm{a}}$, while the corresponding supply and demand curves for $B$ are shown by the lines $D_{b} D_{b}$ and $0 S_{b}$. The prevailing trade price for lumber, under these conditions, is $P$. At this price, $B$ produces $Q_{b} S$ board feet of lumber, of which only $Q_{b}{ }^{D}$ is consumed locally. The difference between the quantity of lumber produced and the quantity demanded by $B$, or $Q_{b}{ }^{S}-Q_{b}{ }^{D}$, is exported to region $A$. At that same price $(P)$, region $A$ produces $Q_{a}{ }^{S}$ board feet of lumber and consumes $Q_{a}{ }^{D}$ board feet. The difference between supply and demand is satisfied by imports from $B$. Thus $Q_{a}{ }^{D}-Q_{a}{ }^{S}=Q_{b}{ }^{S}-Q_{b}{ }^{D}$.

The hypothetical effect of acid deposition is introduced into Figure 3.4 through the movement of the supply curve for lumber in region $B$ from $D S_{b}$ to $0^{\prime} S_{b}$ '. This movement is consistent with an increase in the price of stumpage in $B$ due to the effects of acid deposition on the opportunity cost and the marginal harvesting costs of stumpage. The result of this shift is that the trade price of lumber now increases from $P$ to $P^{\prime}$. At this new price, lumber production in region $B$ falls sharply to $Q_{b} S^{\prime}$, while lumber consumption in that region falls slightly to $Q_{b}{ }^{D^{\prime}}$. While region $B$ is still an exporter at the new trade price, the volume of exports falls dramatically to $Q_{b} S^{\prime}-Q_{b} D^{\prime}$. In region $A$, on the other hand, production now increases to $\mathrm{a}_{\mathrm{S}^{\prime}}{ }^{\prime}$ board feet of lumber while consumption falls by about an equal amount to $Q_{a}{ }^{D^{\prime}}$, reducing the need for exports from $B$ to make up the difference. 


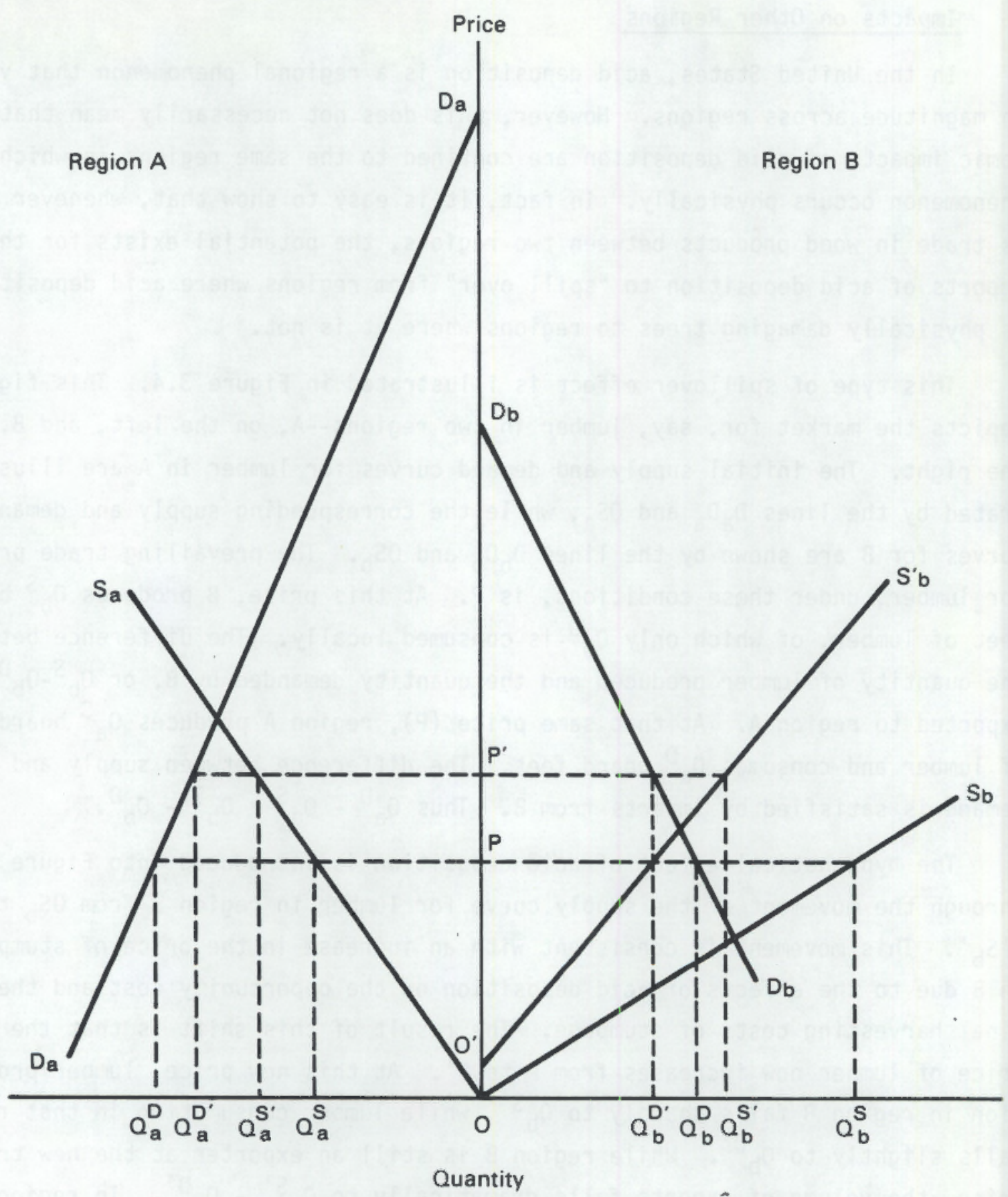

FIGURE 3.4. Hypothetical Impacts of Acid Deposition on Interregional Trade 
The change in the magnitude of exports from $B$ to $A$ is accompanied by at least two different sorts of welfare transfers. First, Figure 3.3 shows that, while producer surplus in region B decreases, producer surplus in region A actually increases due to the higher trade price. The net change in producer surplus is, however, positive. Second, Figure 3.4 shows that consumer surplus in both regions decreases. Furthermore, these decreases involve sizable transfers of consumer surplus to producers in both regions. Both of these types of welfare transfers--between regions and between economic agents in the same region will take on added meaning later in this report in Section 7.0 which shows how simulated changes in timber growth have the potential to reproduce the impacts illustrated in this figure.

The impacts shown in Figure 3.3 represent just one of many potential patterns that could occur as a result of acid deposition-induced spillovers from one region to another. On a more general note, however, this figure illustrates the potential for acid deposition to influence (perhaps dramatically) the comparative advantage which some regions currently enjoy as exporters of wood products.

\section{Synthesis}

The two types of spillovers presented in this section are combined for explanatory purposes in Figure 3.5. The chain of events shown in this diagram is consistent with the pattern depicted in Figure 3.4. However, linkages between the stumpage and product markets in both regions, which could not be shown in Figure 3.4, are now made explicit.

Acid deposition enters into this process in the form of hypothetical reductions in tree growth rates in region $B$ which, in turn, reduces the amount of inventory available for harvesting in current and future periods. This causes stumpage prices to rise and harvest levels to fall in region $B$ in anticipation of future lumber shortages. The increase in stumpage prices in region $B$ means higher wood costs to firms in the product market, leading to increased product prices and reduced production in that region. Since region $A$ and $B$ are joined by trade in wood products, the increase in wood product prices in region $B$ leads to increased output in the product market in $A$ and to 


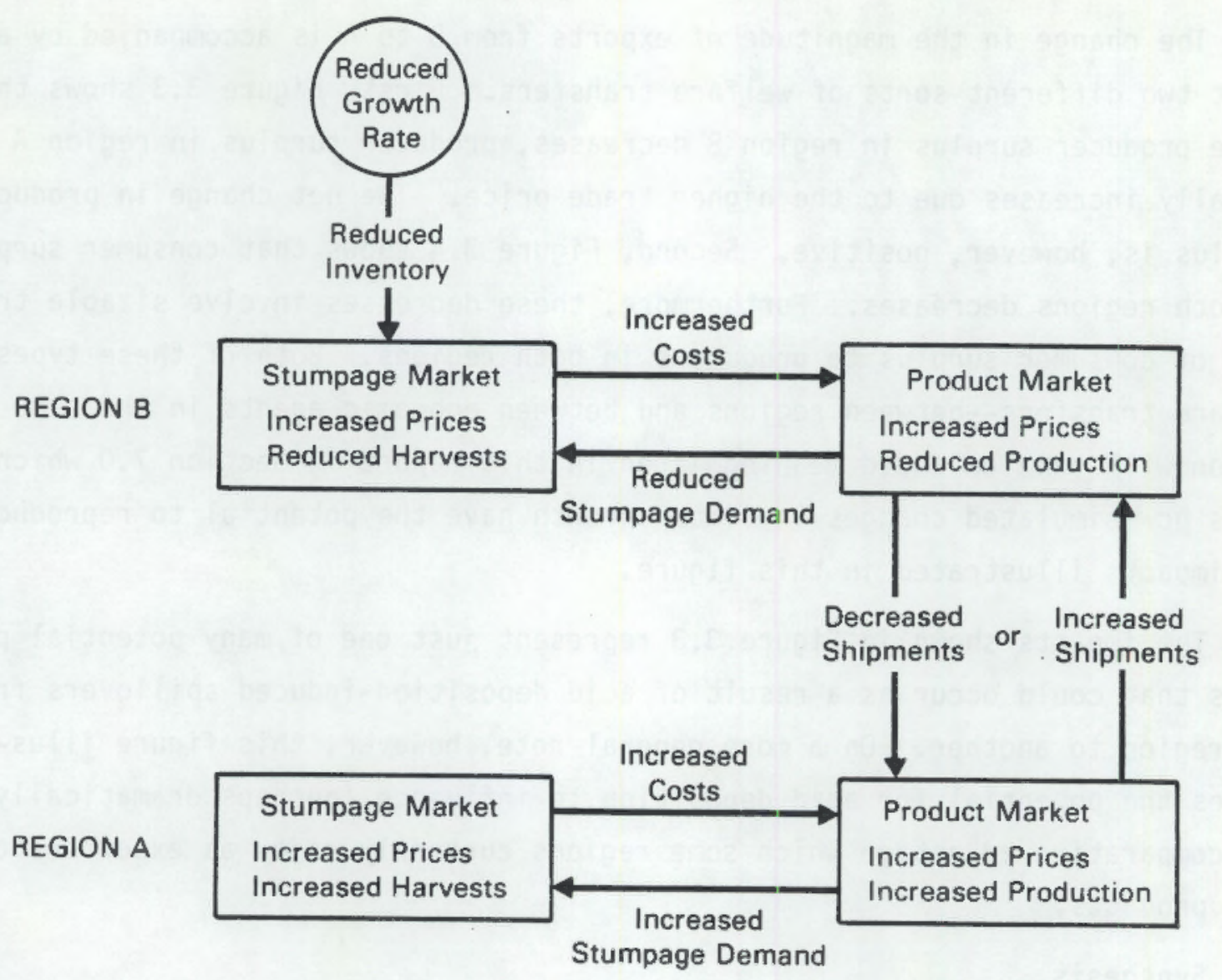

FIGURE 3.5. Schematic Diagram of Hypothetical Effects of Acid Deposition on Stumpage and Produce Markets in Two Regions

increases in the demand for stumpage in that region at higher product prices. As this occurs, region $A$ is in position to increase its exports to $B$ (if A was previously an exporting region) or, as in Figure 3.4, reduce the volume of products which it must import from B. The new trade position is reached and equilibrium established between the two regions when the marginal cost of production in both regions (entailing higher wood input costs in both $A$ and $B$ ) is equal to the prevailing trade price.

\subsection{IDENTIFICATION OF IMPORTANT METHODOLOGICAL FEATURES}

Based on the analysis presented in Sections 3.1-3.2, there appears to be at least five important features that should ideally be built into the methodology that will be used to evaluate the economic impacts of acid deposition or 
other air pollutants on commercial stumpage and primary wood products markets. These features include:

1. A forest inventory model that is not only capable of simulating regeneration, growth and mortality of hardwoods and softwoods on a regional basis, but can also interact directly with a forest sector economic model to simulate the effects of harvesting on inventory size and composition.

2. Stumpage supply curves which will be responsive to acid depositioninduced changes in the size and composition (i.e., age and species) of the forest inventory, as well as to changes in expected future prices.

3. Multi-level market coverage which includes important forward linkages from stumpage markets to primary wood product markets.

4. The capability to simulate the effects of acid deposition-induced spillovers between regions through interregional trade.

5. The capability to value the damages of acid deposition and the benefits of control policies using accepted consumer and producer surplus concepts in multiple markets. 


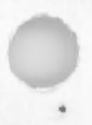

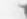

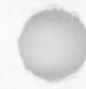

$\checkmark$

- 


\subsection{ANALYSIS OF MARKET MODELS}

The purpose of this section of the report is to describe the structure and critically evaluate the major features of different types of economic models which could be used to trace the effects of pollution stress from the resource base--namely, the inventory of commercial timber--into the markets for hardwood and softwood stumpage and the wood products made directly from this stumpage, principally plywood, lumber and pulp. To achieve this objective, the section has been divided into three parts. Section 4.1 briefly reviews the major types of market models that could be used in the analysis. Section 4.2 focuses on the potential uses of normative (e.g., mathematical programming) models in capturing the market-related effects of pollution stress. Finally, Section 4.3 concentrates on the Timber Assessment Market Mode1 (TAMM). This model was singled out for the closest possible scrutiny hecause, of all the models screened initially for this study, it was the only one which appeared to he immediately suited to performing the types of assessments contemplated by EPA.

\section{1 OVERVIEW OF MARKET MODELS}

There are many different ways of classifying timber market models. Basic differences between them $c$ an be distinguished on a number of grounds, for example: 1) whether they are dynamic or static; 2) whether they are designed primarity for policy analysis or to forecast short-term movements in prices and output; 3) whether linkages to the national economy in the model are explicit or implicit; 4) whether the geographic delineation contained in the model is national or regional, and so on. These distinctions hecome very important when selecting a model to fulfill a specific set of research objectives. However, hecause an individual model may incorporate a great many different attributes, classifying timber market models along multi-dimensional lines often obscures more general differences. Therefore the distinction between timber market models that is used in this report is perhaps the most basic one of all, namely: between models that are constructed in such a way as to show how economic agents should behave in order to achieve a given set of economic 
(and/or non-economic) objectives, which represents a normative approach, and those that are designed to predict the actual behavior of economic agents within timber markets, the so-called positive approach to economic modeling.

Explicitly or implicitly a nomative model is composed of three elements: 1) an objective function that is consistent with the aggregate behavior of relevant decision-making agents (i.e., private industrial fim, non-industrial private firm, public owners, etc.); 2) an alternative set of production activ. ities which describe the various ways in which the resources within the mode? can be used in a production process; and 3) a set of restrictions on the avaj ability of the resources in the model. Given these elements, mathematical programming algorithms or other closely-a?lied "heuristic" methods are then used to allocate the available resources in the model to alternative production activities in order to satisfy the criteria that are specified in the objective function. The results obtained from these models can be validated against actual data. However, doing so will not provide a valid indication of whether the model is a good one or not since the purpose of a normative model is not to forecast the future as it will be. As previously stated, the purpose of a normative model is to forecast what the future would look like if decision-makers faithfully followed specific objectives using a specifically-defined technology.

Models based on the positive approach are often referred to as econometric models, because they involve the application of advanced multiple regression (econometric) methods to the specification of model equations and the estimation of the parameters contained within these equations. Briefly, an econometric model is composed of a series of behavioral equations, each of which relates a single dependent variable to a set of explanatory, or independent variables. The way in which these equations are organized as a whole, as well as the functional form and explanatory variables that are used for each equation, collectively represent a set of hypotheses about how economic agents behave in timber markets. The parameters of these equations, which determine how sensitive the dependent variable will be to changes in each of the explanatory variables, are estimated statistically by means of advanced multivariate 
regression techniques using either historical, time series and/or crosssectional observations on all of the variables. The accuracy of these models as forecasting instruments can then be tested by seeing how well the model actualiy forecasts the behavior of timber product and stumpage prices, production and consumption, using a different data set than the one employed to estimate the parameters of the model. The basic difference between normative and positive models is that with the former one first postulates the physical and biological processes that govern production; imposes a decision rule on that production and then infers what "ought" to be the economic decisions of owners of commercial timberland and producers and buyers of timber products. With positive models, one begins with the decisions of timberland owners and timber products firms, as observed in their harvesting and production decisions, and then infers the technology using various statistical, curve-fitting techniques.

\subsubsection{Overview of Nomative Models}

The basic differences in nomative models that have heen used to assess timber supplies can be traced to the differences between the timber supply problem of the individual firm and the timber market supply problem. These differences were addressed in a somewhat technical fashion in the previous section of the report. For the sake of this overview we can describe these differences in less technical terms as follows. At the level of the individual firm (i.e., commercial timberland owner), the timber supply problem usually takes the form of finding the optimal age (i.e., rotation age) at which to harvest all trees of the same age on a single representative acre of timberland. In this problem, stumpage prices are assumed to be exogenous to the firm or timberland owner. This is because the amount of timber harvested by an individual owner or fim is assumed to be an extremely small fraction of the amount of timber harvested in the market as a whole. At the market level, on the other hand, this is no longer the case since the market demand curve for stumpage in each period is assumed to be downward sloping. Given this condition, the market supply problem consists of finding the profile of timber 
harvests and associated stumpage prices over time which is consistent with wealth-maximizing behavior on the part of all timberland owners.

The rotation problem of the firm is closely allied to the Faustman model, which was outlined in the previous section. In addition to using the model in its basic form to determine the rotation age of an even-age forest, it can aiso be adapted to handle non-time dependent controls such as thinning (Kikki and Vaisanen 1969). Intended originally to apply to a single, homogenous aggregate of timberland (i.e., plot, stand, or forest), the Faustman model can also be applied at the regional Tevel to determine the order in which non-homogenous plots will be harvested as stumpage prices are increased. The resulting schedule of harvest volumes versus stumpage prices represents the long-run supply curve for this larger collection of timberland acres. The history of long-run supply models based on the Faustman model is commonly traced to Vaux's (1954) analysis of the sugar pine resource in California. Extensions of this approach are embodied in the analysis of the timber supply situation in the Douglas Fir Region by the Forest Service (1963) and by Hyde (1980) and in the Southeast by Robinson et al. (1980). The definitive treatment of this approach for using a firm-level model to develop regional market supply curves, from the "bottomup", is given by Jackson (1980). In Section 4.2 we will take a much closer look at Hyde's approach as a possible method for assessing the effects of acid deposition on regional stumpage markets.

Normative models used to simulate market behavior generally differ from Faustman-type modeis in two major respects. First the basic structure of the two types of models is entirely different. In the basic Faustman model one solves for the rotation age which maximizes the net present value of the timber harvests from a representative acre of timberland for either a fixed or infinite time period, given fixed stumpage prices for the current and all future periods. In the market-wide problem, on the other hand, one solves for the optimal trajectory of timber harvests and stumpage prices which maximizes the sum of consumer (e.g., buyer) and producer surplus in the stumpage market subject to the laws of motion for the system. These laws of motion are realiy continuity of mass equations which ensure that the starting inventory for each age or diameter class in each period less the amount of timber harvested in 
that age or diameter class is equal to the ending inventory. Thus, rotation age is not a control variable in the market-wide approach, although the length of the rotation for an individual age class of timberland acres can be determined once the acres in this age class have been harvested.

The second important difference between the two types of normative models relates to the treatment of stumpage prices. In the Faustman model, stumpage prices are fixed outside the model although they do not necessarily have to remain constant over time. This approach assumes that the actions of the timber owner witl have only a negligible effect on current or future stumpage prices. In the market-wide approach, this assumption is no longer maintained. Stumpage prices are determined in these models jointly with harvest levels by changing the objective function to include maximization of the areas under the market demand curve and above the market supply curve for stumpage for the sum of consumer and producer surplus) in each period for which the model is to be run.

The market-wide approach is embodied in two different types of normative model. The first is the traditional optimization model, examples of which can be found in the fixed end point models of Johnson and Scheurman (1977) and also in FORPLAN (Johnson et al. 1980) More recently, Lyon (1980) and Lyon and Sedjo (1982) have extended the earlier work by McDonough and Park (1975) in the area of dynamic optimization by developing a discrete time optimal control model called Supply Potential Optimal Control (SPOC) to model the forest transition. The second type of market-wide optimization model that has been developed is the so called "heuristic" class of models which attempt to duplicate optimal processes by using short-cut rules rather than by appealing to the formalities of dynamic programing (Bellman 1957) or Pontryagin's (1962) maximum principle. This type of model is typically associated with the binary search technique introduced by Walker $(1971,1976)$ which was extended by Tedder et al. (1980) in the Timber Resource Estimation System (TREES). The TREES model has since been used in the timber supply assessment conducted for the Northwest Forest Policy Project by Rahm (1981). In Section 4.3 we will examine both the SPOC and TREES models as possible alternatives for assessing the impacts of acid deposition on regional stumpage markets. 


\subsubsection{Overview of Econometric Models}

Adams and Haynes (1980) identify four different types of econometric timber market models: gap, nonspatial market, quasi-spatial market and spatial market models. We briefly review each of these approaches.

In gap models, forecasts of production and consumption are made using a prespecified price level or price trend. The ensuing "gap" between production and consumption is then examined. If consumption is forecasted to be greater than production, then prices will exceed their predetermined level. If the converse is true, then prices will be less than their predetermined level. Usually the class of forest products considered by gap models is very broad (e.g., softwood lumber production), and the analysis is applied on a national level. Some of studies which have applied this approach are "Timber Resources for Anerica's Future" (USDA Forest Service 1958), "The Outlook for Timber in the U.S." (USDA Forest Service 1973), and "The Nations Renewable Resources--An Assessment, 1975" (USDA Forest Service 1977). The primary reason that gap models cannot be used very effectively to assess the effects of acid deposition on timber products and stumpage markets is that these models do not have any internal price determination mechanisms. Hence, the effects of acid deposition on market equilibrium cannot by investigated systematically.

Nonspatial market models contain explicit representations for market supply and demand relationships so that equilibrium prices, output and consumption levels can be determined endogenously within the model. These models contain oniy one region: suppliers and purchasers are treated as if they participate in a single regional (usually national) market. Most of the nonspatial models that have been developed are for product markets, for example: Gregory's (1960, 1965) treatment of hardwood flooring markets, Schuler and Wallin's more recent (1979) study of the U.S. pallet market and Luppold's (1982) study of the hardwood lumber market. Nonspatial market models that have focused on more than one market level include McKillop's (1969) classic study of the supply and demand for forest products in the U.S., Adams' (1974) timber supply study of Douglas fir region and Adams' and Blackwell's (1973) econometric model of the U.S. forest products industry. However, only one study, by Adams (1977), explicitly includes specific functional representations for timber harvests on 
private and public lands. No examples were found of nonspatial models in which harvest levels were explicitly related to the size or structure of the timber inventory. For this reason and the lack of spatial dynamics, nonspatial market models are not well suited for assessing the effects of acid deposition on regional stumpage and timber product markets in the U.S.

The distinction between quasi-spatial and spatial market models made by Adams and Haynes (1980) is not always clear, so we will ignore the distinction and identify two different types of spatial models based on whether or not they can simulate trade flows between demand and supply regions. The first type of spatial model is one in which the demand structure (usually in the product market) is national, while supply functions are developed for each supplying region. In this type of model prices are equalized in all of the supply markets and in the national demand market by allowing trade from the supply regions to the single demand region: Examples of this type of model are Adams (1975, 1977) and Lange's (1983) multi-level hardwood market model of the U.S. The second type of spatial model contains both supply and demand regions (which may or may not be the same geographically). In this type of model, the parameters of regional supply and demand functions are estimated by econometric methods and then a mathematical programing algorithm is used to find the trade flows between supply and demand regions which equate demand with supply prices. This type of approach is consistent with the neo-classical theory of a spatial price equilibrium (Samuelson 1952; Takayama and Judge 1971). It is exemplified in the multi-level softwood market models of Adams and Haynes (1980).

A final type of spatial model-one which is difficult to fit into any one of the categories suggested by Adams and Haynes (1980)--is the Forest Simulation (FORSIM) model, developed by Veltcamp and described in Cardellichio and Veltcamp (1981) and Oata Resources Inc. (ORI 1982). In FORSIM, supply and demand in each product market are modeled on a regional basis. However, the determination of market clearing prices in each region is handled much differently than in other spatial models. Market clearing is accomplished in the FORSIM model through a network of market share equations which interact simultaneously with regional price and output relations in the following manner. A price for a representative product (lumber or plywood) from each supply region 
is specified in each demand region. The delivered price is then compared to a delivered product price index for all the other supply regions. If the delivered price for the supply region is higher than the price index then that: region will experience a decline in its market share and its output must fall. Conversely, if the delivered price is significantly lower than the price index then the supply region increases its market share and output increases. Market shares, prices and output levels are adjusted by means of this process until a set of market-clearing price conditions are satisfied.

Lange's (1983) hardwood market model and Adams and Haynes' (1980) softwood market models have been implemented in quasi-interactive framework commonly known as the Timber Assessment Market Model or TAMM. These two models and the DRI softwood model (FORSIM) were screened based on the criteria developed in the previous section. While FORSIM contains a number of structural features which are perhaps more theoretically pleasing than those in TAMM, FORSIM does not meet all of the screening criteria. In particular, FORSIM contains no explicit linkages to an inventory projection model whereas both the hardwood and softwood models in TAMM do. In addition, FORSIM is not a "complete" model in the sense that it was developed to deal only with softwoods. DRI currently maintains operational hardwood and pulp models to complement FORSIM. However, there is no interaction between these models, whereas the hardwood and softwood models in TAMM interact on a limited basis through a common pulp model.

The TAMM models will be evaluated critically in much greater detail in Section 4.3.

\subsection{NORMATIVE MODELS}

Normative models have several important features which make them potentially attractive alternatives for assessing the impacts of acid deposition and other pollutants on timber product and stumpage markets. These include:

- Explicit Linkages to Physical Inventory. Normative models have the ability to characterize even and uneven age stand structures; in addition, the continuity of mass is explicitly maintained from regeneration to final harvesting. 
- Dynamic Properties. Normative models are capable of duplicating the long-tem behavior of timber owners, consistent with the behavior of wealth maximizing individuals in both timber product and timber asset markets.

- Welfare-Theoretic Properties. Normative market models (i.e., demand curves for stumpage are downward sloping) have the capability to provide estimates of both short- and long-run consumer and producer surplus which are consistent with rational economic objectives of timber owners and buyers in stumpage markets.

However, nomative models also have several features which makes them more difficult to use in a national assessment of the effects of acid deposition on timber product and stumpage markets. These features include:

- Limited Regional Scope. Normative models are developed at the regional or sub-regional level; as such product flows between regions are not modeled explicitly.

- Limited Market Scope. Normative models do not as a rule include explicit activities to take into account the the processing of stumpage and subsequent sale of products made from stumpage within the region.

- Highly Aggregated Timber Inventory. With one very important exception, the TREES model (Tedder et al. 1980), the resource base carried within normative models is highty aggregated; differences in yields across individual tree species, owner groups, site classes, and other important characteristics of the timberland inventory are frequentiy glossed over.

None of the above problems are due to methodological limitations. They stem instead from practical and computational limitations that emerge when the size of normative model is increased to handle the added structural detail required to extend the regional, market and inventory scope of these models. Nevertheless, these limitations are still very real and one may wonder why we have even bothered to take a closer look at these models. The answer to this question is that, in spite of the difficulties that would be encountered in 
using normative models in a national economic assessment of the effects of acid deposition, most of these models have one very important characteristics which cannot be easily ignored. This characteristic, suggested in the previous section of this report, is the potential of these models to mimic (or closely approximate) the long-run determination of stumpage prices. Econometric models like TAMM can simulate the effects which the behavior of timber owners in the present will have on future stumpage and product market prices because of the explicit linkages in TAMM between the stumpage market and the timber inventory. However, it is more difficult for econometric models to capture the feedback effects of expected future stumpage prices on current period behavior.

of the positive features identified above, the most important relates to the dynamic properties of nomative models. Simulating the behavior of timber owners in and explicitly dynamic framework is important in the case of acid deposition because of the potential for acid deposition to indirectly influence harvesting in the present due to expected future shortages of timber. In the few remaining pages devoted to normative models we will investigate how existing methods and models could be used to address this shortcoming of econometric models in a complementary fashion. To do this, we will take a closer look at the long-run timber supply projection methodology developed by Hyde (1980) and at the TREES (Tedder et al. 1980) and SPOC (Lyon and Sedjo 1982) models.

\subsubsection{Long-Run Timber Supply Projection Methodology}

Hyde's (1980) approach to developing long-run timber supply curves for selected regions was based on the application of a Faustman-type model to a representative single-acre plot of an even-age forest. In Hyde's case study analysis of the 0ouglas fir region in the Pacific Northwest, the inventory of commercial timberland devoted to Douglas fir was broken down by ownership and by site (productivity) classification. On each of these representative acres, the parameters of the biological production function and the per acre production costs in the Faustman model were allowed to vary to reflect different silvicultural practices. Stumpage prices were assumed to be a fixed function of timber quality (or diameter) which was a function of harvest age.

Thus, expected prices, site quality, and ownership are exogenous in the model. The silvicultural regime to be practiced and final harvest date were 
decision variables. Given the site and ownership characteristics of a representative acre and a vector of expected prices, there should be one silvicultural regime and one rotation age (final harvest date) which maximizes the objective function of the Faustman model. Hyde derived the single-acre longrun supply curve for different sites and owners as follows. On each representative acre an expected price was selected and the corresponding rotation age and objective function value was calculated for each silvicultural process. This process was repeated for a vector of alternative expected prices in order to produce a series of points wich together defined the annual supply curve for a given site quality, silvicultural regime, and ownership classification. Holding site quality and ownership constant, Hyde then selected the appropriate long-run supply curve among the available set of supply curves (one per silvicultural alternative) on the basis of the net present value criterion.

The above process yielded long-run supply curves for each representative acre in the Douglas fir region. To obtain the aggregate regional supply curve, the following operations were performed. First, Hyde multiplied the annual harvest level at each price by the number of acres in each site class, by owner, and then cumulated the harvest volumes across owners (holding prices constant) to obtain the regional supply curve. The results of this analysis for the 1975 period showed that, at then-current stumpage prices, timber owners were cutting substantially less timber than indicated by the long-run supply curve for that period. This finding was consistent with the earlier work of Pearse (1967) and a subsequent study by Berck (1979) which showed that producers in the Douglas fir region were harvesting their timber at rotation ages substantially longer than those implied by the Faustman model.

In Hyde's approach, stumpage prices are assumed to be determined outside the region for which the supply curve was developed. Hence, each region is viewed as a price taker in the stumpage market and there are no direct linkages between current and future prices. As such the model is dynamic from the standpoint of the individual region but static with regard to price determination at the mutti-region market level. However, as Samuelson (1976) points out, the market equilibrium implied by the Faustman model (i.e., constant stumpage prices over time) is consistent with the steady state of the fully 
regulated forest. This is also verified, by implication at least, in Berck's (1979) analysis of the long-run supply curve for Douglas fir and Lyon and Sedjo's (1982) paper on the long-term supply of timber in a region. Thus, the static aspects of the model do not necessarity invalidate the long-run market characteristics of the stumpage supply curves that can be derived by this method.

Hyde's approach could be adopted fairly easily to assess the affects of acid deposition on the long-run supply of stumpage in a region. The "only" additional data required to do this would be the necessary yield tables (e.g., schedules of timber volumes versus rotation age by species) to reflect the affects of acid deposition. Estimates of regional producer surplus for speci.. fic stumpage price scenarios could then be determined "with and without" acid deposition. This would provide one means of measuring the economic impacts of acid deposition on long-run timber supplies in a single region.

The chief advantages of this approach lie in its relatively limited data needs and comparative methodological simplicity. However, this approach also possesses several defects. The first problem is that the approach is not explicitly multi-regional, so that market adjustments to acid deposition in the form of interregional factor and product flows could not be made explicit within the model.

This drawback is by no means unique to this approach. As we suggested earlier, normative models tend to focus on stumpage supply in a single region. Consequently, normative models are best evaluated in terms of how well they may be able to simulate the response of the regional stumpage market to changes in acid deposition levels. On this score, Hyde's approach can also be found seriously wanting. The reason for this is that the approach does not contain any explicit provisions for stumpage price determination in the presence of downward sloping demand curves for the resource. While it is true that one could use a downward sloping demand curve in each period to find the periodic equilibrium harvest levels and stumpage prices using Hyde's approach, this formulation would not be theoretically consistent with long-run price determination in a regional stumpage market. In theory, current harvesting and management decisions will be influenced by expected future prices. However, 
the method suggested above does not provide for any explicit flow of information by means of which these price signats could be passed from period to period. Instead, this method produces a series of short-run stumpage market equilibrium conditions without any intertemporal equilibrium imposed between periods. Consequently, this approach really does not possess enough of the favorable dynamic characteristics of most normative models of timber supply to warrant serious consideration for use in a regional assessment of the economic effects of acid deposition. In addition because stumpage demands are not sensitive to changes in stumpage prices, changes in the welfare of stumpage buyers due to increases in acid deposition cannot be determined.

\subsubsection{Timber Resource Economic Estimation System (TREES)}

The TREES model was originally developed to assess the long-run timber supply situation in Oregon (Beuter et a1. 1976) and has been documented more recently by Tedder et al. (1980). The model itself performs three basic functions. First of all, it can act as an inventory projection model for both even-age and uneven age forests composed of either a single or multiple species. Secondly, the TREES model contains features which allow it to simulate a variety of different silvicultural systems. Finally, TREES can simulate a variety of harvest scheduling methods and harvest-priority selection techniques on both even and uneven age forests.

The TREES inventory is organized around the basic resource unit, the BRU, and the grouped resource unit, the GRU. The BRU is the basic building block of the forest inventory. Each BRU in the inventory describes a unit (e.9., number of acres) of commercial timberland with respect to a common set of attributes. These attributes include: location, ownership classification, stocking-level, site or productivity classification, forest type or species and management intensity. For even-aged BRU's, volumes per acre are carried on an age class basis. For uneven-aged BRU's, the number of trees per acre are specified both by diameter class and by average volume. The GRU is a collection of BRU's sufficiently similar with respect to management, growth and yields (or diameter class distribution for uneven-age stands) to managed as a single unit. The growth of even age GRU's can be simulated by using standard yield tables or by "fitting" the observed volumes per acre to an age distribution using multiple 
regression models. The growth of uneven-age GRU's can be simulated by userspecified radial growth rates or by fitting the observed number of trees in each diameter class to the observed diameter class distribution. The parameters of this regression model can then be used to calculate ingrowth (the number of trees growing into the smallest diameter class) and upgrowth (the number of trees moving from an initial diameter class to higher diameter classes in a year).

Regeneration, growth, response to silvicultural treatments and mortality are all simulated within individual GRU's. Harvesting is simulated by aggregating GRU's into an allowable cut unit (ACU) which defines the type of harvesting that will be performed. There are 7 different harvest scheduling methods that can be specified within TREES. However we will concentrate entirely on the Present Net Worth (PNW) method. The PNW method allows the user to specify the harvest priority as oldest trees first, slowest growing trees first, or highest value trees first. Once the harvest priority is determined, the amount to be harvested in each period is found using a binary search algorithm, based partially on the work of Walker $(1971,1976)$. A comparison of Walker's algorithm and the PNW algorithm in TREES is given in Schmidt and Tedder (1981). The following discussion of the PNW algorithm is based largely on Schmidt's and Tedder's analysis.

The search for the optimal harvest volumes (by age class) is started by specifying an initial guess for the total quantity of timber to be harvested in the first period. Stands are then harvested based on the predetermined priority until the harvest level for the first period is reached. The last age class harvested in a period then becomes a "linkage" age class, only part of which is harvested in the current period. Next, the target amount in the second period is calculated using a linkage equation between the first and second periods that is consistent with the mathematical (e.g., Xuhn-Tucker) conditions required to achieve the optimal harvest profile over time, under special circumstances. After the harvest target in the second period has been calculated the stands are again harvested until that target is achieved and the linkage age class and the third period harvest target is determined. The algorithm proceeds sequentially in this manner, linking each harvest to the 
harvest in the previous period until the harvest target is either greater than the volume available or less than zero. When this happens, the algorithm is restarted in the first period with a new starting volume "guess," designed to eliminate the above discrepancy. This second process is repeated until 1) initial the difference between the preselected initial harvest level and the simulated harvest level are very close; 2) every simulated harvest is close to each corresponding harvest; and 3) there are no negative harvests.

Using the TREES model to assess the effects of acid deposition on timber markets could be accomplished in much the same manner suggested for the Hyde approach. Specifically, this would involve developing yield tables (timber volume per acre) for each GRU to reflect the affects of acid deposition on the productivity of commercial timberland. Consumer and possibly even producer surplus could then be determined on a regional basis with and without acid deposition using the PNW method. This approach would provide a theoretically better estimate of the economic impacts of acid deposition on long-run timber supplies than would Hyde's method.

The IREES model has several distinct advantages over the method developed by Hyde. First of all, the inventory carried within TREES contains much greater detail than the inventory embodied within Hyde's approach. Secondly, TREES can simulate forest management and harvest scheduling for stands with any arbitrary age or diameter class distribution whereas the long-run supply curves developed by Hyde are derived explicitly from even-age stands and implicitly from stands in a fully regulated forest. Third, TREES can simulate a much wider range of harvest scheduling methods than is possible using Hyde's approach, which is strictly limited to developing long-run supply curves that are consistent with explicit intertemporal objectives. Fourth, TREES is superior to Hyde's approach in that the PNW algorithm simulates harvest scheduling in the presence of explicit linear demand curves for stumpage. The resulting time profile of harvest volumes that can be simulated with this algorithm approximates the results that can be obtained using a more formal dynamic programing or optimal control model of the long-run timber supply problem (Schmidt and Tedder 1981). Finally, the presence of downward s?oping 
demands for stumpage means that TREES can be used to assess the effects of acid deposition on the welfare of both timber owners and buyers.

These specific features help to make TREES a better candidate for simulat,ing the market impacts of acid deposition than the Hyde approach. However, this approach shares two of the shortcomings that are present in Hyde's method. First of all, TREES is a non-spatial mode1, designed to be implemented in a single region. Secondly, TREES is a single-level model, which includes only the stumpage market within a region. However, these two shortcomings do not restrict the use of TREES in a single region context the same way they do the Hyde approach. The reason for this is that TREES can simulate harvesting in the presence of downward sloping market demand functions so that both stumpage prices and harvest volumes are determined within the model in each period in a manner that is approximately consistent with the theory of natural resource extraction by wealth-maximizing firms. Provided that these stumpage demand functions in TREES can be specified to explicitly reflect the excess demand for stumpage in a region (taking into account exports and imports in the product market, as well as log shipments), then TREES can be used in a quasispatial context. The results obtained from TREES using this formulation would then be consistent with a spatial equilibrium in the product market provided that the presence of acid deposition in other regions did not influence the demand for timber products or log exports in the region being modeled. This is a rather strong assumption and clearly limits the application of TREES in a multi-regional assessment of the economic impacts of acid deposition on regional timber markets. However, the assumption is not so strong that it would preclude using TREES to learn more about the affects of acid deposition on the dynamic aspects of timber supply in a single market.

\subsubsection{Supply Potential Optimal Control (SPOC) Model}

The SPOC model was developed by Lyon and Sedjo (1982) to analyze the forest transition from some existing age distribution to the fully regulated forest. Supply behavior during this transition period is viewed to be of interest because the length of time required to complete the transition typically approximates the optimal rotation age of the forest, or from 30 to 70 years in most cases. This period is sufficiently far away in the future 
that short-run models (like TAMM or FORSIM) may not be able to provide very accurate insights about the time path of stumpage prices and harvest volumes during the transition. However, this period is sufficiently short that firms cannot afford to ignore the expected price of stumpage for the current and possibly the next rotation. Models of this transition, based on economic objectives, have been built in the past (Anderson 1976). However, these models have been extremely simple, assuming an "ageless" inventory base and no management.

SPOC's contribution in this area is that is provides an explicit method for finding the harvesting profile over time that is consistent with the transition to a steady state condition (e.g., fully regulated forest). It does this for an age-differentiated timber inventory which can be subjected to different levels of harvesting and management intensity in response to anticipated future prices. Stumpage prices and harvest levels are determined endogenously by the model, given stationary demands for stumpage. Estimates of consumer and producer surplus in stumpage markets are also provided by the model.

SPOC contains an objective function which represents the difference between (a) the present value of the benefits of harvesting timer in a market with a downwarding sloping demand curve and (b) the present value of the costs associated with planting and managing the timber resource. The objective function is maximized subject to a set of balance equations, or equations of motion, which maintain the continuity of the inventory on commercial timberland over time as trees grow, are harvested and are then replaced by new trees. The solution to this constrained optimization problem provides year-by-year information about inventory levels, harvest volumes, and management levels on an age-specific basis and about the present value of the net benefits associated with these activities. The solution technique is rather involved and is spelled out in detail in Lyon and Sedjo (1982).

SPOC is elegant because, unlike TREES, the harvest priority, the harvest schedule and management intensification are all determined endogenously. The cost of producing so elegant a model is a tremendous loss in practicality. SPOC, as it is currently structured, works only with even age forests. However, an uneven-age model, embodying essentially the same solution technique, 
would not be difficult to implement. More serious is the comparative lack of detail that can be accorded to the inventory in SPOC. While it is theoretically possible to have as many owner groups, species, management practices, site classes and stocking levels (or any other set of characteristics) as one wants in the model, a combination of cost and computational limits prohibits the same level of inventory detail that can be carried, for example, in TREES. Current versions of SPOC have only a single species, two site classifications, and by implication a single owner.

CouTd SPOC be used to assess the effects of acid deposition on regional stumpage markets? Despite the above limitations of the model and the fact that, like TREES, it is a strictly regiona? model (which, like TREES, could be adapted for handling quasi-spatial problems), the answer to this question is a somewhat guarded "yes." The inputs required to conduct such an analysis do not differ markedly from those needed by the Hyde approach or the TREES model. In the case of the SPOC model a schedule of timber volumes per acre for each age class in the model would have to be constructed to reflect the physical effects of acid deposition on tree growth. The additional conditions required to implement SPOC are those which define the current level of inventory detail in the model. Fortuitously enough, these conditions are fairly close to those which currently prevait in the Spruce-fir forests of Maine. This resource is largely owned by a single group (e.g., private industrial owners, representing large pulp and paper firms); its structure is believed by many to be even-aged (Maine Forest Service 1983); and, finally, this farest type may be highly susceptible to the effects of gaseous pollutants based on the experience of west Germany and the Scandinavian countries. To implement SPOC in this particular context would require re-parameterizing the model to fit the unique supply and demand conditions associated with this resource. It might also require adding a northern-hardwoods forest type to take into account substitution of hardwood for softwood in pulp production. Once this work was completed, SPOC could be used in a micro-analytic framework to examine the effects of acid deposition on the determination of long run timber supply in a way that consistent with the extraction of a renewable resource by wealth-maximizing firms. 
In spite of what has been said about the value of applying SPOC in a particular region context (e.g., Maine) three summary points about SPOC in particular and normative models in general must be kept in mind. The first point is that it would be very difficult to justify building a normative model with the capability to simultaneously determine a long-run (e.g., dynamic) and spatial (e.g., explicitly multi-regional) equilibrium at different market levels (e.g., product and stumpage) in all regions. Therefore, if normative models are to be used at all to assess the economic impacts of acid deposition it must be at the regional level in a quasi-spatial framework, focusing on the long-run supply and demand for stumpage. The second point is that in evaluating the comparative worth of SPOC versus TREES in this task, one must be mindful of the tradeoffs that are present between the two models when applied in a particular setting. In the case of Maine, the costs of adopting SPOC to fit the situation may not be so great that they eliminate the theoretical advantages provided by SPOC in this setting. In a different setting, a different result might prevail. The final point is that, if one does choose to apply SPOC, or some variant of it, or TREES in a strictly regional setting, then one must keep in mind the fact that these models are normative. As such, they will at best show how acid deposition might affect perfectly competitive stumpage markets composed of perfectly rational wealth maximizing firms.

\subsection{THE TIMBER ASSESSMENT MARKET MODEL (TAMM)}

At the current time, there is really only one econometric model which possesses all of the features necessary to conduct an assessment of the effects of acid deposition-induced charges in the productivity of commercial timberland on regional product and stumpage markets in the United States. This is the Timber Assessment Market Model (TAMM) which was developed for the 11.S. Forest Service to provide long-range projections of United States' timber inventories, timber products output, and prices. The specific attributes that make TAMM unique in the application currentiy under investigation are as follows:

- Multi-Market Structure. TAMM contains explicit submodels for regional stumpage markets and regional product market for both hardwoods and softwoods. 
- Multi-Market Spatial Equilibrium Features. In TAMM, the determination of market clearing prices and output levels in different markets in different regions allows for physical flows of harvested timber from stumpage markets to product markets and for flows of lumber and plywood from product supply to product demand regions.

- Explicit Linkage to Physical Inventory. TAMM is directly tied to an inventory projection model, the Timber Resource Analysis System (TRAS). Timber removals in TAMM depend on inventory levels shown by the inventory model; removals made by TAMM are then fed back into the TRAS model to update the inventory for the subsequent period.

- Dynamic Properties. Finally, TAMM is an annual model, however, it is also a dynamic model in the sense that some of the variables which are determined by the model in the current period ( $t$ ) are used as exogenous variables (e.g., as model inputs) in the subsequent period $(t+1)$. Thus the model can simulate market behavior over time.

- Welfare-Theoretic Properties. Because demand and supply relations are specified in the model, producer and consumer surplus estimates can be calculated in most markets.

Other models which we investigated possessed some of these features, but none of them combine alt of the features believed necessary to conduct an assessment of the effects of acid deposition on regional stumpage and product markets in the United States. In view of the fact that the TAMM model was designed specifically for conducting assessments similar to the ones currently planned in the case of acid deposition, this advantage is not terribly surprising. In the remaining pages of this section of the report, we will show how al1 these features are combined in the TAMM mode1, followed by a discussion of the models' most prominent strengths and weaknesses. However, before launching into a detailed discussion of the model and the methods used to parameterize it, it may be helpful to provide brief overview of the model.

\subsubsection{Model Overview}

TAMM consists of two separate models--one for softwoods (Adams and Haynes 1980) and one for hardwoods (Lange 1983) - which interact through a common 
pulpwood sector. The two models are virtually identical in structure and will be discussed together, although specific differences between the two will be clearly spelled out.

The general structure of the hardwood and softwood models is shown graphically in Figure 4.1. At the top of this figure we see that equilibrium in the product market is detemined by the interaction between national (hardwood model) or regional (softwood model) product demand relations and regional product market supply relations. In the hardwood model the supply and demand equations in the product market can be solved to determine the market clearing price which equates regional production with national consumption. The softwood model is somewhat more complex because of the need to take into account interregional trade between supply and demand regions. This is consistent with greater volume of interregional trade that takes place in softwood Tumber and plywood markets. Because of the ability of these models to simulate the equilibrating effects of interregional product flows on product prices, both of them can be characterized as spatial equilibrium models after the work of Takayama and Judge (1971).

In both models, regional stumpage supply or harvest relations interact with stumpage demand relations to determine current harvest levels and stumpage prices. The demands for stumpage in each region are derived from the level of output in the different product markets of that region by applying a conversion factor to the output level for each product. These conversion factors, commonly referred to as "product recovery factors" can be varied from region to region and over time to reflect both technological change and the effects of factor price changes on input intensities. Both models use two stumpage supply relations in each supply region; one for private industrial and the other for nonindustrial private commercial forest owners. These supply curves relate the volume of the annual timber harvest to stumpage prices and timber inventories held by each owner group.

In both models, a common inventory projection model is used to update the inventory volumes used in the stumpage supply relations. The flow of information between the stumpage supply sector and the inventory model runs between 


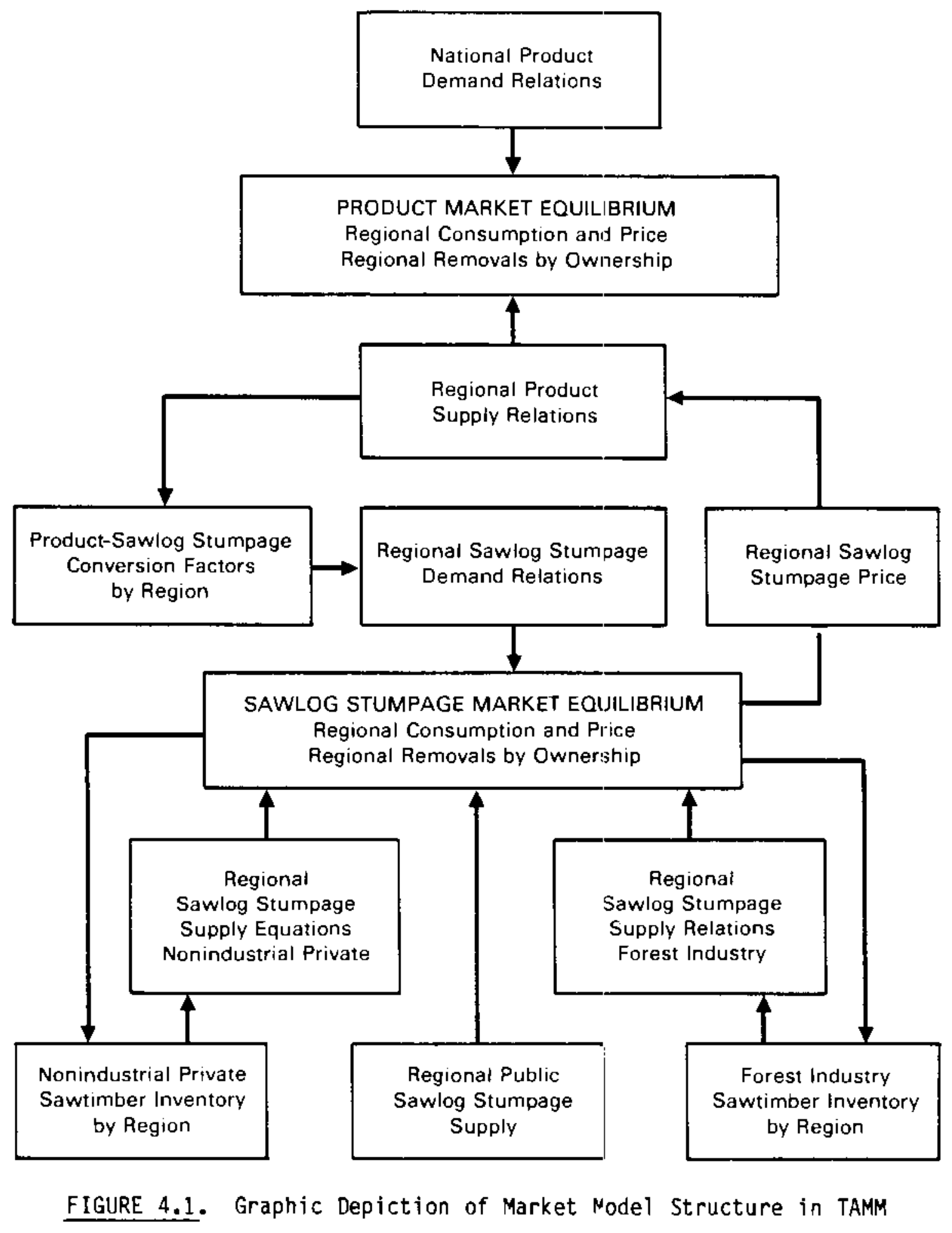


the models in both directions. At the start of each simulation period, inventory volume equals the lagged inventory plus growth, less natural mortality and harvest (which is derived from TAMM) during the previous period. Within the inventory projection model, a number of options are available for simulating management, including the selection of the age (or diameter class)--volume distribution of the harvest, consistent with either the observed or ideal behavior of different ownership groups.

Note that in the TAMM models there is a two-way flow of information between product and stumpage markets. That is, regional stumpage demands are a linear transformation of regional output in the product market, while regional stumpage price influences regional output in the product market. Because of these features and the spatial equilibrium characteristics of the TAMM models, the process of simulating a joint product and stumpage market equilibrium in many different regions must be done iteratively. This process is more involved for the softwood model because of the differentiation between supply and demand regions in the product market. First, market equilibrium solutions are found for each year by reducing the product supply equations to functional forms containing only the prices and quantities of products and predetermined variables from the stumpage sector. These functional forms are then combined with national/regional product demand relations to solve iteratively for the necessary spatial equilibrium prices, consumption and output levels in the product market. This information is then used to compute regional harvest volumes and stumpage prices. This process is repeated for all of the years in the simulation period.

The structural features of the model, as well as the solution technique described immediately above, will be treated in greater detail in a subsequent portion of this section of this report. However, before doing this, we will briefly analyze the methods used to derive the parameters of the TAMM models.

\subsubsection{Estimation Methods}

The supply and demand relations in both the hardwood and softwood models of TAMM consist of linear equations. These equations relate the amount of a particular wood product or the harvest volume of a particular owner group which 
is either consumed (demand) or produced (supply) to a set of explanatory variables. The standard linear model that is consistent with these relationships can be expressed as

$$
y_{t}=\beta_{0}+\sum_{i=1}^{\eta} \beta_{i} x_{i t}+\varepsilon_{t}
$$

where $y_{t}$ is a measure of a consumption or production in period $t ; x_{i t}, \ldots, x_{n t}$ is a vector of explanatory variables in period $t ; \beta_{0}$ and $\beta_{1}, \ldots, B_{n}$ are the constant parameters of the liner model and $\varepsilon_{t}$, the error term, represents the difference between the observed and the predicted value of $Y_{t}$.

In the above model, the $Y_{t}$ 's and $X_{i t}$ 's are given; that is, in any period, $t$, a set of recorded values for these variables is present in a data set. The length of the data set in years $(t=1, \ldots, T)$ defines the number of observations available on each variable. The parameters of the linear model represent the unknowns whose values must be obtained by some appropriate estimation technique. The simplest and most general method for obtaining these parameter estimates is known as Ordinary Least Squares (OLS). The OLS parameters of the linear model are found by minimizing the expression:

$$
\sum_{t=1}^{T}\left(y_{t}-\beta_{0}-\sum_{i=1}^{n} \beta_{i} x_{i t}\right)^{2} .
$$

OLS is an appropriate method for obtaining the parameter estimates of the linear model under the following conditions:

1. The $x_{j} s$ are fixed in repeated samples (e.g., exogenous) and are linearly independent.

2. The error tem is a normally distributed random variable with a mean value of zero and constant variance.

3. The residuals are uncorrelated, so that the covariance of any two residuals is zero. 
4. The number of exogenous variables in the model does not exceed the number of available observations.

Under these conditions, the OLS parameter estimates are said to be unbiased, consistent and efficient estimators of the "true" parameter values. A parameter estimate is unbiased if the expected value of the estimate is the same as the expected value of the "true" parameter. A parameter estimate is consistent if the distribution of the estimated parameter converges on the fixed value of the "true" parameter. Finally, a parameter estimate is efficient if the variance of the estimated parameter is smaller than the variance of any other unbiased estimator of the parameter.

In TAMM, the supply and demand relations are specified as linear, simultaneous equations. As such, both supply and demand equations contain variables that are, in fact, endogenous to the simultaneous equation system and not fixed, as required by Condition 1 above. In addition, these endogenous variables (specifically, product and stumpage prices) are correlated with the error terms in their respective supply and demand relations. Under these conditions, the OLS parameters are both biased and inconsistent. The question of the efficiency of these parameter estimates is academic since it refers to a comparison among unbiased estimators.

The undesirable effect which simultaneous equations have on the properties of OLS parameter estimates can be overcome by applying the method of Two-Stage Least Squares (2SLS). Conceptually, 2SLS involves the applications of oLS in two sequential steps. First, the endogenous variables on the right-hand side of each equation are represented in terms of all predetermined variables in the model. These variables should be independent of the residual term, so that if OLS is applied to this relationship, the predicted values of the right-hand side endogenous variables are uncorrelated with the residual term. In the second stage, the actual values of the right-hand side endogenous variables are replaced with the predicted values obtained from OLS estimation in the first stage, making OLS estimation in the second stage appropriate.

The application of OLS in the first stage of 2SLS in both the softwood and hardwood models of TAMM also violated the fourth condition of OLS estimation. When the number of exogenous variables in a simultaneous equation system is 
greater than the number of observations, the paraneter values in the first stage can be obtained by routine algebraic methods. In this, the completeiy deterministic case, the predicted and actual values of the right-hand side endogenous variables are identical and the second-stage 2SLS parameter estimates would be identical to the OLS parameter estimates for the original supply and demand equations.

To overcome this problem, a subset of exogenous variables must be used to obtain the first-stage estimates in 2SLS. Following McCarthy (1971) and Fair (1970), the same set of first-stage exogenous variables was used for al1 right:hand side endogenous variables in a given supply or demand equation. For each right-hand side endogenous variable, this subset included all predetermined variables in the behavioral relationship, including any lagged endogenous variables. Additional exogenous variables from other behavioral relationships in the model were included using a causal ordering criteria suggested by Fisher (1965). Exogenous variables were included which rnost directly influenced the right-hand side endogenous variable. Where several exogenous variables provided similar information and were highly correlated with one another, one exogenous variable was chosen.

In some cases, there was evidence that residuals of the second-stage 2SLS equations were correlated from year-to-year. This pattern of correlation among the errors in a time series is known as serial correlation. As a general rule, the presence of serial correlation will not affect the bias or consistency of OLS parameter estimates, but it does affect their efficiency. When serial correlation was detected, the second-stage equations were estimated using a procedure developed by Fair (1970), known as Iterative Two-Stage Least Squares (I2SLS). The first stage of I2SLS is identical to 2SLS. However, in the second stage, the error structure of the supply and demand equations is assumed to be:

$$
\mu_{t}=\rho \mu_{t-1}+\varepsilon_{t}
$$

where the $\mu_{t}$ are the estimated 2SLS error terms in year $t$ and $\varepsilon_{t}$ is a normally distributed oLS error term. The error structure postulated above is consistent 
with a first-order (e.g., a one period lag) autoregressive error process in which $\rho$ is the first-order autoregression coefficient. Given this error structure, the second-stage equations were estimated using an iterative method known as the Cochrane-0rcutt procedure (Cochrane and Orcutt 1949) to improve the efficiency of the 2SLS parameter estimates.

In some cases, the parameter estimates derived by the above methods were not reasonable in the sense that the signs of some parameters were not consistent with economic theory and/or the magnitude of some parameters was unreasonably high or low based on a priori information available to the authors. In these cases, the values of the "offending" parameters were constrained at or in the neighborhood of values that were deemed to be consistent with both economic theory and a priori information.

\subsubsection{Model Structure}

This section of the report contains a more detailed discussion of the structure of the softwood and hardwood models than was presented previously in the section, entitled Model Overview. The discussion presented here is based on the same references (Adams and Haynes 1980) and Lange (1983) identified in that previous section. However, these references have been supplemented by a revised user's guide (Adams et al. 1984), by two reviews of these models (Hagenstein and Bruner 1982; Binkley and Cardellichio 1981) and by conversations with the authors of both models.

\subsubsection{Product Demand}

Only two timber products, lumber and plywood, receive explicit treatment in the softwood model. Demands for timber in the form of pulpwood, miscellaneous products (including particleboard), fuelwood and $\log$ exports are assumed to be perfectly price-inelastic. In other words, the amount of each of these products that is purchased in the market is assumed to be insensitive to changes in their own price, or the prices of substitute or complementary products. Product demands for fuelwood, miscellaneous products and log exports are projected exogenously, or outside the model. The demand for pulpwood is treated somewhat more elaborately and will be dealt with shortly. 
The softwood model contains six product demand regions for lumber and plywood--the Northwest, Southwest, Rocky Mountains, North Central, South and the Northeast. These regions are shown in Figure 4.2. A "hybrid" approach was used to obtain the regional demand schedules of product price versus product sales for softwood lumber and plywood. First, national consumption and product prices were projected into the future (up to 2030) for both softwood, lumber and plywood using a gap model. The next step involved computing the own-price elasticity of demand for softwood lumber and for plywood in each of the six regions. (The own-price elasticity of demand for a good measures the percentage change in the quantity demanded of a good due to a one percent change in price.) Estimates of these elasticities for plywood were computed using the parameter values of regional softwood plywood demand functions. The parameters of these demand functions were obtained by conventional econometric methods (OLS) using time series data for the period 1950-1980. For softwood lumber, this approach was not successful since many of the estimated parameters of the

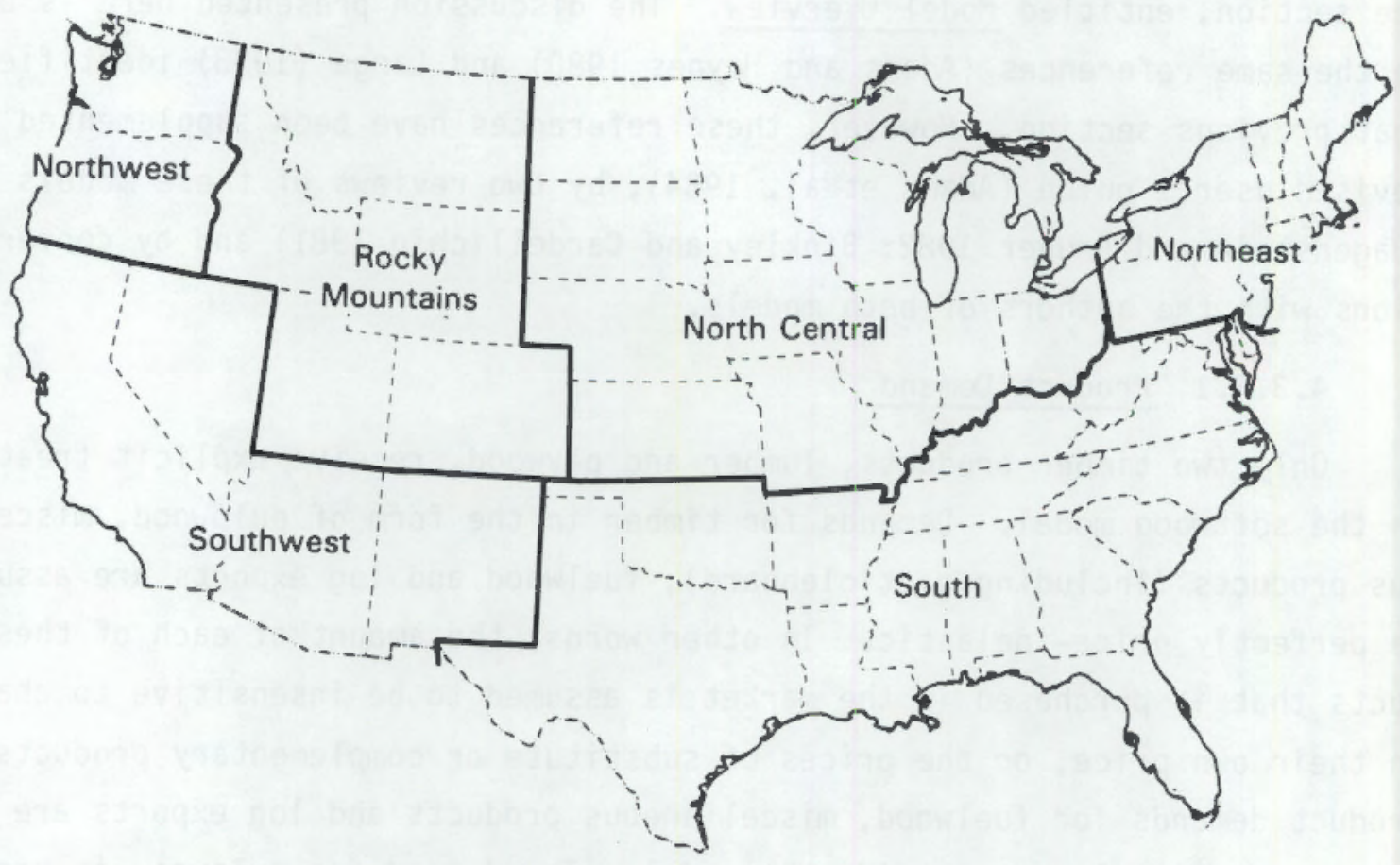

FIGURE 4.2. Softwood Lumber and Plywood Demand Regions in TAMM 
regional demand functions had signs which did not conform to conventional economic theory. In particular, some of the regional softwood lumber demand curves were not downward sloping. Therefore, regional estimates of the ownprice elasticities of demand for softwood lumber were computed by assuming that the ratio of each regional price elasticity to the national price elasticity (assumed to be equal to -0.35 ) was the same as the ratio of regional to national softwood lumber prices.

Next, the slope of demand schedules for a given region and product was computed from the regional elasticity estimates and from estimates of regional quantities and prices. The latter two series for each product and region were derived from the national price and quantity projections that were made in the initial step of the procedure. Nationally projected demands were apportioned regionally based on regional population and per capita consumption projections, by product. National prices were apportioned at the regional level based on the assumption that the mean ratio of regional to national product prices for the period 1951-1976 would remain constant. Finally, given information about the slope of the regional demand functions, along with projected regional prices, quantities and price elasticity estimates for each product, it was possible to construct linear demand schedules for softwood lumber and for plywood in each region for each year of the projection period. These regional product demand schedules have the general form

$$
S D_{j t}^{i}=\gamma_{o j}^{i}+Y_{i j}^{i} S P_{j t}^{i}
$$

where

$$
\begin{aligned}
S D_{j t}^{i}= & \text { the quantity demanded of softwood product } i \text { (lumber or } \\
& \text { plywood) in demand region } j \text { in year } t ; \\
S P_{j t}^{i}= & \text { the delivered price of softwood product } i \text { for carload lots } \\
& \text { in the demand region } j \text { in year } t .
\end{aligned}
$$

There are two different versions of the TAMM hardwood model--the assessment version and the end-use demand version. In the assessment version, the demand for hardwood lumber is modeled on a national rather than a regional 
basis. Otherwise, the approach used was similar to the one employed for the softwood model. That is, a linear hardwood lumber demand schedule was estimated using projected price and consumption levels and an estimate of the ownprice elasticity of demand for hardwood lumber. The elasticity estimate $(-0.69)$ was used to estimate the slope of the national hardwood lumber demand schedule while the projected price and consumption series was used to locate the schedules in each year of the projections. The national product demand schedules have the general form

$$
H D_{t}=\lambda_{0}+\lambda_{1} H P_{t}
$$

where

$$
\begin{aligned}
& H D_{t}=\text { hardwood lumber consumption in the U.S. in year } t \text {; } \\
& H P_{t}=\text { hardwood lumber price in year } t .
\end{aligned}
$$

The end-use version of the hardwood model differs from the assessment version in that explicit lumber demand relationships were developed for the four major end users of hardwood lumbers: manufacturing, shipping, residential, and nonresidential construction. Two forms of the hardwood lumber demand relationship were considered. These were:

$$
\begin{gathered}
H D_{t}^{i}=\pi_{0}^{i} H P_{t}+\pi_{1}^{i} H P_{t}+\pi_{2}^{i} P S_{t}^{i}+\pi_{3}^{i} A_{t}^{i} \\
H D_{t}^{i} / A_{t}^{i}=\psi_{0}^{i}+\psi_{1}^{i} H P_{t}+\psi_{2}^{i} P S_{t}^{i}
\end{gathered}
$$

where

$$
\begin{aligned}
H D_{t}^{i}= & \text { hardwood lumber consumption in the U.S. in year } t ; \\
H P_{t}= & \text { hardwood lumber price in year } t ; \\
P S_{t}^{i}= & \text { the price of substitutes for hardwood lumber in end-use } \\
& \quad \text { industry } i \text {; } \\
A_{t}^{i}= & \text { an activity measure for end use } i \text { in year } t .
\end{aligned}
$$


Activity measures for the end-use industries included production indexes for manufacturing and shipping containers, total housing starts for residential construction, and value put in place of nonresidential construction. Substitute prices were expressed as a weighted average of current-period and in some cases lagged prices for plastic, particleboard, paperboard, softwood plywood, floor coverings and/or concrete prices, depending on the end-use industry demand being considered.

Model and variable selection was initially made using OLS. In all cases Equation $4.3 \mathrm{~b}$ performed best. These equations were subsequently reestimated using 2SLS. Unexpected signs were encountered for the lumber price term in the manufacturing and shipping end-use demand equations. Serial correlation was detected in all four end-use demand equations. The unexpected sign problem was eliminated by excluding observations during the Arab 0il Embargo from the time series data and then reestimating the manufacturing and shipping end-use demand equations. The serial correlation problem was addressed by reestimating all four end-use demand equations using I2SLS. This procedure eliminated the serial correlation problem; however, in each equation two or more of the parameters did not possess "the expected" sign. Consequently the 2SLS parameter estimates were retained in the end-use demand model.

\subsubsection{Product Supply}

For product and timber supply projections the softwood model divides the United States into eight regions: the Pacific Northwest-West (The Douglas fir region), Pacific Northwest-East (eastern Oregon and eastern Washington), Pacific Southwest (California), Rocky Mountains, North Central, South Central, Southeast and the Northeast. These regions are shown in Figure 4.3. Softwood lumber and plywood production in the North Central and Northeast regions is small relative to national production, averaging only 3.5 and 0.3 percent during the period 1970-1976. Therefore, the output of these products in the North Central and Northeast regions is not modeled. Instead, projections of softwood lumber and plywood output from these two regions are projected outside the model. Canadian lumber supply, but not plywood supply, is modeled in TAMM with Canada defined as a single supply region. 


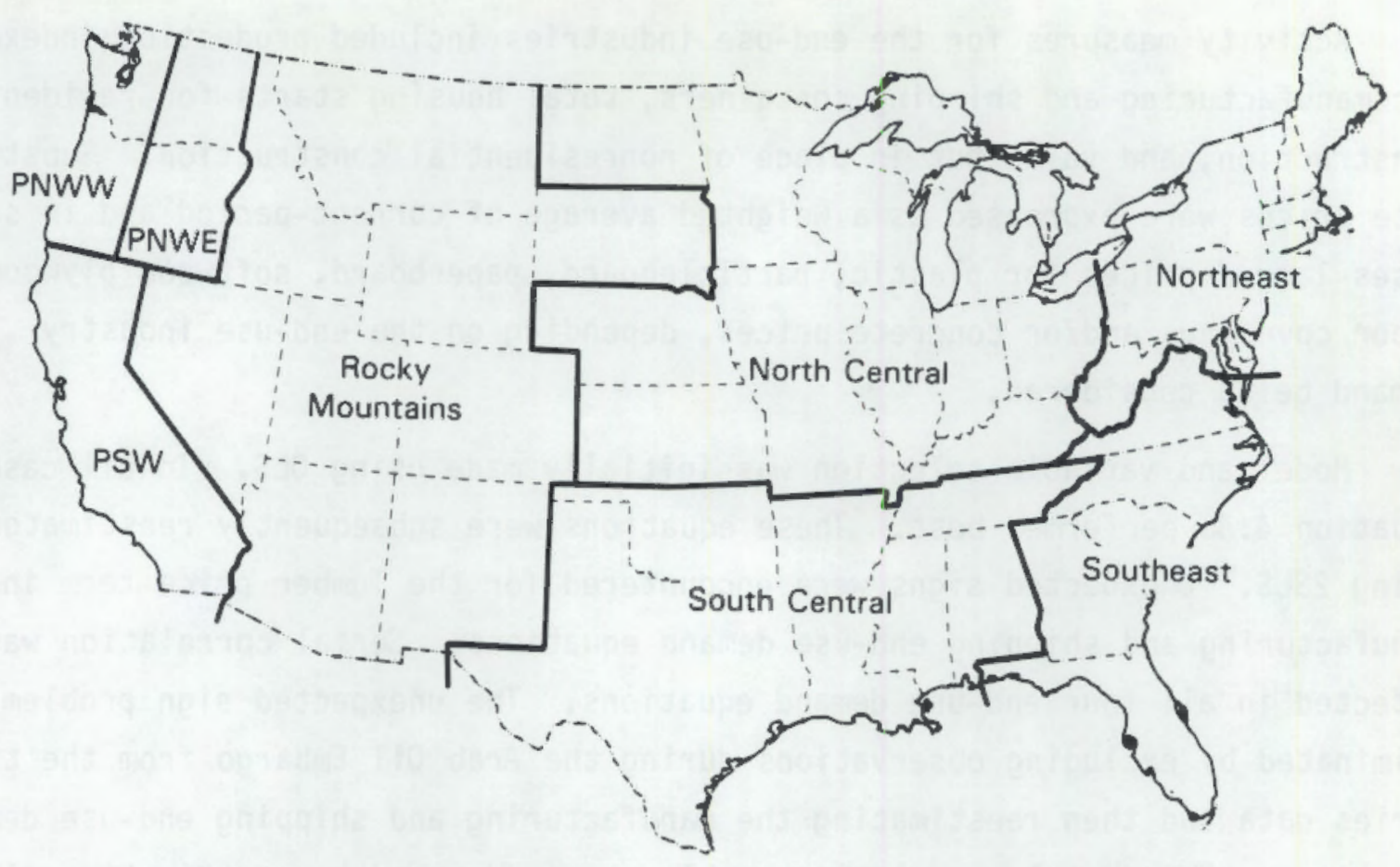

FIGURE 4.3. Softwood Product and Stumpage Supply Regions in TAMM

Domestic softwood lumber and plywood supply are represented in TAMM by a combination of regional supply equations and capacity adjustment processes. In the product supply equations, output by product and region is treated as a linear function of the profit margin per unit of output of the relevant product and the estimated production capacity for the product at the end of the previous year. In addition lumber and plywood output is restricted to be less than or equal to available production capacity in the region. The profit margin term in the product supply equations is expressed as the regional average mi11level price of the product minus the sum of the regional average "stump to car" production cost per unit of output and the regional average stumpage price. (The last two values are converted from dollars per million board feet (MBF) to dollars per unit of output using regional "overrun" factors, which converts them into units comparable to the regional average mill level price.) The regional product supply equations and associated output constraints have the general form 


$$
\begin{aligned}
& S S_{k t}^{j}=\alpha_{0 k}^{i}+\alpha_{1 k}^{i}\left[S P_{k t}^{i}-w_{k t}^{i}\left(C_{k t}^{i}+S P_{k t}\right)\right]+\alpha_{2 k}^{i} S K_{k t-1}^{i} \\
& S S_{k t}^{i}<S K_{k t-1}^{i}
\end{aligned}
$$

where

$$
\begin{aligned}
S S_{k t}^{i}= & \text { the production of softwood product } i \text { (lumber or plywood) } \\
& \text { in softwood supply region } k \text { in year } t ; \\
S P_{k t}^{i}= & \text { the regional average mill level softwood product price in } \\
& \text { year } t ; \\
C_{k t}^{i}= & \text { the regional average "stump to car" softwood production } \\
& \text { cost for product } i \text { in year } t ; \\
W_{k t}^{i}= & \text { the regional average softwood "overrun" factor for } \\
& \text { product } i \text { in year } t ; \\
S P_{k t}= & \text { the regional average softwood stumpage price in year } t ; \\
S K_{k t-1}^{i}= & \text { the estimated regional production capacity for product } i \\
& \text { in year } t-1 \text {. }
\end{aligned}
$$

The product supply equations in the above form are rationalized on the grounds that, in the short run, an increase in regional lumber or plywood output could be caused either by an increase in regional product price or a decline in regional production cost or regional stumpage price, a change to a more efficient production process (due to a smaller regional overrun factor), or by some combination of these effects. In the long run, however, increases or decreases in mill capacity will also influence the profitability of regional softwood products. Large positive margins in a given region relative to other regions should serve as an inducement for firms to increase their milling capacity. As capacity grows, production costs will presumably rise as the demand for stumpage and other inputs increases with greater capacity. In the long run, this process should work to eliminate the margin differential between regions.

Lumber supply was estimated using a pooled cross-section/time series approach with intercept dummy variables for each of the regions, but with equal 
margin and capacity coefficients across all regions. Approximate tests on the plywood relations indicated that both separate intercept and slope terms should be used for the Pacific Northwest Douglas-fir subregion, Southeast, and South Central regions, while a common margin term was maintained for the Pacific Northwest Ponderosa pine subregion, Pacific Southwest, and Rocky Mountains.

Initial simulations that were conducted with the softwood model resulted in unreasonably large margin levels, which persisted over long periods of time. Economic theory, on the other hand, suggests that large profit margins should be eliminated over time by new entrants wanting to take advantage of high profits in that region. A capacity adjustment relationship for lumber and plywood was added in each softwood supply region to simulate this process and thereby eliminate the problems of persistently high margins. In all softwood supply regions, the ratio of current end-of-period capacity to capacity at the start of the period was represented as a distributed lag in the deviation of actual from "target" margin. That is:

$$
S K_{k t}^{i} / S K_{k t-1}^{i}=1.00+\sigma_{k}^{i}\left[.5 \sum_{s=1}^{2}\left(R_{k t-s}^{i}-\hat{R}_{k}^{i}\right)\right]
$$

where

$$
\begin{aligned}
S K_{k t}^{i}= & \text { regional production capacity for product } i \text { in region } k \text {, at } \\
& \text { end of year } t ; \\
R_{k t-s}^{i}= & \text { regional product margin for product } i \text { in region } k \text {, during } \\
& \text { period } t-s ; \\
\hat{R}_{k}^{i}= & \text { margin target for product } i \text { in region } k \text {; and } \\
\sigma_{k}^{i}= & \text { capacity-margin response coefficient for product } i \text { in } \\
& \text { region } k .
\end{aligned}
$$

The coefficients $\sigma_{k}^{i}$ were set on a judgmental basis, based in part on regression estimates. These coefficients averaged 0.005 in all regions for both lumber and plywood.

Canadian lumber supply to the U.S. is modeled differently. Total Canadian softwood lumber production was first estimated as a function of profit margins 
and product output in the previous period. Next, Canadian domestic consumption and exports to non-IJ.S. markets (which are determined outside the model) are subtracted from production to obtain the supply available for the U.S. market. No capacity adjustment is included, and there is no direct linkage to the Canadian softwood stumpage sector.

In the initial version of TAMM, United States' softwood lumber and plywood exports were projected outside the model. These projections of exports were deducted directly from regional supplies and the relevant supply functions were shifted to the left by the amount of exports. In the most recent version of TAMM, however, there are explicit exports demand equations for six of the eight softwood supply regions. These equations are written as:

$$
S x_{k t}^{i}=\delta_{0 k}^{i}+\delta_{1 k}^{i} S P_{k t}^{i}
$$

where

$$
\begin{aligned}
S X_{k t}^{i}= & \text { softwood exports of product } i \text { (lumber or plywood) from } \\
& \text { supply region } k \text { in year } t ; \\
S P_{k t}^{i}= & \text { the regional average mill level softwood product price in } \\
& \text { year } t .
\end{aligned}
$$

These are four production regions in the hardwood lumber model of TAMM: the North Central, South Central, Southeast and the Northeast. Hardwood lumber production in the Western U.S. is determined outside the model. Regional hardwood lumber supply was modeled in a "stock adjustment" (Pindyck and Rubinfeld 1981) framework. The stock adjustment model consists of two basic equations. In the first equation, desired regional hardwood lumber production is considered to be a linear function of the national hardwood lumber price, the price of regional sawlog stumpage, the regional wage rate and the price of petroleum. This relationship can be expressed in a linear form as:

$$
H S_{k t}^{\star}=B_{0 k}+B_{1 k} H P_{t}+B_{2 k} h p_{k t}+B_{3 k} W_{k t}+B_{4} p p_{t}
$$


where

$$
\begin{aligned}
H S_{k t}^{*}= & \text { desired hardwood lumber production in hardwood supply } \\
& \text { region } k \text { during year } t ; \\
H P_{k t}= & \text { the price of hardwood lumber in the U.S. in year } t ; \\
h p_{k t}= & \text { the price of sawlog stumpage in region } k \text { in year } t ; \\
W_{k t}= & \text { the wage rate in region } k \text { in year } t ; \\
\mathrm{PP}_{\mathrm{t}}= & \text { the price of petroleum in the U.S. in year } t .
\end{aligned}
$$

In the second equation of the stock adjustment model, the difference between regional hardwood lumber production in the current and previous periods is assumed to be a constant (but unknown) function of the difference between desired regional production in the current period and actual regional production in the previous period. This adjustment process can be expressed as:

$$
H S_{k t}-H S_{k t-1}=\left(1-\sigma_{k}\right)\left[H S_{k t}^{*}-H S_{k t-1}\right]
$$

where

$0<\sigma<1$.

The two models can be combined to create a linear model in which actual hardwood lumber production is a function of national lumber price, regional sawlog stumpage price, the regional usage rate, and now, hardwood lumber production in the previous period. The resultant hardwood lumber supply equation can be expressed as:

$$
\begin{aligned}
H S_{k t}= & \beta_{0 k}\left(1-\sigma_{k}\right)+\beta_{1 k}\left(1-\sigma_{k}\right) H P_{t}+\beta_{2 k}\left(1-\sigma_{k}\right) h p_{k t}+ \\
& \beta_{3 k}\left(1-\sigma_{k}\right) W_{k t}+\beta_{4 k}\left(1-\sigma_{k}\right) p p_{t}+\sigma_{k} H S_{k t-1}
\end{aligned}
$$

The parameter $\sigma_{k}$ in the regional hardwood lumber supply equations is known as the stock adjustment parameter. When $\sigma_{k}=0$, the adjustment between actual and desired hardwood lumber production is instantaneous, since $\mathrm{HS}_{\mathrm{kt}}=\mathrm{HS}_{\mathrm{kt}}^{*}$ * At the other extreme, when $\sigma_{k}=1, \mathrm{HS}_{\mathrm{kt}}$ never adjusts to the desired level $\left(\mathrm{HS}_{\mathrm{kt}}^{*}\right)$ 
since $\mathrm{HS}_{\mathrm{kt}}$ always equals $\mathrm{HS}_{\mathrm{kt}-1}$ under this condition. For intermediate values of $\sigma_{k}$, the convergence of $\mathrm{HS}_{\mathrm{kt}}$ to $\mathrm{HS}_{\mathrm{kt}}^{\star}$ is asymptotic. The rate of adjustment over time can be determined as follows: after $n$ periods, $1-\sigma^{n}$ of that adjustment is completed. Consequently, the number of periods required to achieve some proportion, $P$, of the desired adjustment must be:

$$
n=\frac{\ln (1-P)}{\ln \sigma}
$$

The hardwood lumber supply equations were estimated for the four eastern regions using 2SLS. For the most part, the results of the estimation process were consistent with conventional economic theory. In all of the regions, hardwood lumber production was positively related to regional hardwood lumber prices and negatively related to the regional sawlog stumpage price. As expected, hardwood lumber production in the previous period had a positive influence on current period supply. In both the Northeast and North Central regions, the wage rate parameter had a positive sign, and these variables were subsequently dropped from the supply equations for these regions. In the remaining two regions, there was a negative relationship between hardwood lumber production and regional wage rates. The petroleum price term was dropped from the model due to lack of significance.

\subsubsection{Stumpage Demand}

In both the hardwood and softwood portions of TAMM, the regional demands for stumpage are treated in a very straightforward fashion as derived demands. In the softwood model, regional stumpage demand is composed, simply, of the roundwood input requirements for each major product category: lumber, plywood, pulp products, miscellaneous products, fuelwood and log exports. The last three inputs requirements are projected exogenously, or outside the model. Lumber and plywood output are converted into stumpage demands by means of product recovery factors, which are also determined outside the model. Regional demands for pulpwood are derived from projections of total U.S. domestic pulp production, which are made outside the model. The aggregate derived demand function for stumpage can be written as: 


$$
s d_{k t}=\sum_{i=1}^{2} r_{k t}^{i} s s_{k t}^{i}+r_{k t}^{3} P_{k t}+M P_{k t}+F_{k t}+L E_{k t}
$$

where

$$
\begin{aligned}
& s d_{k t}=\text { total softwood stumpage demand in softwood } \\
& \text { supply region } k \text { in year } t \text {; } \\
& r_{k t}^{i}=\text { product recovery factors for softwood lumber } \\
& (i=1) \text {, plywood }(i=2) \text {, and pulp }(i=3) \text { in } \\
& \text { softwood supply region } k \text { in year } t \text {; } \\
& S S_{k t}^{i}=\text { regional softwood lumber }(i=1) \text { and plywood } \\
& (i=2) \text { output in year } t \text {; } \\
& P_{k t}=\text { regional softwood pulp production in year } t \text {; } \\
& M P_{k t}, F_{k t}, L E_{k t}=\text { miscellaneous products, fuelwood and log exports } \\
& \text { output in softwood supply region } k \text { in year } t \text {. }
\end{aligned}
$$

In the hardwood lumber model, regional sawlog stumpage demand was determined by applying regional lumber--sawlog stumpage conversion factors (e.g., product recovery factors) to regional lumber production. Other demands for stumpage are specified outside the mode1. Sawlog stumpage demand functions are expressed as:

$$
h d_{k t}=r_{k t} H S_{k t}
$$

where

$$
\begin{aligned}
h_{k t}= & \text { hardwood sawlog stumpage consumption in hardwood supply } \\
& \text { region } h \text { in year } t ; \\
r_{k t}= & \text { the regional product recovery factor for hardwood lumber in } \\
& \text { year } t ; \\
H_{k t}= & \text { regional hardwood lumber production in year } t .
\end{aligned}
$$




\subsubsection{Stumpage Supply}

In the softwood model, regional stumpage supply is subdivided by owner categories--either public or private. The supply of stumpage from National Forests and other public owners is determined outside the model using a set of "timber supply relations" linking harvests on public timberland, stumpage price and public inventories in conjunction with a set of polity rules. However, no documentation could be found in the available published literature to describe the structure of public owner timber supply functions.

The short-run softwood stumpage supply equations that appear in the softwood portion of TAMM are based on two simple assumptions, namely 1) private owners will vary their cut directly with stumpage price and 2) harvests by private timberland owners will be greater if the inventory of timber from which they can draw is larger and harvests will be smaller if timber inventories decline. The parameters of two different stumpage supply functions (both of which embodied the above two assumptions) were estimated. In one form, regional stumpage supply (e.g., the amount harvested) from private timberland was linearly related to the regional softwood stumpage price and the inventory of timber in the previous period. In the other form, the regional harvest from private timberland was first divided by the timber inventory, lagged one period, and this composite dependent variable was regressed against the regional stumpage price. The two alternative functional forms for the regional softwood stumpage supply equations were:

$$
\begin{gathered}
s s_{k t}^{0}=\phi_{0 k}+\phi_{1 k}^{0} s p_{k t}+\phi_{2 k}^{0} s i_{k t-1}^{0} \\
s s_{k t}^{0} / s i_{k t-1}^{0}=\phi_{0 k}^{0}+\phi_{1 k}^{0} s p_{k t}
\end{gathered}
$$


where

$$
\begin{aligned}
s s_{k t}^{0}= & \text { the harvest volume of owner o in softwood supply region } k \\
& \text { in year } t ; \\
s p_{k t}= & \text { the regional stumpage price for softwood in year } t ; \\
s i_{k t-1=}^{0}= & \text { the softwood inventory of owner o in softwood supply } \\
& \text { region } k \text { at the start of year } t \text { (end of year } t-1 \text { ). }
\end{aligned}
$$

In the most recent version of TAMM, private softwood stumpage supply relations in the two southern regions were modified to explain only the volume of harvest for sawtimber uses, i.e., harvest for lumber, plywood, and miscellaneous products. Harvest for pulpwood and fuelwood is computed exogenously (as in earlier versions of the model) and allocated between private owner groups in proportion to growing stock inventory volumes. Public harvests were split between sawtimber and nonsawtimber components on the basis of estimated proportions. The principal effect of, and justification for, this revision is to eliminate the assumption (implicit in earlier model versions) that sawtimber and pulpwood roundwood supplies are fully substitutable. In earlier versions of TAMM, total growing stock harvest for all uses was taken as a function of sawtimber stumpage price and growing stock inventory. Thus, a unit increase in earlier sawtimber or pulpwood output had an equivalent effect on sawtimber price. In the revised model, sawtimber supply depends on sawtimber stumpage price and sawtimber inventory. Pulpwood output can influence sawtimber supply and prices over time through its impacts on forest inventory, but the associated effects on sawtimber price are extremely limited.

Pulpwood harvest, in the revised model, is derived from the level of regional pulp production (in effect, demand is perfectly inelastic). Pulpwood stumpage (supply) price is determined as a function of current sawtimber stumpage price and relative roundwood harvest levels of pulpwood and sawtimber. Private pulpwood harvest is the difference between total pulpwood harvest and public pulpwood harvest, with the latter set by assumption. Private harvest is allocated between industrial and non-industrial owners in proportion to growing stock inventory. 
The softwood stumpage supply equations were estimated for forest industry and other private owners in all eight softwood supply regions, with the exception of the Rocky Mountain region, where a single equation was estimated. All of the equations were initially estimated using 2SLS. The appropriate form chosen for the stumpage supply function within these two groups was based on goodness of fit and consistency with conventional economic theory. The results of the estimation procedure in the initial version of TAMM were mixed, depending on ownership. For the forest industry group, expected signs for both the price and lagged inventory terms were obtained for all equations except in the Pacific Southwest region. In that region, the stumpage supply equation was reestimated while constraining the price term so that it was consistent with the price elasticity of stumpage supply for the forest industry owners in the Pacific Northwest-west region. Efforts to estimate independent supply equations for other private owners was much less satisfactory, except in the two southern regions. In all of the remaining regions, harvest volumes, stumpage prices and inventories were either poorly or negatively correlated. Consequent7y, the inventory and price parameters in these equations had to be constrained based on information obtained from the forest industry supply equations. The same general problems were experienced when the stumpage supply equations were reestimated. As in the earlier results, other private relations in all western regions proved extremely difficult to estimate. Historical harvest levels were generally closely related to inventory trends but appeared to have little, if any, sensitivity to stumpage prices. In these cases, and also for the Pacific Southwest region and the Pacific Northwest Ponderosa pine subregion forest industry relations, the stumpage supply relations were estimated using judgmental elasticity values to constrain one or more of the coefficients.

Very little hardwood is harvested by public owners. Therefore, regional hardwood supply equations were developed only for forest industry and other private owners. Sawlog stumpage supply in the hardwood model is treated as a stock adjustment process in much the same manner described for the regional hardwood lumber supply equations. Nonsawlog stumpage removals are determined outside the model. Two forms of the stock adjustment models were tested, namely: 


$$
\begin{array}{r}
h s_{k t}^{0}=\left(1-\eta_{k}^{0}\right) \xi_{0 k}^{0}+\left(1-\eta_{k}^{0}\right) \xi_{1}^{0} h p_{k t}+\left(1-\eta_{k}^{0}\right) \xi_{2}^{0} h i_{k t-1}^{0}+\eta_{k}^{0} h s_{k t-1}^{0} \\
h s_{k t}^{0} / h i_{k t-1}^{0}=\left(1-\eta_{k}^{0}\right) \xi_{0 k}^{0}+\left(1-\eta_{k}^{0}\right) \xi_{1}^{0} h_{p k t}+\eta_{k}^{0} h s_{k t-1}
\end{array}
$$

where

$$
\begin{aligned}
\mathrm{hs}_{\mathrm{kt}}^{0}= & \text { the hardwood sawlog stumpage removals by owner group o in } \\
& \text { hardwood supply region } \mathrm{k} \text { in year } \mathrm{t} ; \\
\mathrm{hp}_{\mathrm{kt}}= & \text { the hardwood sawlog stumpage price in hardwood supply } \\
& \text { region } \mathrm{k} \text { in year } \mathrm{t} ; \\
\mathrm{hi}_{\mathrm{kt}-1=}^{0} & \text { the hardwood sawtimber inventory of owner o in hardwood } \\
& \text { supply region } \mathrm{k} \text { at the start of year } \mathrm{t} .
\end{aligned}
$$

Hardwood sawlog stumpage supply equations were estimated for both forest industry and other private owners in the four eastern supply regions. Of the eight stumpage supply equations which were first estimated using 0LS, only three yielded the expected signs on the price and lagged inventory terms. These three equations (Northeast forest industry, Southeast forest industry and Southeast nonindustrial private) were reestimated using 2SLS. The parameter estimates in the remaining five stumpage supply equations were reestimated using constrained OLS to eliminate unexpected signs on the price and inventory terms.

At this juncture, two points need to be made about the stumpage supply equations for both softwoods and hardwoods in TAMM. The first point is that these equations embody a short-run approach to timber supply. The stock adjustment framework, embodied explicitly in the stumpage supply equations of the hardwood model and implicitly in the stumpage supply equations of the softwood model, is fairly consistent with economic theory regarding the short-run behavior of a rational timber-owner (Duer 1960). Long-run behavior can be simulated in both models by explicitly linking evolving price and profit trends with the intensity of timber management. This is done by relating changes in the biological parameters of timber growth to the costs and returns associated with investments in different timber management opportunities (Adams et al. 1982). 
The second point that needs to be emphasized here is that the parameter estimates obtained for the stumpage supply equations in both models often had the wrong signs and magnitudes. This problem, as mentioned above, was particularly acute in the hardwood model. The problems associated with developing stumpage supply equations that are consistent with economic theory can be traced to a number of possible sources. These include: 1) the relatively small amount of year-to-year variation in the hardwood stumpage price data series; 2) the fact that nonindustrial private powers frequently "manage" timberland for a wide variety of noneconomic objectives; and 3 ) the failure to explicitly take into account the complex economic objectives of industrial owners in modeling stumpage supply.

\subsubsection{Inventory Projection}

The parameters of the stumpage supply equations for both the softwood and hardwood models within TAMM were estimated using standard U.S. Forest Service data for timber inventories (USFS 1973). However, in simulating market behavior using TAMM both models must be linked, physically, to a model which will at least maintain the continuity of mass associated with (a) removing trees from the inventory and (b) the growth of the remaining trees as well as those that are regenerated after harvesting and (c) mortality. This is necessary not simply for keeping track of the way in which harvesting affects regional timber inventories, but also because the amounts of hardwood and softwood stumpage are both influenced (in the model) by the inventory of timber in the previous period through the regional stumpage supply equations.

In both the hardwood and softwood models, the continuity of mass and inventory feedback with TAMM is maintained by an inventory projection model. In the original versions of TAMM, the inventory projection model was based on the TRAS system developed by Larson and Goforth (1970, 1976). More recently, a second inventory projection model, TRIM, has been developed which is also compatible with the hardwood and softwood portions of TAMM. Both of these models will be discussed in the next major section of the report. 


\subsubsection{Market Clearing in TAMM}

In both the softwood and hardwood models there are two market levels: the product market and the stumpage market, with stumpage flowing from the timber market were it is harvested and then transported to the mil1 where it enters the product market. These activities all take piace in the supplying regions. Softwood and hardwood products are then shipped from these supply regions to satisfy domestic regional (softwood model) or national (hardwood model) demand and to meet export demands. As such, both the stumpage and product markets must balance in each region and nationally. In the hardwood model this is not a particularly complicated problem. In the hardwood product market, lumber production in all regions must equal national lumber consumption plus the difference between exports and imports which is projected exogenously. In the stumpage market no balancing is required on an inter-regional basis; all that is required is that stumpage demand equal stumpage supply.

Market balancing is somewhat more complicated in the softwood model because of the presence of demand and supply regions in the product market. In softwood product markets, three conditions must be met in order to balance product supplies with demand. First, in each demand region, the market clearing levels of lumber and plywood consumption must each be less than or equal to the amount of the relevant product shipped into the region from all the supply regions. Second, the market clearing output levels of lumber and plywood in each supply region must each be greater than or equal to the amount of relevant product shipped from the region to all the demand regions or to meet exports. Finally, at the national level, total regional consumption for lumber and plywood plus total export demand for each product must be less than or equal to the sum of total regional production and imports for each product. In the softwood stumpage markets, stumpage production in each supply region must equal the difference between regional domestic stumpage demand and log exports.

Maintaining the necessary continuity of mass (e.g., market balancing) within and between markets is complicated by the fact that both the hardwood and softwood models are simultaneous equation models. This simuitaneity arises for two reasons: 1) within product and stumpage markets, supply and demand 
both depend on a common market clearing, or equilibrium price, and 2) regiona? product supplies depend on regional stumpage prices.

The critical problem in conducting simulations with both models in TAMM is finding a set of market clearing prices and quantity levels in all regions in all markets wich satisfy the parameters of the structural equations and the market balancing conditions described above. The method for solving this problem in the hardwood model consists of reducing supply and demand equations to expressions in which the endogenous variables of the model (prices and quantities) are linearly related to the exogenous variables. The resulting system of simultaneous equations is then solved for the market clearing prices and output levels in all markets in all regions.

This problem is more difficult to solve in the softwood model because of the spatial equilibrium characteristics of the model. The solution to the model is best approached by considering a simplified version of the softwood model expressed in matrix fom as:

\begin{tabular}{|c|c|c|}
\hline Type of Relation & Functi & ion \\
\hline Product demands & $a_{1} p$ & $=g_{11} 2$ \\
\hline Product supplies & $a_{2} p+b_{2} s$ & $=g_{12^{2}}$ \\
\hline Stumpage demands & $c_{1} p+d_{1} s$ & $=g_{21} z$ \\
\hline Stumpage supplies & $d_{2} S$ & $=g_{22} Z$ \\
\hline
\end{tabular}

where

\author{
$P$ is a $52 \times 1$ vector of demand region prices and consumption \\ levels and supply region prices and production levels for both \\ lumber and plywood, \\ $S$ is a $16 \times 1$ vector of supply region total harvest volumes and \\ stumpage prices, \\ $Z$ is a $47 \times 1$ vector of predetermined variables,
}


$a_{1}, a_{2}, b_{2}, c_{1}, d_{1}$, and $d_{2}$ are, respectively, $12 \times 52,14 \times 52$, $14 \times 16,8 \times 52,8 \times 16$, and $8 \times 16$ arrays of coefficients for endogenous variables, and $g_{11}, g_{12}, g_{21}$, and $g_{22}$ are, respectively, $12 \times 47,14 \times 47,8 \times 47$, and $8 \times 47$ arrays of coefficients for predetermined variables.

The solution procedure consists of three steps. In the first step, the product supply equations are reduced so that they contain only product market prices and quantities and predetermined variables from the stumpage sector. Thus, the demand and supply, Equations 4.16 and 4.17 , can be written as:

$$
\left[\begin{array}{l}
c_{1} \\
0
\end{array}\right] p+\left[\begin{array}{l}
d_{1} \\
d_{2}
\end{array}\right] \quad s=\left[\begin{array}{l}
g_{21} \\
g_{22}
\end{array}\right] z
$$

where 0 is an appropriately dimensioned null matrix. Then:

$$
S=\left[\begin{array}{l}
d_{1} \\
d_{2}
\end{array}\right]-1\left\{\left[\begin{array}{l}
g_{21} \\
g_{22}
\end{array}\right] z-\left[\begin{array}{l}
c_{1} \\
0
\end{array}\right]\right\} P
$$

One can then substitute Equation 4.19 into the product supply Equation 4.15 which, after some manipulation, gives:

$$
\begin{aligned}
\left.\int_{\text {or }} a_{2}-b_{2}\left[\begin{array}{l}
d_{1} \\
d_{2}
\end{array}\right]-1\left[\begin{array}{l}
c_{1} \\
0
\end{array}\right]\right\} p & =\left\{g_{12}-b_{2}\left[\begin{array}{l}
d_{1} \\
d_{2}
\end{array}\right]-1\left[\begin{array}{l}
g_{21} \\
g_{22}
\end{array}\right]\right\} z \\
\bar{a}_{2} p & =\bar{g}_{12} z
\end{aligned}
$$

so that each partially reduced form suppiy equation in 4.20 is a function of both lumber and plywood prices.

In the second step, a reactive programing algorithm (King and Ho 1972 , Tramel 1965) is used to simulate interregional market adjustments in the product market until market clearing prices and, subsequently, quantities are 
found for each region. This aigorithm is consistent with maximizing consumer and producer surplus in the product subject to constraints which define trading opportunities between regions. As such, the algorithm is similar to those proposed by Takayama and Judge (1971) to solve for a spatial price equilibrium between regions, given linear supply and demand functions (which imply a quadratic objective function). Finally, these product price and quantity variables are then treated as predetemined variables and are used for the market clearing stumpage price and output levels in all of the regional stumpage markets. Harvest levels are then transferred to the inventory projection model and inventories are updated to the end of the period. At the same time, current-period variables that will be used as predetermined variables in the solution process during the subsequent period are stored.

\subsubsection{Model Interaction in TAMM}

The hardwood and softwood models in TAMM have been designed to run independently. Their use does, however, involve transferring some information manually between the two models. Specifically, this involves running the hardwood model to determine an initial estimate of hardwood lumber production. This information is transferred to the pulpwood sector of the softwood model which, in turn, produces an estimate of both softwood and hardwood pulpwood output. The estimate of hardwood pulpwood production is then used as an input to the hardwood model and another run of the hardwood model is executed to determine hardwood lumber output. If the resulting projection of hardwood lumber production is sufficiently close to the initial projection of hardwood lumber output the process is stopped. If not, then the new estimate of hardwood lumber output is entered as input to the pulpwood. sector of the softwood model and the process is repeated until the user is satisfied the beginning and ending estimates of hardwood lumber production are sufficiently close together. An alternative procedure for linking these models is presented in Appendix $B$. This procedure was used to simulate the effects of hypothetical reductions in annual tree growth on stumpage and wood produced markets as reported in Section 7.0 . 


\subsubsection{Summary of Inputs and Outputs}

Inputs. The basic parameters and projections required to run the softwood portion of TAMM include:

- Parameter estimates for all supply and demand functions

- Transportation costs for softwood 1 umber and plywood

- Softwood lumber and plywood production costs

- U.S. softwood lumber and plywood imports and exports(a)

- Imports and exports of softwood logs for the Pacific Northwest-West region; softwood log exports from the Pacific Southwest region

- Canadian softwood lumber consumption/production

- Softwood lumber and plywood production in the Northeast and North Central region

- Nonlumber and plywood demands for softwood szumpage

- Projected national consumption and prices for softwood Tumber and plywood

- National softwood lumber and plywood demand elasticities.

The basic parameters and projections required to run the assessment version of the hardwood model include:

- Wage rates in the Southeast and South Central regions

- Lumber imports and exports

- Lumber production in the West

- Regional stumpage removals from National Forests

- Regional stumpage removals from other publicly owned timberland

- Regionar removals of nonsawlog stumpage

- Projected national consumption and prices for hardwood lumber

- National hardwood lumber demand elasticities.

(a) Softwood product exports are treated endogenously in the most resent version of the model. 
In the end-use demand version of the hardwood model, additional exogenous variables include:

- National prices for hardwood lumber substitutes (plastic, particleboard, softwood plywood)

- Indicators of national economic activity (production indexes for manufacturing and shipping containers, total housing starts, value put in place of nonresidential construction).

Outputs. Outputs from the softwood portion of TAMM include annual measures for:

- Regional softwood lumber and plywood consumption and prices

- Regional softwood lumber and plywood production and prices, including imports from Canada

- Regional softwood and hardwood pulp production and pulpwood consumption

- Regional softwood stumpage prices and timber harvest volumes by owner groups

- Distribution of shipments from supply to demand regions for softwood lumber and plywood

- Consumer surpluses(a) in softwood lumber and plywood markets by demand region

- Producer surpluses(a) in softwood lumber and plywood markets by supply region

- Consumer (buyer) surpluses(a) for softwood stumpage by supply region (except for the Northeast and North Central regions)

- Producer surpluses(a) for private owner groups in softwood stumpage markets by supply region.

(a) All of the routines for calculating these welfare measures have been revised and are presented in Appendix $B$. 
Outputs from the hardwood portion of TAMM include annual measures for:

- National hardwood lumber consumption and prices

- Regional hardwood lumber production

- Regional hardwood timber removals for lumber and sawtimber stumpage prices

- Hardwood lumber producer price index.

Consumer and producer surplus measures in both the product and stumpage markets for hardwood are not currently computed within TAMM. However, the information required to calculate these measures on an annual basis can be obtained readily from the structural equations of the model and from the relevant output variables in each period.

\subsubsection{Evaluation of TAMM}

Based on the application of the screening criteria, TAMM is the most comprehensive and flexible model available at the current time to assess the impacts of acid deposition on regional timber product and stumpage markets in the U.S. However, the model also possesses a number of shortcomings which tend to detract from its strong points. These shortcomings are as follows:

1. Limitations on Substitution Opportunities Between Hardwood and Softwood Stumpage

With the exception of the previously mentioned linkage in the pulpwood sector, softwood product and stumpage markets are modeled independently of hardwood product and stumpage markets. This approach appears to be dictated by the short-run supply approach adopted in TAMM. Given the typical short-run situation in which both the technology and the production capacity of lumber, plywood and pulp mills and the relevant end-use industries is relatively fixed, there can be very little substitution between hardwood and softwood pulp. However, when the technology and the output capacity of different types of firms in the wood products industry are both allowed to vary, then the opportunities to substitute hardwood for softwood stumpage (and vice-versa) are enhanced. In particular, an increase in the price of softwood stumpage relative to hardwood stumpage (or vice-versa) can be expected to create additional economic incentives to increase the proportion of hardwood (softwood) stumpage used in a particular end-use, or to convert from a softwood- (hardwood-) intensive technology to a hardwood- (softwood-) intensive technology in a particular 
intermediate or end-use of stumpage. By and large, TAMM cannot capture these types of adjustments. Unfortunately, it is difficult to determine how serious a problem this actually is since we currently have little a priori information about the long-run sensitivities of may different hardwood (softwood) stumpage demands to change in the price of softwood (hardwood) stumpage.

2. Exogenous Treatment of Softwood Product Supplies in the Northeast and North Centra? Regions

Softwood production of lumber and plywood are projected outside the model for these two regions. As previously mentioned, this approach was taken because lumber and plywood production in these two regions is a small function of U.S. production and because the bulk of these products are marketed regionally. This approach probably does not create any serious problems for shortterm, nationally oriented assessments. However, if the assessment is to focus entirely on one or both of these two regions, then the resulting analysis will not benefit greatly from the advantages offered by the multi-market, spatial equilibrium approach embodied in TAMM. In particular, the exogenous specification of softwood lumber and plywood production in these regions carries over into the stumpage market leading to perfectly inelastic demands for softwood stumpage (e.g., stumpage demands are completely insensitive to changes in price). This in turn means that changes in softwood stumpage prices and harvest volumes have no influence on the welfare of buyers in these stumpage markets. Hence, buyer surplus measures cannot be calculated for these two regional softwood stumpage markets.

\section{Uncertain Accuracy of Stumpage Supply Parameters}

The parameter estimates of many of the regional stumpage supply equations in both the hardwood and softwood models may not be very accurate. There are two reasons for this. First of all, the poor performance of many of the different estimation methods required constraining many of the stumpage supply equation parameters at undetermined values, based on a priori information (the accuracy of much of which is open to criticism). The second problem is that the parameters of the regional stumpage supply equations may not accurately reflect the long-run sensitivity of regional stumpage supply to changes in both the size and, much more importantly, the age and species composition of the 
regional timber inventory, if these changes are greater than the variation in the relevant historical data series. Econometric models are generally less accurate as forecasting tools when the range of variation in simulated variables is substantially greater than the range of iistorical variation in the data sets used to estimate model parameters. This problem can become particularly serious in long-term simulations of timber inventories in TAMM since the potential deviations in the size and composition of the inventory from its initial state increase over time.

\section{Extensive Nature of Data Inputs}

Many of the variables that one would prefer to have determined by the model must, in fact, be specified outside of TAMM. This is due, in part, to the fact that the spatial and market coverage of TAMM is so extensive. It is also due, in part, to the fact that much of the market behavior which TAMM tries to simulate is very difficult to model in an econometric framework. The net result of these factors is that TAMM requires a great deal of exogenousiyspecified information to conduct model simulations. This not only makes the preparation of input data sets a relatively time-consuming task, it also introduces additional sources of potential error into model outputs. These errors are compounded over time when TAMM is run for a period of more than a year (which is almost always the case). This compounding occurs because, in each period, errors in input variables partially deternine the errors associated with variables whose values are determined endogenously by the model. Since some of these endogenously determined variables become predetermined variables in the next period of the model simulations these errors are continuously amplified as new errors are added through the values of the exogenous variables in each period. TAMM is a linear model; however, it is not possible to develop closed form expressions for the density functions of the errors associated with forecast variables. This is because the reactive programming algorithm used in the softwood model does not always guarantee interior solutions. However, the forecasts of many (if not all) of the exogenous variables in the model are subject to differences of opinion and the density functions for the distributions of these variables are not easily developed. Thus, the large number of exogenous variables in TAMM represents a very serious source of potential errors in 
the model. For that reason, model results are best interpreted in relative terms--with reference to a fixed base case. Changes in exogenous variables should be kept to a minimum to eliminate additional errors above and beyond those incorporated in the base case.

\section{Lack of Information About Hardwood Grading}

Several references have already been made in this section to the poor performance of hardwood stumpage supply equations. Binkley and Cardellichio (1983) have suggested that some of the poor results for these equations could be eliminated by taking into account the effect which changes in the distribution of hardwood lumber by grade has on the aggregate price of stumpage. Historicaliy, there is considerable justification for this suggestion since major end-uses of lumber are shifting from high quality-oriented end uses to those which use lower quality lumber (e.g., furniture to pallets). For example, the trend in maple lumber prices reflect the trend in aggregate sawlog prices, with the real price differential between high and low quality material following overtime. In contrast, the price differential for high quality oak lumber is rising. Changes such as this in the prices of different grades of hardwood lumber should have some effect on stumpage market prices; however, this variation is currentiy not reflected in the aggregate hardwood stumpage price series used in estimating the parameters of the lumber and stumpage supply equations in the hardwood model. Adding this variation could improve the explanatory power of these equations, as well as introduce a needed behavioral dimension into stumpage and product output and price determination in the hardwood sector.

The major strengths of the TAMM model are related to its ability to provide information about possible future trends in production, consumption and market prices in many different regional product and stumpage markets, for both hardwoods and softwoods on a regional basis. TAMM was designed, originally, to fulfill such a purpose-to provide long-range projections of forest product markets as called for by the Forest and Rangeland Renewable Resource Planning Act (RPA). The model generally functions well in this role for three basic reasons. 
First, TAMM's basic strength is due to the fact that the multi-market, spatial equilibrium approach that is embodied in its structure is generally consistent with the geographic and market structure of the U.S. timber industry. Models that focus on a single market and/or a single region are no: particularly valuable in an assessment framework secause they do not fully capture the interregional and inter-market price-quantity adjustments that are characteristic of the timber economy. The second valuahle feature in TAMM is that it is an extremely flexible policy assessment tool. In the application currently under consideration, TAMM is ideally structured to assess the effects of acid-deposition-induced changes in the productivity of commercial timberland on product and stumpage markets, even though it was not specifically designed for this task. TAMM's chief strength in this area is due to the fact that is directly linked to an inventory projection model. The final, relevant strength of TAMM is that it. provides the policy analyst with a great deal of detailed information, not only about future changes in market prices and production, but also about the distribution of welfare between buyers and sellers in different markets and in different regions. This last feature complements the flexibility of the model by providing information that can be used by analysts and decision-makers with different policy objectives and perspectives. 


\subsection{INVENTORY PROJECTION MODELS}

The purpose of this section of the report is to critically evaluate the major features of three specific inventory projection models which could be used in conjunction with TAMM to simulate the effects of acid deposition on regional timber products and stumpage markets in the U.S. The three models are the Timber Resource Analysis System, or TRAS, (Larson and Goforth 1970, 1974), the Stand and Tree Evaluation and Modeling System, or STEMS, (Belcher 1981; Belcher et al. 1982) and the Timber Resource Inventory Model, or TRIM, (Tedder et a1. 1984). To evaluate these models, this section has been broken down in to four parts. Section 5.1 outlines a set of evaluation criteria which will serve as the basis for assessing the strengths and weaknesses of the three models. These criteria are then applied to each of the three models in Sections 5.2 through 5.4 .

\subsection{EVALUATION CRITERIA}

While the features demanded of an inventory projection model may vary from application to application, such a model ought to be able to generate longrange projections of inventory characteristics such as regeneration, growth, mortality, total inventory volume, age or diameter structure, and it should also be able to simulate forest management in a manner that is consistent with either established or recommended practices. All of the models selected for this analysis can perform the above functions in a general way. However, to correctly evaluate these models we need to look at these models more closely with respect to 1) the special needs associated with conducting a multiregional assessment of the market impacts of acid deposition and 2) any unique structural features of the timber inventory and 3) any tradeoffs between these two sets of needs.

Four criteria will be used to evaluate the three inventory projection models above. These criteria are based on a larger set of criteria that were used by Tedder (1981) to evaluate a number of inventory projection models in connection with their use in the upcoming U.S. Forest Services Resource Planning Act (RPA) assessment. The criteria used in RPA assessment are as follows: 
1. The model must be capable of projecting future inventory and growth for broad timber types and specific region-owner groups as required by TAMM while maintaining the biological integrity associated with the micro-structure of the forest inventory.

2. The model should be able to simulate growth and yield in even- and uneven-age forests.

3. The model must be able to simulate both actual and recommended management and harvesting practices at a realistic level of aggregation.

4. The model must be capable of repeated annual inventory and growth projections at reasonable cost.

\subsubsection{Ability to Project Inventories for Broad Timber Types}

In order to interact with TAMM, the inventory projection model must be able to simulate growth and yield for broad timber categories (softwood and hardwoods and mixed stands) for at least three owner groups (public, forest industry, and nonindustrial private) in each of the stumpage supply regions in TAMM. However, at this fairly broad level of detail (e.g. timber category, by owner, by region) the timber inventory is usually characterized by substantial diversity with respect to the species mix, the age and/or diameter structure, and the productivity of individual stands. It is important to preserve as much of this detail as is reasonably and economically feasible in order to accurately portray regeneration, growth and mortality within individual units (stands or even trees) within the actual inventory. That is what is meant by maintaining the biological integrity of the model. By doing this, a model can provide more accurate projections of both the natural and anthropogenic components of inventory changes at any level of detailed required by the user. In addition, it can provide more detailed information to a wider variety of decision makers.

The key to satisfying this criterion lies 1) in the aggregation scheme that is contained within the model and 2) the level of aggregation within this scheme at which regeneration, growth, mortality and management activity (including harvesting) is simulated. The choice of these features depends to a large extent on the characteristics of the inventory being modeled and on the 
amount of money one has to model the inventory. Consequently, an ideal inventory projection model should have features which allow the user to vary both the type of aggregation scheme used in the analysis and the level at which the components of inventory development (such as regeneration, growth, mortality and harvesting) are to be simulated.

5.1.2 Ability to Simulate Growth and Yield in Even- and Uneven-Age Forests

The model should be able to simulate regeneration, growth and mortality in forests that are managed under both even- and uneven-age silvicultural systems. In addition, the model should be able to simulate both types of structures at whatever level of disaggregation is employed in defining the smallest inventory unit. This feature is particularly important in the hardwood and mixed hard. wood forests in the Northeast and North Central regions of the U.S. where uneven-age stand structures are thought to dominate. The age structure of the most valuable (in terms of revenues only) resource in the Northeast--the Spruce-fir forests of northern Maine--is currently a topic of debate. However, knowledgeable experts in that region believe that this resource can (and should) be modeled in an even-age framework (Maine Forest Service 1983, Seymour $1984)$.

\subsubsection{Ability to Simulate Management}

These are two important aspects of this capability. First, the system must be able to model specific management intensification (MI) treatments at a detailed level. The ability to do this must also be flexible because several management intensification alternatives may be available for a specific species, owner group and region combination. Each of these alternatives MI's would presumably have different growth and yield effects applied under similar conditions to identical stands. However, given differences in the characteristics of the inventory (by species, productivity of the site, etc.) the effects of a single MI on growth and yield will vary across the inventory based on these characteristics. Therefore, the model should have the capability to simulate the effects of different MI levels at the smallest possible level of aggregation in the model. This is necessary to maintain the biological integrity of the forest ecosystem within the model. 
The second important aspect of this capability has to do with harvest scheduling. Given the technical problems associated with developing truly "optimal" harvest scheduling rules from an intertemporal standpoint (see Section 4.2), we do not believe that it is responsible to require this type of capability in a inventory projection mode? to be used for assessment purposes. However, it is important for the model to have a great deal of flexibility in specifying the pattern of removals from the inventory. Flexibility in assigning removals is needed to accurately portray the observed removal pattern among different forest owners. Therefore, a predetermined rule such as "oldest first" or "maximum value first" is not acceptable since it is not in general an accurate representation of actual harvest scheduling policies.

\subsubsection{Ability to Perform Repeated Projections at Reasonable Cost}

The model should be able to perform harvest and growth computations in an efficient manner. This is important because: 1) the amount of inventory data that must be processed in each simulated year of inventory development for a national assessment may be quite large; 2) most timber supply assessments employ 30-50 or more years projection periods; and 3) numerous multi-year projections are required to test the effects of alternative assumptions on timber supplies and to conduct sensitivity tests. These three features of assessments place limits on the amount of computation time and storage that can be used at a reasonable cost. These limits, in turn, imply potential tradeoffs between the degree of detail contained within the inventory representation, the information demands of the assessment (usually for more highly aggregated data), and the cost of making a larger number of inventory projections.

\subsection{TIMBER RESOURCE ANALYSIS SYSTEM (TRAS)}

TRAS is a stand table projection model based on the work of Meyer (1952). It calculates the annual change in the number of trees within a given inventory unit by 2-inch diameter classes. As such it is a diameter-distribution (DD) based inventory model as opposed to an age distribution (AD) based inventory model. (The importance of this distinction will be made clear shortiy). Annual change in TRAS is obtained by subtracting annual removals and mortality 
from the annual increase in numbers of trees in the absence of cutting or mortality. The annual increase in the number of trees, called potential increase, is estimated for each 2 -inch class from a functional relationship between diameter at breast height (d.b.h.) and number of trees. Two different methods for describing this functional relationship are available in TRAS: The $Q$ method which assumes an exponential relationship and the Non Linear Interpolation (NLI) method which assumes a parabolic or quadratic relationship.

The $Q$ method in TRAS assumes that the cumulative number of trees larger than diameter $D$ is an exponentiational function of the lower limits of individual diameter classes. This relationship can be expressed as

$$
A N_{i}=\mathrm{Ke}^{-\mathrm{aD}} \mathrm{i}
$$

where

$$
\begin{aligned}
\mathrm{AN}_{i}= & \text { cumulative number of trees larger than the lower limit of the } i^{\text {th }} \\
& 2 \text {-inch diameter class } \\
\mathrm{D}_{i}= & \text { The lower diameter limit of the } i^{\text {th }} \text { diameter class, } \\
\mathrm{K}, \mathrm{a}= & \text { parameters of the cumulative distribution function to be } \\
& \text { estimated. }
\end{aligned}
$$

Upgrowth within diameter class $i$ is computed by estimating the parameters of (5.1) by means of DLS and using this information to fit an exponentiational curve between $\mathrm{AN}_{j}$ and $\mathrm{AN}_{j+1}$. The estimated curve is then shifted horizontally, as shown in Figure 5.1, by an increment equal to the diameter growth (e.g., radial growth rate) of trees with a diameter equal to $D_{j+1, t^{*}}$ (The subscripted $t$ 's in Figure 5.1 simply denote time). This radial growth is shown in figure 5.1 by the horizontal distance labeled $R G_{i t}$. Given an estimate of $R G_{i t}$, upgrowth can then be calculated as the difference in the number of trees larger than $D_{j+1, t}$ before and after growth, or $A N_{j+1, t+1}-A N_{i+1, t}$. This amount of upgrowth is labeled as $U G_{i t}$. This process is then repeated for the next two successive diameter classes, and so on up to a $22+$ d.b.h. class. 


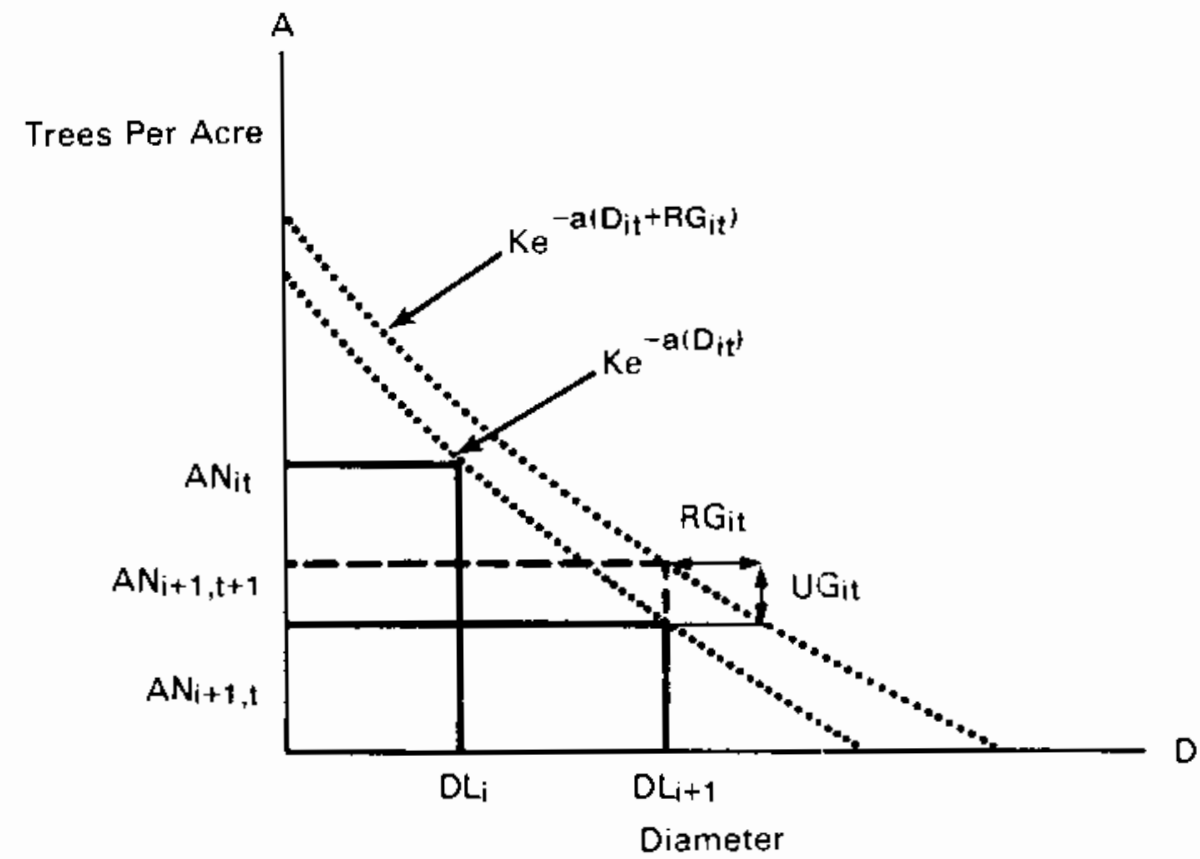

FIGURE 5.1. Graphic Representation of the Q Method for Calculating Upgrowth in TRAS

For the NLI method in TRAS, the following quadratic function is fitted to three successive stand size classes simultaneously:

$$
A N_{i}=A N_{i-1}+B_{1}\left(D_{i}^{\prime}-D_{i-1}^{\prime}\right)+B_{2}\left(D_{i}^{\prime}-D_{i-1}^{\prime}\right)^{2}
$$

where

$$
\begin{aligned}
A N_{i}= & \text { the cumulative number of trees larger than the lower limit of } \\
& \text { the } i^{\text {th }} 2 \text {-inch diameter class, } \\
D_{i=}^{\prime} & \text { the lowest limit of each diameter class plus an increment of } \\
& \text { one year's diameter growth for trat class, } \\
B_{1}, B_{2}= & \text { parameters of the cumulative distribution to be calculated. }
\end{aligned}
$$


Equation (5.2) can be solved for $\mathrm{AN}_{j}^{\prime}$, the cumulative number of trees in stand class $i$ after one year of growth, by substituting $D_{i}-D_{j}^{\prime}$ for $D_{i}^{\prime}-D_{i-1}^{\prime}$ in Equation (5.2). This is equivaient to plotting $A N_{i}$ for three successive stand sizes classes over the corresponding $D_{j}^{\prime}$ values and then interpolating the resultant parabola at the midpoint $D_{j}$ value. Given this type of approach, the parameters of the model do not have to be estimated by curve fitting methods but can be computed directly given information about the current diameter distribution of trees and the radial growth rates for each d.b.h. class. The calculations are:

$$
\begin{aligned}
& \mathrm{b}_{2}=\frac{\frac{A N_{i+1}-A N_{i}}{D_{i+1}^{\prime}-D_{i}^{\prime}}-\frac{A N_{i}-A N_{i-1}}{D_{i}^{\prime}-D_{i-1}^{\prime}}}{D_{i+1}^{\prime}-D_{i-1}^{\prime}} \\
& b_{1}=\frac{A N_{i}-A N_{i-1}}{D_{i}-D_{i-1}^{\prime}}-D_{2}\left(D_{i}^{\prime}-D_{i-1}^{\prime}\right)
\end{aligned}
$$

Once these parameters have been calculated to obtain an estimate for $A_{i}^{\prime}$, ingrowth for diameter class $i$ is simply the difference between $A N_{i}^{\prime}$ and $A N_{i}$.

Several options are available in TRAS for estimating timber removals. First, the user can supply direct estimates of total removals for each year. Second, annual removals can be specified as a proportion of the inventory or net growth in each 2 -inch diameter class. Third, annual removals can be computed as (a) equal to net growth in each diameter class, (b) the difference between net growth and the annual change in the number of trees in each diameter class and (c) the difference between the volume of net growth for all diameter classes and the annual change in inventory volume. Finally, TRAS has the ability to calculate annual removals in conjunction with its own roundwood stumpage supply equations. TRAS uses the roundwood supply equations in each year to calculate the available supply and corrects these estimates to removals 
from growing stock. These removals are allocated among the different diameter classes using removal rates expressed as a percent of inventory in each class.

Continuity of mass within the forest inventory is maintained by the following steps. Assuming that we start with the harvest cycle, trees are removed from each diameter class by one of the four options outlined above. TRAS then uses either the Q or NLI methods to compute upgrowth. (Ingrowth to the smal1est class is specified exagenously as regeneration). The new diameter distribution is calculated and a predetermined percentage of trees in each diameter class are removed to simulate mortality. The remaining number of trees, constituted according to the respecified diameter distribution, represents the inventory available for harvesting at the start of the next cycle.

\subsubsection{Application of Evaluation Criteria}

In this section, we will evaluate the TRAS model in terms of how well it satisfies the four criteria spelled out in Section 5.1 .

Criteria 1: Ability to Project Inventories for Broad Timber Types

As mentioned earlier, TRAS is a stand table projection model - a type of model which is ordinarily used to calculate changes in growth for a relatively small area. One can use a stand table projection model in a large area setting, however, by subdividing the timber inventory into a collection of representative acres. The diameter class distribution along with the associated growth and mortality information for the trees on this acre is assumed to be representative of a given collection of acres in the large area inventory. Because of this property, a version of TRAS was developed to be used in conjunction with TAMM to conduct the 1980 RPA timber assessment. In the 1980 assessment, representative acres within a given supply region were assigned to each of the following owner groups; national forest, other public forest, forest industry, and other private owners. Corresponding to the two major divisions of TAMM, these representative acres were defined in terms of all the acres held by a specific region-owner group within one of two broad species types--softwood or hardwood.

Although this level of aggregation is compatible with TAMM, it cannot capture the effects that pollution stress might induce in individual tree species 
or how differential impacts across species might interact to change the inventory development process of the whole species group. Thus, while it may be appropriate to combine similar species in some cases, the across-the-board stratification of the forest into just two species groups violates some of the biological integrity of the growth model. The division of the forest into two species groups violates biological integrity in another way as well. Instead of being assigned a single acre representing a mixed stand, ownerships in regions that supply both types of timber are assigned two separate representative acres--one for softwood and another for hardwood. Inventory projections are then simulated independently, that is, softwood inventories are projected in one computer run and hardwood inventories are forecast in another. Thus, TAMM's version of TRAS does not capture how differential impacts between softwood and hardwood species groups might interact to change the inventory development process of the whole forest.

These violations of biological integrity are probably not serious defects in the case of short-term projections. However, over periods of longer than 50 years, it would be important to have an inventory model that could take into account possible changes in the species make-up of stands due directly or indirectly to pollution stress. This in turn presumes the availability of much more information about 1) the physical effects of pollution on individual tree species and 2) the supply of and demand for stumpage at the species level than we have at present.

Criteria 2: Ability to Simulate Growth and Yield in Even- and Uneven-Age Timber

TAMM's version of TRAS is basically an uneven-age model. This is appropriate given the levels of geographical, ownership, and species aggregation in TAMM. If the levels of aggregation in future assessments make the simulation of even-age stands appropriate, then TRAS would have to be either modified or replaced.

TRAS can easily be modified to simulate an even-age stand because of the relationship between such a stand's diameter class distribution and its age composition. TAMM's version of TRAS, however, does not contain any provisions within its code to make a translation between radial growth rates and 
age-dependent tree growth explicit. Thus one could use the model to simulate growth and yield in an even-age forest as long as some mechanism were available for translating diameter-dependent-based information into age-dependent-based information. If such a situation were to arise, however, greater efficiency probably would be obtained by replacing TRAS with a model designed specifically for simulating even-age stands.

Criteria 3: Ability to Simulate Management

The TRAS model can and has been used to simulate alternative levels of management intensification (Adams et al. 1982). There are, however, several problems with the way this can be accomplished. The first problem is associated with the level of aggregation employed in the RPA assessment version of TRAS. To adequately simulate alternative silvicultural systems, the inventory needs to he further stratified at least by (a) more detailed species groups, (b) site or productivity class and (c) stocking level. This would enable TRAS to better utilize existing treatment opportunity data and improve the biological integrity of the model vis-a-vis the response of trees to alternative silvicultural treatments. Another problem concerns the timing of management intensification. In actual practice, acres that are originally in one MI category may, over time, develop out of that category and become eligible for different treatments. However, in the current version of TRAS it is not possible to shift acres from one MI to another during the simulation period. Finally, implementation of AD-based silvicultural systems cannot he accomplished explicitly within the current version of TRAS without first transforming $A D$-based treatment information into DD-hased treatment information.

Criteria 4: Ability to Perform Repeated Ann'jal Projections at Reasonable $\underline{\text { Cost }}$

The version of TRAS used in the 1980 RPA assessment is capable of making repeated annuai inventory projections at reasonable costs. Under the current stratification, there are roughly 8 regions, 2 species, and 2 owners, for a total of 32 industry units. A stratification now being considered for a future assessment of pollution stress involves 8 regions, a maximum of 5 forest types per region, 3 owners and 3 productivity classes, for a total of 360 inventory units. The cost of executing TRAS with an inventory of this size would result 
in at least a 10-fold increase above current costs and probably more if one takes into account the need to aggregate results across the various subclasses in the strata.

\subsection{STAND AND TREE EVALUATION AND MODELING SYSTEM (STEMS)}

STEMS is a system of computer programs for projecting the growth of individual trees in stands. It was developed (and is under continual modification) by the staff of the North Central Forest Experiment Station as part of the Forest Resources Evaluation Program (FREP). STEMS has been used in a large area assessment setting to project treatment opportunities for Minnesota (Smith and Jakes 1981) and eastern South Dakota (Smith et al. 1983); to predict the yields associated with selected rotation ages for 14 forest types in northern Minnesota (Jakes and Smith 1980); to assess the yield response of 25 forest types to selected silvicultural treatment options in Michigan (Jakes and Smith 1983) and to update the Wisconsin timber inventory (Raile and Smith 1982).

The heart of STEMS is the Tree Growth Processing System (TGPS). Information about the characteristics of individual plots and the tree lists for each of these plots are read into, and stored by, this program. plot information includes a location identifier, species groups, site index, a plot area expansion factor, and the age of the plot. Each tree list contains information about individual trees in the plot, including species code, diameter, age, and a tree expression factor to a per acre basis. TGPS can also compute the site index and cover type (which defines the representative species make-up of the plot) for a plot based on the tree list data if this data is not read into the program. In addition, this program accepts and stores volume coefficients for each species which can be used to correct diameter-based growth into volumetric equivalents.

TGPS also simulates the growth, regeneration, and management of individual trees on each plot. The growth simulation model consists of four components: 1) a function that estimates the potential diameter growth af an individual tree, 2) a modifier function which reduces the potential growth due to competition between different trees on a plot for available sunlight, 3) a mortality function and 4) a crown ratio function. 
Potential diameter growth for each species is defined in STEMS as the annual diameter increment for a tree in a forest stand in situations where it does not have to compete for sunlight with its "nearest neighbors." Actual growth is assumed to be a multiplicative function of potential growth and a modifier of this potential growth due to competition. That is:

$$
\begin{aligned}
& \text { Annual change in } \\
& \text { tree diameter }
\end{aligned}=\begin{aligned}
& \text { Potential annual } \\
& \text { d.b.h. growth }
\end{aligned} \times \begin{aligned}
& \text { growth modification } \\
& \text { fraction }
\end{aligned}
$$

The potential growth function used in STEMS is based on the work of Halmand Leary (1974). It is represented as:

$$
P A G=\gamma_{0}+r_{1} D^{\gamma_{2}}+Y_{3} S I \star C R \star D{ }^{Y_{4}}
$$

where

$$
\begin{aligned}
P A G & =\text { potential annual d.b.h. growth rate, } \\
D & =\text { initial tree d.b.h., } \\
S I & =\text { plot site index, } \\
C R & =\text { tree crown ratio, } \\
\gamma_{0} \text { through } Y_{4} & =\text { the parameters of the model to be estimated. }
\end{aligned}
$$

The growth modification function used in STEMS was developed in an individual tree basis by Holdaway (1981). This function is represented as

$$
G M F=1-E X P-B_{0} * \frac{B A_{M A X}-B A}{B A} 1 / 2
$$

where

$$
\begin{aligned}
G M F & =\text { the fractional value }(0<G M F<1) \text { of the growth modification, } \\
B_{M A X} & =\text { maximum basal area per acre, } \\
D A & =\text { current basal are per acre, } \\
B_{0} & =f(R)^{*} g(A D), \\
R & =\text { ratio of tree d.b.h. to the average stand diameter, }
\end{aligned}
$$




$$
\begin{aligned}
& \text { AD = average stand diameter, } \\
& \begin{array}{l}
f(R)= \\
\text { a function characterizing the individual tree's relative } \\
\text { diameter affect on the modification fraction, } \\
\qquad f(R)=\beta_{1}\left[1-E X P\left(\beta_{2} R\right)\right] \beta_{3}+\beta_{4}, \\
g(A D)=\text { a function characterizing the average stand diameter } \\
\text { effect, } \\
g(A D)=\sigma_{0}(A D+1)^{\sigma l},
\end{array} \\
& \beta_{1} \text { through } \beta_{4} \\
& \text { and } \sigma_{0}, \sigma_{1}=\text { the parameters of the model to be estimated. }
\end{aligned}
$$

$B_{1}$ through $B_{4}$

The above functional forms for potential growth and the growth modification fraction, while complicated algebraically, can be rationalized as follows. For the growth function (5.5), the potential growth rate of a tree of a given species increases as a function of its diameter up to a point and then decreases at very high d.b.h. values as the tree matures. An increase in either the site index or the tree crown ratio has the effect of enhancing the rate of potential growth. The growth modification function (5.6) reflects the influence of competition. In general, the larger the diameter of the tree in relation to the average diameter of the plot, the smaller the deviation from potential growth. By the same token, trees on less dense plots maintain a higher fraction of their potential growth than do trees on more dense plots.

Mortality by species, is calculated within the TGPS portion of STEMS by applying the mortality function developed by Buchman (1979). This function predicts the probability of death of an individual tree during the year as a function of the tree's current diameter and its annual growth rate. Holding diameter constant, the probability of mortality is fairly constant over broad range of growth rates for most species, but increases sharply at very low growth rates. Once a tree is established, the relationship mortality rates and diameter tends not to vary widely among species until the tree is above a certain age (i.e., size), after which mortality increases. The functional form used to capture these relationships in STEMS is 


$$
P=\left[1+\operatorname{EXP}\left[\alpha_{0}+\alpha_{1} D \mathrm{GR}^{2}+\alpha_{3} 0\right)\right]^{-1}+\alpha_{4}
$$

where

$$
\begin{aligned}
P & =\text { estimated probability of a tree dying } \\
\text { OGR } & =\text { radial growth rate of the tree in inches } \\
D & =\text { initial tree d.h.h. } \\
\text { a through } \alpha_{4} & =\text { parameters of the model to be estimated. }
\end{aligned}
$$

There are two different options for treating mortality in STEMS. The probabilistic mortality option allows the user to draw a random number from a uniform distribution between $D$ and 1 . If $P$ from (5.7) is greater than this random number, the tree and all the trees it represents (through the tree and plot expansions factors) are killed. In the other option, called deterministic mortality, the value of $P$ from (5.7) is simply applied to the number of trees per acre that this tree happens to represent.

The final functional relationship used to simulate growth in STEMS is the crown ratio function. In the original version of STEMS, this ratio was fixed. Subsequently, an explicit crown ratio function was developed to allow the model to respond to changes in stand density during the simulation period. The crown ratio code (CR) $1,2, \ldots, 9,10$ represents crown ratios from 1 to 10 percent, 11 to 20 percent, etc. This code is assumed to be an increasing function of tree diameter (holding average stand basal area constant) and a decreasing function of average stand basal area (holding tree diameter constant). The form of the crown ratio 'functions' is

$$
\mathrm{CR}=\frac{\Psi_{1}}{1+\Psi_{2} B A}+\Psi_{3}\left[1-\operatorname{EXP}\left(-\Psi_{4} 0\right)\right]+C F
$$

where

$$
\begin{aligned}
B A & =10 \text {-year running average of stand basal area per acre, } \\
D & =\text { current tree diameter }
\end{aligned}
$$


$C F=$ correction factor computed as one difference between the initially predicted CR (by STEMS) and the initially observed $C R$ (entered by the user).

$\Psi$ through $\Psi_{4}=$ parameters of the model to be estimated.

The parameters of Equations (5.4) through (5.8) were estimated for 27 species using the method of nonlinear least squares in conjunction with data from the states of Michigan, Minnesota, and Wisconsin. The model has been validated for these states by Holdaway and Brand (1983). The major conclusions that can be drawn from this analysis are as follows:

- STEMS did "reasonably we11" projecting plots from the validation data sets.

- Diameter growth was consistently overpredicted on all validation data sets.

- Crown ratios were consistently overpredicted on all validation data sets.

Of course, the above conclusions apply only to the application of STEMS in the three validation states. The accuracy of the model in other regions of the U.S. can only be tested after Equations (5.4) through (5.8) have been reestimated using calibration data for these other regions.

The developers of STEMS envisioned incorporating three different types of regeneration in the TGPS to simulate the range of regeneration possibilities that may be available within the forest ecosystem. The first type of regeneration includes the small number of trees that will become established each year in almost any stand. The second type consists of new trees that naturaily enter a stand to fill spaces (gaps) in the stand. This type of regeneration is commonly associated with selective cutting under uneven-age management systems and with commercial thinnings under even-age management systems. The third type of regeneration represents the totally new stand that is regenerated after a clear cutting action has taken place. This type of regeneration is common for forest types that are managed under even-age silvicultural regimes. Only this latter type of regeneration called, "initial" regeneration, is currently 
included within STEMS, although research is currently underway to remedy this problem. "Initial" regeneration is simulated in STEMS using species specific management guides.

Management in STEMS is handied through a set of generalized management guides and marking rules (Brand 1979, 1981). Management guides are currently specified in STEMS for 13 different cover types. For those simulations in which management actions are prescribed, the TGPS program searches through the tree list associated with an individual plot, calculates cover type based on the basal area of each tree and then selects the management guide associated with that cover type. The management guides in STEMS can be represented in the form of decision trees. Figure 5.2 shows the management guide associated with the Mixed Swamp Conifer cover type. The diagram in this figure maps out a series of sequential, logical rules and the associated actions to be taken. For example, if the site index (SI) of a plot in this cover type is less than 25 feet, then depending on the age of the plot (i.e., number of years since establishment) two actions are prescribed: 1) if the plot is under 120 years old, no management is to be undertaken and if the plot is more than this age than it should be strip clearcut. Other sequential logical processes are followed for plots with a site index greater than 25 feet.

The management guides in STEMS contain an extremely large number of harvesting rules. For harvest prescriptions like "clearcut" and "do nothing" all trees are either cut or left standing. The more interesting cases occur under selective cutting practices when some trees are left standing. The Mixed Swamp Conifer guide has five such prescriptions with circled numbers at the far right of Figure 5.2. Each of these prescriptions has detailed marking rules which specify the species to be removed and the order of removal. For example, prescription four in Figure 5.2 calls for removals of hardwood and mature balsam fir. The marking rule associated with this prescription consists of the following procedures:

1. remove balsam fir over 5 inches d.b.h.,

2. remove all elms, aspen, and paper birch,

3. remove all black ash, red maple and yellow birch. 


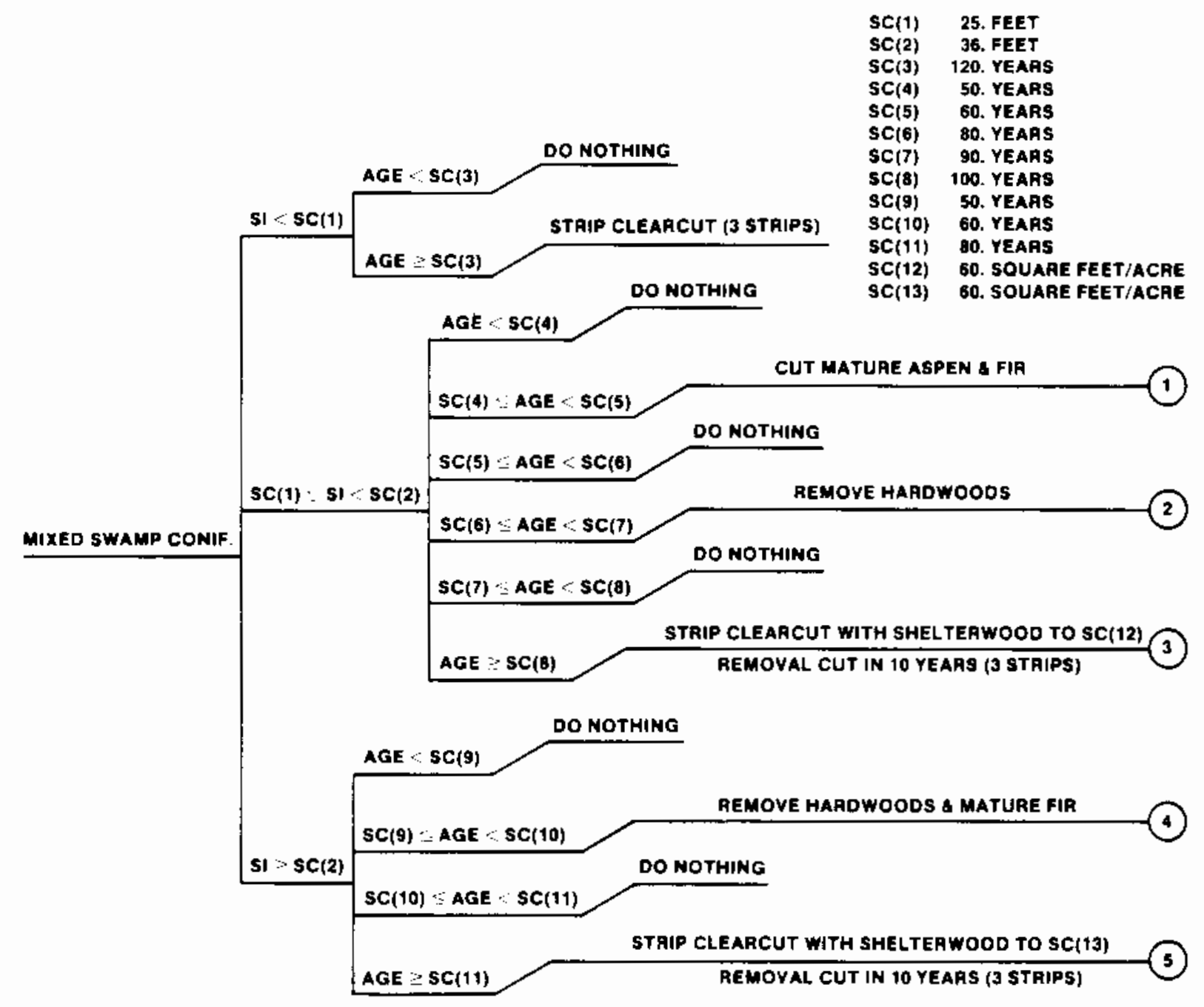

FIGURE 5.2. STEMS Management Guide for the Mixed Swamp Conifer Cover Type

Similar types of marking rules exist for all the cover types contained in STEMS. Each of these sets of rules is based on a hierarchy of characteristics used to rank trees on a plot in order of increasing "vaiue". In general, the rules are structured such that the least valuable trees are removed first, the most valuable last. However, this determination of value is expressed in silvicultural as opposed to strictly economic terms, although the two do coincide at times.

STEMS processes information during the harvest cycle first by plot and then by the trees on each plot, tree-by-tree. STEMS grows each tree in each 
plot separately; it determines what trees will die and removes them from the trees list and the plot record, and then manages the remaining trees in each of the plots based on the management guide for the plot cover type. Trees are harvested according to these same guides; and "initial" regeneration is calculated for clearcut plots. Finally, the cover type of each plot is recalculated to take into account shifting of acres due to management and the new plot summarizes and tree lists are updated on an output file to take into account changes in the diameter and age distributions of trees on each plot and the timber volumes associated with these distributions. The information in this output file can then be aggregated in a variety of ways to show, for example, 1) the net volume of saw timber by species and diameter class 2) the components of inventory growth by species in $\mathrm{ft}^{3}, 3$ ) or average annual yields of growing stock from harvest by species group, and forest type.

\subsubsection{Application of Evaluation Criteria}

In this section, we will evaluate the STEMS model in terms of how well it: satisfies the four criteria spelled out in Section 5.1 .

Criterion 1: Ability to Project Inventories for Broad Timber Types

STEMS can project growth and yield of individual trees on forest plots for 27 species groups. While it is clear from the numerous large area studies conducted with STEMS that inventory volumes and numbers of trees can be aggregated by diameter class and species groups for large areas, it is not clear if the most current version of STEMS can aggregate this same information by separate owner groups. In the short-run, this is clearly a problem. In the long-run, however, the capability to aggregate inventories by owner group and broad species groups (softwoods, hardwoods, and mixed stands) can easily be programmed into STEMS by adding the necessary labeling information on the plot summaries and tree lists. Since the aggregation of information and resultant table writing within STEMS is done after all of the plots have been processed by the TGPS program, adding more labels does not pose any computational problems or in any way interfere with the growth, mortality, and management subroutines in the TGPS program. 
The most basic problem in this area does not lie with the way in which STEMS can aggregate information internally; it stems from the fact that the growth, mortality, and crown ratio functions shown by Equation $(5.4)$ through (5.7) are specific to the region and states for which the parameters of these functions were estimated. If the model is to be used outside of the three Great Lakes states, then these parameters must be reestimated for the appropriate species $\rightarrow$ region combinations. To accomplish this would involve a substantial commitment of resources by the U.S. Forest Service over at least a two or three year period. The second most serious problem to be identified in connection with this criteria is that STEMS can simulate regeneration only after clearcutting. Thus, the present version cannot be run for long periods, $i$.e. more than 30 or so years at a time without beginning to "run out" of forest due to selective cutting without regeneration. This defect is currently in the process of being remedied by on-going research at the University of Minnesota.

Criterion 2: Ability to Simulate Growth and Yield in Even- and Uneven-Age Forests

STEMS can simulate growth and yield (but not regeneration) in both unevenand even-aged forest plots. While STEMS is primarily a DD-based model, there are no difficulties associated with using the model in an $A D$ environment since all plots are identified according to their age. While STEMS grows individual trees based on a DD approach, this method is applicable biologically to trees in both uneven-and even-aged stands. What counts here is not the method used to grow trees, that is general. What really matters is whether STEMS can manage both even and uneven-aged stands with equal efficiency--which takes us to the next criterion.

\section{Criterion 3: Ability to Simulate Management}

An extensive discussion has already been devoted to the management approach contained in STEMS. Therefore, we will concentrate, first, on the question of even-versus uneven-age management in STEMS. Management on evenage plots is accomplished, just as it is on uneven-aged plots, using the management guide and marking rules for the appropriate cover type. For trees that are cut on even-age plots, harvests by species groups can be expressed in terms 
of the number of trees harvested (using functional relationships in the model to predict volume given d.b.h.) or total acres harvested (using the tree and plot specific expansion factors from the forest inventory data types). In addition, area and or volume controls can be imposed upon the marking rules so that harvesting will cease when a specific number of cubic feet or acres of a given species group have been removed from all plots. In STEMS, unlike TRAS, plots are not locked into a specific management intensity for the entire simulation period. Instead, management within individual plots varies over time as harvesting and growth over time influences the path of trees within plots through the decision process implied by the management guide. Also, the management guides are structured in such a way that it is possible for a plot to change its cover types during the simulation period. This is not a problem for STEMS since the cover type for each plot is recalculated at the end of every harvesting cycle.

Criterion 4: Ability to Perform Repeated Annual Projections at Reasonable Cost

STEMS is very expensive to run in a large area assessment when all plots in the region and the tree lists associated with these plots constitute the basic inventory units. It costs approximately a penny per plot per year to simulate changes in the forest inventory using STEMS. To put this figure in some perspective, there are about 10,000 plots which are designated as commerciai timberland in the Northeast region of the U.S. To conduct a 30 year assessment in that region alone would cost $\$ 3,000$ for a single 30-year run. Obviously, if STEMS is ever to be used in a national or even a multi-state assessment, this cost must be reduced substantially. The onty way to do this would be to aggregate the basic inventory data up to some representative plot level and then use these representative plots and their representative tree lists as the basic inventory units in the model. This approach would unlikely be valid for uneven-age plots, provided that the level of aggregation associated with the representative plot was not so grosis as that used in TRAS. However, as Tedder (1981) has pointed out, even-age stands do present somewhat of a problem since each age class would have to be represented as a separate stand. Thus, if there were 8 regions, 5 species groups, 3 owner groups, 
3 productivity classes, and 20 even-age classes, 7200 even-age representative plots would have to be carried in the model. Under the same conditions, the number of uneven-age representative plots would be only 360 !

\subsection{TIMBER RESOURCE INVENTORY MODEL (TRIM)}

The TRIM model was developed by Tedder et al. (1984) in response to the inadequacies of the TRAS model. The TRIM model is basically an outgrowth of the inventory programs contained within the TREES model, discussed previously in this report in Section 4.2.2. TRIM differs substantially in this regard from both TRAS and STEMS in that it was designed specifically to be used in large area assessments and in conjunction with TAMM. The TRAS model, on the other hand, is a stand-oriented model, while STEMS is an individual tree model. Both of these models can and have been used in large area assessments, but neither is ideal for this purpose. Early versions of the TRIM model have been used to simulate inventory changes in the Pacific Northwest and Pacific Southwest. The model is currently being used to predict future timber supplies in the Southeast region of the U.S. Unfortunately a TAMM-compatible version of TRIM for the United States as a whole is not yet available.

In TRIM, as in TREES, the Basic Resource Unit (BRU) represents the lowest level of disaggregation found in the model. Information to characterize each BRU in TRIM is obtained directly from plot survey information contained in the forest inventory data base prepared by the U.S. Forest Service. Each BRU in TRIM represents a collection of acres, identified according to location (region), owner group, site or productivity class and species group. The inventory information contained within each BRU consists of age-specific entries for total volume per acre and average diameter. Volume and diameter information is carried for up to 19 age classes and these inputs (e.g. volume and diameter information for ail 19 age classes) can also vary by stocking level and up to five different MI levels. This means that each BRU can contain up to 15 different schedules of volume and diameter by age class.

The next largest unit in the TRIM inventory scale is the Grouped Resource Limit, or GRU. A single GRU contains all the information required to project the growth and management of the BRU(s) assigned to the GRU in the future. 
BRUs of like region/owner/site and species are grouped into a single GRU. A GRU can be identical to a BRU or it can contain more acres due to internal aggregation of plots within one or more of the four basic identifying characteristics of BRU's and GRUs. For example a regional GRU could be composed of a collection of state BRU's.

Each GRU in TRIM also contains all of the necessary control and management information required to simulate all of the different components of inventory deveiopment. This consists basically of three different types of information. The first type of information is related to the "shifting" of areas in each GRU from one condition, or status, to another either before or after harvest. This information is broadly related to: (a) restocking of harvested plots, (b) shifting acres by age class within a given MI to higher or lower MIs, (c) adding or deleting acres from the timberland base, and (d) different harvesting options. The second type of information includes the price and cost information associated with the GRU. These costs are used to reflect alternative levels of management, associated with each MI, and can be entered in TRIM on a period-by-period basis to reflect actual or expected changes associated in per acre management and harvesting costs. The third type of information is related to the growth and yield of the GRUs. To project the entire growth of the timberland inventory into the future requires the generation of yield tables (voiume per acre by age) for each GRU. Up to five such yield tables-one for each MI--can be utilized per GRU. This information also includes age specific mortality rates for each $M I$, as well as thinning tables to reflect the impact of thinnings on inventory volumes by age.

The final type of inventory unit used in TRIM is the Allowable Cut Unit, or ACU. Each ACU defines the collection of GRUs which can be harvested as a single unit. An ACU can be the same as a GRU or it can represent a collection of GRUs. For example, in conducting large area assessments it may be sufficient to have only three ACUs to correspond to the tree broad timber types (softwoods, hardwoods, and mixed stands). TRIM operates on the inventory in a hierarchical fashion, one ACU at a time. Once an ACU is brought into the mode] each GRU in the ACU is sequenced through the model. It is through this process that the biological integrity of TRIM is maintained: the growth of the 
inventory and the shifting of acres in and out of the inventory and among the various MIs occurs at the GRU level, while harvesting occurs at the ACU level on consistently aggregated "bunches" of GRUs.

TRIM performs these various functions as follows. When a GRU is initially brought into the model in period zero, no growth occurs. The inventory contained in the GRUs is summed and the inventory volume is calculated for softwood, hardwoods, mixed stands and the total of these broad timber types. Next, the "exogenous harvest" is performed. This harvest includes the volumes obtained from (a) the conversion of acres from one species to another, (b) a\}l commercial thinnings and mortality salvage. These amounts are all specified exogenously for each GRU on a percent of inventory by age class basis. The next step involves the aggregation of all available harvest volumes. That is accomplished in order from the oldest to the youngest age class which the user has specified as being eligible to harvest. Next, a check is made to determine if there are any more GRUs in the current ACU. If so, the process continues and if not, a calculation is made that determines the total amount of harvest volume that will come from each GRU in the ACU. As all GRUs in each ACU are processed and when a 11 ACUs have been processed, the model initializes the time level and each ACU (with its GRUs) is brought back into the model so that the harvest allocation among the GRUs can take place. Once that occurs, reports are prepared that indicate the previous inventory before harvest in time period zero and the inventory after harvest. Growth for the period length is also printed. Once this has been done, harvesting takes place. The volume is removed from each GRU within an ACU based upon the amount of total harvest volume available from an individual GRU relative to the total volume avaflable from all the GRUs in the ACU. Harvest volumes can be specified in three ways, as softwood, hardwood, or as mixed combined volume. The harvest age priority is free to be specified by the user.

Once the harvest has been simulated, the areas that have been harvested along with those that have been shifted into the timberland base from the unstocked category are regenerated at levels specified by the user. All restocked acres are put in the same MI from which they originated but are free to be shifted during subsequent periods, if this is called for. TRIM next 
shifts acres in and out of the timberland base to simulate the expansion of timber opportunities and the transfer of commercial timberland into alternative land uses.

The next process that is simulated by TRIM consists of shifting commercial timberland within the various MIs. The shifting of MIs can be accomplished by one of the following three methods:

1. Exagenous Shifts. Average shifts within each MI are specified by the user on a percentage basis.

2. National Expectations, Pre-Determined Species. Acreage shifts within each MI are based on the soil expectation value which is calculated for each MI and age class within each MI, using predetermined stumpage prices. Acres are shifted into higher MIs if the soil expectation value of the timberland is higher than for the MI currently associated with those acres.

3. National Expectations--TAMM Prices. Prices generated by TAMM are used to calculate soil expectation values for each MI and age class. Acres are shifted alternately to higher and lower MIs unti] the MI with the highest soil expectation value is found.

Once the shifting of acres has been completed by TRIM, precommercial thinnings and fertilization are simulated for those acres in which this action is called for by a specific MI. This simply amounts to a set of volume adjustments for affected age classes in the relevant MIs. Precommercial thinning has the effect of reducing the amount of volume per acre at early ages to enhance future growth. Fertilization increases volumes per acre for those acres assigned this treatment. The effects of these treatments are included in the yield tables for the relevant MIs which have these activities associated with them.

The next step in TRIM involves growing the timberland base. There are basically two options for doing this both of which are AD-based, but which can be extended to DD-based stand structures to simulate growth in uneven-age forests. The first approach is to base growth or yield tables, five of which (one per MI) can be carried for each GRU. In addition, the midpoint for each 
age group in each one of these "tables" can be adjusted to reflect stocking levels. These yield tables can be based on standard yield tables, available for different species groups in selected U.S. Forest Service publications, or they can be generated by simulation models specifically developed for a particular species and location. In some areas, using yields provided from these sources may not be satisfactory. Consequently, approach-to-normality options (Tedder 1980) are available. Approach-to-normality is frequently the only economically feasible means to adjust for the effects of abnormal stand stocking on yields. The approach-to-normal volume method is based on the following functional relationship

$$
V_{i+1, j+1}=S V_{i+1}\left[\alpha+B\left(\frac{V_{i j}}{S V_{i}}\right)\right]
$$

where

$$
\begin{aligned}
v_{i j}= & \text { actual net volume per acre, age class } i \text {, after harvest in } \\
& \text { period } j, \\
v_{i+1, j+1=} & \text { volume per acre for age class } i+1 \text { before harvest in period } \\
& j+i, \\
S v_{i+1}= & \text { standard or normal volume per acre, age class } i+1, \\
\alpha, \beta= & \text { user supplied constants defining the approach to normal. }
\end{aligned}
$$

The approach to normal growth routine is somewhat different in that:

$$
V_{i+1, j+1}=V_{i j}\left(S V_{i+1}-S V_{j}\right)\left[\alpha+\beta\left(\frac{V_{i j}}{S V_{i}}\right)\right]
$$

where

$$
S V_{i+1}-S V_{i}=\text { normal growth. }
$$

AD-based growth can be adjusted to affect growth in uneven-age stands as follows. As noted earlier, both volume per acre and average diameter for 19 different age classes are carried by MI for each GRU in TRIM. This information is entered directly from U.S. Forest Service plot summary records. The 
relationship between the observed volumes per acre and age for a single MI in a given GRU can be expressed as

$$
\hat{v}_{i}=f_{1}\left(A_{i}\right)
$$

where

$V_{j}=$ The observed volume per acre net of mortality in age group $i$

$A_{j}=$ mid-point age for age class $i$.

The corresponding relationship for the observed average diameters (D) and age is

$$
\hat{D}_{i}=f_{2}\left(A_{i}\right)
$$

Since both the observed volumes per acre and the average diameter are functions of $A_{j}$ we can form the implicit function

$$
\phi\left(\hat{D}_{i}, \hat{V}_{i}\right)=0
$$

and estimate the parameters of this function from the observed data. If we assume that the structure of the relationship described by (5.13) is the same as the structure of the "true" relationship for arbitrary values of $D_{i}$ and $v_{j}$, then we can use (5.13) transform the growth taken from the yield tables or the approach-to-normality equations on age specific basis to corresponding diameter-based values.

Once growth has been simulated for a GRU, TRIM calculates growth in each age class by subtracting the inventory after harvest from the current inventory level. At that point inventories are summed for each age class and $M I$ and the model again moves to the exogenous harvest remova: portion of the program. As pointed out previously, this whole process is repeated for all of the GRUs in 
an ACU on a period-by-period basis. At the end of the simulation, all of the ACU and GRU level information is printed out in a series of detailed summary reports.

\subsubsection{Application of Criteria}

In this part of the report, the criteria developed earlier in Section 5.2 will be used to evaluate the TRIM model.

\section{Criterion 1: Ability to Project Future Inventories for Broad Timber Types}

The TRIM model is currently capable of projecting future inventory and net annual growth for three broad timber types, softwoods, hardwoods, and mixed stands. Total inventory volumes are carried in TRIM using the following accounting and aggregation scheme

$$
V=\sum_{i=1}^{30} \sum_{j=1}^{5} \sum_{k=1}^{5} \sum_{1=1}^{18} v_{i j k 1} x_{k j k 1}
$$

where

$$
\begin{aligned}
& V=\text { total inventory volume, } \\
& v=\text { volume per acre, } \\
& X=\text { number of acres, } \\
& L=1, \ldots, 30 \text { indicates species group, } \\
& j=1, \ldots, 5 \text { indicates site or productivity class, } \\
& k=1, \ldots, 5 \text { management intensity, } \\
& l=1, \ldots, 18 \text { age class. }
\end{aligned}
$$

Biological integrity is maintained in TRIM (to the extent that it can ever be maintained in an accounting model) by performing all growth, management, harvesting and shifting of acres at a very basic level of aggregation (the GRU) and then using the structure described by (5.14) to obtain total inventory volumes.

From a comparative standpoint, TRIM clearly satisfies this criteria better than TRAS. The comparison between STEMS and TRIM is mixed. On the one hand, the TRIM inventory can be broken down into subcategories that are more 
compatible with TAMM than the current version of STEMS. STEMS, on the other hand, operates on individuai plots and trees and therefore maintains a substantial greater degree of biological integrity than does TRIM. However, as noted in the discussion of STEMS, this is a benefit for which one must pay a very high price indeed.

Criterion 2: Ability to Simulate Growth and Yield in Even- and Uneven-Age Forests

TRIM, in its current configuration, is basically an area-hased AD model which is ideal for use in even-age forests. AD-based growth is calculated either from yield tables, which specify volume per acre by age for five different MI levels in each GRU. Alternatively, approach-to-normality equations can be used to compute growth. TRIM can also be used in uneven-age forests. This capability exists by virtue of the fact that a relationship between volume per acre and average diameter can be developed for each age class and MI within a given GRU and, once developed, this relationship can be used to distribute agespecific inventory volumes across the different diameter classes. However, the current version of TRIM does not carry the inventory on a true diameter distribution basis (e.g., number of trees by diameter class) and this prevents the model from being classed as a $D D$ as well as an $A D$ model. An uneven-age version of TRIM is currently in the planning stages. This model would be based on the DD capability already present in the TREES model and would apply a stand table projections method to simulate growth and yield "n uneven-age stands.

TRIM is clearly superior is TRAS in simulating even-age growth and, given the dubious nature of the assumed diameter distribution used in the $Q$ approach, TRIM may also do a better job of simulating growth and yield in uneven-age forests than does TRAS. The comparison between TRIM and STEMS as predictors of growth in even-age forests cannot really be made until the appropriate validation of TRIM is conducted and the validation of STEMS is expanded to regions other than the Lakes States. Comparative validation trials would also have to be accomplished to compare TRIM and STEMS as predictors of growth in uneven-age stands. However given that the approach used in the current version of TRIM to project uneven-age growth is untested, STEMS is is probably the superior mode? on this score. 
All of these comparative points may be somewhat mute. Recall that 1) the current version of STEMS does not have the ability to simulate regeneration other than stocking after clearcutting and 2) the parameters of the normal growth, the modified growth, the mortality, and the crown ratio functions in STEMS have only been estimated for three states. TRIM on the other hand can employ standard yield tables and/or a wide variety of tree simulation models currently available for a large number of region-species groups on an "off the shelf" basis.

\section{Criterion 3: Ability to Simulate Management}

TRIM can simulate intensive management actions for even-age forests. It also has the ability so simulate intensive management for uneven-age forests, although the technical features of the approach are somewhat questionable. Intensive management is accomplished within TRIM by providing a set of five yield tables for each GRU to reflect five alternative management treatments available for the representative acres in each GRU. Treatment selection, including the shifting of acres between alternative MIs, can be accomplished on a year to year basis, either by the user to reflect $h$ is or her judgment about optimum silvicultural systems or on the basis of the effect which alternative treatments have on the future value of timber ( $i$.e., soil expectation values). In addition, TRIM has the ability to shift acres in and out of the inventory on a period-by-period basis to reflect changing economic opportunities. In the case of acid deposition, this capability could be used to simulate change in the species composition of individual GRUs due to the indirect effects of acid deposition on competition within the forest.

On a comparative basis, the management approach used in TRIM is clearly superior to that of TRAS. However, the comparison with the STEMS capability is mixed. The economic features in the MI shifting routines of TRIM are much more consistent with rational economic behavior than the management guides and marking rules in STEMS which tend to reflect physical as opposed to economic objectives. On the other hand, the uneven-age management capability in TRIM has not yet been demonstrated. 
Criterion 4: Ability to Perform Repeated Annual Projections at Reasonable Cost

The costs of running the current version of TRIM have not been calculated and vary considerably based on the number and detail of the reports required by the user. For an older and less efficient version of TRIM, the cost to run the model ranged between 2 and 5 cents per GRU per cycle. Since TRIM is usually run on a five-or ten-year cycle basis the cost to conduct a 50 year simulation for TRIM is substantially below that of STEMS, even if STEMS could be run witn representative (i.e. GRU-like) as opposed actual plots. Thus, TRIM is cleariy the superior model based on this criterion.

\subsubsection{Evaluation of TRIM}

Based on the four criteria used to evaluate inventory projection models in this report, TRIM clearly holds the greatest potential for use in evaluating the economic impacts of acid deposition on stumpage and primary wood product markets in the United States. However, TRIM has not yet been linked physically to the TAMM models in a manner that will permit its use in an environmentai assessment which is national in scope. In addition, the necessary inventory data bases needed to run TRIM for all hardwood and softwood supply regions in the United States are not available. Consequently, the TRAS model will be used in the quantitative analysis reported in Section 7.0. This decision is based on 1) the availability of a version of TRAS aTready linked to the TAMM models and 2) the availability of supporting regional inventory data to run TRAS in concert with TAMM. 


\subsection{SIMULATIONS}

To test the model and analyze the potential economic effects of hypothetical reductions in growth, several scenarios were simulated using the TAMM-TRAS models. The scenarios were developed in consultation with representatives from other NAPAP research groups, the U.S. Forest Service, and the forest products industries. These scenarios represent various alternative hypotheses about the future and include:

- a base case, in which there are no reductions in growth

- nine cases in which radial growth rates of trees in growing stock inventories in the Northeast or Southeast are reduced

- three cases in which changes in alternative base case assumptions that are not related to radial growth rates are assumed to occur. The base case serves as the standard in the analysis. By comparing the base case results with the results of the reduced growth cases, an indication of how severe the effects of reduced growth might be is obtained. The results of the alternative base case scenarios are used to check the validity of the model as well as to place the results of the pollution stress cases in greater perspective. By comparing the results of the alternative base case scenarios with the results of the reduced growth cases one can determine whether the economic impacts due to hypothetical growth reductions are greater or smaller than the impacts that might be caused by changes in traditional economic factors.

\subsection{THE BASE CASE}

The assumptions for the base case in the analysis are, for the most part, identical to the assumptions about the future used by the U.S. Forest Service (1982, 1983). Because these assumptions are described in detail by Haynes and Adams (1985), only the highlights that are central to this analysis are presented and discussed here.

Table 6.1 shows the major demographic and economic assumptions underlying the base case. The population of the United States is assumed to increase to about 300 million people by 2030 , while the nation's gross national product 
TABLE 6.1. Population, Gross National Product, and per Capita Disposal Income in the United States for 1977, with Projections to 2030

\begin{tabular}{ccccc} 
Year & $\begin{array}{c}\text { Population } \\
\text { (Millions) }\end{array}$ & $\begin{array}{c}\text { Gross National } \\
\text { Product (Billion } \\
1972 \text { Dollars) }\end{array}$ & $\begin{array}{c}\text { Per Capita Dis- } \\
\text { posable Personal } \\
\text { Income (1972 Dollars) }\end{array}$ \\
\cline { 2 - 3 } & 220.2 & 1,370 & 4,280 \\
2000 & 249.7 & 1,970 & 5,590 \\
2010 & 268.0 & 2,580 & 6,910 \\
2020 & 283.1 & 3,310 & 8,530 \\
2030 & 296.3 & 4,070 & 10,150
\end{tabular}

Source: "Simulations of the effects of alternative assumptions on demand-supply determination on the timber situation in the United States," Haynes and Adams, 1985.

grows to about 5 trillion 1972 dollars. Personal disposable income per person is expected to be more than $\$ 12,000$ in real terms.

More directly relevant to forest economics are the assumptions about 1) the number of housing starts, 2) the processing efficiency of solid wood products, and 3) the amount of commercial timberland acreage. The number of housing starts, for example, is a major determinant of the demand for softwood Tumber and plywood. Table 6.2 shows that housing starts are expected to be about 1.5 million units in 2030. Technological advances in lumber and plywood manufacturing are expected to increase processing efficiency by $10 \%$ (about $2 \%$ per decade) over the projection period. This implies that less stumpage witl be required to produce a given amount of lumber or plywood in 2030 than in 1980. Conversion of commercial timberland to other land uses reduces the amount of growing stock available for harvesting. As is shown in Table 6.2, the acreage of comnercial timberland held by private owners in the lower 48 states is expected to decline to 319 million acres. Finally, the assumptions about the growing stock inventories are identical to those used by the U.S. Forest Service (1983).

The major differences in the base case developed for this analysis and the u. S. Forest Service's base case pertain to the consumption and production of 
TABLE 6.2. Housing Starts and Commercial Timberland Acreage in the United States: Projections to 2030

\begin{tabular}{|c|c|c|}
\hline Year & $\begin{array}{c}\text { Housing } \\
\text { Starts } \\
\text { (Thousands) (a) } \\
\end{array}$ & $\begin{array}{c}\text { Commercial } \\
\text { Timberland } \\
\text { (Million Acres) (b) }\end{array}$ \\
\hline 1990 & 1,941 & 338 \\
\hline 2000 & 1,733 & 332 \\
\hline 2010 & 1,949 & 327 \\
\hline 2020 & 1,801 & 323 \\
\hline 2030 & 1,516 & 319 \\
\hline
\end{tabular}

(a) Includes both single and multiple family units

(b) Includes only privately owned commercial timberland in the lower 48 states.

Source: "Simulations of the effects of alternative assumptions on demand-supply determination on the timber situation in the United States," Haynes and Adams, 1985.

pulp. As is indicated by Table 6.3, this analys is assumes lower levels of pulp consumption in the future. We also assume that more nongrowing stock, e.g., branches and roots, will be used to produce pulp over the projection period.

TABLE 6.3. Pulp Consumption in the United States for 1980, with Projections to 2030

\begin{tabular}{|c|c|c|}
\hline Year & $\begin{array}{c}\text { U.S. Forest } \\
\text { Service (1983) }\end{array}$ & $\begin{array}{r}\text { Current } \\
\text { Analysis }\end{array}$ \\
\hline 1980 & 52.10 & 51.83 \\
\hline 1990 & 70.80 & 63.69 \\
\hline 2000 & 84.40 & 77.44 \\
\hline 2010 & 98.00 & 89.44 \\
\hline 2020 & 111.80 & 98.11 \\
\hline 2030 & 124.50 & 108.10 \\
\hline
\end{tabular}

(a) Based on information provided by Or. Richard Haynes. 
Specifically, we assume that nongrowing stock inputs will gradually increase so that by the year 2000, 5\% more of the pulp produced in the Northern and Southern regions witl use branches and roots instead of pulpwood as an input. This increased use of nongrowing stock in pulp production is assumed to remain constant at $5 \%$ for the rest of the projection period. This is simulated by gradually reducing the levels of pulp production allocated to the Northern and Southern region until the year 2000 , when $5 \%$ reductions are obtained. These reductions are then held constant at $5 \%$ until the year 2030 .

\subsection{REDUCED GROWTH CASES}

As reported in earlier sections of this document, no direct or indirect linkages have been established between levels of pollution and recently reported decreases in the radial growth rates of some species of trees (principally conifers) in the Northeast or Southeast regions. Because of the uncertainty caused by this lack of information about the specific physical impacts that might be induced by pollution, several different scenarios were devel. oped. Although based on simple hypotheses, the scenarios are organized to facilitate comparative analyses and, together, depict a wide range of possible futures.

Pollution stress in these cases is simulated by reducing the average annual radial growth data used by TRAS to calculate the net growth of trees from one diameter class to the next. This simplification implies that pollution stress only affects the radial growth rate of trees--not mortality or regeneration. We also assume that, in percent terms, growth reductions induced by pollution stress are the same for all two-inch diameter classes and for both types of private ownership. The reductions do not, however, interfere with the constraints on radial growth, ingrowth, and mortality that are triggered by high basal areas in TRAS's representative acres.

The pattern underlying the construction of the reduced growth cases is depicted in Table 6.4. Due to this organization, the impacts of growth reductions in different regions, of various magnitudes, and on different species types are easily compared. For example, the first two scenarios are designed to compare the economic impacts of reduced growth when its physical effects are 
TABLE 6.4. Hypothetical Reductions of Average Annual Radial Growth Rates Used to Simulate the Physical Effects of Pollution

(Percent)

Species Type/Region

\begin{tabular}{|c|c|c|c|}
\hline \multicolumn{2}{|c|}{ Softwood } & \multicolumn{2}{|c|}{ Hardwood } \\
\hline Northeast & Southeast & Northeast & Southeast \\
\hline 15 & 0 & 15 & 0 \\
\hline 0 & 15 & 0 & 15 \\
\hline 10 & 10 & 10 & 10 \\
\hline 15 & 15 & 15 & 15 \\
\hline 20 & 20 & 20 & 20 \\
\hline 0 & 0 & 15 & 15 \\
\hline 15 & 15 & 0 & 0 \\
\hline $15^{(a)}$ & 0 & 15 & 0 \\
\hline $15^{(b)}$ & 15 & 15 & 15 \\
\hline
\end{tabular}

(a) Projections of softwood lumber and plywood production in the Northern regions decreased relative to the base case.

(b) Projections of softwood lumber and plywood production in the Northern regions increased relative to the base case.

confined to either the Northwest or Southeast regions. The results of the next three scenarios yield information about the levels of economic impacts that might be caused by different magnitudes of physical damage in the Northeast and Southeast regions. The sixth and seventh scenarios in Table 6.4 isolate the economic impacts of reduced growth when its physical effects are confined to either hardwood or softwood species.

The last two scenarios listed in Table 6.4 reflect the same hypotheses about the physical effects of pollution stress that are used in the first and fourth scenarios, respectively. The last two scenarios differ from the first and fourth scenarios in that the production levels of softwood lumber and plywood in the Northern regions also are modifjed. Recall that the softwood division of TAMM exogenously projects lumber and plywood production in the Northeast and North Central regions. This predetermination of production 
implies that, at any point in time, supply is completely inelastic. This means that price signals in either the product or stumpage markets will not affect the behavior of producers in those regions. Because the Northeast region plays a central role in this analysis, projections of ibrthern production levels in the last two scenarios were modified to simulate the direction (if not the exact magnitude) of the expected changes.

The methodology used to make the modifications is based on the specification of product supply in those regions where the quantities supplied are endogenous. These equations are:

$$
\begin{aligned}
& S S_{k t}^{j}=a_{0 k}^{i}+a_{1 k}^{i}\left[S P_{k t}^{i}-w_{k t}^{j}\left(c_{k t}^{i}+S P_{k t}\right)\right]+a_{2 x^{i}}^{i} S k_{k t-1}^{j} \\
& S S_{k t}^{i}<S K_{k t-1}^{i} \\
& S K_{k t}^{i} / S K_{k t-1}^{i}=1.00+\sigma_{k}^{i}\left[.5 \sum_{s=1}^{2}\left(R_{k t-s}^{i}-\hat{R}_{k}^{i}\right)\right]
\end{aligned}
$$

By substituting the product margin as it is specified in equation (4.4) into Equation (4.5), we obtain:

$$
\begin{aligned}
S K_{k t}^{j} / S K_{k t}^{i}-1 & =1.00+\sigma_{k}^{j}\left\{. 5 \sum _ { s = 1 } ^ { 2 } \left[S P_{k t-s}^{j}-W_{k t-s}^{j}\left(c_{k t-s}^{j}\right.\right.\right. \\
& \left.\left.\left.+S P_{k t-s}\right)-\hat{R}_{k}^{i}\right]\right\}
\end{aligned}
$$

Equation (4.4) and Equation (6.1) indicate that product supply, $\mathrm{Ss}_{\mathrm{kt}}^{\mathrm{i}}$, is a function of only two endogenously derived data series--mill level product prices, $\mathrm{SP}_{\mathrm{kt}}^{i}$, and softwood stumpage prices, $\mathrm{SP}_{\mathrm{kt}}$. The other variables and parameters in these equations are derived entirely from exogenous data series and an initial set of capacities, $S K_{k 0^{*}}^{\dagger}$. Equation (6.1) also implies that the endogenously derived product margins, $R_{k t}^{i}$, will gravitate toward the neighborhood of the target margins, $\hat{\mathrm{R}}_{\mathrm{kt}}^{i}$, in any simulation. Hence, the product margins 
derived in one simulation should be similar in magnitude to the product margins derived in another simulation.

We simply assume that the product supply equations implied by the exogenous projections of production in the Northern regions could be formulated in a similar manner. This means that sets of product margins generated for the Northern regions by different simulations also should be similar. Fortunately, TAMM does in fact generate price series that can be used to calculate product margins for the Northeast and North Central regions. In addition, these price series are linked to the exogenous projections of production for the two regions.

Each of the regions, for example, has a supply function for softwood stumpage which uses inventory levels to calculate stumpage prices. The inventory levels in turn are linked by TRAS to the stumpage requirements of the product projections. Product prices for the Northern regions, on the other hand, are derived from regional demand functions which include local production levels as variables. These retail product prices are appropriate substitutes for mill level prices. In the Northern regions, the major difference between retail product prices and mill level product prices would be the transportation costs required to distribute the products within the regions. First, the Northern demand regions are almost identical to the Northern supply regions (see Figure 4.2 and Figure 4.3 above). Second, both regions rely primarily on imports to satisfy their local demands for softwood products. The small amounts that are produced locally are consumed locally. Because the same set of within-region transportation costs for the Northern regions are used in all simulations, product margins derived from retail product prices should behave the same way as margins derived from mill level product prices. If they do not, corrective action can be taken by modifying the projections of production in the regions.

Table 6.5, for example, shows the margins between the retail price of softwood lumber and the price of softwood stumpage in the Northern regions over the projection period for the Base Case and the first and fourth reduced growth scenario listed in Table 6.4, $i . e .$, the scenarios for which projections of the production of softwood lumber and plywood in the Northern regions are the same 
TABLE 6.5. Product Margins (a) for Softwood Lumber in the Northeast and North Central Regions: Decade Projections, 1990 to 2030

$$
\text { (1967 Dollars per Thousand Board Feet) }
$$

\begin{tabular}{|c|c|c|c|}
\hline Region/Year & Base Case & $\begin{array}{c}\text { Timber Growth } \\
\text { Mortheast } \\
\text { Only }\end{array}$ & $\begin{array}{c}\text { Reduced by } 15 \% \text { in: } \\
\text { Northeast } \\
\text { and Southeast }\end{array}$ \\
\hline \multicolumn{4}{|l|}{ Northeast } \\
\hline 1990 & 142.14 & 140.46 & 144.67 \\
\hline 2000 & 154.39 & 151.98 & 160.81 \\
\hline 2010 & 150.22 & 147.11 & 160.40 \\
\hline 2020 & 147.24 & 143.79 & 153.93 \\
\hline 2030 & 142.09 & 135.16 & 151.77 \\
\hline
\end{tabular}

\section{North Central}

$\begin{array}{llll}1990 & 136.29 & 135.36 & 139.23 \\ 2000 & 151.55 & 149.63 & 157.11 \\ 2010 & 145.25 & 142.13 & 155.23 \\ 2020 & 139.30 & 135.87 & 146.97 \\ 2030 & 140.38 & 135.73 & 149.88\end{array}$

(a) Product Margin = Retail Lumber Price - Stumpage Price

as in the Base Case. Relative to the Base Case, the margins for the Northeast Only scenario are decreasing, while the margins for the Northeast and Southeast scenario are increasing. These differences indicate that the projections of softwood Tumber production in the Northern regions for these two reduced growth scenarios do not accurately reflect the implicit supply functions for the regions that are inherent in the Base Case. Indeed, the results indicate that the production projections for the Northeast Only scenario should be reduced, while the projections for the Northeast and Southeast scenario should be increased. A similar pattern would be shown by plywood product margins.

Modifying the production projections can also be defended on purely economic grounds. In the Northeast Only scenario, annual radial growth for the 
Northeast's inventories is $15 \%$ lower than in the Base Case. This causes inventories to decrease and stumpage prices to increase relative to the Base Case. Stumpage price increases in the Northeast region spillover into the North Central region as pulp producers shift some of their activity from the Northeast to the North Central region. Increased stumpage prices in turn would ordinarily cause a decrease in the local supply of lumber in each of the regions all else being equal.

Stumpage prices in the Northern regions also increase in the Northeast and Southeast scenario. In this scenario, however, radial growth for the Southeast's inventories also is reduced by $15 \%$ relative to the Base Case. This in turn reduces the local supply of lumber in both the Southeast and South Central regions. Because the Northern regions obtain much of their lumber from the Southern regions, decreases in the local supply of 1 umber in the Southern regions spillover into the Northern regions in the form of higher retail prices. Hence, although stumpage prices in the Northern regions increase, retail sales prices increase by greater amounts. This would induce local producers to increase their production relative to the Base case.

Table 6.6 shows projected margins between the retail price of softwood lumber and the price of softwood stumpage for the Base Case, and the last two reduced growth scenarios 1 isted in Table 6.4. These reduced growth scenarios are identical to the reduced growth scenarios in Table 6.5 except that the production projections of softwood lumber and plywood in the Northern regions have been modified. Projections of softwood lumber and plywood production in the Northern regions are reduced for the Northeast Only scenario and increased for the Northeast and Southeast scenario. In the Northeast Only scenario, projections of both lumber and plywood production in the Northeast are gradually reduced beginning in 1985 until by 2030 production is $15 \%$ lower than production in the Base Case. In the North Central region, a similar procedure is used to reduce lumber projections (there is no plywood production) $19.5 \%$ by 2030 . In the Northeast and Southeast scenario, projections of lumber and plywood production in the Northern regions are gradually increased until by 2030 production is $25 \%$ higher than production in the Base Case. These modifications yield product margins that are much more similar to the Base Case product 
TABLE 6.6. Product Margins(a) for Softwood Lumber in the Northeast and North Central Regions, when the Production of Softwood Lumber and Plywood is Adjusted: Decade Projections, 1990 to 2030

\begin{tabular}{|c|c|c|c|}
\hline Region/Year & Base Case & $\begin{array}{c}\text { Timber Growth } \\
\text { Northeast } \\
\text { Only } \\
\text { (Production } \\
\text { Decreased) }\end{array}$ & $\begin{array}{r}\text { Reduced by } 15 \\
\text { Northeas } \\
\text { and Southe } \\
\text { (Product } \\
\text { Increased }\end{array}$ \\
\hline \multicolumn{4}{|l|}{ Northeast } \\
\hline 1990 & 142.14 & 140.78 & 143.65 \\
\hline 2000 & 154.39 & 153.20 & 158.64 \\
\hline 2010 & 150.22 & 151.60 & 157.45 \\
\hline 2020 & 147.24 & 145.34 & 149.43 \\
\hline 2030 & 142.09 & 140.57 & 144.55 \\
\hline \multicolumn{4}{|l|}{ North Central } \\
\hline 1990 & 136.29 & 135.47 & 139.29 \\
\hline 2000 & 151.55 & 150.24 & 151.94 \\
\hline 2010 & 145.25 & 144.57 & 155.03 \\
\hline 2020 & 139.31 & 138.88 & 141.42 \\
\hline 2030 & 140.38 & 140.88 & 143.55 \\
\hline
\end{tabular}

(a) Product Margin = Retail Lumber Price -- Stumpage Price

margins than the product margins derived from the reduced growth scenarios in which Northern production is not adjusted. This indicates that the direction as well as the magnitude of the modifications are appropriate. To obtain the exact magnitude of the production change, however, would require fully specified product supply functions.

\subsection{ALTERNATIVE, BASE CASE SCENARIOS}

To place the potential effects of growth reductions in perspective, three alternative base case scenarios also were simulated in which the effects of lower housing starts, greater processing efficiency in lumber and plywood 
production, and fewer acres of commercial timberland than projected in the base case were forecast. These scenarios represent a range of alternative, but nevertheless fairly likely, assumptions about the values of key variables which are known to affect levels of economic activity in stumpage and forest product markets. As such, the economic consequences associated with these scenarios can be used to bound the base case results with a set of alternative outcomes. By comparing the results of the reduced growth cases with the results of the alternative base case scenarios one can detemine whether the economic impacts due to growth reductions lie outside the range of effects due to other factors. If not, this is a potential indication that it may be difficuit to distinguish between the economic impacts due to pollution stress and those impacts which may occur due, say, to land use changes. Also, because the alternative base case scenarios are similar to those proposed by Haynes and Adams (1985), an independent check on the validity of the version of TAMM used in this analysis is available.

\subsubsection{Low Housing Starts}

Projections of housing demand are based primarily on demographic and economic trends. One current area of contention is the extent to which recent increases in real interest rates will offset the high demand for housing that demographic trends indicate for future. Two possible futures concerning the behavior of real interest rates and its impact on the number of new housing starts are illustrated in Table 6.7 .

The Base Case assumes a gradual reduction of real interest rates, leading to housing starts of 1.9 million units in 1990 and declining to 1.5 million units in 2030. The Low Housing Case, on the other hand, assumes that real interest rates will remain high, resulting in housing starts of only $1.5 \mathrm{mil}$ 1 ion units in 2000, which in turn falls to 1.0 mitlion units by 2030 . Also, the Low Housing Case assumes that the average size of new housing units will be smaller and that new units will use less lumber and plywood per square foot of floor space than the Base Case.

These assumptions entail a substantial reduction of wood consumption in residential end-uses. The demand for softwood lumber and plywood are particularly affected (residential construction is a minor component of hardwood 
TABLE 6.7. New Housing Starts, Projections to $2030^{(\alpha)}$

(thousands)

\begin{tabular}{|c|c|c|}
\hline Year & Base Case & $\begin{array}{c}\text { Low Housing } \\
\text { Case }\end{array}$ \\
\hline 1990 & 1,941 & 1,415 \\
\hline 2000 & 1,733 & 1,455 \\
\hline 2010 & 1,949 & 1,275 \\
\hline 2020 & 1,801 & 1,140 \\
\hline 2030 & 1,516 & 1,000 \\
\hline
\end{tabular}

(a) Includes both single and
multiple family units. Source: Haynes and Adams, 1985.

demand). Hence, the Low Housing Case simulates the effects of reducing the demand for softwood lumber and plywood.

\subsubsection{Increased Processing Efficiency}

This simulation assumes that the efficiency of processing sawlogs and vereer logs to produce 1 umber and plywood will increase by $25 \%$ over the projection period, rather than the $10 \%$ increase assumed by the Base Case. The Increased Efficiency Case also assumes that lumber and plywood producers will adopt the necessary technology in the immediate future because of rapidly rising wood costs and the current availability of substantially more efficient technology. Adoption will gradually slow as the increasing costs of wood are moderated and the costs of implementing additional improvements increase. Thus the rates of increase per decade over the projection period are assumed to conform to the following progression: $9 \%, 7 \%, 5 \%, 3 \%$, and $1 \%$. The Base Case, on the other hand, assumes a constant rate of increase of $2 \%$ per decade.

Changes in the rates of recovery improvements are made for all supply regions (including Canada) and for both softwood and hardwood products. The major impact of efficiency improvements is on regional overrun factors. A products overrun factor defines how much stumpage is required to produce a given amount of lumber or plywood. Table 6.8 shows tha:, by 2030 , l unber and plywood 
TABLE 6.8. Product Overrun Factors in 2030

(board feet and square feet, product

scale per board feet $\log$ scale)

\begin{tabular}{|c|c|c|c|c|}
\hline \multirow[b]{2}{*}{ Species Group Region(s) } & \multicolumn{2}{|c|}{ Base Case } & \multicolumn{2}{|c|}{ Improved Efficiency } \\
\hline & Lumber & Plywood & Lumber & Plywood \\
\hline \multicolumn{5}{|l|}{ Softwood } \\
\hline Eastern & 1.42 & 2.50 & 1.67 & 2.93 \\
\hline Rocky Mountain & 1.46 & 2.57 & 1.71 & 3.01 \\
\hline Pacific Southwest & 1.34 & 3.09 & 1.57 & 3.62 \\
\hline $\begin{array}{l}\text { Pacific Northwest, } \\
\text { West }\end{array}$ & 1.53 & 3.09 & 1.79 & 3.62 \\
\hline $\begin{array}{l}\text { Pacific Northwest, } \\
\text { East }\end{array}$ & 1.33 & 3.06 & 1.56 & 3.59 \\
\hline \multicolumn{5}{|l|}{ Hardwood } \\
\hline Eastern & 1.53 & 2.50 & 1.79 & 2.93 \\
\hline
\end{tabular}

overrun factors increase by about $18 \%$, which in turn cause the supply of these products to increase. At the same time, the derived demand for saw timber stumpage is reduced. The demand for pulpwood stumpage, however, increases because fewer residues are available for pulp production.

\subsubsection{Reduced Timberland Acreage}

The long-term supply of forest products in the United States will depend largely on the future of the nation's commercial timberland. Thus, the land use decisions of private owners, who now hold about $72 \%$ of the commercial timberland in the United States, will continue to be an important yet uncertain variable. As is shown in Table 6.9, the Reduced Timberland Case assumes, that, relative to the Base Case, private owners will convert an additional 40 million acres of timberland to agricultural, urban, or other land uses by 2030 . Table 6.10 shows that about $75 \%$ of the additional losses occur in the North Central, South Central, and Southeast regions. Both softwood and hardwood inventories are affected. 
TABLE 6.9. Private Commercial Timberland in the United States, Projections to 2030

$$
\text { (million acres) }
$$

$\begin{array}{lccc}\frac{\text { Year }}{1990} & & \text { Base Case } & \begin{array}{c}\text { Reduced } \\ \text { Timberland Case }\end{array} \\ 2000 & 338 & 332 & 309 \\ 2010 & 327 & 297 \\ 2020 & 323 & 386 \\ 2030 & 319 & 279\end{array}$

TABLE 6.10. Private Commercial Timberland in the United States by Region, 2030 Projections

$$
\text { (million acres) }
$$

\begin{tabular}{|c|c|c|}
\hline Region & Base Case & $\begin{array}{l}\text { Reduced } \\
\text { Timberland Case }\end{array}$ \\
\hline Northeast & 66.16 & 62.26 \\
\hline North Central & 61.62 & 54.37 \\
\hline Southeast & 72.88 & 64.27 \\
\hline South Central & 82.15 & 67.24 \\
\hline Rocky Mountain & 12.82 & 10.57 \\
\hline $\begin{array}{l}\text { Pacific Northwest, } \\
\text { West }\end{array}$ & 10.74 & 8.94 \\
\hline $\begin{array}{l}\text { Pacific Northwest, } \\
\text { East }\end{array}$ & 5.61 & 5.35 \\
\hline Pacific Southwest & 7.11 & 6.20 \\
\hline
\end{tabular}

The Reduced Timberland Case is similar to the reduced growth cases in that growing stock inventories are the immediate targets for manipulation. The major difference is that inventories are directly reduced in only one or two regions in the reduced growth cases, where as the inventories are directly reduced in all of the domestic supply regions in the Reduced Timberland Case. 


\subsection{RESULTS}

The primary objective of this section is to present the important results of the simulations previously described in Sections $6.1-6.3$. To achieve this objective, this section is divided into three parts. Section 7.1 discusses the potential impacts of assumed reductions in timber growth on growing stock inventories. The effects of reducing timber growth by different amounts, in different regions, and for different species groups are emphasized. In Section 7.2, the potential economic impacts of reductions in timber growth in stumpage and forest product markets are presented. For brevity, we concentrate primarily on how reducing timber growth rates by different amounts affects prices, production, and consumption in stumpage and lumber markets.

The welfare implications of timber growth reductions are discussed in Section 7.3. Estimates of the welfare effects that different timber growth rates induce in stumpage, lumber, and plywood markets are presented for various economic agents and regions and for the United States overall. Detailed results of all the cases are contained in Appendix C. We wish to emphasize that the results in this chapter are for hypothetical reductions in timber growth.

There is no direct evidence linking growth reductions to air pollution or acid deposition.

\subsection{IMPACTS ON GROWING STOCK INVENTORIES}

Our assessment of the effects of growth slowdowns on growing stock inventories consists of two separate analyses. These analyses differ in assumptions regarding the response of lumber and plywood producers in the Northern region to changes in growth rates in the Northeast and Southeast. The unmodified version uses the assumption of unchanged production levels in the Northern region. It was felt that such an assumption may be unrealistic and, so, modifications to this version were made to allow Northern producers to increase production. The methodology for this modification is described in Appendix $B$. We first describe the results of the unmodified scenario, then the results of the modified version. 
Recent analyses of the timber supply situation in the United States, the U.S. Forest Service $(1982,1983)$ predicted that growing stock inventories would continue to increase until early in the next century, but then begin to decline. Thus, although a physical shortage of timber is unlikely in the decades immediately ahead, there are potential long run problems. Slower timber growth in the Northeast and Southeast could exacerbate the future inventory declines projected by the Forest Service.

Figure 7.1 and Table 7.1 illustrate this point by comparing projections of growing stock inventories derived from the Base Case with projections of inventories derived from three scenarios in which timber growth rates in the Northeast and Southeast are hypothetically reduced by $10 \%, 15 \%$ and $20 \%$ per year. Consistent with the predictions published by the U.S. Forest Service (1982), the Base Case predicts that inventories will grow until early in the next century and then begin to decline. The hypothetical reductions of timber growth rates in the Northeast and Southeast do not alter the general pattern of growth and decline shown in the Base Case. However, when timber growth rates are reduced, the particulars of this pattern are altered in three basic ways. First, reducing the annual growth rates of trees leads to decreases in inventory volumes in the Northeast and Southeast in a11 three reduced growth cases. Second, the magnitude of these decreases is sharpest in the Southeast region. Third, reduced tree growth in the Northeast and Southeast spills over into other regions causing timber inventories to fall below Base Case levels after 2000. Together these forces result in dacrases in growing stock inventories for the United States which are roughly $10 \%$ to $20 \%$ less than those in the Base Case by the year 2030.

The inventory reductions in the Northeast and Southeast which are depicted in the upper panels of Figure 7.1 are due, directly, to the lower growth rates hypothesized for the two regions. The inventory reductions in the other supply regions illustrated in the lower left panel of Figure 7.1 are due to the spillovers discussed in Section 3.2.3. In regions directly subjected to growth reductions, stumpage price increases also cause the prices of locally produced lumber and plywood to increase. Because of the nationwide trade in lumber and 
Growth Reduction
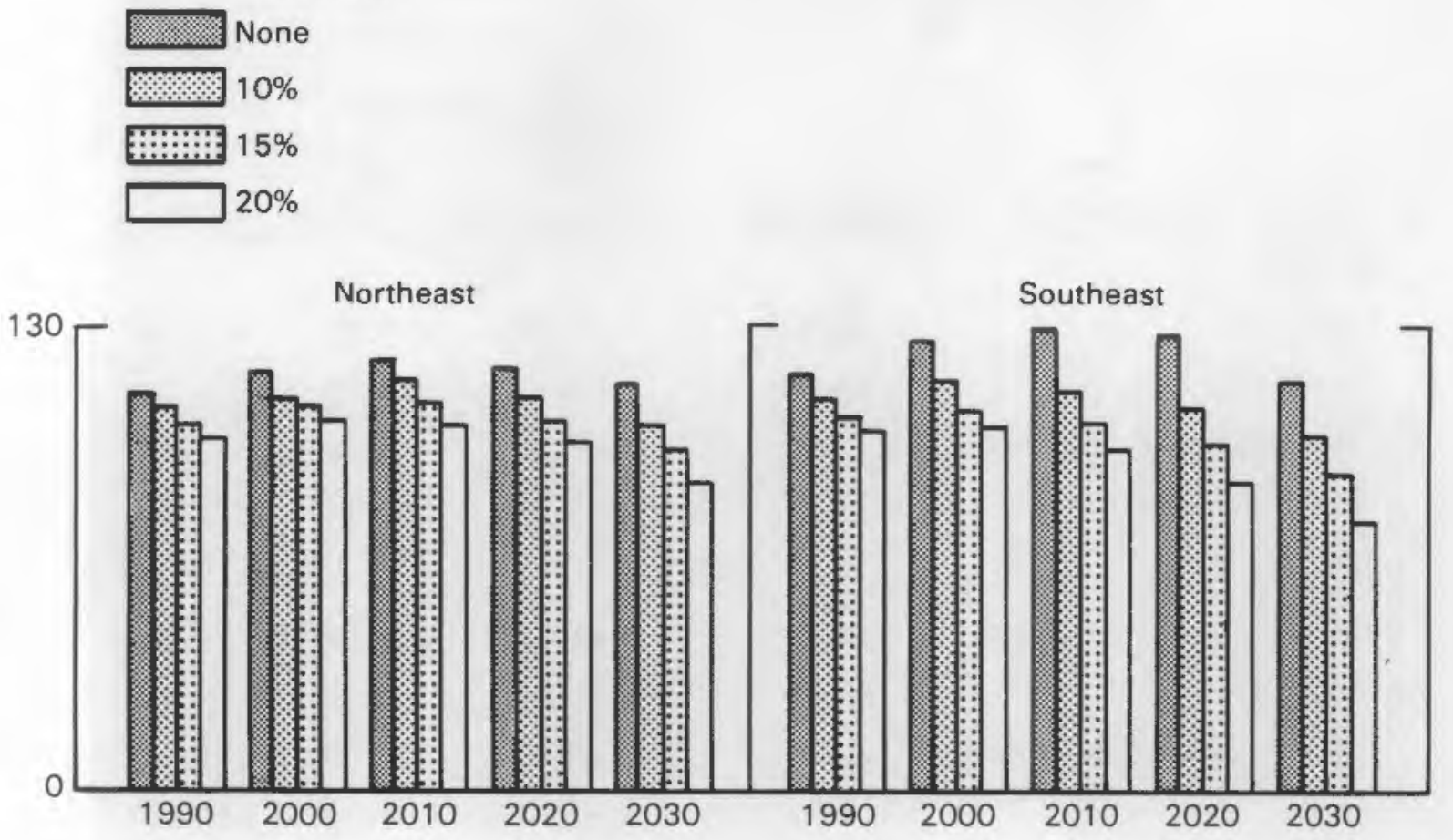

Other Regions

All Regions

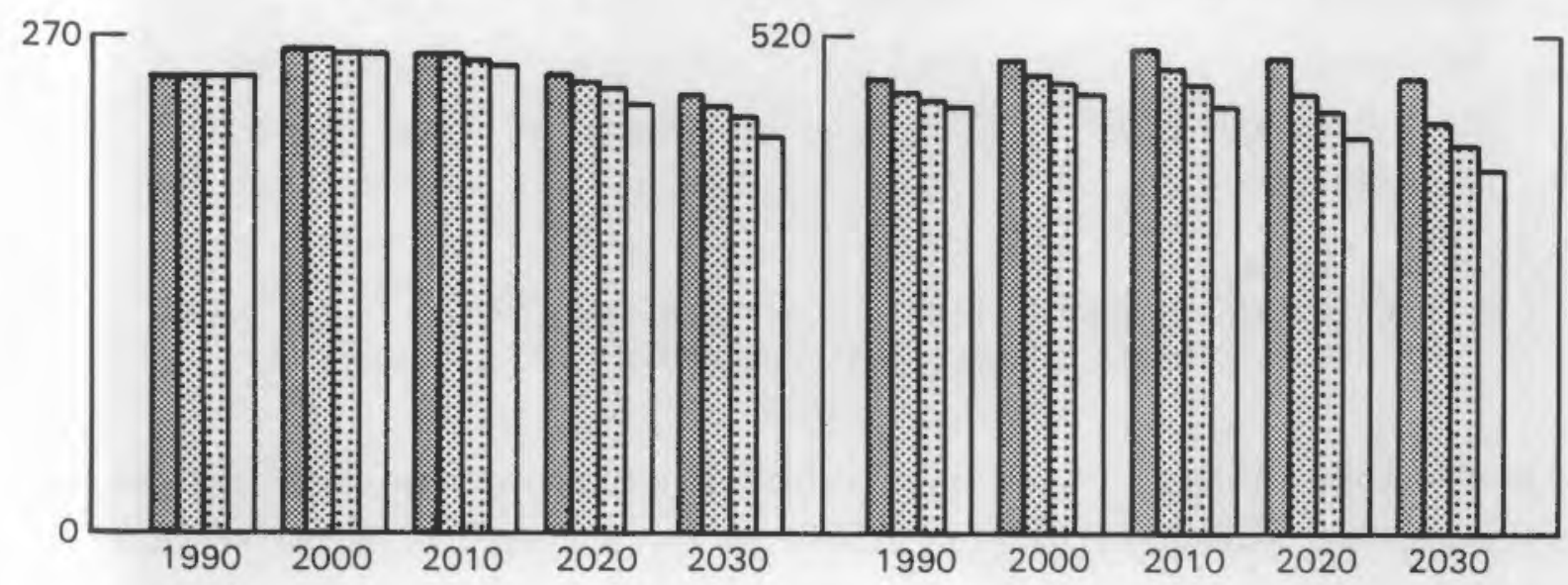

FIGURE 7.1. Changes in Privately Owned Growing Stock Inventories (billion cubic feet) Due to Hypothetical Reductions in Radial Growth in the Northeast and Southeast: 1990-2030 Forecasts of the Combined Softwood and Hardwood Stock 
TABLE 7.1. Changes in Growing Stock Inventories (billion cubic feet) Due to Hypothetical Reductions in Radial Growth in the Northeast and Southeast: 2030 Forecasts.

\begin{tabular}{|c|c|c|c|c|}
\hline Species Type/Region & Base Case & $\begin{array}{c}\text { Hypothetical } \\
\text { the Northea } \\
10 \% \\
\text { (Percentage }\end{array}$ & $\begin{array}{l}\text { Growth } \\
\text { ast and } \\
15 \% \\
\text { Change }\end{array}$ & $\begin{array}{c}\text { Reductior } \\
\text { Southeast } \\
20 \% \\
\text { from Bas } \\
\end{array}$ \\
\hline \multicolumn{5}{|l|}{ Softwood } \\
\hline Northeast & 41.42 & -9.54 & -14.85 & -20.38 \\
\hline Southeast & 56.70 & -27.85 & -38.30 & -50.09 \\
\hline Other Supply Regions & 118.95 & -5.09 & -8.36 & -14.29 \\
\hline Lower 48 States & 217.07 & -11.89 & -17.48 & -24.80 \\
\hline \multicolumn{5}{|l|}{ Hardwood } \\
\hline Northeast & 71.06 & -8.11 & -12.69 & -18.34 \\
\hline Southeast & 68.41 & -14.49 & -21.50 & -28.49 \\
\hline Other Supply Regions & 120.31 & -1.83 & -3.76 & -5.91 \\
\hline East & 259.78 & -6.88 & -10.87 & -15.2 \\
\hline
\end{tabular}

Combined Softwood

and Hardwood

Northeast

112. 48

$\begin{array}{lll}-8.63 & -13.47 & -19.09\end{array}$

Southeast

125.11

Other Supply Regions

239.26

$-20.54$

$-29.21$

$-38.28$

Lower 48 States

476.85

$-3.45$

$-6.05$

$-10.08$

$-9.16 \quad-13.88 \quad-19.60$

(a) Annual radial growth rates in softwood and hardwood inventories in the Northeast and Southeast reduced by 10,15 , and $20 \%$.

plywood, these higher local prices induce manufacturers in other regions to increase their output either for export to the directly affected regions or as substitutes for previously obtained imports. To increase their output, however, manufacturers in regions that are not directly affected by growth reductions require greater quantities of stumpage. Larger harvests in turn cause the inventories in these regions to decline.

One way to place the simulated effects of air pollution on growing stock inventories in perspective, is to compare these inventory changes with those 
due to insect and disease pests. Forest resource surveys conducted by the U.S. Forest Service (1984) show that the unsalvaged growing stock mortality from a!l causes on eastern commercial timberland averages about 2.3 billion cubic feet per year. Eastern commercial timberland includes all commercial timber, public and private, in the Northeast, North Central, Southeast, and South Central regions depicted in Figure 4.3 except in the States of North Dakota, Nebraska, and Kansas. Of this amount, insects and diseases account for about 1.4 billion cubic feet, or $62 \%$ of total mortality. The projected differences between the combined hardwood and softwood growing stock inventories in all the supply regions for the base case and the scenarios in which growth is reduced by 10 , 15 , and $20 \%$, are 44, 66, and 93 billion cubic feet, respectively, in 2030 . Averaged over the 45-year period 1985 through 2030, the damages are estimated at about $1.0,1.5$, and 2.0 billion cubic feet per year, respectively. Thus, the physical effects of a $15 \%$ growth reduction of timber in the Northeast and Southeast are roughly comparable to the physical damage caused by insect and disease pests on all eastern commercial timberland.

To further clarify the potential impact of growth slowdown on the nation's growing stock inventories, comparison scenarios were developed in which hypothetical reductions in tree growth were varied by region (i.e., Northeast or Southeast) and then by species type (i.e., hardwoods or softwoods). Tables 7.2 and 7.3 present forecasts of inventories in 2030 for scenarios in which timber growth reductions are confined to the Northeast and Southeast, respectively. In each scenario, the radial growth rates of both softwood and hardwood species are reduced by $15 \%$. The results shown in Table 7.2 indicate that, by 2030 , timber growth reductions of $15 \%$ in the Northeast only could cause the combined softwood and hardwood growing stock inventory in the United States to decline by about $4 \%$ relative to the Base Case. (a) Table 7.3 shows that when tree

(a) Unless otherwise noted, references in the text to percentage changes in the magnitude of key variables are assumed to be in relation to the Base Case. 
TABLE 7.2. Impacts of a 15\% Growth Reduction in the Northeast Region on Growing Stock Inventories: 2030 Projections

\begin{tabular}{lrc} 
Species Type/Region & $\begin{array}{c}\text { Base Case } \\
\text { (Billion Cubic feet) }\end{array}$ & $\begin{array}{c}15 \% \text { Growth Reduction } \\
\text { in the Northeast }\end{array}$ \\
\cline { 1 - 2 } Softwood & 41.42 & -14.87 \\
Northeast & 175.65 & -0.42 \\
Other Supply Regions & 217.07 & -3.18 \\
Lower 48 States & & -12.64 \\
Hardwood & 71.06 & -1.59 \\
$\quad$ Northeast & 188.72 & -4.62 \\
Other Supply Regions & 259.78 & -3.96 \\
East & 476.85 &
\end{tabular}

TABLE 7.3. Impacts of a $15 \%$ Growth Reduction in the Southeast Region on Growing Stock Inventories: 2030 Projections

\begin{tabular}{lrc} 
Species Type/Region & $\begin{array}{c}\text { Base Case } \\
\text { (Billion cubic feet) }\end{array}$ & $\begin{array}{c}15 \% \text { Growth Reduction } \\
\text { in the Southeast }\end{array}$ \\
\cline { 1 - 1 } $\begin{array}{l}\text { Softwood } \\
\text { Southeast }\end{array}$ & 56.70 & -38.43 \\
Other Supply Regions & 160.37 & -5.60 \\
Lower 48 States & 217.07 & -14.18 \\
Hardwood & & -21.43 \\
Southeast & 68.41 & -0.84 \\
Other Supply Regions & 191.37 & -6.26 \\
East & 259.78 & -9.86 \\
Combined Softwood and & 476.85 &
\end{tabular}

growth is reduced by $15 \%$ in the Southeast only, the corresponding decline in the growing stock inventory in the United States relative to the Base Case is about $10 \%$. 
This analysis further emphasizes the relatively greater impact of reductions in tree growth rates in the Southeast, as opposed to the Northeast, on both local and national inventory levels. This phenomenon is due in large part to the composition of the regional growing stock inventory in the Southeast, which contains a relatively larger share of young, faster growing trees than the Northeast. Removing a fixed proportion of this growth has a more immediate and longer lasting negative effect on total inventory volumes than does removing the same fixed proportion of old growth trees.

Table 7.4 shows the impacts of reducing the growth of either hardwood or softwood timber in both the Northeast and Southeast regions. Reducing softwood timber growth by $15 \%$ causes softwood and hardwood inventories in the U.S. to decrease $17 \%$ and $1 \%$, respectively, by 2030 . Reducing hardwood timber growth, on the other hand, causes the nation's hardwood inventory to decrease $8 \%$ by 2030 , but has almost no effect on the nation's softwood inventory. In these

TABLE 7.4. Impacts of Reducing the Growth of Only Hardwood or Only Softwood Species in the Northeast and Southeast Regions on Growing Stock Inventories: 2030 Projections

\begin{tabular}{|c|c|c|c|}
\hline Species Type/Region & $\begin{array}{l}\text { Base Case } \\
\text { (Bi11ion } \\
\text { Cubic Feet) } \\
\end{array}$ & $\begin{array}{c}\text { Species Affected hy } \\
\text { Reduction in the Northe } \\
\text { Hardwood Only } \\
\text { (Percent Change }\end{array}$ & $\begin{array}{l}\text { y a 15\% Growth } \\
\text { east and Southeast } \\
\text { Softwood Only } \\
\text { from Base) }\end{array}$ \\
\hline \multicolumn{4}{|l|}{ Softwood } \\
\hline Northeast & 41.42 & -0.10 & -14.78 \\
\hline Southeast & 56.70 & -0.28 & -38.32 \\
\hline Other Supply Regions & 118.95 & 0.04 & -8.37 \\
\hline Lower 48 States & 217.07 & -0.07 & -17.42 \\
\hline \multicolumn{4}{|l|}{ Hardwood } \\
\hline Northeast & 71.06 & -15.04 & 1.98 \\
\hline Southeast & 68.41 & -20.80 & -0.72 \\
\hline Other Supply Regions & 120.31 & -0.41 & -3.30 \\
\hline East & 259.78 & -9.78 & -1.17 \\
\hline $\begin{array}{l}\text { Combined Hardwood and } \\
\text { Softwood Total }\end{array}$ & 476.85 & -5.36 & -8.57 \\
\hline
\end{tabular}


simulations, both softwood and hardwood inventory decline even though only one is directly subjected to growth reductions because softwood and hardwood pulpwood are substitutes in pulp production. When growth reductions in softwood inventories are simulated, for example, the declines of softwood inventories are translated into lower production levels of softwood lumber and plywood. This in turn means that fewer softwood residues are available for pulp production. The shortfall in softwood resjdues is made up by larger harvests of pulpwood, both softwood and hardwood. (a)

So far, this presentation of the reduced growth cases has emphasized comparative analyses: reduced growth of $10 \%, 15 \%$ or $20 \%$; reduced growth in the Northeast as opposed to the Southeast; and reduced growth of hardwood species versus reduced growth of softwood species. We now turn to the reduced growth cases in which production levels of softwood lumber and plywood in the Northern regions are modified as well. The modifications of production levels (modified version) in these scenarios simulate the adjustment of local producers of softwood products in the Northern regions to the changes in stumpage and product prices that occur within the regions when timber growth is reduced. The methodology used to determine the direction and magnitude of the adjustment is described in Appendix B.

Table 7.5 shows the results of the modified version of the scenario in which the annual growth of trees in the Northeast's softwood and hardwood inventories is reduced by $15 \%$. In the modified version, production levels of softwood 1 umber and plywood in the Northeast are lower than in the Base Case. This adjustment simulates the response of local producers to higher stumpage prices but unchanging lumber and plywood prices. The results of the unmodified version of this scenario are also presented in Table 7.5 to facilitate the comparison. In the unmodified version, production levels of softwood lumber and plywood in the Northwest are the same as in the Base Case.

(a) Other substitution processes, i.e. the substitution of hardwood lumber for softwood lumber, could be simulated which wculd cause 1) greater decilines in inventories that are not directly affected by growth slowdowns and 2) smaller declines in inventories that are directly affected by growth slowdowns than the declines indicated in Table 7.4 . 
TABLE 7.5. The Inventory Effects of Adjusting Northern Softwood Lumber and Plywood Production when Timber Growth in the Northeast is Reduced by 15\%: 2030 Projections

\begin{tabular}{|c|c|c|c|c|}
\hline Species Type/Region & $\begin{array}{l}\text { Base Case } \\
\text { (Billion } \\
\text { Cubic Feet) } \\
\end{array}$ & \multicolumn{3}{|c|}{$\begin{array}{l}\text { Production Adjustment in } \\
\text { Regions When Timber Growt } \\
\text { the Northeast Reduced by } \\
\text { Production Production } \\
\text { Decreased as in Base } \\
\text { (Percentage Change From }\end{array}$} \\
\hline \multicolumn{5}{|l|}{ Softwood } \\
\hline Northeast & 41.42 & -13.79 & & -14.87 \\
\hline Other Supply Regions & 175.65 & -0.34 & & -0.42 \\
\hline Lower 48 States & 217.07 & -2.90 & & -3.18 \\
\hline \multicolumn{5}{|l|}{ Hardwood } \\
\hline Northeast & 71.06 & -13.27 & & -12.64 \\
\hline Other Supply Regions & 188.72 & -1.44 & & -1.59 \\
\hline East & 259.78 & -4.67 & & -4.62 \\
\hline $\begin{array}{l}\text { Combined Softwood and } \\
\text { Hardwood Total }\end{array}$ & 476.85 & -3.87 & & -3.96 \\
\hline
\end{tabular}

A comparison of the two $15 \%$ growth reduction cases indicates that the response of softwood lumber and plywood manufacturers in the Northeast to changing stumpage prices would have little impact on growing stock inventories if growth rates in the region were reduced. Because lower production levels of softwood lumber and plywood require less softwood stumpage, the modified version projects slightly larger softwood inventories than the unmodified version projects. However, because lower production levels of softwood products means that fewer residues are available for pulp production, the modified version projects slightly smaller hardwood inventories than the unmodified version. The net effect is that the modified version's projection of the combined softwood and hardwood inventory for the U.S. is only slightly larger than the unmodified version's projection.

The results of the modified version of the scenario in which timber growth in both the Northeast and Southeast is reduced by $15 \%$ are presented in Table 7.6. To simulate the adjustment of local producers to higher stumpage 
TABLE 7.6. The Inventory Effects of Adjusting Northern Softwood Lumber and Plywood Production when Timber Growth in the Northeast and Southeast is Reduced by 15\%: 2030 Projections

\begin{tabular}{|c|c|c|c|c|}
\hline Species Type/Region & $\begin{array}{l}\text { Base Case } \\
\text { (Billion } \\
\text { Cubic Feet) } \\
\end{array}$ & $\begin{array}{c}\text { Production Adj } \\
\text { Regions When } \\
\text { Northeast and So } \\
\text { Production } \\
\text { Decreased } \\
\text { (Percentage }\end{array}$ & $\begin{array}{r}\text { justment } \\
\text { Timber } \\
\text { joutheast } \\
\text { Proc } \\
\text { as } \\
\text { Change }\end{array}$ & $\begin{array}{l}t \text { in No } \\
\text { Growth } \\
t \text { Reduc } \\
\text { duction } \\
\text { in Base } \\
\text { From B }\end{array}$ \\
\hline \multicolumn{5}{|l|}{ Softwood } \\
\hline Northeast & 41.42 & -16.97 & & -14.85 \\
\hline Southeast & 56.70 & -38.20 & & -38.52 \\
\hline Other Supply Regions & 118.95 & -8.58 & & -8.36 \\
\hline Lower 48 States & 217.07 & -17.92 & & -17.48 \\
\hline \multicolumn{5}{|l|}{ Hardwood } \\
\hline Northeast & 71.06 & -12.00 & & -12.69 \\
\hline Southeast & 68.41 & -21.59 & & -21.50 \\
\hline Other Supply Regions & 120.31 & -3.80 & & -3.76 \\
\hline East & 259.78 & -10.73 & & -10.87 \\
\hline $\begin{array}{l}\text { Combined Softwood and } \\
\text { Hardwood Total }\end{array}$ & 476.85 & -14.00 & & $-13.88^{\circ}$ \\
\hline
\end{tabular}

prices and even higher lumber and plywood prices, the Northeast's production levels of softwood lumber and plywood are higher in the modified version than in the Base Case. In the unmodified version, Northeastern production levels of softwood lumber and plywood are the same as in the Base Case. In the modified version, higher production levels of softwood products in the Northeast requires greater quantities of softwood stumpage, so softwood inventories are Smaller than in the unmodified version. Also, because higher production levels of softwood products means that more residues are available for pulp production, the modified version projects larger hardwood inventories than the unmodified version. The combined softwood and hardwood inventory for the U.S. projected by the modified version is slightly smaller than the inventory projected by the unmodified version. Overall, the simulated quantity adjustments made by Northern manufacturers of softwood products to changing market conditions induced by timber growth reductions in both the Northeast and Southeast 
appears to have little impact on growing stock inventories relative to those cases in which lumber and plywood production in the two Northern regions is fixed.

Table 7.7 shows the impacts of lower housing starts, increased wood processing efficiency and more rapid rates of conversion of timberland to other 1 and uses on growing stock inventories in 2030. As expected, the effects of reducing the demand for housing and increasing wood processing efficiency on 2030 inventory levels result in slight increases in the combined softwood and hardwood inventory of timber in the United States in 2030.

In the Low Housing Case, decreased demand for housing is translated into lower production levels of softwood products and smaller softwood harvests. slightly more hardwood is harvested as pulpwood to offset some of the softwood residues that are lost. In the Increased Efficiency Case, improvements in

TABLE 7.7. Impacts of Lower Housing Starts, Greater Efficiency, and Faster Conversion of Timberland on Growing Stock Inventories: 2030 Projections

\begin{tabular}{|c|c|c|c|c|}
\hline \multirow[b]{2}{*}{ Species Type/Region } & \multirow[b]{2}{*}{$\begin{array}{l}\text { Base Case } \\
\text { (Billion } \\
\text { Cubic Feet) } \\
\end{array}$} & \multicolumn{3}{|c|}{ Alternative Base Case Scenarios } \\
\hline & & $\begin{array}{l}\text { Low } \\
\text { Housing } \\
\text { (Percent }\end{array}$ & $\begin{array}{l}\text { Increased } \\
\text { Efficiency } \\
\text { age Change }\end{array}$ & $\begin{array}{c}\text { Reduced } \\
\text { Timberl and } \\
\text { From Base) } \\
\end{array}$ \\
\hline \multicolumn{5}{|l|}{ Softwood } \\
\hline Northeast & 41.42 & 0.00 & 0.14 & -6.52 \\
\hline Southeast & 56.70 & 9.08 & -0.11 & -27.69 \\
\hline Other Supply Regions & 118.95 & 13.21 & 9.30 & -36.86 \\
\hline Lower 48 States & 217.07 & 9.61 & 5.10 & -28.68 \\
\hline \multicolumn{5}{|l|}{ Hardwood } \\
\hline Northeast & 71.06 & 0.00 & 0.27 & -8.70 \\
\hline Southeast & 68.41 & -0.67 & 0.23 & -19.25 \\
\hline Other Supply Regions & 120.31 & -0.35 & 0.50 & -30.11 \\
\hline East & 259.78 & -0.34 & 0.37 & -21.39 \\
\hline $\begin{array}{l}\text { Combined Softwood and } \\
\text { Hardwood Total }\end{array}$ & 476.85 & 4.19 & 2.52 & -24.71 \\
\hline
\end{tabular}


technology directly and simultaneously affect the movements of both the product supply and stumpage demand curves. Product supply curves shift to the right, whereas stumpage demand curves shift to the left. At the same time, fewer residues are available for pulp production. Despite the larger pulpwood harvests, however, total softwood and hardwood harvests are smaller. The impacts of converting more commercial timberland to other land uses on growing stock inventories are generally similar in direction to the impacts induced by reducing the growth of timber. In the Reduced Timberland Case, the nation's softwood and hardwood inventories decline by roughly $29 \%$ and $21 \%$, respectively, by 2030. This is greater than the $9 \%$ and $20 \%$ reduction in inventory levels for the reduced growth cases shown in Table 7.1 .

A comparison of the results presented in Table 7.7 with the results generated by the reduced growth cases indicates that the alternative, base case scenarios provide the upper and lower bounds for national projections of softwood and hardwood inventories. The Low Housing Case provides the upper bound for the nation's softwood inventory in 2030--238 billion cubic feet (bcf). The upper bound for the nation's hardwood inventory is generated by the Increased Efficiency Case--261 bcf. Lower bounds for the nation's softwood and hardwood inventories in 2030 are provided by the Reduced Timberland Case--155 bcf and 204 bcf, respectively. All of the national inventories projected for 2030 by the reduced growth scenarios fall within these bounds.

This result can be explained in part because the shocks that are simulated in the alternative, base case scenario are national in scope, whereas the shocks simulated in the hypothetical pollution stress cases have direct impacts in only one or two regions. However, simulations of greater reductions of timber growth in the Northeast and Southeast regions might have larger impacts on the national inventories than the nationwide trend of timberland conversion simulated in the Reduced Timberland Case. For example, the steady decline that occurs in the nation's inventories as timber growth in the Northeast and Southeast regions is reduced from $10 \%$ to $20 \%$ (see Table 7.1 ) indicates that a reduced growth scenario simulating a $25 \%$ or $30 \%$ reduction of timber growth might yield projections of national inventories lower than the projections provided by the Reduced Timberland Case. 
At the regional level, the inventory impacts of the reduced growth cases are larger or smaller than the alternative, base case scenarios depending on whether the regions are directly or indirectly affected by reduced growth. Table 7.1, for example, shows that even a $10 \%$ growth reduction of timber in the Northeast and Southeast regions would cause softwood inventories in these regions to decrease more than would the timberland losses that are projected by the Reduced Timberland Case for those regions.

In summary, the results of the sensitivity analysis indicate that:

- because of the spillovers generated by interregional trade in forest products, timber growth reductions in the Northeast or Southeast would cause reductions in the growing stock inventories of other regions as well.

- as timber growth in the Northeast and Southeast is reduced, the projected size of the nation's inventories decreases at an increasing rate.

- timber growth reductions in the Southeast would have a greater impact on the nation's inventories than timber growth reduction in the Northeast.

- timber growth reductions of softwood species in the Northeast and Southeast would have a greater impact on the total U.S. inventory than timber growth reductions of hardwood species.

- national inventories projected by the alternative base case scenarios bound the national inventories projected by the reduced growth cases. In regions directly affected by timber growth reductions, however, smaller inventories are projected by the reduced growth scenarios than by the alternative base case scenarios.

\subsection{ECONOMIC IMPACTS}

Because of the interregional trade in forest products discussed in Section 3.2.3, reductions of timber growth in the Northeast and Southeast regions should affect regional stumpage and product markets throughout the United States. For example, smaller harvests and higher prices are expected in 
the stumpage markets in the regions where the growth rates of timber are reduced. In regions where timber growth rates remain unchanged, higher stumpage prices can be expected to lead to larger harvests because of the increased demand for these substitutable inventory resources. Similar events would occur in product markets. Because of higher stumpage costs, one can expect production of lumber and plywood to decline in regions directly affected by timber growth reductions. However, production of lumber and plywood in other regions can be expected to increase because stumpage costs in these regions are, by comparison, relatively lower. At the same time, one would expect lumber and plywood prices throughout the U.S. to increase, thereby causing consumption of these products to decrease.

For the most part, the results of this analysis conform to the general theoretical expectations, delineated immediately above and in Section 3.2.3. For brevity, this presentation emphasizes the results of scenarios in which timber growth is reduced in both the Northeast and Southeast's softwood and hardwood inventories. Also, only 2030 forecasts of prices and quantities in stumpage and product markets are discussed. In addition, because the behavior of prices and quantities in softwood lumber market is similar to the behavior of prices and quantities in softwood plywood markets, only the former are presented.

\subsubsection{Effects on Stumpage Markets}

Focusing first on stumpage markets, Table 7.8 shows the effects of reducing timber growth in the Northeast and Southeast by 10 to $20 \%$ on softwood and hardwood harvests in various regions. As expected, the size of the combined softwood and hardwood harvest for the United States declines as the magnitude of the timber growth reduction is increased. The percentage changes in the combined harvest, however, are small, i.e., less than $1.5 \%$ when timber growth in the Northeast and Southeast is reduced by $20 \%$. These small harvest reductions help to explain the relatively large declines in the nation's timber inventory presented for these scenarios in Table 7.1.

There are two reasons why the reductions in national harvest levels are so small: 1) smaller harvests in regions directly affected by reduced growth are 
TABLE 7.8. Impacts of Hypothetical Growth Reductions in the Northeast and Southeast on Harvests: 2030 Projections

\begin{tabular}{|c|c|c|c|c|}
\hline Species Type/Region & $\begin{array}{c}\text { Base Case } \\
\text { (Billion } \\
\text { Cubic Feet) } \\
\end{array}$ & $\begin{array}{l}\text { Growth Rate } \\
\text { and South } \\
10 \% \\
\text { SPercentage }\end{array}$ & $\begin{array}{c}\text { s in the } \\
\text { least Rec } \\
15 \% \\
\text { Change }\end{array}$ & $\begin{array}{c}\text { Northeast } \\
\text { duced By: } \\
20 \% \\
\text { from Base) }\end{array}$ \\
\hline \multicolumn{5}{|l|}{ Softwood } \\
\hline Northeast & 1.05 & -2.86 & -3.81 & -5.71 \\
\hline Southeast & 3.23 & -9.60 & -16.72 & -21.78 \\
\hline Other Supply Regions & 8.69 & 1.61 & 2.99 & 3.22 \\
\hline Lower 48 States & 12.97 & -1.54 & -2.47 & -3.78 \\
\hline \multicolumn{5}{|l|}{ Hardwood } \\
\hline Northeast & 2.04 & -3.43 & -4.90 & -6.37 \\
\hline Southeast & 1.79 & -0.12 & -1.12 & -2.23 \\
\hline Other Supply Regions & 4.73 & 2.54 & 5.07 & 7.19 \\
\hline East & 8.56 & 0.82 & 1.40 & 1.99 \\
\hline $\begin{array}{l}\text { Combined Softwood and } \\
\text { Hardwood Total }\end{array}$ & 21.53 & -0.60 & -0.93 & -1.49 \\
\hline
\end{tabular}

partially offset by larger harvests in other regions, and 2) smaller softwood harvests are partially of fset by larger hardwood harvests. Hardwood harvests increase as softwood harvests decrease because hardwood pulpwood is substituted for softwood pulpwood in the pulp sector of the model. It should be noted, however, that the harvest levels projected by the reduced growth cases are biased upward because the total demand for pulpwood in the model does not respond to stumpage price changes. Theoretically, the amount of pulpwood harvested should decrease as relatively higher pulpwood prices cause the supply of pulp to decrease. This upward bias means that inventories projected by the reduced growth scenarios should be larger than those indicated by Figure 7.1 and Table 7.1 , but the magnitude of this difference is not known.

Projections of stumpage prices for the Northeast, Southeast, and Pacific Northwest West regions are presented in Table 7.9. For brevity, the only 
TABLE 7.9. Impacts of Hypothetical Growth Reductions in the Northeast and Southeast on Stumpage Prices: 2030 Projections

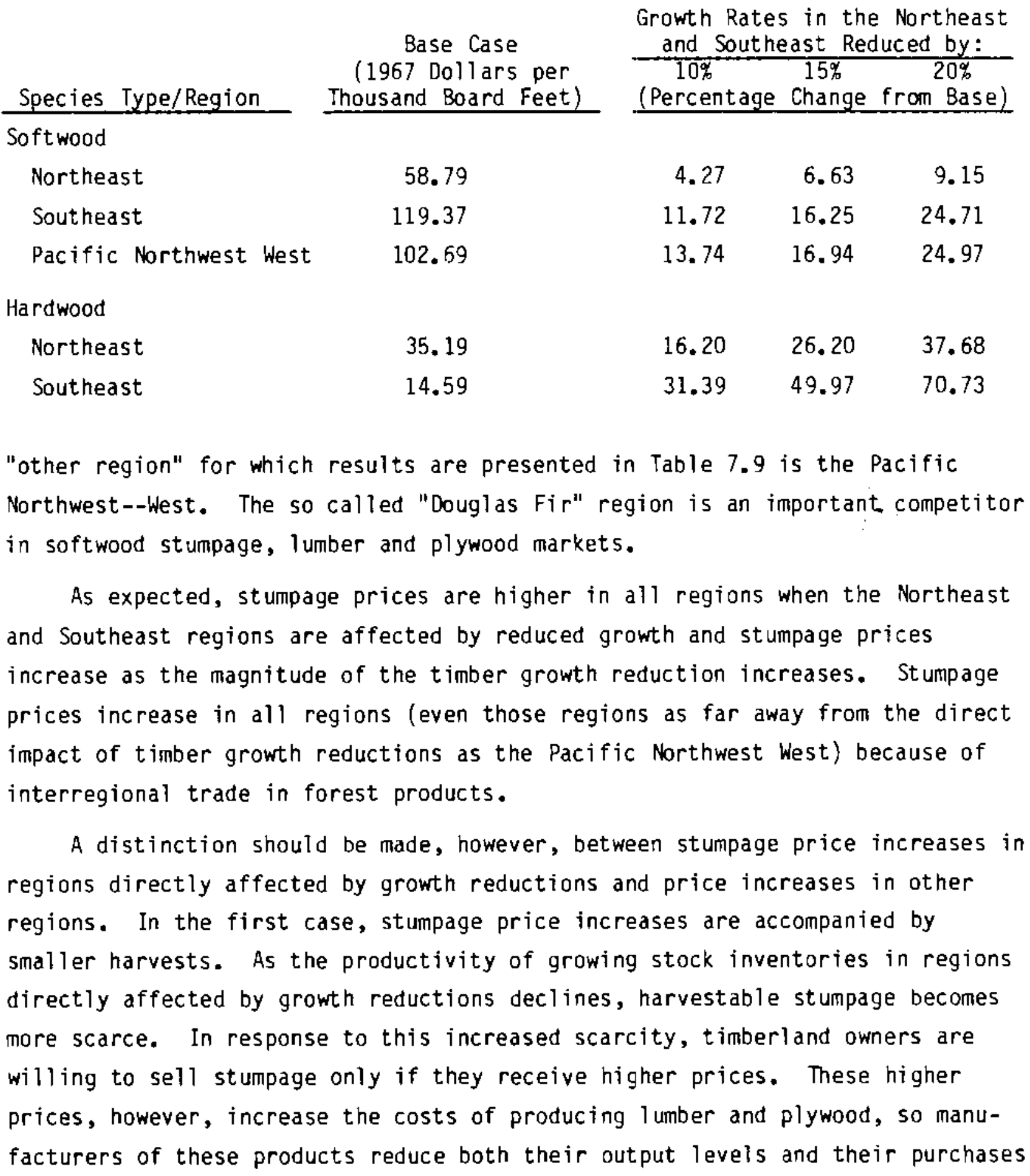


of inputs, i.e., stumpage. The net effect is to increase stumpage prices and reduce harvest levels in those regions directly affected by reduced growth.

In regions where timber growth remains unchanged, both stumpage prices and harvest levels increase. Even though manufacturers of lumber and plywood in regions directly affected by growth reductions reduce their output, they still must sell their products at higher prices if they are to recover the higher production costs caused by higher stumpage prices. These higher product prices increase the competitiveness of 7 umber and plywood produced in other regions where growth rates remain unchanged. Manufacturers of these products in other regions, therefore, increase both their output levels and their purchases of stumpage inputs. As a result, stumpage prices and harvest levels in other regions rise.

The effects of adjusting softwood lumber and plywood production in Northern regions where timber growth in the Northeast and Southeast is reduced by 15\% are presented in Tables 7.10 and 7.11. Recall that production of softwood 1 umber and plywood in Northern regions was increased to simulate the response of manufacturers not only to rising stumpage prices but al so to even faster rising product prices. Except for the softwood harvest in the Northeast, the pattern of harvest and stumpage price changes depicted in Tables 7.10 and 7.11 is similar to the pattern of changes presented in Tables 7.8 and 7.9. Thus, harvests in regions directly affected by timber growth reductions are smaller, harvests in other regions are larger, and stumpage prices in all regions are higher. Harvest levels of softwood stumpage in the Northeast remain the same as the Base Case because of the interaction between softwood sawtimber and pulpwood markets simulated in the model. Increased production of softwood lumber and and plywood in the Northeast requires larger harvests of softwood sawtimber in the region and causes stumpage prices to increase. These higher stumpage prices in turn cause pulp producers to reduce their demand for pulpwood, so harvests of softwood pulpwood are smaller. The fact that these two effects, i.e., larger sawtimber harvests and smaller pulpwood harvests, cancel each other out relative to the Base case is coincidental. (a)

(a) In the reduced growth scenario with no changes in Northern production, only the smaller pulpwood harvest in the Northeast is simulated. 
TABLE 7.10. Harvest Impacts of Adjusting Northern Softwood Lumber and Plywood Production when Timber Growth in the Northeast and Southeast is Reduced by 15\%: 2030 Projections

\begin{tabular}{|c|c|c|c|}
\hline Species Type/Region & $\begin{array}{l}\text { Base Case } \\
\text { (Billion } \\
\text { Cubic Feet) } \\
\end{array}$ & \multicolumn{2}{|c|}{$\begin{array}{l}\text { Production Adjustment in No } \\
\text { Regions When Timber Growth } \\
\text { Northeast and Southeast Reduc } \\
\text { Production Production } \\
\text { Increased as in Base } \\
\text { (Percentage Change From B }\end{array}$} \\
\hline \multicolumn{4}{|l|}{ Softwood } \\
\hline Northeast & 1.05 & 0.00 & -3.81 \\
\hline Southeast & 3.23 & -16.41 & -16.72 \\
\hline $\begin{array}{l}\text { Other Supply } \\
\text { Regions }\end{array}$ & 8.69 & 3.11 & 2.99 \\
\hline Lower 48 States & 12.97 & -2.00 & -2.47 \\
\hline \multicolumn{4}{|l|}{ Hardwood } \\
\hline Northeast & 2.04 & -6.86 & -4.90 \\
\hline Southeast & 1.79 & -0.56 & -1.12 \\
\hline $\begin{array}{l}\text { Other Supply } \\
\text { Regions }\end{array}$ & 4.73 & 5.29 & 5.07 \\
\hline East & 8.56 & 1.17 & 1.40 \\
\hline $\begin{array}{l}\text { Combined Softwood } \\
\text { and Hardwood Total }\end{array}$ & 21.53 & -0.74 & -0.93 \\
\hline
\end{tabular}

A comparison of the changes forecast by the reduced growth scenario in the unmodified version (Northern production levels remain the same as in the Base Case) with the changes projected by the modified version of the model (Northern production levels are increased) indicates that the adjustment has only a minor impact on harvest levels and hardwood stumpage prices. The adjustment does reduce the range of softwood stumpage price changes, however, in that the percentage increase of softwood stumpage prices in the Northeast is more in line with the percentage increases of softwood stumpage prices in other regions.

Projections of 2030 harvest and stumpage price changes for the alternative base case scenarios are presented in Tables 7.12 and 7.13 and, 1 ike the results discussed in Section 7.1 above, bound the results of the reduced growth cases 
TABLE 7.11. Stumpage Price Impacts of Adjusting Northern Softwood Lumber and Plywood Production when Timber Growth in the Northeast and Southeast is Reduced by 15\%: 2030 Projections

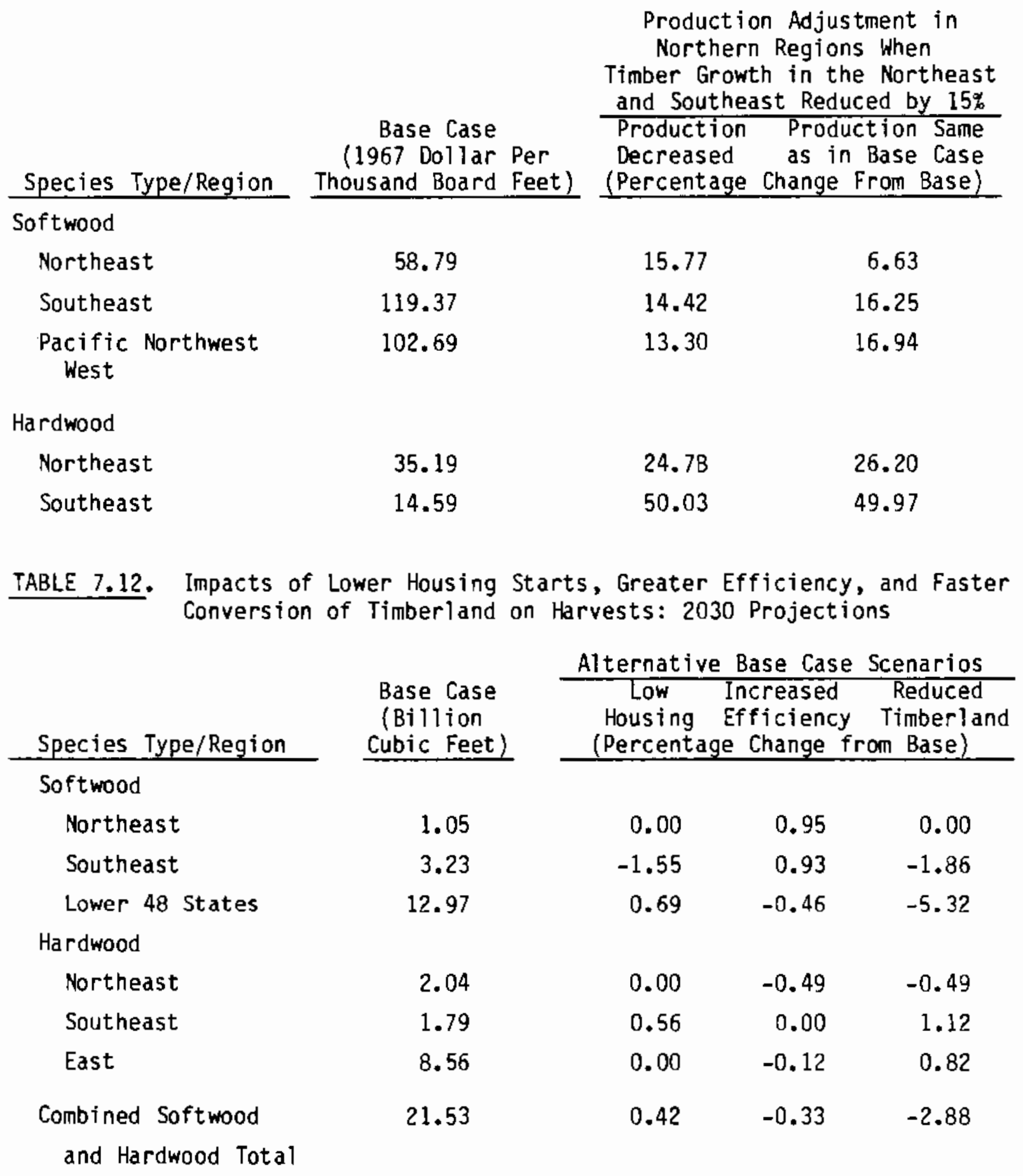


TABLE 7.13. Impacts of Lower Housing Starts, Greater Efficiency, and Faster Conversion of Timberland on Stumpage Prices: 2030 Projections

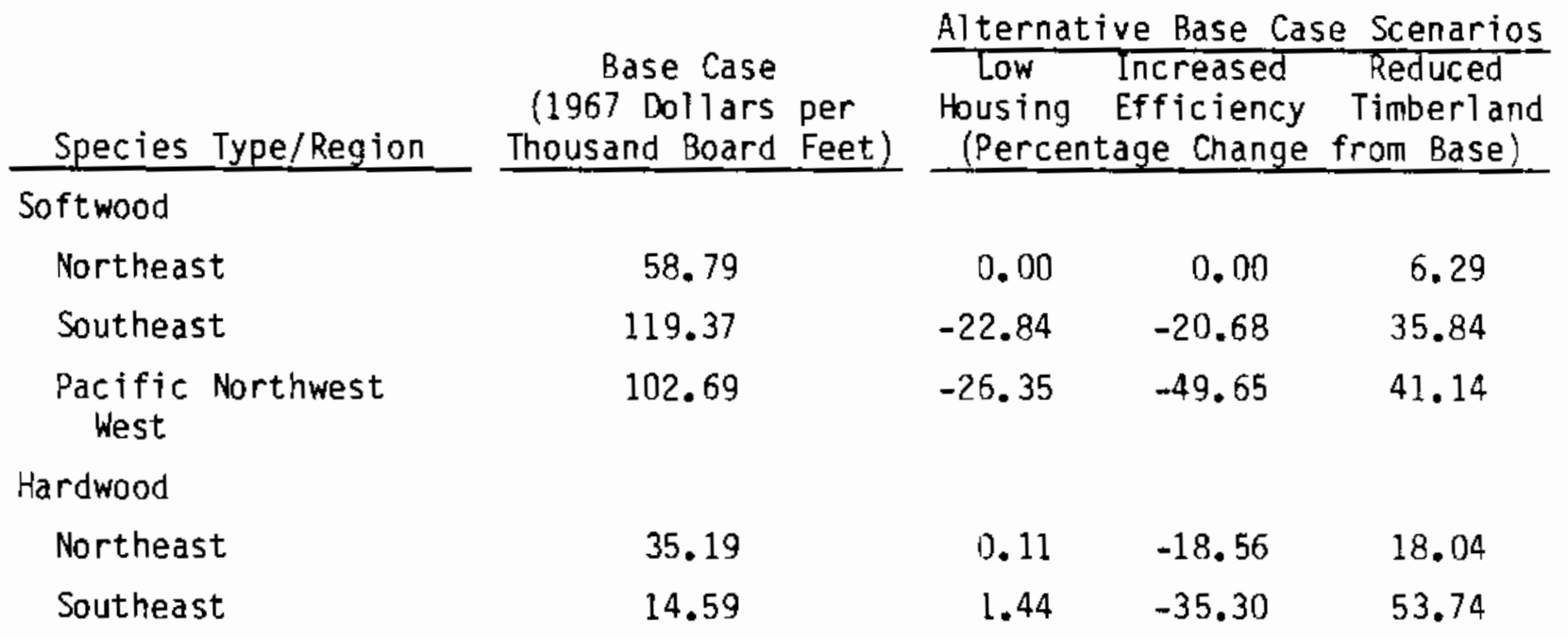

at the national, but not at the regional, level. In both the Low Housing and Increased Efficiency Cases, softwood stumpage prices fall fairly dramatically in response to decreases in stumpage demands (except in the Northern regions where lumber and plywood production is fixed). However, there is little or no change in harvest levels in these two cases because of the relatively priceinsensitive nature of the supply curves for stumpage on the part of private owners. In the Reduced Timberland Case, decreases in timber supplies due to land use changes have the same general effect on stumpage markets as do hypothetical decreases in annual tree growth rates. However, the percentage decrease in the total harvest (2.88\%) for the Reduced Timberland Case is almost twice that of the most severe growth reduction case (1.49\%) shown in Table 7.8. This is easily explained by the fact that the reductions in timberland occur in all regions, whereas the reductions in the annual growth rates of trees were confined to two regions.

\subsubsection{Effects on Product Markets}

Because of the vertical Tinkages between stumpage and product markets, many of the impacts that timber growth reductions induce in stumpage markets are duplicated in product markets. While timber growth reductions tend to decrease the quantities of products supplied by those regions directly affected, interregional trade causes output in other regions to increase. The 
changes in interregional trade are driven by the higher prices which manufacturers of wood products in regions directly affected by growth reductions must obtain to recover their increased input costs. These higher prices reduce the competitiveness of these products in the national market. As a result, regions directly affected by growth reductions generally either import more or export fewer wood products.

At the same time, higher product prices in regions directly affected by growth reductions induce manufacturers of wood products in other regions to increase their output either for export or import replacement. But, because the demand for stumpage in other regions increases as output increases, input costs and product prices in these regions also rise.

A similar process occurs at the international level. As prices of wood products in the U.S. rise, the nation exports fewer and imports more wood products. By distributing the impacts of growth reductions confined to one or two regions over a broader geographical area, these changes in domestic and international trading patterns cushion the decreases in total U.S. production and consumption of wood products that growth reductions in the Northeast and Southeast might cause in production markets.

Some of these changes in trading patterns are depicted in Table 7.14 which shows the impacts of reducing timber growth rates in the Northeast and Southeast by 10 to $20 \%$ on Tumber production and imports into the United States. Domestically, lower levels of lumber production in regions directly affected by growth reductions(a) are partially offset by higher levels of lumber production in other regions. Imports of lumber from Canada also increase.

A comparison of the impacts of these three reduced growth scenarios yields a number of interesting results. First, total softwood and hardwood 1 umber production in 2030 decreases at an increasing rate as the magnitude of the growth reduction increases. This relationship between timber growth reductions

(a) Softwood lumber production in the Northeast is fixed in the model and does not change in these scenarios. 
TABLE 7.14. Impacts of Growth Reductions in the Northeast and Southeast Regions on U.S. Lumber Supplies: 2030 Projections

\begin{tabular}{|c|c|c|c|c|}
\hline $\begin{array}{l}\text { Source of Lumber Supply } \\
\text { by Lumber Type and Region }\end{array}$ & $\begin{array}{l}\text { Base Case } \\
\text { (BiTlion } \\
\text { Board Feet) } \\
\end{array}$ & $\begin{array}{l}\text { Growth Rate } \\
\text { Hardwood Sp } \\
10 \% \\
\text { (Percentage }\end{array}$ & $\begin{array}{l}\text { es of Sot } \\
\text { Specjes Re } \\
15 \% \\
\text { e Change }\end{array}$ & $\begin{array}{l}\text { ftwood and } \\
\text { educed by: } \\
20 \% \\
\text { from Base) }\end{array}$ \\
\hline $\begin{array}{l}\text { Domestic Softwood Production } \\
\text { Northeast (a) }\end{array}$ & 1.16 & 0.00 & 0.00 & 0.00 \\
\hline Southeast & 9.39 & -26.52 & -36.42 & -43.56 \\
\hline Other Supply Regions & 29.67 & 3.37 & 3.57 & 2.36 \\
\hline Lower 48 States & 40.22 & -3.70 & -5.87 & -8.43 \\
\hline \multicolumn{5}{|l|}{ Domestic Hardwood Production } \\
\hline Northeast & 2.25 & -2.67 & -4.44 & -6.67 \\
\hline Southeast & 2.78 & -4.68 & -7.19 & -10.07 \\
\hline Other Supply Regions & 6.81 & 0.73 & 0.88 & 0.88 \\
\hline Lower 48 States & 11.84 & -1.18 & -2.04 & -3.13 \\
\hline $\begin{array}{l}\text { Imports of Canadian } \\
\text { Softwood Lumber }\end{array}$ & 9.62 & 8.21 & 12.27 & 16.84 \\
\hline
\end{tabular}

(a) Softwood lumber supplies in the liortheast are fixed in the model and do not change in these scenarios.

and total lumber production is due to a second important result--the relationship between timber growth reductions and lumber production in regions that are not directly affected by growth slowdowns. In these other regions, lumber production in 2030 first increases and then either remains the same, i.e., hardwood lumber production, or even decreases, i.e., softwood lumber production, as the magnitude of the growth reduction increases. This leveling off of output in other regions is due in part to shrinking inventories in these regions and indicates that producers of wood products in other domestic regions may find it difficult to maintain higher output rates in the 1 ong run. The difficulty would increase if growth reductions of greater magnitude than those simulated in this analysis occurred because inventories in other regions would decrease at a faster rate (see Table 7.1). 
Finally, imports of Canadian lumber increase at an increasing rate as the magnitude of the growth reduction increases. Along with shrinking inventories, larger wood imports from Canada explain why the output of wood products from other domestic regions levels off as the magnitude of the growth reduction increases. As inventories in other domestic supply regions are reduced, the costs of producing wood products in these regions increases. Thus, the competitiveness of Canadian wood products in the U.S. increases.

The impacts of reducing timber growth rates in the Northeast and Southeast by 10 to $20 \%$ on regional softwood lumber prices in selected regions are presented in Table 7.15. The results confirm what trade theory suggests; that is, lumber prices in all regions increase when timber growth reductions are confined to only a few regions. The results also indicate that lumber prices in al1 regions increase at an increasing rate as the magnitude of the growth reduction increases.

Projections of lumber supplies and prices in 2030 are presented in Tables 7.16 and 7.17 for the alternative base case scenarios. As is the case with inventories, harvests, and stumpage prices, the alternative base case scenarios provide the upper and lower bounds for lumber production at the national level, but not at the regional level. The alternative base case

TABLE 7.15. Impacts of Hypothetical Growth Reductions in the Northeast and Southeast Regions on Softwood Lumber Prices: 2030 Projections

\begin{tabular}{|c|c|c|c|c|}
\hline Region & $\begin{array}{c}\text { Base Case } \\
\text { (1967 Dollars per } \\
\text { Thousand Board Feet) }\end{array}$ & $\begin{array}{l}\text { Growth Rate } \\
\text { Hardwood Sp } \\
10 \% \\
\text { (Percentage }\end{array}$ & $\begin{array}{l}\text { s of So } \\
\frac{\text { ecies Re }}{15 \%} \\
\text { Change }\end{array}$ & $\begin{array}{l}\text { ftwood and } \\
\text { educed by: } \\
20 \% \\
\text { from Base) }\end{array}$ \\
\hline Northeast (a) & 200.88 & 4.12 & 6.76 & 10.84 \\
\hline Southeast $(b)$ & 187.36 & 5.43 & 8.31 & 12.16 \\
\hline Canadian Imports (b) & 171.16 & 4.70 & 7.68 & 11.33 \\
\hline
\end{tabular}

(a) Retail prices.

(b) Mill level prices. 
TABLE 7.16. Impacts of Lower Housing Starts, Greater Efficiency, and Faster Conversion of Timberland on U.S. Lumber Supplies: 2030 Projections

Source of Lumber Supply by Lumber Type and Region

Domestic Softwood

Production

Northeast (a)

Southeast

Lower 48 States

Domestic Hardwood

Production

Northeast

Southeast

Lower 48 States

Imports of Canadian

Softwood Lumber $\frac{\text { Alternative Base Case Scenarios }}{\text { Low Increased }}$

Base Case

(Billion Housing Efficiency Timberlanc (Percentage Change from Base)
Board Feet)

1.16

9.39

40.22

2.25

2.78

11.84

9.62
0.00

0.00

0.00

$-6.82$

$-1.38$

$-6.07$

3.23

4.10

$-13.25$

(a) Softwood lumber supplies in the Northeast are fixed in the model and do not change in the scenarios.

TABLE 7.17. Impacts of Lower Housing Starts, Greater Efficiency, and Faster Conversion of Timberland on Softwood Lumber Prices: 2030 Projections

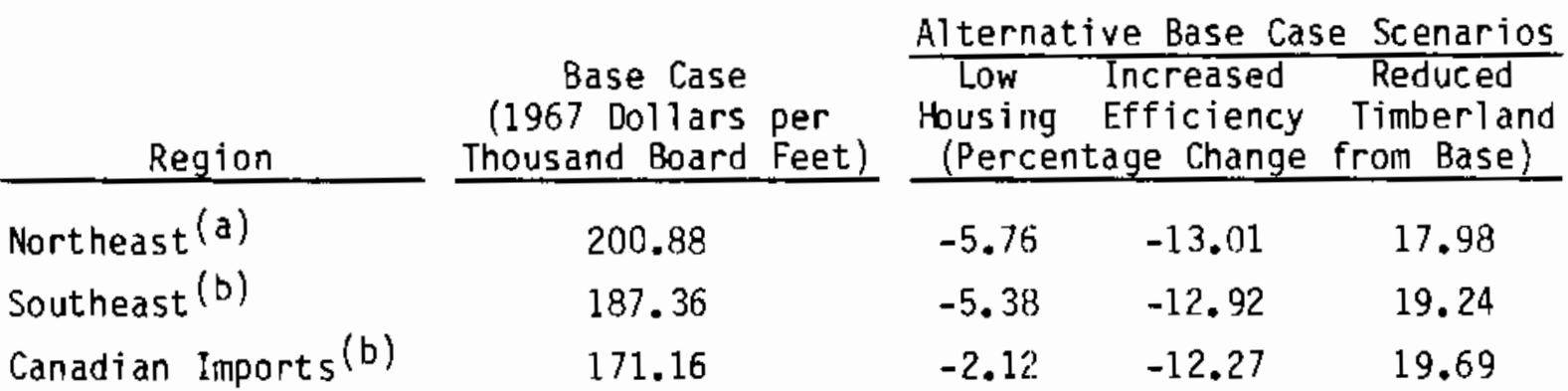

(a) Retail price.

(b) Mill level price. 
scenarios do, however, provide the upper and lower bounds for regional lumber prices. As in previous comparisons, the relatively sharp decrease in timber supplies that occurs in the Reduced Timberland Case produces market impacts that are similar in direction but greater in magnitude than those associated with the reduced growth cases. The similarity in the nature of the effects between the two sets of cases is important for two reasons. First of all, it suggests that, from a comparative standpoint at least, the "worst" effects of hypothetical growth reductions may be similar in character, but smaller in magnitude, to a different but still fairly plausible Base Case. Second, the parallels between the two sets of uses suggests that policies designed to conserve timberland may be equally successful (or unsuccessful) in dealing with the adverse consequences of reduced timber growth, irrespective of its causes.

So far the results have shown that lower rates of timber growth in the Northeast and Southeast regions of the United States induce smaller future inventories of softwood and hardwood growing stock in all regions of the United States. These smaller inventories shift the aggregate domestic supply curves of softwood and hardwood lumber to the left and result in less domestic lumber production. The impacts are moderated, however, by increasing imports from sources outside the United States. Canadian imports of softwood lumber, for example, increase (see Table 7.14).

Table 7.18 shows the effects of increasing the severity of potentia? damages on 1 umber consumption and prices by 2030. Consistent with the forecasts of lumber production generated by these cases, increasing the severity of damages causes consumption levels to decrease and prices to increase for both softwood and hardwood lumber. In all of the cases, lumber consumption decreases, nationally, and lumber prices increase. This trend has important consequences for the effects of reduced timber growth on the welfare of consumers of lumber and plywood, to be discussed in Section 7.3.

Projections of lumber consumption and wholesale price indices in 2030 are presented in Table 7.19 for the alternative, no-pollution cases. These cases 
TABLE 7.18. Impacts of Hypothetical 10\%, 15\%, and $20 \%$ Growth Reductions in the Northeast and Southeast Regions on Lumber Consumption and Wholesale Price Indices: 2030 Projections

\begin{tabular}{|c|c|c|c|c|}
\hline Lumber Type/Item & $\begin{array}{l}\text { Base } \\
\text { Case }\end{array}$ & $\begin{array}{l}\text { Growth Rate } \\
\text { Hardwood Sp } \\
10 \% \\
\text { (Percentage }\end{array}$ & $\begin{array}{l}\text { es of Sof } \\
\frac{\text { ecies Re }}{15 \%} \\
\text { Change }\end{array}$ & $\begin{array}{l}\text { ftwood and } \\
\text { educed by: } \\
20 \% \\
\text { from Base) }\end{array}$ \\
\hline \multicolumn{5}{|l|}{ Softwood } \\
\hline Consumption (a) & 47.26 & -1.50 & -2.54 & -3.70 \\
\hline $\begin{array}{l}\text { Wholesale Price } \\
\text { Index (b) }\end{array}$ & 220.98 & 4.98 & 8.19 & 12.09 \\
\hline \multicolumn{5}{|l|}{ Hardwood } \\
\hline Consumption $\langle a\rangle$ & 12.33 & -1.05 & -1.87 & -2.84 \\
\hline $\begin{array}{l}\text { Wholesale Price } \\
\text { Index (b) }\end{array}$ & 165.29 & 0.93 & 1.59 & 2.35 \\
\hline
\end{tabular}

(a) Billion board feet.

(b) Index of price per thousand board feet, $1967=100.00$.

TABLE 7.19. Impacts of Lower Housing Starts, Greater Efficiency, and Faster Conversion of Timberland on Lumber Consumption and Wholesale Price Indices: 2030 Projections

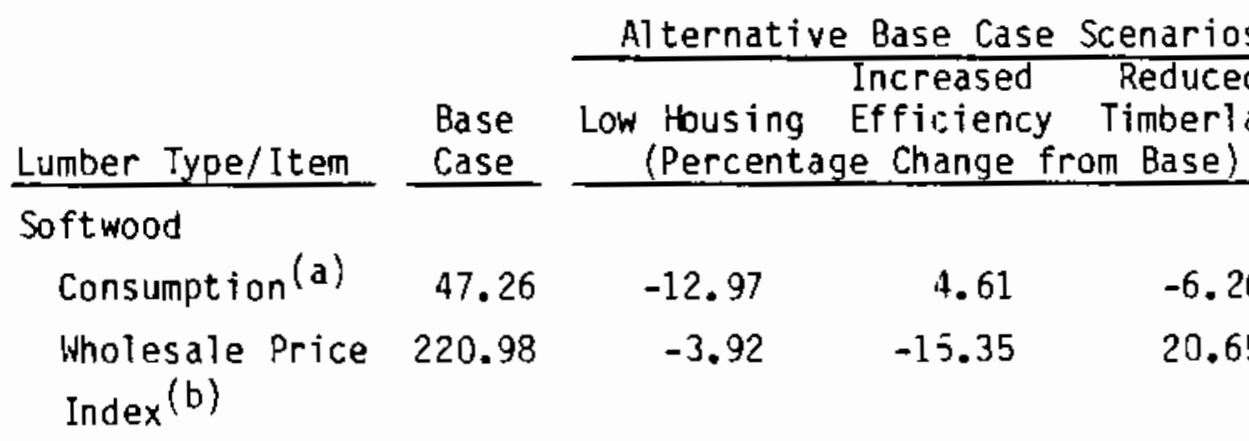

Hardwood

$\begin{array}{lrrrr}\text { Consumption(a) } & 12.33 & -0.08 & 2.60 & -5.35 \\ \text { Wholesale Price } & 165.29 & 0.08 & -2.17 & 4.48 \\ \text { Index (b) } & & & & \end{array}$

(a) Billion board feet.

(b) Index of price per thousand board feet, $1967=100.00$. 
provide the upper and lower bounds for national lumber consumption and wholesale prices. Note once more the similarity in the direction of the impacts caused by reducing the timberland base with the effects of the reduced growth cases.

The lumber supply effects of adjusting Northern lumber and plywood production when timber growth is reduced by $15 \%$ are presented in Table 7.20. Recall that production of softwood lumber and plywood in the Northern regions is increased when timber growth in both the Northeast and Southeast is reduced to simulate adjustments to rising stumpage prices but also to even faster rising product prices. The results in Table 7.20 indicate that increasing softwood

TABLE 7.20. Effects on U.S. Lumber Supply of Adjusting Northern Sof twood Lumber and Plywood Production when Timber Growth in the Northeast and Southeast is Reduced by $15 \%$ : 2030 Projections

\begin{tabular}{|c|c|c|c|}
\hline \multirow[b]{2}{*}{ Source of Lumber Supply } & \multirow[b]{2}{*}{$\begin{array}{l}\text { Base Case } \\
\text { (Billion } \\
\text { Board Feet) }\end{array}$} & \multicolumn{2}{|c|}{$\begin{array}{l}\text { Production Adjustment in } \\
\text { Northern Regions When } \\
\text { Timber Growth in the Northeast } \\
\text { and Southeast Reduced by } 15 \%\end{array}$} \\
\hline & & $\begin{array}{l}\text { Production } \\
\text { Increased } \\
\text { Percentage }\end{array}$ & $\begin{array}{l}\text { Production Same as } \\
\text { in Base Case } \\
\text { Change from Base) }\end{array}$ \\
\hline \multicolumn{4}{|l|}{ Domestic Softwood Production } \\
\hline Northeast & 1.16 & 25.00 & 0.00 \\
\hline Southeast & 9.39 & -37.17 & -36.42 \\
\hline Other Supply Regions & 29.67 & 3.54 & 3.57 \\
\hline Lower 48 States & 40.22 & -5.35 & -5.87 \\
\hline \multicolumn{4}{|l|}{ Domestic Hardwood Production } \\
\hline Northeast & 2.25 & -4.44 & -4.44 \\
\hline Southeast & 2.78 & -7.55 & -7.19 \\
\hline Other Supply Regions & 6.81 & 0.88 & 0.88 \\
\hline Lower 48 States & 11.84 & -2.11 & -2.04 \\
\hline Imports of Canadian Softwood & 9.62 & 11.43 & 12.27 \\
\hline
\end{tabular}


lumber production in the Northeast and North Central regions reduces the level of softwood lumber production outside those regions. Relative to the unadjusted reduced growth case, for example, softwood lumber production in the Southeast declines. This reduction in Southeastern production is due to the greater comparative advantage that Northern manufacturers obtain when the Southeast is directly affected by growth slowdowns. Because the Northern regions produce relatively little softwood lumber, however, the magnitude of the impacts on lumber production in other regions is small. Nevertheless, softwood lumber production for the U.S. as a whole increases relative to the unadjusted reduced growth scenario.

The increased output of softwood Iumber by U.S. manufacturers in turn reduces softwood lumber prices relative to the unadjusted version of this reduced growth scenario as is shown in Table 7.21 . These relatively lower prices enhance the comparative advantage of domestic softwood Tumber so that the increase in softwood lumber imports from Canada is smalier (see Table 7.20). These relatively lower prices also mean that the consumption of softwood lumber increases relative to the unadjusted reduced growth case as is shown in Table 7.22 .

\subsubsection{Summary of Economic Impacts}

In summary, the results of the sensitivity analysis indicate that relative to a zero-reduction-in-growth scenario, timber growth slowdowns in the Northeast and Southeast cause

- timber harvests and lumber production in the U.S. to decrease. Harvests and production levels do not decline in all regions, however, because of interregional trade. Smaller harvests and production levels in regions directly affected by growth slowdowns are partially offset by larger harvests and production levels in other regions.

- stumpage and lumber prices to increase throughout the U.S. Higher prices occur in all regions because interregional trade tends to distribute price increases caused by shocks in one region over all trading partners. 
TABLE 7.21. Effects on Softwood Lumber Prices of Adjusting Northern Lumber and Plywood Production when Timber Growth in the Northeast and Southeast is Reduced by 15\%: 2030 Projections

\begin{tabular}{|c|c|c|c|}
\hline \multirow[b]{2}{*}{ Region } & \multirow[b]{2}{*}{$\begin{array}{r}\text { Base Case } \\
\text { (1976 Dollars } \\
\text { Thousand Board } \\
\end{array}$} & \multicolumn{2}{|c|}{$\begin{array}{l}\text { Production Adjustment in } \\
\text { Northern Regions When } \\
\text { Timber Growth in the Northeast } \\
\text { and Southeast Reduced by } 15 \%\end{array}$} \\
\hline & & $\begin{array}{l}\text { Production } \\
\text { Increased } \\
\text { Percentage } \\
\end{array}$ & $\begin{array}{c}\text { Production Same as } \\
\text { in Base Case } \\
\text { Change from Base) } \\
\end{array}$ \\
\hline Northeast (a) & 200.88 & 5.84 & 6.76 \\
\hline Southeast $(b)$ & 187.36 & 7.26 & 8.31 \\
\hline Imports from Canada & 171.16 & 6.99 & 7.68 \\
\hline
\end{tabular}

(a) Retail prices

(b) Mill level prices

Tahle 7.22. Effects on Lumber Consumption and Wholesale Price Indices of Adjusting Northern Softwood Lumber and Plywood Production when Timber Growth in the Northeast and Southeast is Reduced by 15\%: 2030 Projections

\begin{tabular}{|c|c|c|c|}
\hline \multirow[b]{2}{*}{ Lumber Type/Item } & \multirow[b]{2}{*}{$\begin{array}{l}\text { Base } \\
\text { Case }\end{array}$} & \multicolumn{2}{|c|}{$\begin{array}{l}\text { Production Adjustment in } \\
\text { Northern Regions When } \\
\text { Timber Growth in the Northeast } \\
\text { and Southeast Reduced by } 15 \%\end{array}$} \\
\hline & & $\begin{array}{l}\text { Production } \\
\text { Increased } \\
\text { (Percentage }\end{array}$ & $\begin{array}{c}\text { Production Same as } \\
\text { in Base Case } \\
\text { Change from Base) }\end{array}$ \\
\hline $\begin{array}{l}\text { Softwood } \\
\text { Consumption (a) } \\
\text { Wholesale Price Index (b) }\end{array}$ & $\begin{array}{r}47.26 \\
220.98\end{array}$ & $\begin{array}{r}-2.29 \\
7.01\end{array}$ & $\begin{array}{r}-2.54 \\
8.19\end{array}$ \\
\hline $\begin{array}{l}\text { Hardwood } \\
\text { Consumption (a) } \\
\text { Wholesale Price Index (b) }\end{array}$ & $\begin{array}{r}12.33 \\
165.29\end{array}$ & $\begin{array}{r}-1.87 \\
0.96\end{array}$ & $\begin{array}{r}-1.87 \\
1.59\end{array}$ \\
\hline
\end{tabular}

(a) Billion board feet

(b) Index of price per thousand board feet, 1967=100.00 
- imports of softwood lumber from Canada to increase. Greater quantities of softwood lumber are imported from Canada because the international competitiveness of U.S. lumber is reduced by higher domestic lumber prices.

- lumber consumption in the U.S. to decrease. Lumber consumption decreases because higher lumber prices reduce the competitiveness of lumber as a manufacturing input.

\subsection{WELFARE IMPACTS}

As shown in the preceding two sections, reductions of timber growth in the Northeast and Southeast regions affect economic activity in stumpage and product markets not just in these regions, but in other regions as well. In this section, we focus on the welfare implications of these economic effects and show that overall, the welfare of the nation decreases. The burden of losses, however, is not equally distributed across all economic agents or regions. In fact, there are winners as well as losers. Thus, most of this analysis concentrates on the distributional impacts that growth reductions in the Northeast and Southeast regions might have.

\subsubsection{Overview of Welfare Measures}

Three kinds of measures are used to quantify the changes in economic welfare resulting from reduced growth: 1) economic surplus, 2) economic profit, and 3) the value of the growing stock inventory left standing in 2030. Two types of economic surptus are used in the analysis--consumer surplus and producer surplus. Recall from Section 3.2.1 that consumer surplus is defined as the difference between the maximum amount of money a consumer would be willing to pay for a good, rather than do without it, and the amount the consumer actually pays for each unit of the good. Similariy, producer surplus is defined as the difference between the amount of money which a producer actually receives from the sale of a good and the minimum amount which the producer would accept rather than forego the sale of the good.

The second measure, economic profit, is defined as the difference between the total revenues that a firm or industry receives for selling its product and 
the total costs incurred by the firm or industry in producing its product. Economic profit is a useful welfare measure in this analysis because it, unlike short-run producers' surplus, nets out the costs of investing in new plant and equipment over the long-run.

The third measure used to quantify changes in welfare is the value of a region's growing stock inventory in 2030. This value is, after Berck (1979), simply the number of board feet of growing stock per region times the regional stumpage price in 2030.

Justification for the use of economic surpluses in policy analyses is well documented in Willig (1976) and Just, Hueth, and Schmitz (1982). Modifications made to TAMM to generate estimates of a) short-run consumer surplus for lumber and plywood buyers and b) short-run producer surplus for lumber and plywood producers and for private timberland owners, annually, are presented in Appendix B. Information about the relationship between short-run producers surplus and economic profit as well as the methodology used to derive annual economic profits in this analysis are also presented in Appendix B.

Table 7.23 shows which measures are used to del ineate the welfare changes incurred by each of the three types of economic agents whose behavior is simulated in TAMM. Producers' surpluses in stumpage markets, together with the value of inventory remaining in 2030, are used to indicate welfare changes that affect private owners of comnercial timberland. Welfare changes that affect firms in the forest products industry are measured by 1) changes of producers' surpluses in softwood and hardwood lumber markets and softwood plywood markets, or 2) changes in economic profits in softwood and hardwood 1 umber markets and softwood plywood markets. Consumers' surpluses in softwood and hardwood lumber markets and softwood plywood markets are used to indicate welfare changes that affect consumers of forest products.

Regional measures of the welfare of a particular group of economic agents are calculated by cumulating the appropriate regional welfare measures derived annually, i.e. short-run consumers' and producers' surplus and economic profit, over the projection period from 1985 to 2030. A discount rate of $10 \%$ is used to convert the future values of these annual measures as well as the value of 
TABLE 7.23. Welfare Measures Used to Quantify Changes in the Economic Well-Being of Various Economic Agents in the United States

Economic Agent

Private Owners of Commercial Timberland

Producers of Softwood and Mardwood Lumber and Softwood Plywood

Consumers of Softwood and Hardwood Lumber and Softwood Plywood
Welfare Measure(s)

Short-Run Producers' Surpluses in Stumpage Markets

$\underline{\text { Plus }}$

The Value of the Growing Stock Inventory Remaining in 2030

Short-Run Producers' Surpluses in Softwood and Hardwood Lumber and Softwood Plywood Markets

\section{$\underline{\text { or }}$}

Economic Profits in Softwood and Hardwood Lumber and Softwood Plywood Markets

Short-Run Consumers' Surpluses in Softwood and Hardwood Lumber and Softwood Plywood Markets

the inventory remaining in 2030 into present value terms. A summation of all the cumulated regional measures provides a measure of the economic welfare of a particular group of economic agents in the U.S. as a whole. Finally, summing across the U.S. measures for the three major groups of economic agents yields a measure of the total economic welfare obtained in all the markets of interest, i.e. softwood and hardwood stumpage, softwood and hardwood lumber, and softwood plywood. This approach is consistent with the aggregation results presented by Just, Hueth and Schmitz (1982) and avoids double counting of producer surpluses in input and output markets.

Before presenting the results of the welfare analysis, however, the limitations associated with the use of these welfare measures should be mentioned. First and foremost, changes in the economic welfare derived from the production and consumption of many forest products are not included in the analysis. For example, there are no welfare measures for pulpwood buyers in the model. The equilibrium quantities of pulp dernanded and supplied nationally 
are fixed over the projection period for all cases. Theoretically, however, we would expect these equilibrium quantities to decrease relative to the Base Case as growth reductions caused inventories to decline, pulpwood prices to rise, and the supply of pulp to decrease. This, in turn, would cause consumers' surpluses in pulp markets to decline. This means that the magnitude of the overall welfare impacts of growth reductions are underestimated, particularly because both the Northeast and Southeast are important pulp producing regions. There also are distributional effects associated with pulp production as is shown in Table 7.24. Pulp production decreases in the Northeast and Southeast when those regions are directly affected by reduced growth and increases in the North Central and South Central regions, respectively. The magnitudes of the welfare changes due to these shifts in pulp production also are not known. Other important market goods that are excluded from the analysis because equilibrium quantities are fixed over the projection period for all scenarios include hardwood plywood, and various types of board products, i.e. particle board, waferboard, etc.

Second, potential welfare changes associated with various nonmarket goods provided by the nation's forests are not measured. In addition to providing the U.S. with basic raw materials such as Tumber, plywood, and pulp, timberland also provides habitat for wildlife, helps control soil erosion, and offers scenic vistas. Changes in the welfare obtained from these environmental amenities are not evaluated in this analysis.

Third, the welfare impacts caused by sustained timber growth reductions are evaluated only through the year 2030. Changes in economic welfare that

TABLE 7.24. Impacts of $15 \%$ Growth Reductions in the Northeast and Southeast Regions on Pulp Production: 2030 Projections

$\begin{array}{cccc}\text { Region } & \begin{array}{c}\text { Base Case } \\ \text { (Million Tons) }\end{array} & \frac{\begin{array}{c}\text { Regions Affected by Reduced Growth } \\ \text { (Percentage Change from Base) }\end{array}}{\text { Northeast }} & \begin{array}{c}\text { Northeast and } \\ \text { Southeast }\end{array} \\ \text { Southeast } & 18.49 & -5.90 & -8.82 \\ 0.05 & 0.00 & -8.99\end{array}$


occur during the latter half of the 2lst century and beyond are not considered. Fourth, only those welfare changes which directly affect the population of the U.S. are taken into account. Changes in the economic welfare of economic agents in Canada and other foreign countries are not evaluated.

Finally, the analysis of the welfare changes that occur in the stumpage, Tumber, and plywood markets under consideration is conducted within a partialequilibrium framework. Treating lumber and plywood as "final goods," for example, is somewhat arbitrary. Lumber and plywood are in fact used as inputs into the production of other goods, primarily durables, from which additional economic welfare is obtained. Also, the level of efficiency with which lumber and plywood is processed from saw logs and the level of intensity at which timberland owners manage their growing stock inventories are not linked to price changes induced by timber growth reductions. Theoretically, producers of lumber and plywood would adopt more efficient methods of manufacturing these products so as to reduce the impact of rising costs caused by higher stumpage prices. Similarly, higher stumpage prices would increase the rate of return on silvicultural investments in regions not directly affected by timber growth reductions and stimulate timberland owners to implement more of these managerial practices. Thus, this analysis implicitly assumes that 1) changes in consumers' surpluses in 1 umber and plywood markets capture all the changes in economic welfare experienced by producers and consumers of products using lumber and plywood as inputs and 2) the benefits of increasing the levels of processing efficiency or management intensity abcve the levels forecast by the model are just offset by the costs of imp? ementing such increases.

\subsubsection{Results of Welfare Analysis}

The results of the welfare analysis are presented and discussed in the remainder of this section. For brevity, the presentation is limited to the same set of cases considered in the section on economic impacts (Section 7.2 above). These cases include the base case, the reduced growth scenarios in which the growth rates of trees in softwood and hardwood inventories in both the Northeast and the Southeast are reduced, and the alternative base case scenarios. 
All the welfare measures presented in this section are cumulative whenever appropriate and in present value tems (the discount rate used is $10 \%$ ). Present values of cumulative welfare measures for the scenarios not discussed here as well as future values of selected welfare measures are contained in Appendix $C$.

Changes in the present value of cumulative short-run economic surplus due to various hypothetical growth reductions are presented in Table 7.25. Values

TABLE 7.25. Changes in the Present Value (a) of Cumulative Short-Run Economic Surplus in the United States Due to Hypothetical Reductions in Radial Growth in the Northeast and Southeast

$$
\text { (Million } 1984 \text { Dollars) }
$$

\begin{tabular}{|c|c|c|c|c|}
\hline Cumulative Welfare Measure & Base Case & \multicolumn{3}{|c|}{$\begin{array}{c}\frac{\text { Percent Reduction in Growth }}{10 \%} \\
10 \% \text { (Change from Base) } \\
\text { (C) }\end{array}$} \\
\hline $\begin{array}{l}\text { Consumers' Surplus for Softwood and } \\
\text { Hardwood Lumber and Softwood Plywood }\end{array}$ & $396,254.7$ & $-3,376.7$ & $-5,091.8$ & $-8,667.7$ \\
\hline $\begin{array}{l}\text { Producers' Surplus for Softwood and } \\
\text { Hardwood } \text { Lumber and Softwood } \\
\text { Plywood }(c)\end{array}$ & $235,589.7$ & -625.4 & -398.6 & $1,459.5$ \\
\hline $\begin{array}{l}\text { Producers' Surplus for Softwood and } \\
\text { Hardwood St umpage }\end{array}$ & $49,272.0$ & 634.5 & $1,166.8$ & $2,361.7$ \\
\hline $\begin{array}{l}\text { Value of the Inventory Remaining } \\
\text { in } 2030\end{array}$ & $5,995.6$ & -9.3 & -83.2 & -185.2 \\
\hline $\begin{array}{l}\text { Value of Change in Total Economic } \\
\text { Surplus }\end{array}$ & & $-3,376,9$ & $-4,406.8$ & $-5,031.7$ \\
\hline $\begin{array}{l}\text { Annualized Value of the Change in } \\
\text { Total Economic Surplus }\end{array}$ & & -342.4 & -446.8 & -510.2 \\
\hline
\end{tabular}

(a) Base year is 1985; discount rate is $10 \%$; ending year in 2030.

(b) Annual radial growth rates of trees in softwood and hardwood inventories in the Northeast and Southeast reduced by 10,15 , and $20 \%$.

(c) Producers' surpluses for softwood lumber and plywood in the Northeast and North Central regions are not available.

(d) Includes changes in the value of the inventory remaining in 2030. 
of the change in total economic surplus indicate that as the magnitude of growth reductions increases from 10 to $20 \%$, the total welfare of the nation decreases, but at a decreasing rate.

This sequence of changes in the value of total economic surplus can be explained by the different effects that growth reductions have on the welfare of the various participants in the forest products industry. For example, changes of cumulative short-run consumers surplus in lumber and plywood markets indicate that the welfare of lumber and plywood consumers decreases at an increasing rate as the magnitude of the growth reductions increases from 10 to 20\%. The welfare of timberland owners, on the other hand, increases at an increasing rate when the magnitude of the growth reductions increases as is indicated by the changes of cumulative short-run producers' surplus in stumpage markets. Thus, the overall welfare impacts of timber growth reductions are eased somewhat by a redistribution of welfare from consumers of lumber and plywood to timberland owners.

The welfare implications of growth reductions for producers of lumber and plywood are more complex. As is shown in Table 7.25, cumulative short-run producers' surplus in lumber and plywood markets decreases when timber growth is reduced by 10 and $15 \%$, but increases when timber growth is reduced by $20 \%$. These changes imply that the welfare of lumber and plywood producers depends on the extent to which timber growth in the Northeast and Southeast is reduced.

The increase in the welfare of timberland owners can be explained by the relatively price insensitive nature of stumpage demands. While timberland owners in the Southeast experienced decreased welfare (not shown), timberland owners were able to pass along increased costs to stumpage buyers in the form of higher prices. Producers, in turn, sustained losses in welfare for the $10 \%$ and $15 \%$ growth reduction costs because they were unable to pass along all of these cost increases to consumers. This was particularly true of producers in the Southeast.

In the $20 \%$ growth reduction case, on the other hand, prices edged high enough to substantially alter the relative terms cf trade so that producers in other regions could take advantage of sharply reduced lumber and plywood production in the Southeast and higher 1 umber and plywood prices, nationwide. 
This resulted in a simulated net gain in the producer surplus of lumber and plywood producers (despite large decreases in producer surplus in the Southeast).

Finally, buyers of lumber and plywood sustained welfare losses in all three reduced growth cases because the increases in their costs could not be passed along to consumers at a fast enough rate to keep pace with rising lumber and plywood prices. This explanation is consistent with the simulated pattern of changes in the welfare of lumber and plywood producers over time. That is: the improving welfare position of Tumber and plywood producers over time is due to welfare transfers of consumer surplus from lumber and plywood buyers to the producers of these products as lumber and plywood prices increase.

Changes of cumulative short-run producers' surplus, however, do not take the changing pattern of investment into account. Accounting for changes in investment is important in this analysis because timber growth slowdowns not only reduce the total output of 1 umber and plywood over the projection period, but also reduce the amount of resources tied up in lumber and plywood mills. Any of these resources freed by timber growth reductions represent a saving to society because they could be employed in other economic endeavors and therefore should be given a positive welfare value.

Welfare measures that take investments in lumber and plywood mills into account are presented in Table 7.26, where changes in cumulative economic profit are used to delineate the welfare impacts of growth reductions on lumber and plywood producers instead of cumulative short-run producers' surplus. As is shown in Table 7.26, economic profits in lumber and plywood markets increase, and at an increasing rate, when the magnitude of the growth reductions increases from 10 to $20 \%$. This implies that the overall welfare impacts of timber growth reductions are cushioned not only by a redistribution of welfare from consumers of lumber and plywood to timberland owners, but a 150 by a redistribution of welfare from consumers to producers of lumber and plywood. The amount of cushioning is evident in the values of the change in total economic surplus and profit presented in Table 7.26, which are much smaller than the values of the change in total economic surplus presented in Table 7.25 . 
Table 7.26. Changes in the Present Value ${ }^{(a)}$ of Cumulative Short-Run Consumers' Surplus and Economic Profit in Lumber and Plywood Markets and Producers' Surplus in Stumpage Markets Due to Hypothetical Reductions in Radial Growth in the Northeast and Southeast

(Million 1984 Dollars)

\begin{tabular}{|c|c|c|c|c|}
\hline \multirow[b]{2}{*}{ Cumulative Wel fare Measure } & \multirow[b]{2}{*}{ Base Case } & \multicolumn{3}{|c|}{ Percent Reduction in Growth(b) } \\
\hline & & $10 \%$ & $\begin{array}{l}15 \% \\
\text { age from }\end{array}$ & $20 \%$ \\
\hline $\begin{array}{l}\text { Consumers' Surpl us for Softwood and } \\
\text { Hardwood Lumber and Softwood Plywood }\end{array}$ & $396,284.7$ & $-3,376.7$ & $-5,091.8$ & $-8,667.7$ \\
\hline $\begin{array}{l}\text { Producers' Surpl us for Softwood and } \\
\text { Hardwood Lumber and Softwood } \\
\text { Plywood }(c)\end{array}$ & $-16,890.3$ & $2,134.3$ & $-2,981.5$ & $5,263.3$ \\
\hline $\begin{array}{l}\text { Producers' Surplus for Softwood and } \\
\text { Hardwood St umpage }\end{array}$ & $49,272.0$ & 634.5 & $1,166.8$ & $2,361.7$ \\
\hline $\begin{array}{l}\text { Value of the Inventory Remaining } \\
\text { in } 2030\end{array}$ & $5,995.6$ & -9.3 & -83.2 & -185.2 \\
\hline $\begin{array}{l}\text { Value of Change in Total Economic } \\
\text { Surplus }\end{array}$ & & -617.2 & $-1,026.7$ & $-1,227.9$ \\
\hline $\begin{array}{l}\text { Annualized value of the Change in } \\
\text { Total Economic Surplus }\end{array}$ & & -62.6 & -104.1 & -124.5 \\
\hline
\end{tabular}

(a) Base year is 1985; discount rate is $10 \%$; ending year in 2030.

(b) Annual radial growth rates of trees in softwood and hardwood inventories in the Northeast and Southeast reduced by 10,15 , and $20 \%$.

(c) Not an accurate measure for any one scenario such as the Base Case. The changes from the Base Case, however, are accurate.

(d) Includes changes in the value of the inventory remaining in 2030.

Additional details about the welfare impacts induced by timber growth reductions are presented by focusing on the $15 \%$ growth reduction scenario in which the production of softwood lumber and plywood in the Northwest and North Central regions is increased. Regional changes in the present value of cumulative short-run consumers' surplus in lumber and plywood markets due to this reduced growth scenario are presented in Table 7.27. Consumers' surplus in 
TABLE 7.27. Regional Changes in the Present Value(a) of Cumulative Short-Run Consumers' Surplus in Lumber and Plywood Markets when Timber Growth in the Northeast and Southeast is Reduced by $15 \%$ and Production of Softwood Lumber and Plywood in the Northeast and North Central Regions is Increased by $25 \%$

(Mitlion 1984 Dollars)

\begin{tabular}{|c|c|c|c|}
\hline Cumulative Welfare Measure & Demand Region & Base Case & $\begin{array}{l}15 \% \text { Growth Reduction }(b) \\
\text { (Change from Base) }\end{array}$ \\
\hline $\begin{array}{l}\text { Consumers' Surplus in } \\
\text { Softwood Lumber and } \\
\text { Plywood Markets }\end{array}$ & $\begin{array}{l}\text { Northeast } \\
\text { South } \\
\text { Other Regions } \\
\text { A11 Regions }\end{array}$ & $\begin{array}{r}34,926.8 \\
102,767.4 \\
224,899.4 \\
362,593.6\end{array}$ & $\begin{array}{r}-584.1 \\
-1,259.3 \\
-2,098.5 \\
-3,941.9\end{array}$ \\
\hline $\begin{array}{l}\text { Consumers' Surplus in } \\
\text { Hardwood Lumber Markets }\end{array}$ & All Regions & $33,691.1$ & -353.0 \\
\hline Total Consumers' Surplus & All Regions & $396,284.7$ & $-4,294.9$ \\
\hline
\end{tabular}

(a) Base year is 1985 ; discount rate is $10 \%$; ending year is 2030 .

(b) Annual radial growth rates of trees in softwood and hardwood inventories in the Northeast and Southeast reduced by $15 \%$ and production of softwood lumber and plywood in the Northeast and North Central regions increased by $25 \%$.

lumber and plywood markets decreases in alt regions for the same reasons identified in previous cases. The magnitude of the decrease in total consumers' surplus is smaller in this case, however, than in the $15 \%$ growth reduction case in which the output of softwood lumber and plywood in the Northern regions is not adjusted (see Table 7.25 or 7.26). Consumers of lumber and plywood are better off when manufacturers in Northern regions increase their output because prices are lower and greater quantities of lumber and plywood are consumed in all regions.

Regional changes in the present value of cumulative short-run producers' surplus and economic profit in lumber and plywood markets are presented in Table 7.28. Changes in producers' surplus induced by this production-adjusted reduced growth scenario indicate that the welfare of 1 umber and plywood producers in some regions decreases, whereas the welfare of producers in other regions increases. For example, producers' surplus in Northeastern hardwood 
TABLE 7.28. Regional Changes in the Present Value(a) of Cumulative Short-Run Producers' Surplus and Economic Profit in Lumber and Plywood Markets when Timber Growth in the Northeast and Southeast is Reduced by $15 \%$ and Production of Softwood Lumber and Plywood in the Northeast and North Central Regions is Increased by $25 \%$

(Mil1ion 1984 Dollars)

\begin{tabular}{|c|c|c|c|}
\hline Cumulative Welfare Measure & Supply Region & Base Case & $\begin{array}{l}15 \% \text { Growth Reduction (b) } \\
\text { (Change from Base) }\end{array}$ \\
\hline Producers' Surplus in & Northeast (d) & $7,819.2$ & -111.3 \\
\hline Softwood Lumber and & Southeast & $46,659.6$ & $-4,800.3$ \\
\hline Plywood and Hardwood & Other Regions & $181,110.9$ & $3,469.9$ \\
\hline Lumber Markets $(c)$ & Al1 Regions & $235,589.7$ & $-1,441.7$ \\
\hline Economic Profit in & Northeast & 398.0 & 112.6 \\
\hline Softwood Lumber and & Southeast & $-1,733.9$ & 361.9 \\
\hline Plywood and Hardwood & Other Regions & $-15,554.4$ & $1,994.9$ \\
\hline Lumber Markets (e) & All Regions & $-16,890.3$ & $2,469.3$ \\
\hline
\end{tabular}

(a) Base year is 1985; discount rate is $10 \%$; ending year is 2030 .

(b) Annual radial growth rates of trees in softwood and hardwood inventories in the Northeast and Southeast reduced by $15 \%$ and production of softwood lumber and plywood in the Northeast and North Central regions increased by $25 \%$.

(c) Producers' surpluses for softwood lumber and plywood in the Northeast and North Central regions not available.

(d) Producers' surplus for hardwood lumber only.

(e) Not an accurate measure for any one scenario such as the Base Case. The changes from the Base Case, however, are accurate.

lumber markets decreases. Similarly producers' surpluses in softwood and hardwood lumber and softwood plywood markets in the Southeast decrease. These decreases occur even though prices are higher because the output of these manufacturers is much lower than in the base case. In other supply regions, however, producers' surpluses in lumber and plywood markets increase because 
prices are higher and output levels are greater. (a) Producers' surplus in lumber and plywood markets for the nation as whole decreases.

Changes in cumulative economic profits, on the other hand, tell a different story about the welfare of 1 umber and plywood producers when timber growth in the Northeast and Southeast is reduced. As is shown in Table 7.28, economic profit in 1 umber and plywood markets increases in every supply region, including the Northeast and Southeast.

The difference between the welfare changes implied by short-run producers' surpluses and the changes implied by economic profit are due to changes in the pattern of investment that occur when timber growth in the Northeast and Southeast is reduced. For example, as the output of 1 umber and plywood in the Southeast declines, fewer resources are invested in lumber and plywood mills. By taking this saving into account, the change in economic profit in Southeastern lumber and plywood markets indicates that the welfare of the owners of lumber and plywood mills remains about the same when timber growth in the region is reduced. The lumber and plywood industry in the region, however, will be smaller.

Conversely, as the output of lumber and plywood in other supply regions increases, more resources have to be invested in lumber and plywood mills. This additional investment represents a cost to the region and should be assigned a negative value. By taking this additional cost into account, the change in economic profit in lumber and plywood markets in other supply regions indicates a smaller increase in the welfare of 1 umber and plywood manufacturers in these other regions than is indicated by the change in short-run producers' surplus.

Finally, the increase in economic profit is smaller in this case than in the $15 \%$ growth reduction case in which the output of softwood 1 umber and plywood in the Northern regions is not adjusted (see Table 7.26). Economic profits are smaller when the production of softwood lumber and plywood in

(a) Because prices and output of softwood lumber and plywood in the Northeast and North Central regions are also higher in this reduced growth scenario, producers' surpluses for these products should increase in these regions as well. 
Northern regions is increased because the selling price and output level of these products are lower in other regions.

Regional changes in the present value of cumulative short-run producers' surplus in stumpage markets and of the inventory remaining in 2030 are presented in Table 7.29. For the Southeast, both the change in producers' surplus and the change in the value of the inventory indicate that the welfare of Southeastern timberland owners decreases when timber growth in the Northeast and Southeast is reduced by $15 \%$. This decrease in welfare occurs even though stumpage prices are higher because harvests in the region are much smaller. In all other regions, including the Northeast, the changes in producers' surplus

TABLE 7.29. Changes in the Present Value(a) of Cumulative Short-Run Producers' Surplus in Stumpage Markets and of the Inventory Remaining in 2030 when Timber Growth in the Northeast and Southeast is Reduced by 15\% and Production of Softwood Lumber and Plywood in the Northeast and North Central Regions is Increased by $25 \%$

(Million 1984 Dollars)

\begin{tabular}{|c|c|c|c|}
\hline Welfare Measure & Supply Region & Base Case & $\begin{array}{l}15 \% \text { Growth Reduction (b) } \\
\text { (Change from Base) }\end{array}$ \\
\hline $\begin{array}{l}\text { Cumulative Consumers' } \\
\text { Surplus in Softwood } \\
\text { and Hardwood Stumpage } \\
\text { Markets }\end{array}$ & $\begin{array}{l}\text { Northeast } \\
\text { Southeast } \\
\text { Other Regions } \\
\text { All Regions }\end{array}$ & $\begin{array}{r}2,727.5 \\
10,720.4 \\
35,824.1 \\
49,272.0\end{array}$ & $\begin{array}{r}208.0 \\
-772.0 \\
1,464.1 \\
900.1\end{array}$ \\
\hline $\begin{array}{l}\text { Present value of } \\
\text { Softwood and Hardwood } \\
\text { Inventory Remaining } \\
\text { in } 2030\end{array}$ & $\begin{array}{l}\text { Northeast } \\
\text { Southeast } \\
\text { Other Regions } \\
\text { Alt Regions }\end{array}$ & $\begin{array}{l}1,066.1 \\
1,710.7 \\
3,218.8 \\
5,995.6\end{array}$ & $\begin{array}{r}30.8 \\
-401.6 \\
267.9 \\
-103.0\end{array}$ \\
\hline $\begin{array}{l}\text { Total Producers' } \\
\text { Surplus and Value of } \\
\text { the Inventory Remain- } \\
\text { ing in } 2030\end{array}$ & $\begin{array}{l}\text { Northeast } \\
\text { Southeast } \\
\text { Other Regions } \\
\text { All Regions }\end{array}$ & $\begin{array}{r}3,793.6 \\
12,431.1 \\
39,035.9 \\
55,267.6\end{array}$ & $\begin{array}{r}238.8 \\
-1,173.6 \\
1,739.0 \\
797.1\end{array}$ \\
\hline
\end{tabular}

(a) Base year is 1985 ; discount rate is $10 \%$; ending year is 2030 .

(b) Annual radial growth rates of trees in softwood and hardwood inventories in the Northeast and Southeast reduced by $15 \%$ and production of softwood lumber and plywood in the Northeast and North Central regions increased by $25 \%$. 
and in the value of the remaining inventory indicate that the welfare of timberland owners increases. These increases in welfare occur because stumpage prices are higher and harvest levels are the same or greater in all other regions.

The magnitude of the increase in total producers' surplus in stumpage markets is smaller for this case, however, than for the $15 \%$ growth reduction case in which the output of softwood lumber and plywood in the Northern regions is not adjusted (see Table 7.25 or 7.26). Producers' surplus in stumpage markets is smaller when the production of softwood lumber and plywood in Northern regions is increased because stumpage prices and harvest levels are lower in other regions. Putting the smaller increase for producers' surplus in stumpage markets together with the smaller increase for economic profit and small decrease in consumers' surplus in lumber and plywood markets leads to an interesting result. Adjusting the supply of softwood lumber and plywood in the Northern regions reduces the redistribution of welfare from consumers of lumber and plywood to producers of lumber and plywood and to timberland owners by about 800 million 1984 dollars. Changes in total economic surplus and profit for these two $15 \%$ growth reduction scenarios, however, are almost exactly the same: -1,028.5 million 1984 dollars for the production adjusted scenario and $-1,026.7$ million 1984 dollars for the scenario with no adjustment.

So far the results presented in Tables $7.27,7.28$, and 7.29 show that, due to growth reductions in the Northeast and Southeast, the welfare of 1) consumers of lumber and plywood in each demand region decreases, 2) producers of lumber and plywood in each supply region increases, 3) Southeastern timberland owners decreases, and 4) timberland owners in other supply regions increases. However, these results also indicate that the total welfare of the inhabitants in the Northeast and Southeast decreases, but increases for the inhabitants in the rest of the United States. For example, Table 7.27 shows that consumers' surplus in lumber and plywood markets for the Northeast demand region decreases by 584.1 million 1984 dollars. Tables 7.28 and 7.29 indicate that economic profit in lumber and plywood markets and producers' surplus in stumpage markets 
for the Northeast supply region increase by 112.6 and 238.8 million 1984 dollars, respectively. The change in total economic surplus and profit for the Northeast demand region is thus at least -232.7 million 1984 dollars. (a) For the Southeast supply region, Tables 7.28 and 7.29 indicate that economic profit in lumber and plywood markets increase by 361.9 million 1984 dollars, whereas producers' surplus in stumpage markets decreases by $1,173.6$ million 1984 dollars. The decrease in total economic surplus and profit in the Southeast supply region is thus at least 811,7 million 1984 dollars. (b) Adding the changes for the two regions shows that the total decrease in economic surpius and profit for the Northeast and Southeast to be at least 1,044.4 mi11ion 1984 dollars. But this decrease for the Northeast and Southeast is larger than the $1,028.5$ million 1984 dollar decrease in total economic surplus and profit for the United States as a whole, indicating that the change in total economic surplus and profit for the rest of the United States must be positive. Thus, tjmber growth reductions in the Northeast and Southeast supply regions redistributed welfare from those two regions to the rest of the United States.

\subsubsection{Summary of Welfare Analys is}

To summarize, the results of this analysis indicate that hypothetical reductions of timber growth in the Northeast and South east regions induce welfare changes in lumber, plywood, and stumpage markets throughout the United States. Specifically, total economic surplus and profit for the U.S. over the projection period decreases, but at a decreasing rate as timber growth in these two regions is reduced. Not all economic agents or regions are equally affected, however. The welfare of some agents and regions decreases, while the welfare of other agents and regions actually increases. Thus, although consumers of lumber and plywood in all regions suffer declines in consumers' surplus, economic profits obtained by producers of lumber and plywood in all regions, including the Northeast and Southeast, increase. Similarly, the welfare of private commercial timberland owners in all but the Southeast regions

(a) At least, because the Northeast supply region includes more than the Northeast demand region (see Figures 4.2 and 4.3 ).

(b) At least, because consumers' surplus in lumber and plywood markets in the "Southeast" demand region also decreases. 
increases as is indicated by the increases of producers' surplus in these regions' stumpage markets. In spite of the welfare increases for timberland owners or lumber and plywood producers in the Northeast and Southeast regions, the total welfare in these two regions declines. These declines are partially offset by increases of the total welfare in other regions of the United States. 
- 


\section{REFERENCES}

Adams, D. M. 1974. "Forest Products Prices and National Forest Timber Supply in the Douglas-Fir Region." Forest Science 20:243-259.

Adams, D. M. 1975. "A Model of Pulpwood Production and Trade in Wisconsin and the Lake States." Forest Science 21:301-312.

Adams, D. M. 1977. "Effects of National Forest Timber Harvest on Softwood Stumpage, Lumber, and Plywood Markets: An Econometric Analysis." Oregon State University, Forest Research Laboratory Bulletin 15, Corvallis, Oregon.

Adams, D. M. and R. W. Haynes. 1980. "The 1980 Softwood Timer Assessment Market Model: Structure, Projections, and Policy Simulations." Forest Science Monograph 22. Supplement to Forest Science 26(3):1-64.

Adams, D. M., J. Gourley, and R. W. Haynes. 1984. "Timber Assessment Market Model: Revised User's Guide." Forest Research Laboratory, Oregon State University, Corvallis, Oregon.

Belcher, D. M. 1981. "User's Guide to STEMS." General Technical Report NC-70. North Central Forest Experiment Station. USDA Forest Service, St. Paul, Minnesota.

Belcher, D. M., M. R. Holdaway, and G. J. Brand. 1982. "A Description of STEMS." General Technical Report NC-79. North Central Forest Experiment Station. USDA Forest Service, St. Paul, Minnesota.

Bellman, R. 1957. Dynamic Programing. Princeton University Press, Princeton, New Jersey.

Berck, P. 1979. "The Economics of Timber: A Renewable Resource in the Long-Run." Bell Journal of Econ. 10(2):447-462.

Beuter, J. H., K. N. Johnson, and H. L. Scheurman. 1976. "Timber for Oregon's Tomorrow, an Analys is of Reasonably Possible Occurrences." Forest Research Laboratory Bulletin 19. Oregon State University, Corvalilis, Oregon.

Binkley, C. S. and P. A. Cardellichio. 1981. "Modeling the Hardwood Sector: Issues and Prospect." Paper presented at the North American Conference on Forest Sector Models, December 2-4, 1981, Williamsburgh, virginia.

Brand, G. J. 1979. "A Generalized Forest Growth Projection System Applied to the Lakes States Region." General Technical Report NC-49. North Central Forest Experiment Station. USDA Forest Service, St. Paul, Minnesota. 
Brand, G. J. 1981. "Simulating Timber Management in Lake States Forests." General Technical Report NC-69. North Central Forest Experiment Station. USDA Forest Service, St. Paul, Minnesota.

Bruck, R. I. 1985. "Observations of Boreal Montane Forest Decline in the Southern Appalachian Mountains. Paper presented at the International Symposium on Acid Precipitation, September 15-20, 1985, Minett, Ontario, Canada.

Buchman, R. G. 1979. "Mortality Functions." In "A Generalized Forest Growth Projection System Applied to the Lakes State Region." General Technical Report NC-49. North Central Forest Experiment Station. USDA Forest Service, St. Paul, Minnesota.

Cardellichio, P. A. and J. Veltkamp. 1981. Demand for Pacific Northwest Timber and Timber Products. Pacific Northwest Regional Commission Forest Policy Project, OTympia, Washington.

Data Resources Incorporated (DRI). 1982. U.S. Timber Supply Study: Reassessing Timber Values in a Disinflationary Economy. Mc Graw Hill-Data Resources, Inc., Lexington, Massachusetts.

Duerr, W. A. 1960. Fundamentals of Forestry Economics. McGraw-Hill Book Co., Inc., New York, New York.

Fair, R. C. 1970. "The Estimation of Simultaneous Equation Models with Lagged Endogenous Variables and First-Order Serially Correlated Errors." Econometrice 38(3):507-516.

Gregory, G. R. 1960. "A Statistical Investigation of Factors Affecting the Market for Hardwood Flooring." Forest Science 6:123-134.

Gregory, G. R. 1965. "More on Factors Affecting the Market for Hardwood Flooring." Forest Science 11:200-203.

Hagenstein, P. R. and W. E. Bruner. 1982. "Timber and Wood Products Supply and Demand Analysis." Resource Issues, Inc., Wayland, Massachusetts.

Haynes, R. W. and D. M. Adams. 1985. Simulations of the Effects of Alternative Assumptions on Demand-Supply Determinants on the Timber Situation in the United States. Forest Economics Research Branch USDA Forest Service, Washington, D.C.

Holdaway, M. R. and G. J. Brand. 1983. "An Evaluation of the STEMS Tree Growth Projection System." Research Paper NC-234. North Central Forest Experiment Station. USDA Forest Service, St. Paul, Minnesota. 
Hotelling, H. 1931. "The Economics of Exhaustible Resources." Journal of Political Economy 39(2):137-175.

Hyde, W. F. 1979. "Implications of Economic Forest Management." Policy Analys is 5(2):29-312.

Hyde, H. F. 1980. Timber Supply, Land Allocation, and Economic Efficiency, John Hopkins University Press, Baltimore, Maryland.

Integrated Task Force on Acid Precipitation (ITFAP). 1982a. "Operating Research Plan for National Acid Precipitation Assessment Program."

Draft. Washington, D.C.

Integrated Task Force on Acid Precipitation (ITFAP). 1982b. "National Acid Precipitation Plan." Washington, D.C.

Jackson, D. 1980. The Microeconomics of the Timber Industry. Westview Press, Boulder, Colorado.

Jakes, P. J. and W. B. Simith. 1980. "Predicted Yields from Selected Cutting Prescriptions in Northern Minnesota." Research Paper NC-188. North Central Forest Experiment Station. USDA Forest Service, St. Paul, Minnesota.

Jakes, P. J. and W. B. Smith. 1983. "Michigan's Predicted Timber Yields." Research Paper NC-243. North Central Forest Experiment Station. USDA Forest Service, St. Paul, Minnesota.

Johnson, A. H., T. G. Siccama, D. Wang, R. S. Turner, and T. H. Barringer. 1981. "Recent Changes in Patterns of Tree Growth Rate in the New Jersey Pinelands: A Possible Effect of Acid Rain." J. Environ. Qual. $10: 427-430$.

Johnson, K. N. and H. L. Scheurman. 1977. "Techniques for Prescribing Optimal Timber Harvests and Investments Under Different Objectives--Discussion and Synthesis." For. Sci. Monograph 18.

Johnson, K. N., D. B. Jones, and B. Kent. 1980. "A User's Guide to the Forest Planning Model (FORPLAN)." Land Management Planning Branch, USDA Forest Service, Ft. Collins, Colorado.

Just, R. E. and D. L. Hueth. 1979. "Welfare Measures in a Multi-Market Framework." American Economic Review 69(5):947-954.

Just, R. E., D. L. Hueth, and A. Schmitz. 1982. Applied Welfare Economics and Public Policy. Prentice-Hall, Inc., Englewood Cliffs, New Jersey.

Kikki, P. and U. Vaisunen. 1969. "Detemination of the Optimal Policy for Forests Stands by Means of Dynamic Programming." 102(1):100-112. 
King, R. A. and F. S. Ho. 1972. "Reactive Programming: A Market Simulation Spatial Equilibrium Algorithm." Economic Research Report No. 28, North Carolina State University, Raieigh, North Carolina.

Lange, W. J. 1983. "An Econometric Model of Hardwood Lumber and Stumpage Markets in the United States." Ph.D. Thesis, Oregon State University, Corvallis, Oregon. $244 \mathrm{pp}$.

Larson, R. W. and M. H. Goforth. 1970. TRAS: A Computer Program for the Projection of Timber Volume. USDA Forest Serv. Agric. Handbook 377, Washington, D.C.

Larson, R. W. and M. H. Goforth. 1974. TRAS: A Timber Volume Projection Model. USDA Forest Serv. Tech. Bull. 1508, Washington, D.C.

Leuschner, W. A. 1973. "An Econometric Analysis of the Wisconsin Aspen Pulpwood Market." Forest Sci. 19:41-46.

Luppold, W. G. 1982. "An Econometric Model of the Hardwood Lumber Market." Research Paper NE-512. Northeastern Forest Experiment Station. USDA Forest Service, Broomal1, Pennsylvania.

Lyon, Kenneth. 1980. "Mining of the Forest and the Time Path of the Price of Timber." Journal of Environmental Economics and Management

$8(3): 330-344$.

Lyon, K. S. and R. A. Sedjo. 1982. "Discrete Time Optimal Control Algorithm for Analysis of Long-Run Timber Supply." RFF Discussion Paper D-96. Resources for the Future, Washington, D. $\hat{C}$.

Majne Forest Service. 1984. "Spruce-Fir Wood Supply/Demand Analysis." State of Maine Department of Conservation, Maine Forest Service, Augusta, Maine.

McCarthy, M. D. 1971. "Notes on the Selection of Instruments for Two-Stage Least Squares and K Class Type Estimators of Large Mode1s." Southern Economic Journal 23(1):251-259.

McDonough, J. M. and D. E. Park, Jr. 1975. "A Discrete Maximum Principle Solution to an Optimal control Formulation of Timberland Management Problems." Paper presented at the Western Forest Economics Association, annual conference, June 12-14, 1975, Wemme, Oregon.

McKillop, W. L. 1967. "Supply and Demand for Forest Products, an Econometric Study." University of California Agric. Exp. Sta., Hilgardia $38: 1-132$.

McKillop, W. L. 1969. "An Econometric Model of the Market for Redwood Lumber." Forest Science 15:159-170. 
Meyer, H. A. 1952. "Structure, Growth and Drain in Balanced Uneven-Aged Forests." Journal of Forestry 50(1):85-92.

National Acid Precipitation Program (NAPAP). 1984. Operating Research Plan. Washington, D.C.

Pearse, P. H. 1967. "The Optimum Forest Rotation." Forestry Chronicle $43(4): 178-195$.

Peterson, F. M. and A. C. Fisher. 1977. "The Exploitation of Extractive Resources." Economic Journal 87(4):681-721.

Pontryagin, L. S. 1962. The Mathematical Theory of Optimal Processes. Wi Iey-Interscience, New York, New York.

Raile, G. K. and W. B. Smith. 1982. "A Simulated Inventory Update: Wisconsin's 1979 Timber Resources." Research Paper NC-209. North Central Forest Experiment Station. USDA Forest Service, St. Paul, Minnesota.

Robinson, V. J., A. A. Montgomery, and J. D. Strange. 1980. "Economic Growth Goal for Timber in the Southeast." For. Prod. J. 31(1):69-76.

Samuelson, P. A. 1976. "Economics of Forestry in an Evolving Society." Economic Inquiry $14(4): 466-492$.

Schmidt, J. S. and P. L. Tedder. 1981. "A Comprehensive Examination of Economic Harvest Optionization Simulation Models." Forest Science $27(3): 523-536$.

Schuler, A. T. and W. B. Wallin. 1979. "An Econometric Model of the U.S. Pallet Market." Forest Service Research Paper NE-449. Northeastern Forest Experiment Station. USDA Forest Service, Broomall, Pennsylvania.

Seymour, R. S. 1984. "Forecasting Growth and Yield of 8udworm-Infested Forests." Cooperative Forestry Research Unit Report. College of Forest Resources, University of Maine, Orono, Maine.

Sheffield, R. M., N. D. Cost, W. A. Bechtold, and J. P. McClure. 1985. Pine Growth Reductions in the Southeast. U.S. Department of Agriculture, Forest Service, Southeastern Forest Experiment Station Resource Bulletin SE-83. Asheville, N.C.

Siccama, T. G., M. Bliss, and H. W. Vogelmann. 1982. Decline of Red Spruce in the Green Mountains of Vermont. Bulletin of the Torrey Botanical CTub 109: 163 .

Smith, V. R. 1982. "Economic Impact Analysis and Climate Change: A Conceptual Introduction." Climatic Change 4(1):5-22. 
Smith, W. B. and P. J. Jakes. 1981. "Projecting Treatment Opportunities for Current Minnesota Conditions." Research Paper NC-215. North Central Forest Experiment Station. IISDA Forest Service, St. Pau?, Minnesota.

Smith, W. B, R. A. Sowers, and P. J. Jakes. 1883. "Forest Treatment Opportunities for Eastern South Dakota 1980-1989." Research Note NC-305. North Central Forest Experiment Station. USDA Forest Service, St. Paul, Minnesota.

Takayama, T. and G. G. Judge. 1971. Spatial and Temporal Price and Allocation Models. North Holland Publishing Co., Amsterdam, The Netherlands.

Tedder, P. L. 1981. "Evaluation of Alternative inventory Projection Systems for National Assessments." Forest Research Lab, Oregon State University, Corvallis, Oregon.

Tedder, P. L., J. C. Gourley, and R. N. Lamont. 1984. "The Timber Resource Inventory Model (TRIM): A Timber Inventory Projection Model for National Timber Supply Projections and Policy Analysis." Forest Research Lab, Oregon State University, Corvallis, Oregon.

Tramel, T. E. 1965. "Reactive Programming--An Algorithm for Solving Spatial Equilibrium Problems." Mississippi Agricultural Experiment Station Technical Publication No. 9. Mississippi State University, State College, Missippi.

U.S. Forest Service. 1982. An Analys is of the Timber Situation in the United States 1952-2030. Forest Resource Report No. 23, Washington, D.C.

U.S. Forest Service. 1983. America's Renewable Resources: a Supplement to the 1979 Assessment of the Forest and Range Land Situation in the United States. FS-386, washington, D.C.

U.S. Forest Service. 1984. Forest Insect and Disease Conditions in the United States: 1983. Washington, D.C.

USDA Forest Service. 1958. Timber Resources for America's Future. Forest Resource Report 14. Washington, D.C.

USDA Forest Service. 1963. Timber Trends in Western Oregon and Western Washington. Research Paper PNW 5. Pacific Northwest Forest and Range Experiment Station, Portiand, Oregon.

USDA Forest Service. 1973. The Outlook for Timber in the United States. Forest Resource Report 20. Washington, D.C.

USDA Forest Service. 1977. The Nation's Renewable Resources--An Assessment. Forest Resource Report 21. Washington, D.C. 
USDA Forest Service. 1983. America's Renewable Resources: A Supplement to the 1979 Assessment of the Forest and Rangeland Situation in the United States.

Vaux, H. J. 1954. "Economics of the Young--Growth Suger Pine Resource." California Agric. Exp. Sta. Bulletin 738. Berkeley, California.

Vaux, J. J. 1969. "Public Timber Supply Alternatives in the Douglas Fir Region." Department of Printing, Oregon State University, Corvallis, Oregon.

Walker, J. L. 1971. "An Economic Model for Optimizing the Rate of Timber Harvesting." Ph.D. Thesis, University of Washington, Seattle, $117 \mathrm{pp}$. Diss. Abstr. 32(5):2276-A.

Walker, J. L. 1976. "ECHO: Solution Technique for a Nonlinear Economic Harvest Optimization Model." In Systems Analysis and Forest Resource Management. J. Meadows, B. Bare, K. Ware, and C. Row, (eds.),

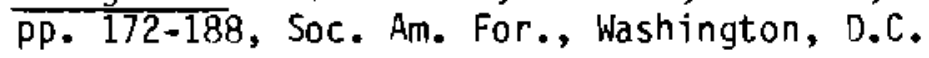

Willig, R. D. 1976. "Consumer's Surplus without Apology." American Economic Review 66(4):589-597. 

APPENDIX A

ECONOMIC FRAMEWORK 
APPENDIX A

ECONOMIC FRAMEWORK

\section{A.1 DETERMINATION OF THE OPTIMAL ROTATION PERIODS FOR AN EVEN-AGED STAND}

This appendix explores the problem confronting an individual timber owner who wants to determine the sequences of rotation periods, $t_{1}<t_{2}<$. . , which will maximize the net present value (NPV) of the timber sales from a fixed quantity of uniformly productive land. To facilitate the reader's understanding of this problem, we assume that 1) all trees will be harvested simultaneously (e.g., an even-aged rotation); 2) expected market conditions are such that only one species of tree will be grown on the land; 3) that the real opportunity cost of capital to the timber owner is expected to remain constant over time; 4) that the market for timber land is competitive; and 5) once trees are planted on the land, no additional management takes place until harvesting. While the assumptions made here are heroic, they can be relaxed. However, the problem then becomes so complex that the relevant parts of the analysis, which do not change, are obscured.

Under the conditions described above, the problem of the timber owner can be expressed in terms of the following problem. Find $t_{1}, t_{2},$. . which maximizes

$$
N P V=e^{-r t} 1\left[\hat{P}_{2} G\left(t_{1}\right)-c_{1}\right]+e^{-r\left(t_{1}+t_{2}\right)}\left[\hat{p}_{2} G\left(t_{2}\right)-c_{2}\right]+\ldots,
$$

where

$$
\begin{aligned}
r= & \text { the opportunity cost of capital or discount rate, expressed in } \\
& \text { real terms; } \\
P_{i}= & \text { the expected price of stumpage for the } i^{\text {th }} \text { harvest; } \\
\mathrm{G}\left(t_{i}\right)= & \text { the yield function which relates the volume of stumpage available } \\
& \text { for harvest to the age of trees being cut in the } i^{\text {th }} \text { rotation; }
\end{aligned}
$$


$C_{j}=C\left[G\left(t_{j}\right)\right]+k$ is the sum of harvesting costs, which varies with tree age (size), and planting cost ( $k$ ), which is fixed.

The problem described above is similar to the classical Faustmann model (Samuelson, 1976), except that future timber prices are not expected to remain constant. The effect of relaxing this assumption is that rotation length, which is fixed in the Faustmann model, now becomes variable. This creates certain practical problems in obtaining a solution to Equation (A.1). However, these problems are not difficult to overcome by applying an iterative process that will be discussed shortly.

\section{A.1.1 First-0rder Conditions}

The first-order conditions associated with the first two harvests in Equation (A.1) are:

$$
\begin{aligned}
& \left(\hat{p}_{1} \frac{d G}{d t_{1}}-\frac{d C}{d G} \frac{d G}{d t}\right) e^{-r t} 1=r e^{-r t_{1}}\left[\hat{p}_{1} G\left(t_{1}\right)-C_{1}\right]+ \\
& \operatorname{re}^{-r}\left(t_{1}+t_{2}\right)\left[\hat{p}_{2} G\left(t_{2}\right)-c_{2}\right]+\ldots \\
& \left(\hat{p}_{2} \frac{d G}{d t_{2}}-\frac{d C}{d G} \frac{d G}{d t_{1}}\right) e^{-r\left(t_{1}+t_{2}\right)}=r^{-r\left(t_{1} t_{2}\right)}\left[\hat{p}_{2} G\left(t_{2}\right)-C_{2}\right]+ \\
& -r\left(t_{1}+t_{2}+t_{3}\right)\left[\hat{p}_{3} G\left(t_{3}\right)-c_{3}\right]+\ldots
\end{aligned}
$$

Since the first-order condition for each rotation contains an infinite series of terms on the right-hand sides of Equations (A.2.1), (A.2.2), etc., no analytical solution to the problem is possible. In practice, this problem can be overcome by defining a planning period of, say, $N$ rotations which are of interest to the timber owner. The problem descrijed by Equation (A.1) can then be solved for a longer period, say $N+T$ rotations. The value of $T$ is determined by an iterative solution process: $T$ is chosen such that making the problem one 
period longer, $T+1$, has only a very small influence on the lengths of the optimal rotations during the planning period, $t_{1}, t_{2}, \ldots . t_{N}$.

\section{A.1.2 Explanation}

The first-order conditions described by Equations (A.2.1) and (A.2.2) provide rules which, when followed by the timber owner, will maximize the expected net present value of timber harvests over an appropriately defined planning period. The left-hand side of each first-order condition represents the discounted cost associated with delaying the $i^{\text {th }}$ harvest for an increment of time. This term measures the time rate of change in the discounted value of the timber owner's assets--the trees growing on his land during each separate rotation. The right-hand side of each first-order condition represents the net benefits that the timber owner will receive if he harvests his trees at $t_{j}$. For each rotation, these benefits are equal to the discounted interest that can be earned if the net revenue from the $i^{\text {th }}$ rotation is invested at interest rate $r$ plus the discounted interest that can be earned from each successive rotation. The former benefit is given by the first expression on the righthand side of each first-order condition, while the latter benefits, or soil expectation value, are represented by the sum of the remaining sequence of expressions.

The first-order conditions for this dynamic problem are conceptually similar to the first-order conditions of a static profit maximization problem in that they call for economic agents to equalize the marginal benefits of product sales with marginal costs. However, while the marginal cost pricing rule is maintained in the dynamic problem, there is a fundamental difference in the nature of the costs incurred. In the static problem, efficient production leads to the equation of marginal benefits with marginal costs in the product market. In the dynamic problem described above, the difference between marginal benefits and costs in the product market must be equalized with the opportunity cost of timber and timber land in the asset market. Consequently, production will not be efficient if the timber owner follows the rules of static efficiency because, in doing so, he ignores the opportunity costs that arise from being able to allow his assets to grow in value. 


\section{A.1.3 Replanning}

By appropriate definition of the planning horizon ( $N$ ) and terminal period (T), Equation (A.2) can be solved for the optimal values of $t_{1}, t_{2}, \ldots .$. , $t_{N}$. The choice equations for each rotation can be expressed as

$$
t_{i}=t_{i}^{*}\left(\hat{p}_{i}, \ldots, \hat{p}_{N}, r\right) \text { for all } i
$$

so that the projected rotation lengths will, in general, depend upon all expected future prices during the planning period and the opportunity cost of capital. This result is derived very simply from standard optimization theory.

In addition, conventional comparative static analysis (albeit in a dynamic setting) can be applied to Equations (A.2) to derive the signs of the partial derivatives of $P_{\hat{i}}, \ldots . ., P_{\hat{N}}$ and $r$ with respect to each $t_{i}$. Holding prices constant, it is easy to show that an increase in the discount rate will always shorten the length of rotations. This result follows, trivially, from the second-order conditions for a maximum and the symmetry of the Hessian matrix derived from the first-order conditions. The impact of changes in future prices on rotation length is more difficult to determine. This is due to the fact that as $r$ rises, the value of additional growth increases, but so does the opportunity cost of timber. As the discount rate increases, the soil expectation value rapidly approaches zero so that expected price increases for the future do not have much impact on rotation lengths in early periods. However, as timber harvests proceed through time (assuming the expected increase in price continues to hold), then rotation lengths probably will begin to decrease over time in order to take advantage of higher future prices.

The dependence of rotation length upon expected future prices is important because it provides the rationale for replanning on the part of the timber owner. Given new information about the variables which affect future timber prices, the timber owner can be expected to use this new information to recalculate $P_{\hat{1}}$, . . $P_{\hat{N}}$ and then solve Equations (A.2) to find a new vector of rotation lengths that are consistent with this new information. This process 
is repeated, annually, so that all available current information can be used on an iterative basis to harvest trees under the conditions specified by Equation (A.2).

\section{A.2 DERIVATIONS OF PERIODIC SUPPLY FUNCTIONS FOR STUMPAGE}

This appendix explores the derivation of the period supply functions for individual timber owners and for the stumpage market. The method described here is consistent with the derivation suggested first by Vaux $(1954,1969)$ and later adopted by Hyde $(1979,1980)$ in his long-run projections of U.S. timber supply.

To simplify the exposition, we define the total quantity of timber har vested in period $i$ as

$$
Q_{i}=\begin{array}{lllllll}
\Sigma & \Sigma & \Sigma & \Sigma \\
h & j & k & t
\end{array} Q_{i} h j k t
$$

where

$i=0, \ldots ., N$ represents the period in which a harvest takes place

$h=1, \ldots ., H$ defines individual timber owners in the market

$j=1, \ldots . . J$ defines the species being harvested

$k=1, \ldots . ., k$ defines the site class on which timber is grown

$t=1, \ldots ., T$ refers to the age class of trees.

In fact, the quantity of aggregate stumpage that is harvested varies along a number of other dimensions in addition to those described above. These include access class, management intensity, owner group, etc. However, the use of additional indices only serves to clutter up the analysis.

In constructing the periodic stumpage supply functions, we assume that timber owners conduct their harvests so as to maximize the net present value (NPV) of their timber sales from all acres of land at their disposal. Since it

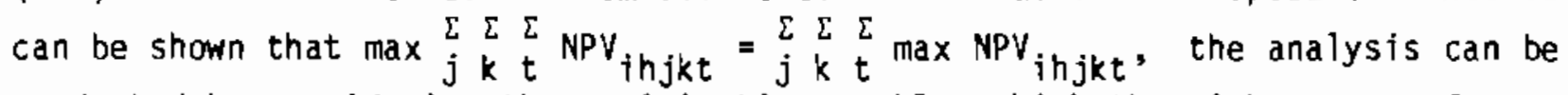
conducted by considering the optimization problem which the timber owner faces on each $A_{h j k t}$ acre of 1 and separately from all other acres. The method used to 
solve for the optimal rotation schedule for this type of problem is discussed in detail in Equations (A.1) through (A.3).

\section{A.2.1 Derivation of Owner Supply}

The information required to derive the periodic supply curve for the current period is contained in the first-order conditions of the optimal rotation problem (Equation A.2). Since the first-order conditions must hold for each optimal rotation, one can use these conditions to obtain the value for the minimum price that will cause the trees that are growing on a particular parcel of $l$ and to be harvested in the current period. For example, if the trees that are growing on a given parcel of land are 50 years old, there is some price at which the time rate of change in the net stumpage value of 50 yearmold trees will exactly equal the interest on that stumpage plus the discounted interest on the earnings obtained from future harvests on that parcel. The quantity of timber that will be harvested in the current period is simply equal to the total volume of harvestable timber that can be obtained from the 50 year-old trees that are growing on the parcel of land. Assuming that each $A_{h j k t}$ is unique, then this price/quantity combination will define a single point on the periodic supply curve of the individual timber owner for the current period. The process described above is then repeated for all parcels of 1 and on which trees are currently being grown. The locus of all resulting price/quantity combinations represents the periodic supply curve of the timber owner in the current period (Figure A.1).

The supply curve in Figure $A .1$ is drawn as a stepped function, owing to indivisibilities that are created by the assumption that all acres of a particular parcel of land will be harvested if it is profitable to do so. Note that, even when the price is zero, the owner will harvest $Q_{0}^{0}$ trees. This is the volunteer supply of timber. At price $P_{0}^{1}$, it will pay for the owner to harvest a quantity of stumpage equal to $Q_{0}^{1}-Q_{0}^{0}$. This stumpage is composed of older trees on the best site classes. The price inust then rise to $P_{0}$ before additional stumpage, equal to $Q_{0}^{2}-Q_{0}^{1}$, will be supplied to the market. This stumpage reflects harvests of younger trees on intermediate site classes. Finally at $P_{0}$, the youngest trees on the poorest site classes will be harvested. 


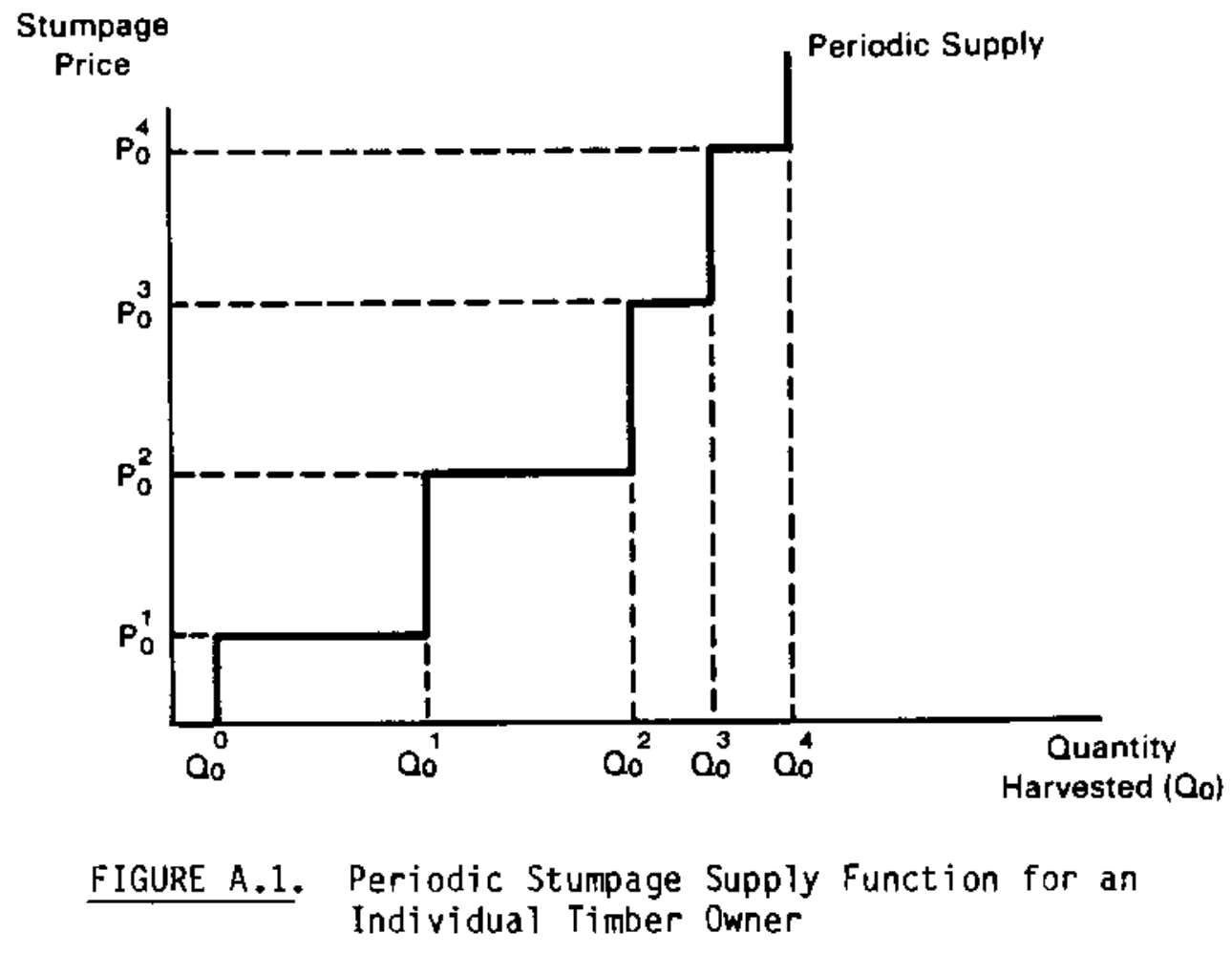

The periodic supply curve of the individual timber owner has two important properties that need to be stressed. The first is that it contains an extraordinarily rich amount of information about the composition of supply. This is because each point on the supply curve can be decomposed into specific acres of trees, by species, by site class, and by age. This feature is in marked contrast to the information contained in supply curves that are estimated by statistical methods using time series and/or cross-sectional data.

The second important feature of the supply curve is that it is stepped upward. This property of the supply curve is independent of the impact of static costs related to harvesting, poor access to lower quality sites, etc. Even if these costs vary directly with output, as one would expect, the supply curve for timber would still be upward sloping due to the increased opportunity cost associated with harvesting larger volumes of timber. This opportunity cost is derived from the change in the value of timber as an asset that grows over time, rather than as a commodity that can be bought and sold in the product market for stumpage. Hence, as shown in Figure A.l, the marginal cost condition associated with efficient production by the timber owner is to equate 
net price (e.g., the difference between product price and marginal harvesting costs) with the opportunity cost of timber. Neglecting opportunity costs will, in general, lead to a larger harvest and higher profits in the current period, but ultimately to a lower NPV over time than will be true if the individual owner takes the opportunity cost of timber into consideration.

\section{A.2.2 Derivation of Market Supply Functions}

The market supply curve for stumpage in the current period is derived by aggregating the supply curves for individual owners, horizontally. If the market contains a large number of producers and/or substantial heterogenity with respect to the composition of timber, the market supply function will be approximately continuous, or smooth. The periodic market supply function contains the same amount of information a do the supply curves of individual timber owners, except that the information about the composition of supply along each point on the curve can be disaggregated to an individual owner basis and then by species, site class, and age.

A hypothetical market supply curve is shown in Figure A.2. The supply curve is drawn specifically to illustrate the importance of including the opportunity cost of timber in the market clearing condition for efficient resource utilization in the product and asset markets. Thus, the curve $\hat{S}$ is drawn to show that the marginal cost of harvesting timber increases with the quantity of timber harvested. The curve $S$, on the other hand, illustrates the true supply curve for timber, taking into account the opportunity cost of timber. Given a market demand curve for stumpage, DD, efficient production occurs at point $M$ where the market clears at price $P$ and an associated harvest level of $Q$. At this point, the marginal harvesting cost is equal to $M C$ and the opportunity cost of stumpage $(\lambda)$ is equal to $P \rightarrow M C$.

If individual timber owners uniformly neglect the opportunity cost of their timber harvesting decisions and equate market price with the marginal harvesting cost, a different market equilibrium is achieved at point $M$ ', where $P^{\prime}=M C^{\prime}$. At this point, more timber is harvested, at a lower market price. Under these conditions, it can be shown that, while society is better off in 


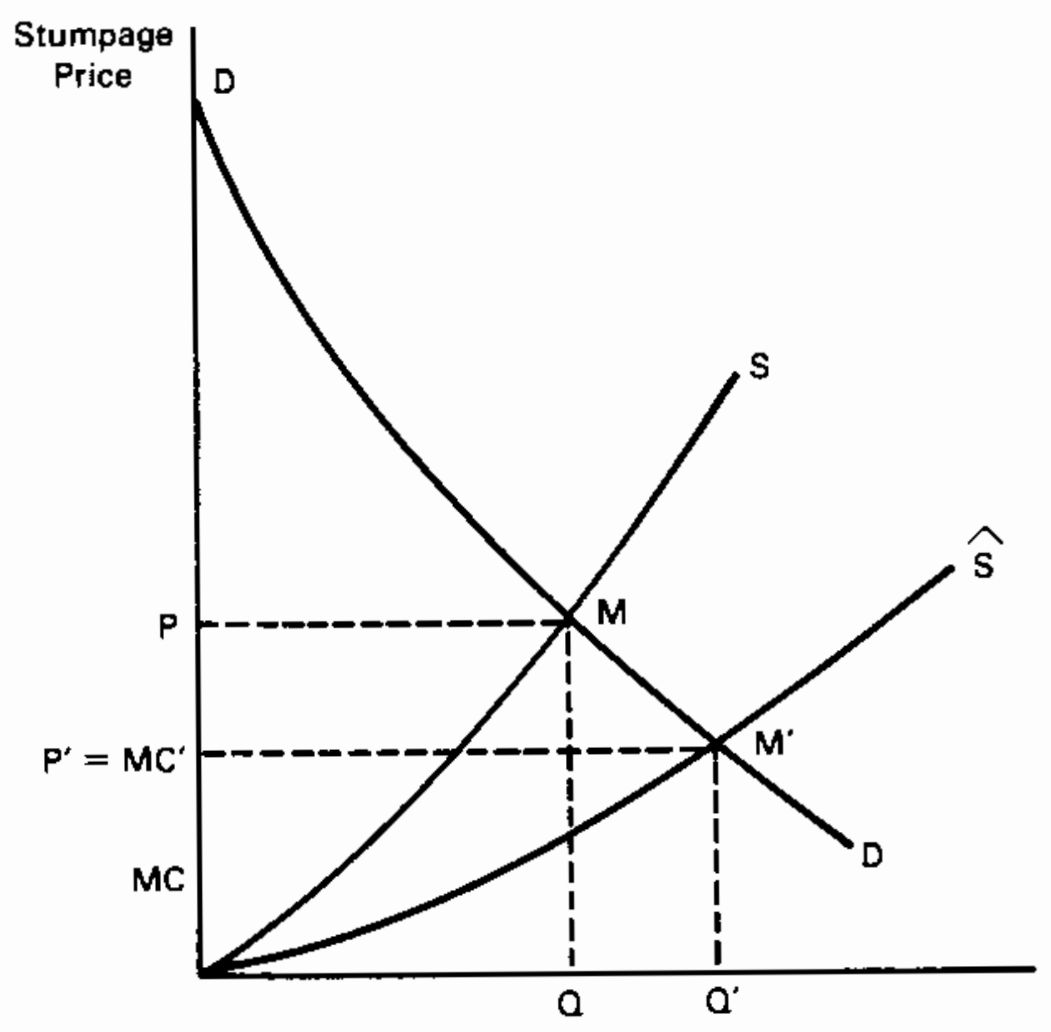

FIGURE A.2. Periodic Market Supply Function for Stumpage and Associated Market Equilibrium

the present as a result of this action, higher production in the current period will unduly penalize society in future periods when less timber is available for harvesting.

A second point that needs to be stressed about the periodic supply curves for the individual timber owner and the stumpage market is that both depend upon the objectives which individual timber owners pursue in managing the resource. The derivation in this appendix assumes that individual owners seek to maximize the expected net present value of their timber sales over some planning period. The points that are established on both types of supply from this hypothetical norm. Given that public timber owners rarely employ such an objective, and the almost incidental nature of timber profits to many large corporate timber owners, this point is far from trivial. Thus, any attempt to 
develop market supply curves based on the approach outlined above ant in some way come to terms with the differing objective functions that prevail across different classes of timber owners.

A final point of concern regards the influence of changes in exogenous factors on the periodic market supply curve. While the assumptions employed in this analysis do not provide an analytical solution for the periodic market supply curve, it can be shown that in the current period ( $i=0$ ):

$$
Q_{i}=q_{i}^{\star}\left(\hat{P}_{0}, \ldots, \hat{P}_{N}, r\right) \text { for all } i
$$

where $P_{i}=\lambda_{i}+\frac{\partial C}{\partial Q_{i}}$ is the marginal cost of stumpage. As indicated in Appen$\operatorname{dix} A$, the effects of changes in the discount rate and future prices on rotation length are ambiguous. Thus, the results discussed here must be viewed with some caution. Holding $P_{0}$ constant, an increase in $r$ will decrease the length of rotation periods and, in the current period, this will mean that the periodic supply curve will shift to the right, inducing a larger harvest. Over time, however, the resource base will be depleted more rapidly and the opportunity cost of timber will increase. Thus, smaller trees will have to be harvested at higher prices, and the supply curve will shift back to the left of the original supply curve, inducing a decrease in harvest.

An increase in future prices, holding $P_{0}$ constant, can be expected to have the opposite effect under most circumstances. Inttially, the supply curve will shift to the left as timber owners hold back their stumpage in anticipation of higher prices. However, as the resource base increases over time, the opportunity cost of timber will fall and the supply curve will shift back to the right. This will induce a larger supply response in some set of future periods than would otherwise be the case.

In both of these cases, changes in $r$ or $P_{t}$ directly influence harvest decisions that are made in the current period. These decisions, in turn, influence the size of the resource base available for future periods. As the stock of timber changes, this influences the opportunity cost of timber and causes the supply curve to shift in a direction consistent with the decreasing 
or increasing value of timber assets. Thus, changes in the opportunity cost of timber over time represent the single most important mechanism through which the market is able to communicate signals to timber owners about the impacts of their current behavior on the resource base and the resultant impacts of changes in the resource base on their future behavior.

\section{A.3 ECONOMIC IMPACTS OF ACID DEPOSITION DN ROTATION LENGTH}

Very little is known about the actual effects of acid deposition on the productivity of managed forests. While several empirical studies have linked acid deposition to forest die-back and reduced rates of growths, the results have not been powerful and the physical and chemical mechanisms which relate increases in acid deposition levels to forest productivity are not well understood at this time. Within that general framework, the purpose of this appendix is to illustrate how hypothetical increases in acid deposition over time may affect optimal rotation lengths, given assumptions about the relationship between tree growth and acid deposition.

For the purposes of this analysis, we assume that the effect of acid deposition on the growth can be modeled by the following growth function:

$$
Y\left(t_{i}, n\right)=G\left(t_{i}, Z(n)\right)
$$

where $Y$ stands for the harvestable volume of stumpage produced by the $t r e e ; t_{j}$ represents the length of rotation $i$; and $Z(n)$ is a function which relates the level of acid deposition to time $(n)$. We assume that $\frac{\partial G}{\partial Z}<0$ : acid deposition retards the growth and reduces the volume of stumpage available for harvest. In addition, we assume that $\frac{\partial Z}{\partial n}>0$ : acid deposition is increasing over time. If the level of $Z$ is established at the time of the first rotation, $t_{j}$ can be linked to $n$ so that Equation (A.6) can be expressed in terms of the rotation lengths in the optimal harvest scheduling problem. Thus,

$$
\begin{aligned}
& Y\left(t_{1}\right)=G\left(t_{1}, Z\left(t_{1}\right)\right) \text { for the first rotation, } \\
& Y\left(t_{2}\right)=G\left(t_{2}, Z\left(t_{1}+t_{2}\right)\right) \text { for the second rotation, }
\end{aligned}
$$


and so forth.

The optimal rotation problem can be expressed as follows:

find $t_{1}<t_{2}<$. . that maximizes

$$
\begin{array}{r}
\left.N P V=e^{-r t_{1}}\left[\frac{P_{1} G\left(t_{1}, Z\left(t_{1}\right)\right)-c}{e^{-r}\left(t_{1}+t_{2}\right)}\right] e^{-}\right] \\
{\left[P_{2} G\left(t_{1}, Z\left(t_{1}+t_{2}\right)\right)-c\right]+\cdots \cdot}
\end{array}
$$

This problem is identical to the optimal-rotation probien discussed in Appen$\operatorname{dix} A$, except that we assume that the planting and harvesting costs expressed by $C$ are fixed and not variable with tree growth. This modification does not change the basic properties of the problem and allows us to focus more clearly upon the impact of acid deposition on rotation length.

\section{A.3.1 First-0rder Conditions}

The first-order conditions for the first rotation in (A.8) can be expressed as:

$P_{1}\left[\frac{\partial G^{1}}{\partial t_{1}}+\frac{\partial G^{1}}{\partial Z} \frac{d Z}{d t_{1}}\right] e^{-r t_{1}}+P_{2}\left[\frac{\partial G^{2}}{\partial Z} \frac{d Z}{d t_{2}}\right] e^{-r\left(t_{1}+t_{2}\right)}+\ldots$.
$r\left[P_{1} G^{1}\left(t_{1}, Z\left(t_{1}\right)\right)-c\right] e^{-r t_{1}}+r\left[P_{2} G^{2}\left(t_{2}, Z\left(t_{1}+t_{2}\right)\right)-c\right] e^{-r\left(t_{1}+t_{2}\right)+\ldots}+$. 
where the superscripts on the growth functions are simply used for accounting convenience and do not imply any structural changes in the growth functions over time. The remaining first-order conditions are conceptually similar to Equation (A.9). The corresponding first-order condition without acid rain is

$$
P_{1} \frac{d G}{d t_{1}} e^{-r t} 1=r\left[P G\left(t_{1}\right)-c\right] e^{-r t} 1+r\left[P_{2} G\left(t_{2}\right)-c\right] e^{-r\left(t_{1}+t_{2}\right)}+\ldots .(A .10)
$$

\section{A.3.2 Explanation}

We first review the meaning of (A.10). The left-hand side of (A.10) is the change in discounted marginal stumpage value associated with an increment of tree growth. The left-hand side of (A.10) represents the discounted opportunity cost of the standing timber at each rotation in the future. This opportunity cost is equal to the time rate of change in net stumpage value, discounted back to the present. This represents the increase in the value of the stumpage that occurs as a result of delaying the harvest by a single time period. By equating this opportunity cost with the interest that can be earned from current and future harvests, the timber owner will be able to achieve the highest net present value possible from the resource base at his disposal.

The left-hand side of Equation (A.9) is conceptually similar to the lefthand side of Equation (A.10), except that the discounted opportunity cost is now changed (i.e., reduced) by

$$
P_{1}\left[\frac{\partial G^{1}}{\partial Z} \frac{d Z}{d t_{1}}\right] e^{-r t} 1+P_{2}\left[\frac{\partial G^{2}}{\partial Z} \frac{d Z}{d t_{2}}\right] e^{-r\left(t_{1}+t_{2}\right)}+\ldots
$$

This expression represents the impact of acid deposition over time on the opportunity cost of timber at the time the first rotation takes place. The impact on the current rotation is understandable. Acid deposition increases over time; therefore, the decision not to harvest the resource exposes the timber in the current rotation to more damaging levels of acid deposition. This effect carries into subsequent rotations because, by delaying the current 
rotation, one is also exposing future rotations to higher, and again, more damaging levels of acid deposition. Consequently, these external effects reduce the opportunity cost of timber. The effect is negative owing to

$$
\frac{\partial G}{\partial Z}<0
$$

Note that the right-hand sides of Equation (A.9) and Equation (A.10) are conceptually similar. Under most circumstances, however, one can expect that if rotation lengths were held constant across the two problems, the net revenue (and, hence, the interest earned) from each rotation would be lower (or never larger) in the problem with acid deposition present than in the problem with no acid deposition. This is based on the untested biological assumption that acid deposition reduces (or does not increase) the growth of timber at all ages.

The effects of a small change in the parameters of the damage function, $Z(t)$, on rotation lengths cannot be determined a priori without specific information about the structure of this functional relationship or the re?ationship between $G$ and $Z$, as well. Even then, the direction of this effect is ambiguous in most cases. The reason for this is that, while an increase in acid deposition, as modeled, reduces the opportunity cost of stumpage, it also reduces the interest that can be earned from the timber that is harvested in current and future rotations. The former effect on the cost of holding timber leads to shorter rotations, ceteris paribus. The latter effect on the benefits of harvesting timber leads to longer rotations, ceteris paribus, because it now takes timber longer to grow in va?ue. Since the two effects are in opposite directions, the net effect on rotation lengths is generally ambiguous. However, the total volume harvested must decrease (or never increase) if it is assumed that an increase in acid deposition, at any age, can never increase growth. 


\section{REFERENCES}

Hyde, W. F. 1979. "Implications of Economic Forest Management." Policy Analysis. 5(2):29-312

Hyde, W. F. 1980. Timber Supply, Land Allocation, and Economic Efficiency. Johns Hopkins University Press, Baltimore, Maryland.

Samuelson, P. A. 1976. "Economics of Forestry in an Evolving Society." Economic Inquiry. 14(4):466-492.

Vaux, H. J. 1954. Economics of the Young - Growth Sugar Pine Resource. California Agricultural Experiment Station Bulletin 738. Berkeley, California.

Vaux, J. J. 1969. Public Timber Supply Alternatives in the Douglas Fir Region. Department of Printing, Oregon State University, Corvallis, Oregon. 
APPENDIX B

TECHNICAL ADJUSTMENTS TO TAMM 


\section{APPENDIX B}

\section{TECHNICAL ADJUSTMENTS TO TAMM}

As discussed in Section 4.0, TAMM was selected to perform this assessment because of its suitability and availability. We did, however, make a few modifications and additions to the programing so as to obtain

- more consistent projections from the softwood and hardwood divisions

- more flexibility in the pulp production sector of the model

- more accurate short-run welfare measures in the softwood division

- short-run welfare measures in the hardwood division

- estimates of long-run economic profits.

This section focuses on the details of these modifications and additions.

\section{B.1 LINKING THE SOFTWOOD AND HARDWOOD DIVISIONS}

Although the two divisions of TAMM can be run independently, in fact each division uses information that is or can be generated by the other. As is shown in Figure B.l, for example, hardwood lumber and plywood projections are derived in the hardwood division--endogenously in the case of lumber and exogenously in the case of plywood. Coincident with the manufacture of these products, however, hardwood residues also are produced. Hardwood residues in turn are utilized in pulp production, which is modeled by the softwood division. Going in the opposite direction, the softwood division generates projections of hardwood pulpwood harvests, which in turn affect hardwood lumber forecasts through their impact on hardwood inventories. Obtaining consistent projections from the two divisions requires that this interdependence he taken into account.

To solve this problem, we use an iterative procedure. First, the hardwood division calculates annual estimates of hardwood residues. The initial estimates of hardwood residues (lagged one year) are then used by the softwood division to derive an initial set of hardwood pulpwood estimates. The hardwood pulpwood estimate in turn are used by the hardwood division to produce revised 


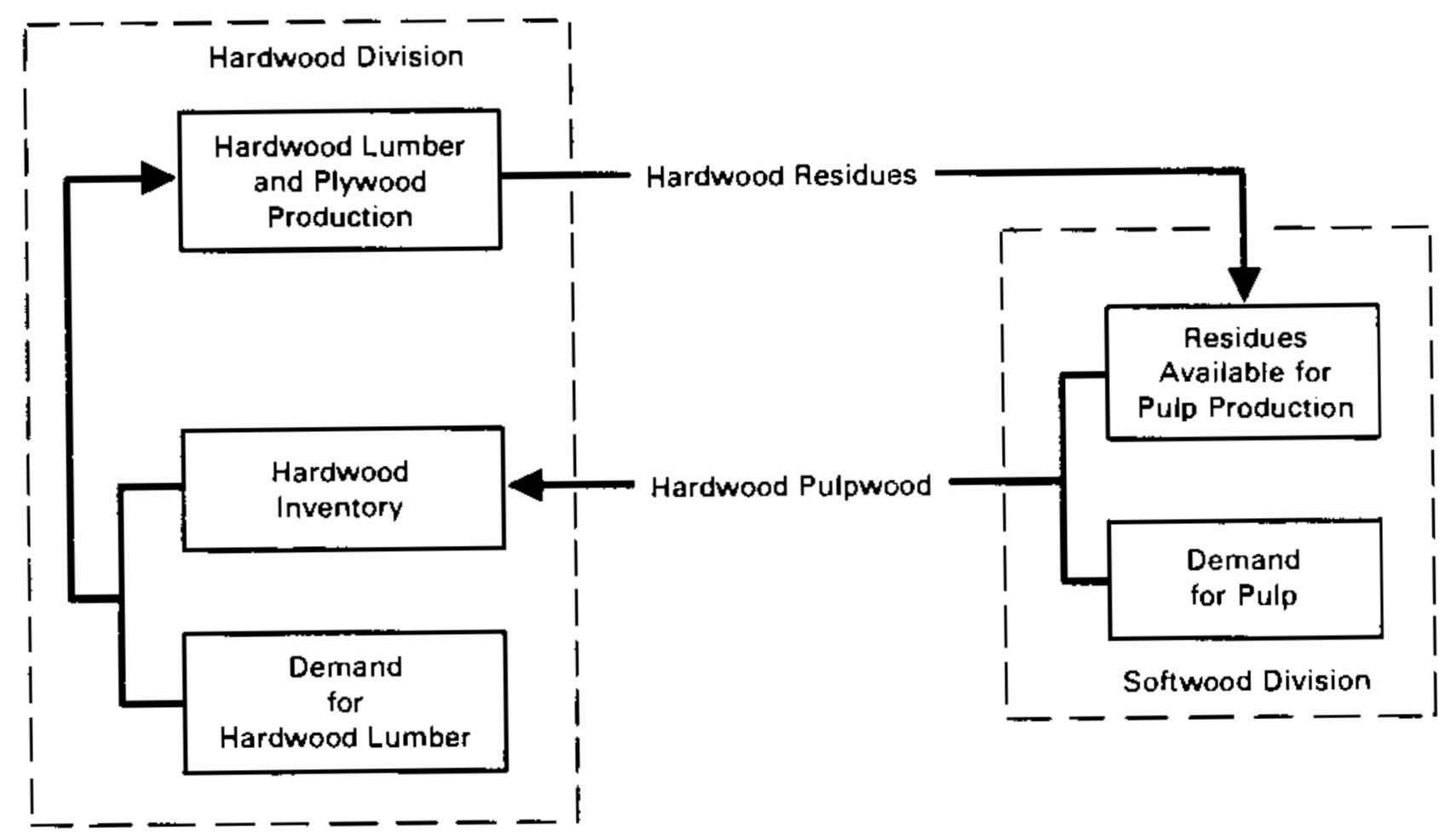

FIGURE B.1. Interdependence Between the Hardwood and Softwood Divisions of TAMM

estimates of hardwood residues. This interactive procedure continues until the differences between current and previous projections of hardwood residues and pulpwood are less than or equal to $5 \%$. This occurs after only two cycles.

In addition to obtaining consistency, linking the two divisions in this manner better simulates the interactions between the pulp and solid wood processing sectors of the economy. Also, events that occur in one division will over time affect events in the other division. Finally, these procedures allow us to simulate changes of the efficiency in solid wood processing in both divisions simultaneously.

\section{B.2 PULP PRODUCTION IN THE SOUTHEAST AND SOUTH CENTRAL REGIONS}

National pulp consumption in TAMM is exogenousiy predetermined. Pulp production is allocated to the supply regions primarily by using simple trend equations based on time. Originally, only the pulp allocations to the Northeast and Central regions were modified on the basis of endogenous price 
information. Because our analysis focuses on both the Northeast and Southeast regions, we devised a method that uses endogenous price information to modify the allocation of pulp production between the Southeast and South Central regions as well.

The trend equations are used to calculate preliminary pulp production shares for the following regions: 1) Pacific Northwest West, 2) Pacific Northwest East, 3) Pacific Southwest, 4) Rocky Mountains, 5) North, and 6) South. Additional share factors are used to allocate pulp production within the Northern and the Southern regions. The regional share factors used to allocate the North's pulp production between the Northeast and North Central regions are modified over the simulation period by softwood stumpage prices. First, a three-year moving average of these endogenously detemined prices is calculated for each region. These averages are then used to derive current regional share factors by modifying the factors which were used in the previous year to allocate pulp production between the Northeast and North Central regions. The effect is to move pulp production out of the region with relatively higher stumpage price into the region with relatively lower stumpage price.

In the original model, the regional share factors used to allocate the South's pulp production between the Southeast and the South Central regions were fixed. In our model, these share factors are modified over the simulation period by pulpwood prices. Pulpwood prices are in turn linked to the endogenously detemined prices for softwood sawtimber stumpage in the regions. The procedure is similar to that used in the North. Three-year moving averages of pulpwood prices are derived for both regions. These averages are then used to modify the regional share factors of the previous year so as to obtain current factors. As in the North, the effect is to move some pulp production out of the region with the higher pulpwood price into the region with the lower pulpwood price. To account for the historically higher pulpwood prices in the Southeast, movement of pulp production from the Southeast to the South Central region occurs only if the price per cubic foot of pulpwood in the Southeast is more than 4 cents higher than the pulpwood price in the South Central region.

Although this procedure introduces some additional flexibility between the Southeast and South Central regions, other problems remain. The model still 
lacks mechanisms that link stumpage prices with national pulp consumption. Also, the allocation of pulp production does not respond to differences in stumpage prices between the North and the South or between the East and the West. Thus, pulp production can move from the Southeast to the South Central region, but cannot move from the South to the North or West. Finally, only softwood prices are used to modify the allocation of pulp production within the Northern and Southern regions. Hardwood stumpage prices are assumed to have no effects on pulp production. This assumption may not be valid, especialiy in the Northern regions where the use of hardwoods in pulp production has increased during the past two decades.

\section{B.3 SHORT-RUN WELFARE MEASURES}

Three measures are used to analyze the potential welfare impacts of pollution stress. These measures consist of changes in:

- consumers' surpluses in product markets--which captures changes in the welfare of the buyers of Iumber and plywoods

- producers' surpluses in product markets--which measures changes in the welfare of lumber and plywood producers

- producers' surpluses in stumpage markets--which measures changes in the welfare of timberland owners.

The theoretical justification for the use of these measures was presented earlier in Section 3.2.1. The selection of producer's surplus in product markets to measure changes in the welfare of lumber and plywood deserves further comment. Just, Hueth and Schmitz (1984) have shown that changes in the welfare of firms can be measured entirely either in the market for the output of the firm or in any one input market. This implies directly an equivalence between changes in the producer surpluses of firms producing lumber and plywood as measured in these product markets and the consumer surpluses of these same firms as measured in regional stumpage markets. Since aggregate welfare is correctly measured across groups (e.g., consumers, producers, land owners, etc.) and not across markets, using both measures would result in double counting. 
The softwood division of TAMM contained most of the programming necessary to calculate these indices. Modification of the softwood division's calculations for the welfare indices were necessary because of adjustments made by Haynes and Adams in the division's product and stumpage markets. These adjustments, which are described in Haynes and Adams (1985) included 1) replacing the previous year's production level with capacity as a variable in the product supply equations (see Equation 4.4 above), and 2) modifying the stumpage supply equations in the Southern regions to reflect just the supply of sawtimber stumpage (see Section 4.3 above). The hardwood division on the other hand did not contain any programning to calculate welfare indices.

The use of capacity in the product supply equations introduces a set of constraints that did not appear in the original version of TAMM's softwood division. The possible effects of a capacity constraint in a product market are illustrated in Figure 8.2. Given the supply curve, S, and the demand curve, $D_{0}$, the equilibrium price and quantity are unambiguously $P_{0}$ and $Q_{0}$. The situation defined by the supply curve, $S$, and the demand curve, $D_{1}$, is more complicated. The equilibrium quantity is unambiguously $Q_{1}$, which is equal to

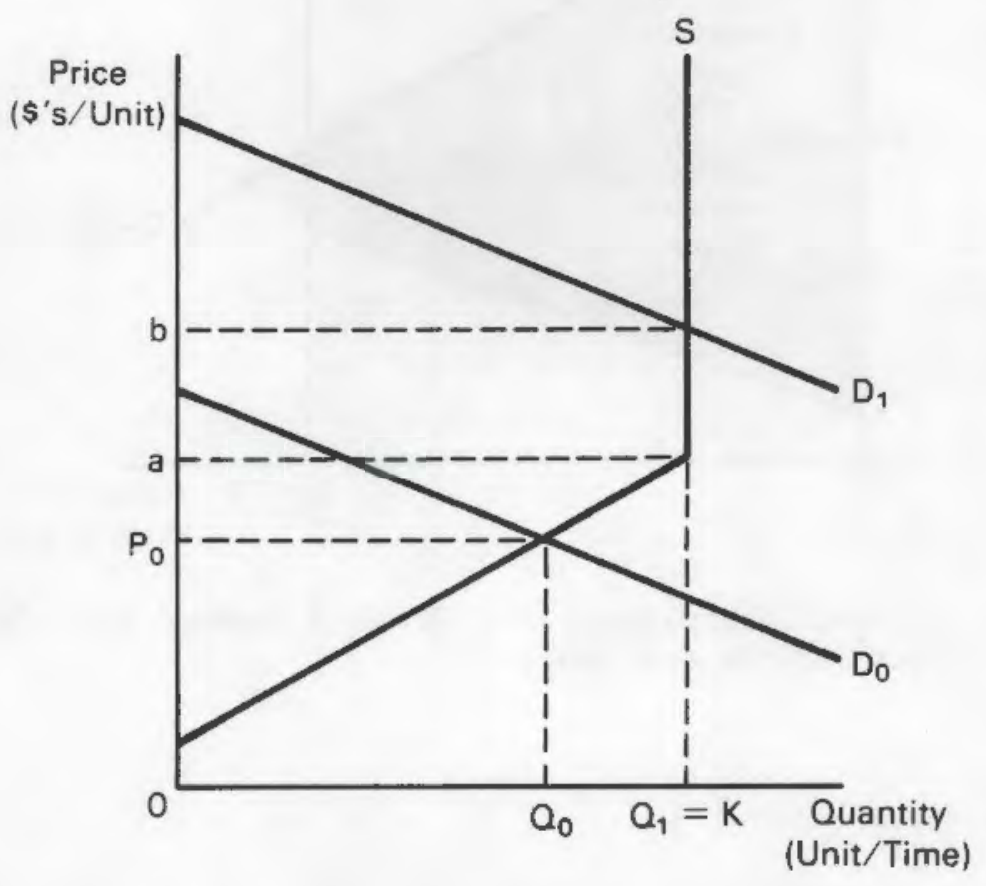

FIGURE B.2. The Effect of Capacity Constraints in Product Markets 
capacity, K. The equilibrium price, however, could be at point a, b or any point in between $a$ and $b$. The current welfare programming assumes that when the firms manufacturing forest products are operating at capacity, the equilibrium price is at point $b$.

Figure B.3 indicates the area representing producers' surplus in a product market under those conditions. When capacity constraints are in effect, the shape of the area may be trapezoidal rather than triangular (as is shown in Figure 3.1). To account for this possibility, the programming used to calculate producers' surpluses in product markets was modified. Note that the shape of the area representing consumers' surplus in the product market is still triangular. Hence, the programming used to calculate consumers' surpluses in product markets was not modified.

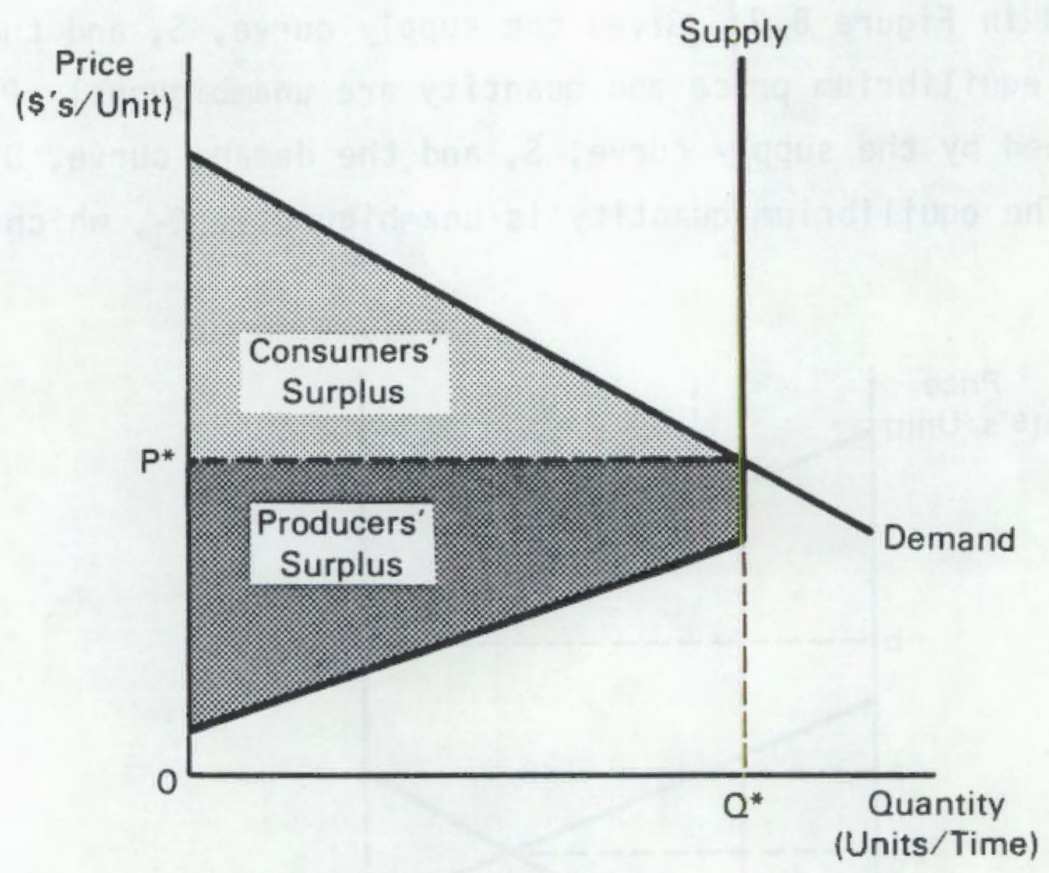

FIGURE B.3. Economic Surpluses in a Product Market when Capacity Constraints are Operable 
Similar situations are possible in stumpage markets as is shown in Figure B.4. Given the derived demand for stumpage, $d$, and the supply of stumpage, $s_{0}$, the equilibrium price and quantity are unambiguously $p_{0}$ and $q_{0}$. Also, given stumpage demand, $d$, and stumpage supply, $s_{1}$, the equilibrium quantity of stumpage is unambiguously $q_{1}(=k)$, which is the quantity of stumpage required when the firms manufacturing forest products are operating at capacity. The equilibrium price could be at point $a, b$ or any point in between $a$ and $b$. The current welfare programming assumes that when the firms manufacturing forest products are operating at capacity, the equilibrium price is at point a.

Figure B.5 indicates the area representing producers' surplus in a stumpage market under those conditions. Because the shape of this area continues to be triangular, the programming used to calculate producers' surpluses in stumpage markets was not modified to account for capacity constraints in product markets. The calculations for producers' surpluses in southern stumpage markets were modified, however, so that they now reflect only the impact of sawtimber sales. The programming for the other supply regions was used as

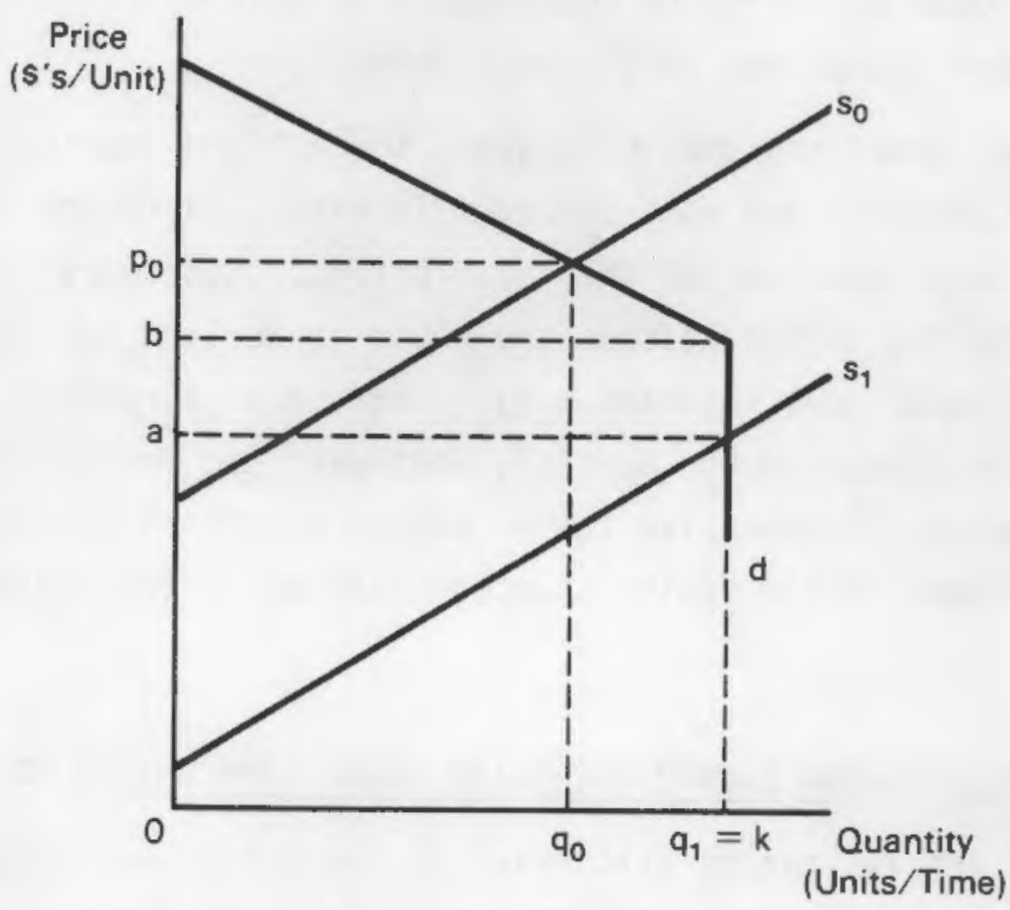

FIGURE B.4. The Effect of Product Capacity Constraints in Stumpage Markets 


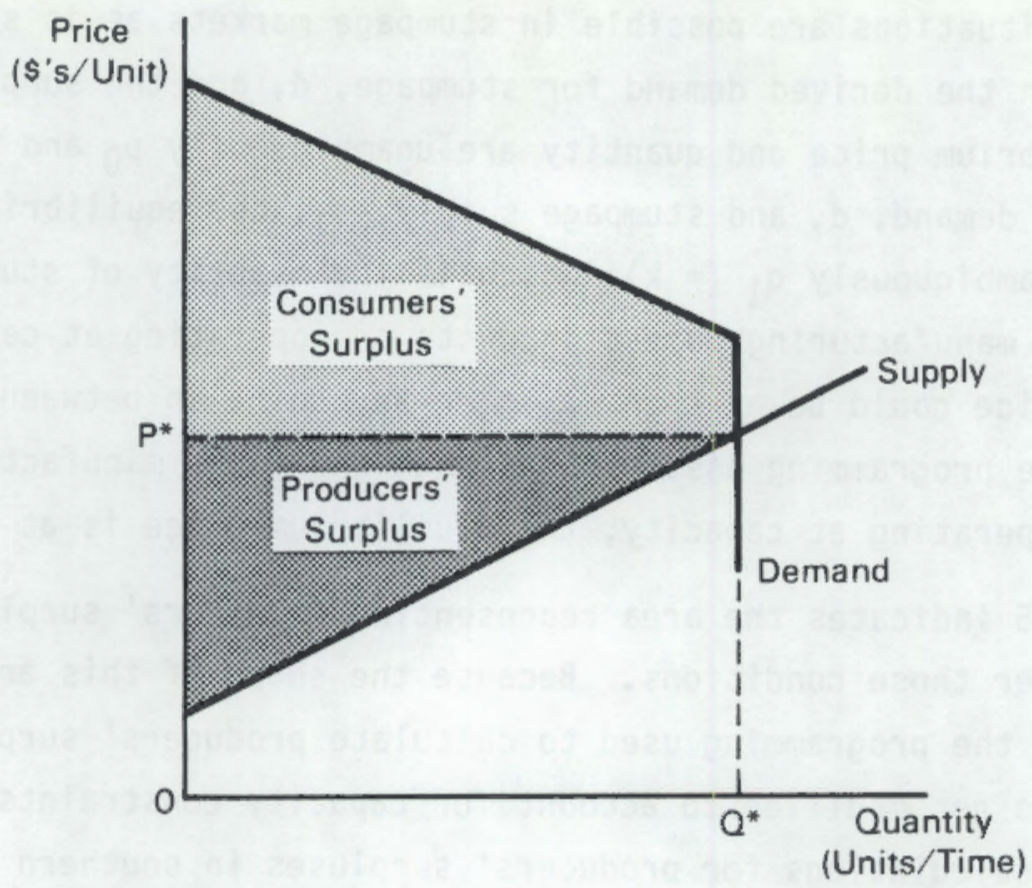

FIGURE B.5. Economic Surpluses in a Stumpage Market when Capacity Constraints are Operable

originally deyeloped and reflects the impacts of both sawtimber and pulpwood sales on producers' surpluses in stumpage markets.

The economic surpluses used to analyze the welfare implications of changes in the hardwood division are more straight forward. There are no capacity constraints to complicate any of the calculations. Consumers' surplus in the lumber market for the United States as a whole is derived for the divisions' national demand curve (see Equation 4.2). producers' surpluses in the lumber markets of the Northeast, North Central, Southeast and South Central regions are derived from their respective Tumber supply equations (see Equation 4.9). Producers' surpluses in the sawlog stumpage markets of the region also are derived.

\section{B.4 CALCULATING LONG-RUN ECONOMIC PROFITS USING TAMM OUTPUT FILES}

Producers' surplus can be calculated as the difference between total revenue and total variable costs, i.e., 


$$
P S_{t}=T R_{t}-T V C_{t}
$$

where

$$
\begin{aligned}
P S_{t} & =\text { producers' surplus in period, } t \\
T R_{t} & =\text { total revenue in period, } t, \text { and } \\
T V C_{t} & =\text { total variable cost in period, } t
\end{aligned}
$$

Economic profit, which includes a normal rate of return on capital investment and entrepreneurial ability as a cost, is defined as the difference between total revenue and total cost, i.e.,

$$
\pi_{t}=T R_{t}-T C_{t}=T R_{t}-T V C_{t}-T F C_{t}=P S_{t}-T F C_{t}
$$

where

$$
\begin{aligned}
\pi_{t} & =\text { economic profit in period, } t \\
T C_{t} & =\text { total cost in period, } t \\
T F C_{t} & =\text { total fixed cost in period, } t
\end{aligned}
$$

Fixed costs are costs incurred by the firms or industry for the use of inputs whose quantity cannot be changed during the period of time under consideration. Costs associated with an industry's plant and equipment are often cited as examples of fixed costs. A period of time in which some inputs are fixed is called a short-run period or simply the short-run. In TAMM, the supply curves which are used to calculate producers' surplus are short-run supply curves hecause capacity, i.e., plant and equipment, is assumed to be fixed during the period.

The long-run, on the other hand, is that period of time in which all inputs, including plant and equipment, are variable. In the long-run, firms within an industry can either increase or decrease their capacity and new firms can enter the industry or old firms can exit the industry. Thus, in the longrun, all costs are variable which implies that producers' surplus and economic profit converge. Because TAMM simulates capacity changes from one period to the next, economic profit is an appropriate welfare measure to use in this analysis. 
Unfortunately, economic profit for any one period cannot be directly estimated from TAMM output files because the data do not include values for total fixed cost or investment. It is possible, however, to estimate the change in economic profit from one period to the next using TAMM data. consider, for example, the situation depicted in Figure B.6. In Figure B.6, the line $S_{0}$ represents the short-run industry supply of lumber or plywood in the initial period and line $S_{1}$ represents the short-run industry supply of lumber or plywood in the subsequent period. Points $\left(Q_{0}^{*}, P_{0}^{*}\right)$ and $\left(Q_{1}^{*}, P_{1}^{*}\right)$ represent the equilibrium quantities and prices for the initial and subsequent period, respectively. For clarity, the demand curves for the two periods are not drawn.

Short-run producers' surplus in the initial period, $\mathrm{PS}_{0}$, is represented by area $\varsigma$. In terms of Equation B.1, area $\varepsilon$ must equal total revenue in the initial period, $T R_{0}$, minus total variable cost in the initial period, $T V_{0}$.

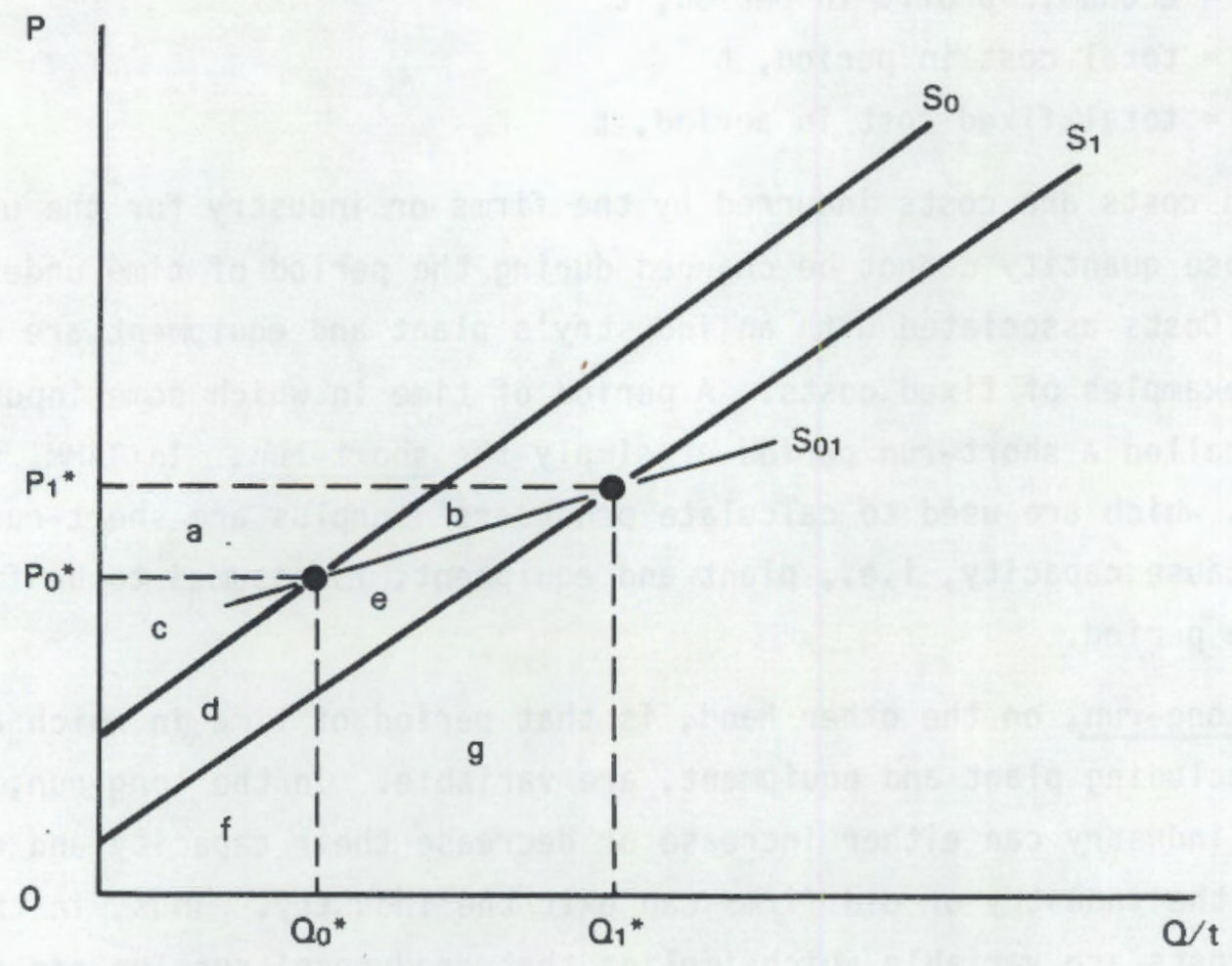

FIGURE B.6. Short-Run and Long-Run Product Supply Within a Two-Period Framework 
Total revenue in the initial period is represented in Figure $B .6$ by area $\underline{c}+\underline{d}+\underline{f}$ (or $p_{0}^{\star}$ times $Q_{0}^{\star}$ ). Total variable cost in the initial period is represented by area $d+f$, the area directly under the short-run industry supply curve in the initial period from the origin, 0 , to $Q_{0}^{\star}$. Thus, short-run producers' surplus in the initial period is:

$$
P S_{0}=T R_{0}-T V C_{0}=(c+d+f)-(d+f)=c
$$

IJsing a similar procedure, short-run producers' surplus in the subsequent period, ${ }^{P S_{1}}$, is

$$
P S_{1}=T R_{1}-T V C_{1}=a+b+c+d+e
$$

The change in producers' surplus over the two periods, $\triangle P S_{01}$, is

$$
\Delta P S_{01}=P S_{1}-P S_{0}=a+b+d+e
$$

Using Equation B.2, the change in economic profit over the two periods, $\Delta \pi_{01}$, $c$ an be defined as

$$
\Delta \pi_{01}=\pi_{1}-\pi_{0}=\left(P S_{1}-T F C_{1}\right)-\left(P S_{0}-T F C_{0}\right)=\Delta P S_{01}-\Delta T F C_{01}
$$

Equation B.5 shows that the change in economic profit over the two periods could be calculated from the change in producers' surplus if the change in total fixed cost over the two periods, $\Delta T F C_{01}$, were known. Let line $S_{01}$ in Figure B.5 represent the long-run supply curve for the industry over the two periods. Line $\mathrm{S}_{01}$ is a long-run supply curve because the industry has had time to adjust the amount of plant and equipment used to produce lumber or plywood. Therefore, the area e+g which is located under the long-run supply curve, $S_{01}$, and between $Q_{0}^{*}$ and $Q_{1}^{*}$ represents the change in total cost over the two periods, $\Delta \mathrm{TC}_{01}$, such that 


$$
\Delta T C_{01}=\Delta T V C_{01}+\Delta T F C_{01}=e+g
$$

where

$$
\begin{aligned}
\Delta T C_{01}= & \text { the change in total cost from the initial to subsequent } \\
& \text { period, } \\
\Delta T V C_{01}= & \text { the change in total variable cost from the initial to sub- } \\
& \text { sequent period, and. } \\
\Delta T F C_{01}= & \text { the change in total fixed cost from the initial to subse- } \\
& \text { quent period }
\end{aligned}
$$

Now the change in total variable cost over the two periods is

$$
\Delta T V C_{01}=T V C_{1}-T V C_{0}=(f+g)-(d+f)=g-d
$$

Using Equations 8.7 and B.8, the change in total fixed cost over the two periods is

$$
\Delta T F C_{01}=\Delta T C_{01}-\Delta T V C_{01}=(e+g)-(g-d)=d+e
$$

Substituting Equation B.9 into Equation B.6 yields the change in economic profit over the two periods:

$$
\Delta \pi_{01}=\Delta P S_{01}-\Delta T F C_{01}=(a+b+d+e)-(d+e)=a+b
$$

The change in economic profit over the two periods can he estimated from TAMM data if the long-run supply curve, $S_{01}$, between points $\left(Q_{0}^{*}, P_{0}^{\star}\right)$, and $\left(Q_{1}^{*}\right.$, $\left.P_{1}^{\star}\right)$ is assumed to be a straight line. In that case, the shape of area $\underline{a}+\underline{b}$ is a simple trapezoid and the change in economic profit over the two periods can be calculated as

$$
\Delta \pi_{01}=\left(P_{1}^{*}-P_{0}^{*}\right)\left(Q_{1}^{*}+Q_{0}^{*}\right) / 2
$$


Because TAMM output files do contain equilibrium price and quantity information about lumber and plywood for all periods, changes in economic profit can be obtained.

One advantage of this approach is that short-run industry supply curves are not required to estimate changes in economic profit. This is important because the Northeast and North Central supply regions lack short-run supply curves for softwood lumber and plywood. TAMM output files do, however, contain equilibrium price and quantity information for these products in the two regions. Changes in economic profit for these two supply regions are simply derived by using retait prices from their corresponding demand regions instead of mill level prices. This method is appropriate given two assumptions, both of which are implicit in TAMM: 1) all of the softwood lumber and plywood manufactured in each of the two supply regions is consumed locally in the corresponding demand region, and 2) the difference between retail prices and mill level prices within the regions, i.e., the intraregional transportation costs, are constant from one period to the next. (a)

The use of long-run, i.e., two-period, supply curves can be extended over the entire projection period to obtain a series of changes in economic profit such as that depicted in Table B.1. The structure of the equations used to define economic profit for each period indicates that if economic profit in the initial period, $\pi_{0}$, were known, then the economic profit in all subsequent periods could be derived. The present value of cumulative economic profit for the entire projection period then would be:

$$
I=\sum_{t=0}^{T} \delta t^{\pi} t
$$

(a) Let $p^{r}=p^{m}+p$ where $p^{r}$ is the retail price, $p^{m}$ is the mill level price, and $\rho$ is the intraregional transportation cost. The change in retail prices over two periods is:

$$
\Delta P_{01}^{r}=P_{1}^{r}-P_{0}^{r}=\left(P_{1}^{m}+\rho_{1}\right)-\left(p_{0}^{m}+\rho_{0}\right)=\left(P_{1}^{m}-p_{0}^{m}\right)+\left(\rho_{1}-\rho_{0}\right)=\Delta P_{01}^{m}+\Delta \rho_{01}
$$

which indicates that the change in retail prices equals the change in mill level prices if the change in intraregional transportation costs, $\Delta \rho_{01}$, is equal to zero. 
TABLE B.1. Changes in Economic Profit Within an Extended Multi-Period Framework

Change in

Economic Profit Economic Profit for Period, $t$

$$
\begin{aligned}
& \Delta \pi_{01}=\pi_{1}-\pi_{0} \quad \pi_{1}=\pi_{0}+\Delta \pi_{01} \\
& \Delta \pi_{12}=\pi_{2}-\pi_{1} \quad \pi_{2}=\pi_{1}+\Delta \pi_{12}=\pi_{0}+\Delta \pi_{01}+\Delta \pi_{12} \\
& \Delta \pi_{23}=\pi_{3}-\pi_{2} \quad \pi_{3}=\pi_{2}+\Delta \pi_{23}=\pi_{0}+\Delta \pi_{01}+\Delta \pi_{12}+\Delta \pi_{23} \\
& \Delta \pi_{T-1, T}=\pi_{T}-\pi T-1 \quad \pi_{T}=\pi_{T-1}+\Delta \pi T-1, T=\pi_{0}+\sum_{t=1}^{T} \Delta \pi_{t-1, t}
\end{aligned}
$$

where

$\Pi=$ the present value of cumulative economic profit, and

$\delta_{t}=$ the appropriate discount factor for period, $t$

If economic profit in the initial period is not known (as is the case in this analysis) then total economic profit, $\pi$, cannot be accurately estimated for a given scenario. In sensitivity analysis, however, accurate estimates of total economic profit for each scenario are not required to obtain accurate measures of the change in total economic profit induced by changing basic deteminants of economic behavior from one scenario to another so long as economic profit in the initial period is the same in alt scenarios. Assume, for example, that economic profit in the initial period is equal to some constant in all scenarios, $i . e ., \pi_{0}=k$, but that economic profit in the initial period is arbitrarily set equal to zero, $i . e ., \hat{\pi}_{0}=0$ such that $\pi_{0}=\hat{\pi}_{0}+k$. For the $i^{\text {th }}$ scenario, the true value of total economic profjt, $\pi^{i}$, can be represented by

$$
I^{i}=\sum_{t=0}^{T} \delta_{t}\left(\hat{\pi}_{t}^{i}+k\right)=\sum_{t=0}^{T} \delta \hat{\pi}^{i}+k \sum_{t=0}^{T} \delta t
$$


where

$\sum_{t=0}^{T} \delta t^{\pi}+{ }^{i}$ represents the value of total economic profit actually

$\mathrm{k} \sum_{\mathrm{t}=0}^{T} \delta \mathrm{t}$ is the error.

Similarly, the true value of total economic profit for the $j^{\text {th }}$ scenario, $\Pi^{j}$, is

$$
\Pi^{j}=\sum_{t=0}^{T} \delta_{t}\left(\hat{\pi}_{t}^{j}+k\right)=\sum_{t=0}^{T} \delta \hat{\pi}_{t}^{j}+k \sum_{t=0}^{T} \delta_{t}
$$

The true value of the change in economic profit between the two scenarios, $\Delta \Pi^{i j}$, is

$$
\begin{aligned}
\Delta \Pi^{i j} & =\Pi^{j}-\Pi^{i}=\left(\sum_{t=0}^{T} \delta t^{\pi_{t}^{j}}+k \sum_{t=0}^{T} \delta_{t}\right)-\left(\sum_{t=0}^{T} \hat{\hat{t}}^{i} \mathbb{t}+k \sum_{t=0}^{T} \delta\right) \\
& =\sum_{t=0}^{T} \delta \hat{\pi}_{t}^{j}-\sum_{t=0}^{T} \delta \hat{t}^{i} t=\hat{\Pi}^{j}-\hat{\Pi}^{i}
\end{aligned}
$$

Equation B.15 thus shows that an accurate measure of the change in total economic profit between two scenarios can be estimated even though accurate measures of total economic profit for any one scenario cannot be estimated. 


\section{APPENDIX $C$}

SIMULATED ECONOMIC IMPACTS OF VARIOUS POLLUTION STRESS SCENARIOS 
APPENDIX C

\section{SIMULATED ECONOMIC IMPACTS OF VARIOUS POLLUTIDN STRESS SCENARIOS}

This appendix contains simulation results for a base case and for various reduced growth scenarios. Provided for comparative purposes are the results of the alternative base case scenarios which assume lower housing starts, greater efficiency in solid wood processing, or faster conversion of commercial timber1 and to other 1 and uses in the future than do the base case. The results for both sets of scenarios include growing stock inventories, harvests, stumpage prices, lumber and plywood production, 1 umber and plywood consumption, wholesale price indices for lumber and plywood, and economic surpluses. Short descriptions of the scenarios are given below. For more details about the scenarios, see Section 6.0 .

The base case assumptions used in this analysis are, for the most part, consistent with those used by the U.S. Forest Service (1983) and reported by Haynes and Adans (1985). Major assumptions include:

- future housing starts at 1.7 million units in $1990,1.9$ million units in 2000 , and 1.5 million units in 2030

- a $10 \%$ increase in solid wood processing efficiency over the projection period

- 319 mitlion acres of commerciat timberland in 2030.

Differences between the base case results derived in this analys is and those presented by Haynes and Adams (1985) are due to differences in modeling pulpwood. Compared to the base case described by Haynes and Adams (1985), the base case used in this analysis:

- assumes that less pulp will be consumed nationally in the future

- uses a different method of allocating pulp production within the southern regions 
- assumes that more nonwood growing stock (e.g., branches, roots, or bark) will be used in pulp production

- uses a procedure simitar to that described by Adams, Gourley, and Haynes (1981) to ensure consistent flows of residues and pulpwood between the softwood and hardwood models.

The possible physical effects of pollution were simulated by reducing the radial growth rates used to model the growing stock inventories in the base case. To compensate for the lack of any specific evidence linking pollution with decreases in radial growth rates of some species of trees in the Northeast and Southeast regions, nine reduced growth scenarios were devised. Radial growth rates are uniformly reduced by 10,15 , or $20 \%$ in each case. In some cases, growth rates are reduced in just one region, while in others, growth rates are reduced in both. In most cases, the growth rates of both softwood and hardwood inventories are reduced, but two scenarios simulate growth reductions that are confined to either one or the other wood types. In two cases, possible responses of lumber and plywood producers in the Northeast and North Centrat regions to changes in product and/or stumpage prices are simulated. The results of these scenarios, therefore, reflect a number of different assumptions about the severity of, location of, and species susceptibility to pollution-induced stress and thereby depict a wide range of possible futures. specifically, the cases are:

Case 1: Annual radial growth rates of softwood and hardwood growing stock in the Northeast region reduced by $15 \%$. Softwood lumber and plywood production projections in the Northeast and North Central supply regions reduced approximately $15 \%$ by 2030 to simulate possible adjustments by producers to product and stumpage price changes.

Case 2: Annual radial growth rates of softwood and hardwood growing stock in the Northeast and Southeast regions reduced by $15 \%$. Softwood lumber and plywood production projections in the Northeast and North Central supply regions increased approximately $25 \%$ by 2030 to simulate possible adjustments by producers to product and stumpage price changes. 
Case 3: Annual radial growth rates of softwood and hardwood growing stock in the Northeast region reduced by $15 \%$.

Case 4: Annual radial growth rates of softwood and hardwood growing stock in the Southeast region reduced by $15 \%$.

Case 5: Annual radial growth rates of softwood and hardwood growing stock in the Northeast and Southeast regions reduced by $10 \%$.

Case 6: Annual radial growth rates of softwood and hardwood growing stock in the Northeast and Southeast regions reduced by $15 \%$.

Case 7: Annual radial growth rates of softwood and hardwood growing stock in the Northeast and Southeast regions reduced by $20 \%$.

Case 8: Annual radial growth rates of hardwood growing stock in the Northeast and Southeast regions reduced by $15 \%$.

Case 9: Annual radial growth rates of softwood growing stock in the Northeast and Southeast regions reduced by $15 \%$.

The simulation results for the base case and Cases 1 through 9 are contained in Table C.l.

Three alternative base case scenarios were devised for comparative purposes. These scenarios represent a range of alternative assumptions about the values of traditional key variables which will affect future levels of economic activity in stumpage and forest product markets. By comparing the results of the alternative base case scenarios with the base case and reduced growth cases, one can determine the relative potential importance of pollution-induced impacts on economic activity. The scenarios are:

Low Housing: The base case modified by projecting housing starts at 1.4 million units in $1990,1.5$ million units in 2000 , and 1.0 million units in 2030. Housing construction is a major determinant of the demand for softwood lumber and plywood.

Increased Efficiency: The base case modified by assuming a $25 \%$ increase in lumber and plywood processing efficiency over the projected period. The increase is staged in the progression $9 \%, 7 \%$, $5 \%, 3 \%$, and $1 \%$ per decade for both softwood and hardwood products. 
Reduced Area: The base case modified by projecting 279 million acres of commercial timberland at 2030. Both softwood and hardwood timberlands are affected.

The simulation results for these three alternative base cases are presented in Table C.2. 
TABLE C.1. Simulated Effects of Various Scenarios on Growing Stock Inventories, Harvests, Stumpage Prices, Lumber and Plywood Production, Lumber and Plywood Consumption, the Wholesale Price Indices of Lumber and Plywood, and Economic Surpluses

\begin{tabular}{c} 
Item and Year \\
\hline Softwood Inventory Northeast \\
1990 \\
2000 \\
2010 \\
2020 \\
2030
\end{tabular}

Softwood Inventory Southeast 1990

2000

2010

2020

2030

$\frac{\begin{array}{c}\text { Unit of } \\ \text { Measurement }\end{array}}{\text { Billion cubic feet }}$

Billion cubic feet

West
1990
2000
2010
2020
2030

Sof twood Inventory Lower 48 States

1990

2000

2010

2020

2030

Hardwood Inventory Northeast

$$
\begin{aligned}
& 1990 \\
& 2000 \\
& 2010 \\
& 2020 \\
& 2030
\end{aligned}
$$

\begin{tabular}{|c|c|c|c|}
\hline \multicolumn{4}{|c|}{ Reduced Growth Scenarios } \\
\hline Case 1 & Case 2 & Case 3 & Case 4 \\
\hline $\begin{array}{l}34.10 \\
36.41 \\
37.27 \\
36.95 \\
35.71\end{array}$ & $\begin{array}{l}34.07 \\
36.23 \\
36.83 \\
36.13 \\
34.39\end{array}$ & $\begin{array}{l}34.08 \\
36.36 \\
37.16 \\
36.70 \\
35.26\end{array}$ & $\begin{array}{l}36.49 \\
40.23 \\
42.03 \\
42.30 \\
41.43\end{array}$ \\
\hline
\end{tabular}

Billion cubic feet

8 illion cubic feet

Billion cubic feet

\begin{tabular}{c} 
Base \\
Case \\
\hline \\
36.49 \\
40.23 \\
42.03 \\
42.29 \\
41.42
\end{tabular}

55.22

60.06

61.30

59.67

56.70

55.21
60.00
61.20
59.58
56.61

48.16

47.93

44.85

40.31

35.04

55.22

60.06

61.31

59.71

56.73

48.16

47.94

44.83

40.27

71.59
70.66
69.87
68.00
66.27

71.59
70.74
69.90
67.95

71.51

70.29

68.76

65.94

66.17

62.96

$\begin{array}{ll}71.59 & 71.50 \\ 70.66 & 71.23 \\ 69.87 & 68.61 \\ 67.97 & 65.73\end{array}$

\subsection{2}

237.13

238.24

229.88

217.07

223.18
233.20
233.20
224.11

215.97

220.12

213.85

198.45

178.18

223.17

233.10

233.04

223.75

210.17

215.44

225.32

70.47
75.57
76.50
74.49
71.06

66.84
69.72
69.19
66.08

66.84

66.84

69.77

69.78

69.40

66.58

61.63

62.53

66.37

62.08

186.30

70.47 75.56 76.48 74.46 71.01 
TABLE C.1. Simulated Effects of Various Scenarios on Growing Stock Inventories, Harvests, Stumpage Prices, Lumber and Plywood Production, Lumber and Plywood Consumption, the Wholesale Price Indices of Lumber and Plywood, and Economic Surpluses

\begin{tabular}{|c|c|c|}
\hline \multicolumn{3}{|c|}{ Item and Year } \\
\hline Hardwood & Invento & $\begin{array}{l}\text { ry Southeas } \\
1990 \\
2000 \\
2010 \\
2020 \\
2030\end{array}$ \\
\hline Hardwood & Invento & $\begin{array}{l}\text { ry East } \\
1990 \\
2000 \\
2010 \\
2020 \\
2030\end{array}$ \\
\hline Sof twood & Harvest & $\begin{array}{l}\text { Hortheast } \\
1990 \\
2000 \\
2010 \\
2020 \\
2030\end{array}$ \\
\hline Softwood & Harvest & $\begin{array}{l}\text { Southeast } \\
1990 \\
2000 \\
2010 \\
2020 \\
2030\end{array}$ \\
\hline Softwood & Harvest & $\begin{array}{l}\text { West } \\
1990 \\
2000 \\
2010 \\
2020 \\
2030\end{array}$ \\
\hline
\end{tabular}

$\frac{\begin{array}{l}\text { Unit of } \\ \text { Measurement }\end{array}}{\text { Billion cubic feet }}$

Billion cubic feet

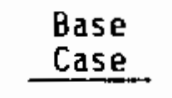

\subsection{8 \\ 66.16 \\ 68.65 \\ 68.85 \\ 68.41}

248.31

267.50

272.56

267.53

259.78

Billion cubic feet

$$
\begin{aligned}
& 0.57 \\
& 0.71 \\
& 0.85 \\
& 0.96 \\
& 1.05
\end{aligned}
$$

Billion cubic feet

2.74

3.07

\begin{tabular}{|c|c|c|c|}
\hline Case I & Case ? & Case 3 & Case 4 \\
\hline $\begin{array}{l}60.28 \\
66.14 \\
68.63 \\
68.82 \\
68.35\end{array}$ & $\begin{array}{l}55.98 \\
58.49 \\
58.08 \\
56.00 \\
53.64\end{array}$ & $\begin{array}{l}60.28 \\
66.14 \\
68.63 \\
68.80 \\
68.35\end{array}$ & $\begin{array}{l}55.98 \\
58.50 \\
58.11 \\
56.05 \\
53.75\end{array}$ \\
\hline $\begin{array}{l}244.59 \\
261.17 \\
264.23 \\
257.36 \\
247.64\end{array}$ & $\begin{array}{l}240.27 \\
253.54 \\
253.64 \\
244.13 \\
231.91\end{array}$ & $\begin{array}{l}244.59 \\
261.17 \\
264.23 \\
257.40 \\
247.79\end{array}$ & $\begin{array}{l}244.01 \\
259.79 \\
261.82 \\
253.97 \\
243.51\end{array}$ \\
\hline
\end{tabular}

3.21

3.23

Billion cubic feet
Reduced Growth Scenarios

$\begin{array}{llll}0.55 & 0.56 & 0.56 & 0.57 \\ 0.67 & 0.70 & 0.68 & 0.71 \\ 0.79 & 0.83 & 0.81 & 0.85 \\ 0.90 & 0.95 & 0.92 & 0.96 \\ 0.98 & 1.05 & 1.01 & 1.05\end{array}$

\subsection{0}

2.76

3.07

3.22

3.24

2. 32

2.60

2.76

2.75

2.70

2.40

2.74

3.08

3.21

3.25

2.32

2.60

2.76

2.76

2.71
4. 32

4.13

4. 38

4.47

4.52
4.35

4.32

4.14

4. 41

4.55

4.61

4.36

4.36
4.15

4. $36 \quad 4.40$

$\begin{array}{ll}4.45 & 4.45 \\ 4.50 & 4.61\end{array}$ 
TABLE C.1. Simulated Effects of Various Scenarios on Growing Stock Inventories, Harvests, Stumpage Prices, Lumber and Piywood Production, Lumber and Plywood Consumption, the Wholesale Price Indices of Lumber and Plywood, and Economic Surpluses

\begin{tabular}{|c|c|c|c|c|c|c|c|}
\hline & & Unit of & Base & & sced Gro & h Scenar & \\
\hline Item and & Year & Measurement & Case & Case I & Case? & Case 3 & Case 4 \\
\hline Sof twood Harvest & & Billion cubtc feet & & & & & \\
\hline & $\begin{array}{l}1990 \\
2000 \\
2010 \\
2020 \\
2030\end{array}$ & & $\begin{array}{l}10.32 \\
11.08 \\
12.23 \\
12.81 \\
12.97\end{array}$ & $\begin{array}{l}10.31 \\
11.06 \\
12.20 \\
12.77 \\
12.93\end{array}$ & $\begin{array}{l}10.29 \\
10.98 \\
12.07 \\
12.63 \\
12.71\end{array}$ & $\begin{array}{l}10.31 \\
11.07 \\
12.21 \\
12.78 \\
12.97\end{array}$ & $\begin{array}{l}10.29 \\
10.98 \\
12.04 \\
12.62 \\
12.68\end{array}$ \\
\hline Hardwood Harvest & $\begin{array}{l}\text { Northeast } \\
1990 \\
2000 \\
2010 \\
2020 \\
2030\end{array}$ & Billion cubic feet & $\begin{array}{l}0.96 \\
1.29 \\
1.63 \\
1.90 \\
2.04\end{array}$ & $\begin{array}{l}0.94 \\
1.26 \\
1.58 \\
1.84 \\
1.96\end{array}$ & $\begin{array}{l}0.94 \\
1.24 \\
1.55 \\
1.80 \\
1.90\end{array}$ & $\begin{array}{l}0.94 \\
1.25 \\
1.57 \\
1.82 \\
1.94\end{array}$ & $\begin{array}{l}0.96 \\
1.29 \\
1.63 \\
1.91 \\
2.04\end{array}$ \\
\hline Hardwood Harvest & $\begin{array}{l}\text { Southeast } \\
1990 \\
2000 \\
2010 \\
2020 \\
2030\end{array}$ & Billion cubic feet & $\begin{array}{l}1.14 \\
1.45 \\
1.70 \\
1.83 \\
1.79\end{array}$ & $\begin{array}{l}1.14 \\
1.45 \\
1.70 \\
1.83 \\
1.79\end{array}$ & $\begin{array}{l}1.13 \\
1.46 \\
1.70 \\
1.82 \\
1.78\end{array}$ & $\begin{array}{l}1.14 \\
1.45 \\
1.70 \\
1.83 \\
1.79\end{array}$ & $\begin{array}{l}1.13 \\
1.46 \\
1.70 \\
1.82 \\
1.78\end{array}$ \\
\hline Hardwood Harvest & $\begin{array}{l}\text { West } \\
1990 \\
2000 \\
2010 \\
2030\end{array}$ & Billion cubic feet & $\begin{array}{l}0.10 \\
0.10 \\
0.10 \\
0.10\end{array}$ & $\begin{array}{l}0.10 \\
0.10 \\
0.10 \\
0.10\end{array}$ & $\begin{array}{l}0.10 \\
0.10 \\
0.10 \\
0.10\end{array}$ & $\begin{array}{l}0.10 \\
0.10 \\
0.10 \\
0.10\end{array}$ & $\begin{array}{l}0.10 \\
0.10 \\
0.10 \\
0.10\end{array}$ \\
\hline $\begin{array}{l}\text { Hardwood Harvest } \\
\text { Lower } 48 \text { States }\end{array}$ & & Billion cubic feet & & & & & \\
\hline & $\begin{array}{l}1990 \\
2000 \\
2010 \\
2020 \\
2030\end{array}$ & & $\begin{array}{l}5.11 \\
6.48 \\
7.71 \\
8.48 \\
8.56\end{array}$ & $\begin{array}{l}5.11 \\
6.49 \\
7.73 \\
8.51 \\
8.59\end{array}$ & $\begin{array}{l}5.11 \\
6.50 \\
7.76 \\
8.56 \\
8.66\end{array}$ & $\begin{array}{l}5.11 \\
6.49 \\
7.73 \\
8.50 \\
8.58\end{array}$ & $\begin{array}{l}5.10 \\
6.50 \\
7.75 \\
8.55 \\
8.66\end{array}$ \\
\hline
\end{tabular}


TABLE C.1. Simulated Effects of Various Scenarios on Growing Stock Inventories, Harvests, Stumpage Prices, Lumber and Plywood Production, Lumber and Plywood Consumption, the Wholesale Price Indices of Lumber and Plywood, and Economic Surpluses

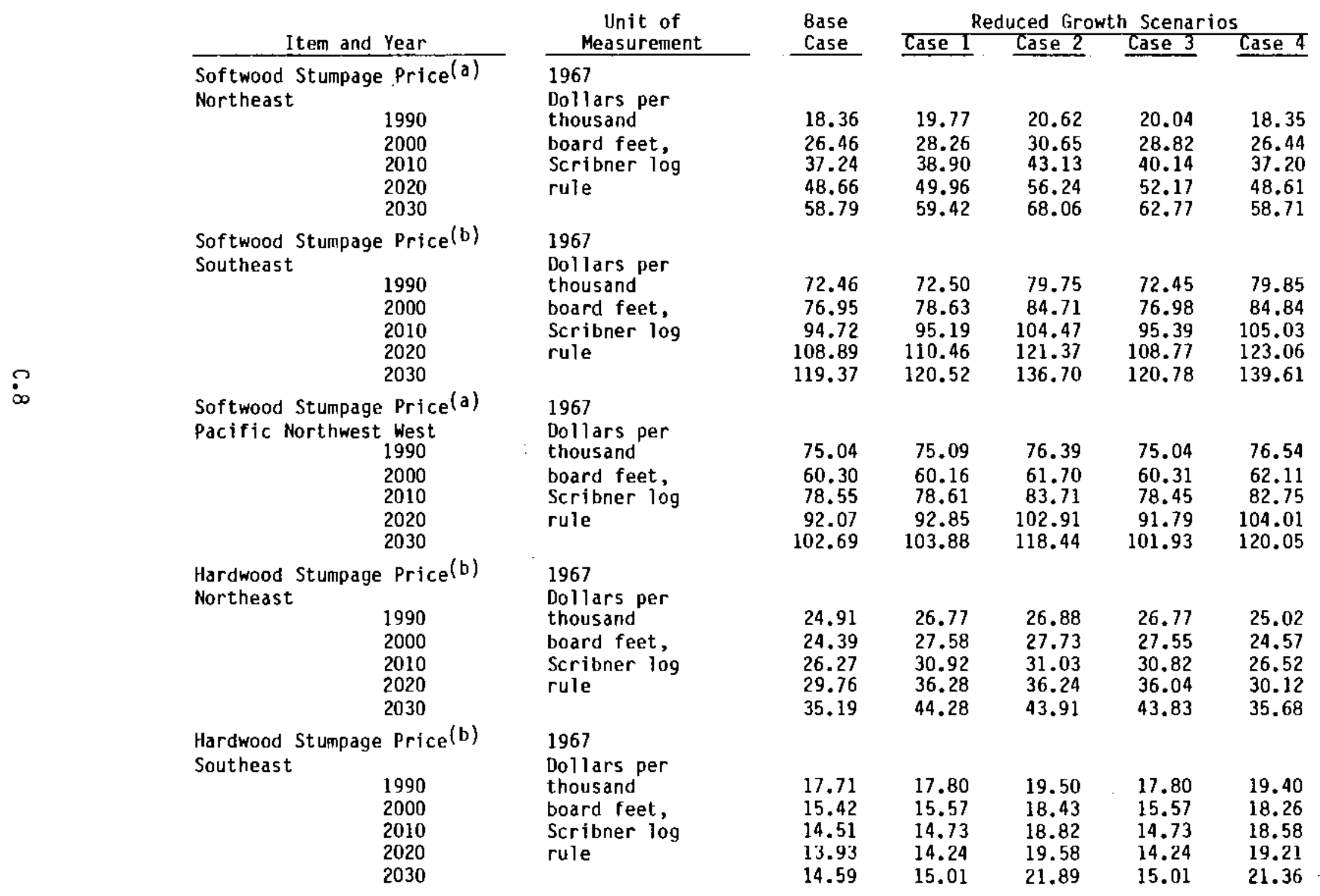


TABLE C.1. Simulated Effects of Various Scenarios on Growing Stock Inventories, Harvests, Stumpage Prices, Lumber and Plywood Production, Lumber and Plywood Consumption, the Wholesale Price Indices of Lumber and Plywood, and Economic Surpluses

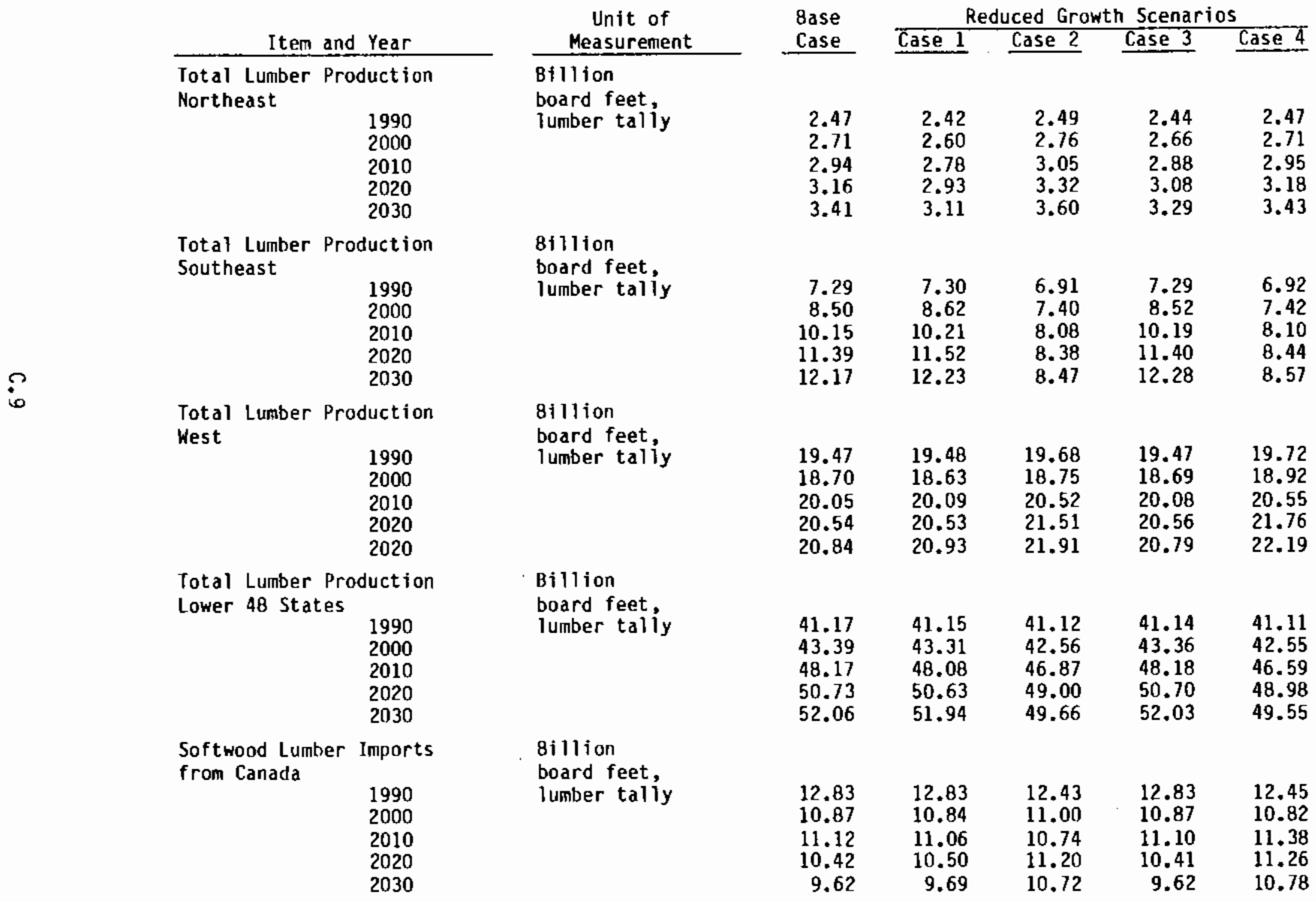


TABLE C.1. Simulated Effects of Various Scenarios on Growing Stock Inventories, Harvests, Stumpage Prices, Lumber and Plywood Production, Lumber and Plywood Consumption, the Wholesale Price Indices of Lumber and Plywood, and Economic Surpluses

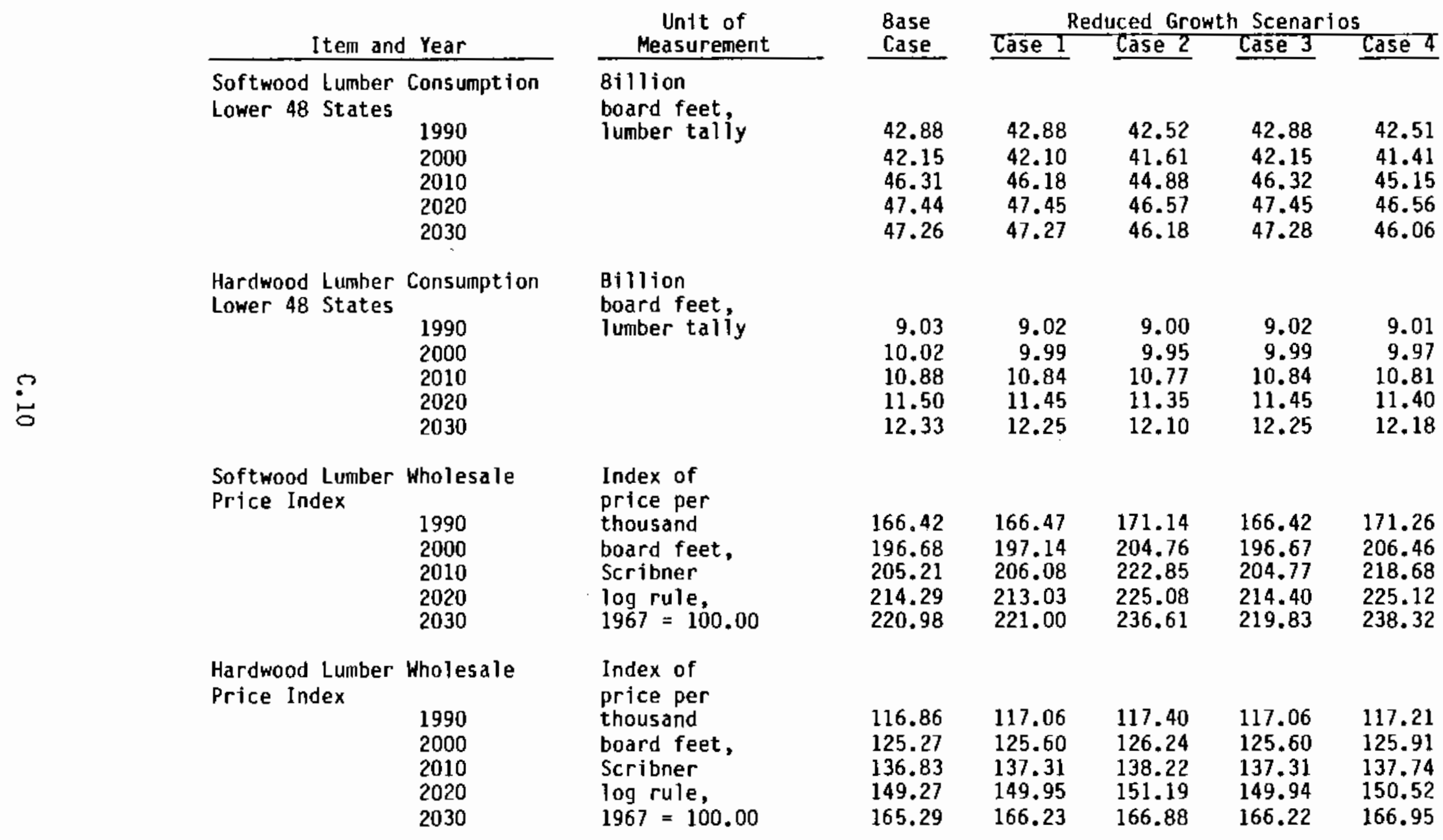


IABLE C.1. Simulated Effects of Various Scenarios on Growing Stock Inventories, Harvests, Stumpage Prices, Lumber and Plywood Production, Lumber and Plywood Consumption, the Wholesale Price Indices of Lumber and Plywood, and Economic Surpluses

Iten and Year

Softwood Plywood Consumption Lower 48 States

1990

2000

2010

2020

2030

Softwood Plywood Wholesale Price Index
Unit of

Measurement

Billion

square feet,

3/8-inch basis

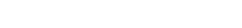

Index of price per per thousand

square feet,

3/8-inch basis, $1967=100.00$
1990

2000

2010

2020

2030
18.95

19.65

21.32

22.35

22.75

Base

Case

171.55

178.49

191.69

202.36

208.18
Reduced Growth Scenarios

Case 1 Case 2 Case 3 Case 4

$$
\begin{aligned}
& 18.95 \\
& 19.64 \\
& 21.33 \\
& 22.29 \\
& 22.67
\end{aligned}
$$

18.75
19.38
20.79
21.54
21.86

18.95

19.66

21.31

22.75

18. 74

19.37

20.73

21.46

21.76

$\begin{array}{llll}171.58 & 172.63 & 171.55 & 172.82 \\ 179.04 & 181.59 & 179.53 & 180.22 \\ 191.68 & 196.12 & 191.79 & 196.46 \\ 201.34 & 207.90 & 201.80 & 208.67 \\ 208.60 & 219.28 & 207.63 & 220.40\end{array}$


TABLE C.1. Simulated Effects of Various Scenarios on Growing Stock Inventories, Harvests, Stumpage Prices, Lumber and Plywood Production, Lumber and Plywood Consumption, the Wholesale Price Indices of Lumber and Plywood, and Economic Surpluses

\begin{tabular}{|c|c|c|c|c|c|c|}
\hline \multirow[b]{2}{*}{ Item and Year } & Unit of & Base & \multicolumn{4}{|c|}{ Reduced Growth Scenarios } \\
\hline & Measurement & Case & Case I & Case 2 & Case 3 & Case 4 \\
\hline $\begin{array}{l}\text { Consumers' Surplus in North- } \\
\text { eastern Softwood Lumber and } \\
\text { Plywood Markets } \\
\text { Point estimates of future } \\
\text { value in }\end{array}$ & $\begin{array}{l}\text { Billion } \\
1984 \text { dollars }\end{array}$ & & & & & \\
\hline $\begin{array}{r}2000 \\
2015 \\
2030\end{array}$ & & $\begin{array}{l}3.21 \\
3.91 \\
4.73\end{array}$ & $\begin{array}{l}3.21 \\
3.87 \\
4.74\end{array}$ & $\begin{array}{l}3.15 \\
3.68 \\
4.49\end{array}$ & $\begin{array}{l}3.21 \\
3.91 \\
4.77\end{array}$ & $\begin{array}{l}3.14 \\
3.66 \\
4.45\end{array}$ \\
\hline $\begin{array}{l}\text { Cumulatiye net present } \\
\text { value, }(c) \text { 1985-2030 }\end{array}$ & & 34.93 & 34.85 & 34.34 & 34.93 & 34.24 \\
\hline $\begin{array}{l}\text { Consumers' Surplus in South- } \\
\text { ern Softwood Lumber and } \\
\text { Plywood Markets } \\
\text { Point estimates of future } \\
\text { value in }\end{array}$ & $\begin{array}{l}\text { Billion } \\
1984 \text { dollars }\end{array}$ & & & & & \\
\hline $\begin{array}{r}2000 \\
2015 \\
2030\end{array}$ & & $\begin{array}{r}9.52 \\
11.17 \\
13.04\end{array}$ & $\begin{array}{r}9.52 \\
11.11 \\
13.08\end{array}$ & $\begin{array}{r}9.36 \\
10.46 \\
12.35\end{array}$ & $\begin{array}{r}9.52 \\
11.17 \\
13.09\end{array}$ & $\begin{array}{r}9.35 \\
10.65 \\
12.29\end{array}$ \\
\hline $\begin{array}{l}\text { Cumulatije net present } \\
\text { value, }(c) \text { 1985-2030 }\end{array}$ & & 102.77 & 102.72 & 101.51 & 102.78 & 101.39 \\
\hline
\end{tabular}


TABLE C.1. Simulated Effects of Various Scenarios on Growing Stock Inventories, Harvests, Stumpage Prices, Lumber and Plywood Production, Lumber and Plywood Consumption, the Wholesale Price Indices of Lumber and Plywood, and Economic Surpluses

\begin{tabular}{|c|c|c|c|c|c|c|c|}
\hline & & Unit of & Base & & uced Gro & h Scenar & \\
\hline & Item and Year & Measurement & Case & Case I & Case 2 & Case 3 & Case 4 \\
\hline & $\begin{array}{l}\text { Consumers' Surplus in Soft- } \\
\text { wood Lumber and Plywood } \\
\text { Markets in the } \\
\text { Lower } 48 \text { States } \\
\text { Point estimates of future } \\
\text { value in }\end{array}$ & $\begin{array}{l}\text { Billion } \\
1984 \text { dollars }\end{array}$ & & & & & \\
\hline & $\begin{array}{r}2000 \\
2015 \\
2030\end{array}$ & & $\begin{array}{l}33.61 \\
39.47 \\
46.31\end{array}$ & $\begin{array}{l}33.60 \\
39.30 \\
46.30\end{array}$ & $\begin{array}{l}33.04 \\
37.19 \\
44.13\end{array}$ & $\begin{array}{l}33.61 \\
39.48 \\
46.36\end{array}$ & $\begin{array}{l}33.02 \\
37.57 \\
43.88\end{array}$ \\
\hline & $\begin{array}{l}\text { Cumulatiye net present } \\
\text { value, }(c) \text { 1985-2030 }\end{array}$ & & 362.59 & 362.46 & 358.65 & 362.61 & 358.06 \\
\hline$\stackrel{8}{\circledR}$ & $\begin{array}{l}\text { Consumers' Surplus in Hard- } \\
\text { wood Lumber Markets in the } \\
\text { Lower } 48 \text { States } \\
\text { Point estimates of future } \\
\text { value in }\end{array}$ & $\begin{array}{l}8 \text { illion } \\
1984 \text { dollars }\end{array}$ & & & & & \\
\hline & $\begin{array}{r}2000 \\
2015 \\
2030\end{array}$ & & $\begin{array}{l}3.05 \\
3.64 \\
3.88\end{array}$ & $\begin{array}{l}3.04 \\
3.61 \\
3.83\end{array}$ & $\begin{array}{l}3.03 \\
3.57 \\
3.74\end{array}$ & $\begin{array}{l}3.04 \\
3.62 \\
3.82\end{array}$ & $\begin{array}{l}3.03 \\
3.59 \\
3.79\end{array}$ \\
\hline & $\begin{array}{l}\text { Cumulatije net present } \\
\text { value, }(c) \text { 1985-2030 }\end{array}$ & & 33.69 & 33.57 & 33.34 & 33.57 & 33.46 \\
\hline
\end{tabular}


TABLE C.1. Simulated Effects of Various Scenarios on Growing Stock Inventories, Harvests, Stumpage Prices, Lumber and Plywood Production, Lumber and Plywood Consumption, the Wholesale Price Indices of Lumber and Plywood, and Economic Surpluses

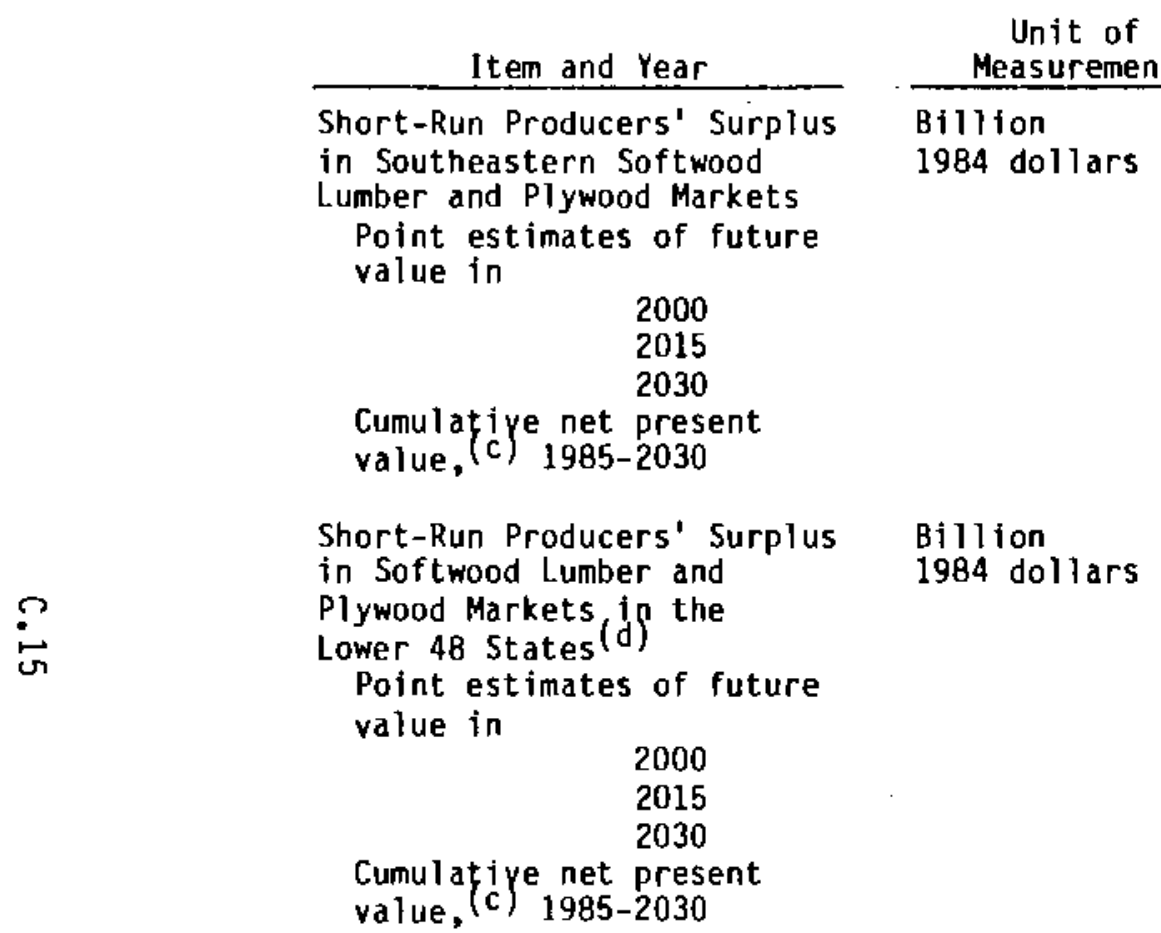

$\begin{array}{rrrrr}2.98 & 2.98 & 2.78 & 2.98 & 2.80 \\ 4.84 & 4.88 & 3.73 & 4.85 & 3.75 \\ 6.04 & 6.07 & 4.17 & 6.00 & 4.26 \\ 36.29 & 36.40 & 31.75 & 36.27 & 31.89\end{array}$

Short-Run Producers' Surplus twood Lumber and

Sood Markets in the

48 States

Point estimates of future

value in

2000

2030

value, $(c)$ 1985-2030

$\begin{array}{rrrrr}16.43 & 16.44 & 16.62 & 16.43 & 16.68 \\ 22.53 & 22.55 & 22.48 & 22.41 & 22.44 \\ 25.81 & 25.86 & 25.15 & 25.76 & 25.38 \\ 195.23 & 195.26 & 193.87 & 195.22 & 194.54\end{array}$


TABLE C.1. Simulated Effects of Various Scenarios on Growing Stock Inventories, Harvests, Stumpage Prices, Lumber and Plywood Production, Lumber and Plywood Consumption, the Wholesale Price Indices of Lumber and Plywood, and Economic Surpluses

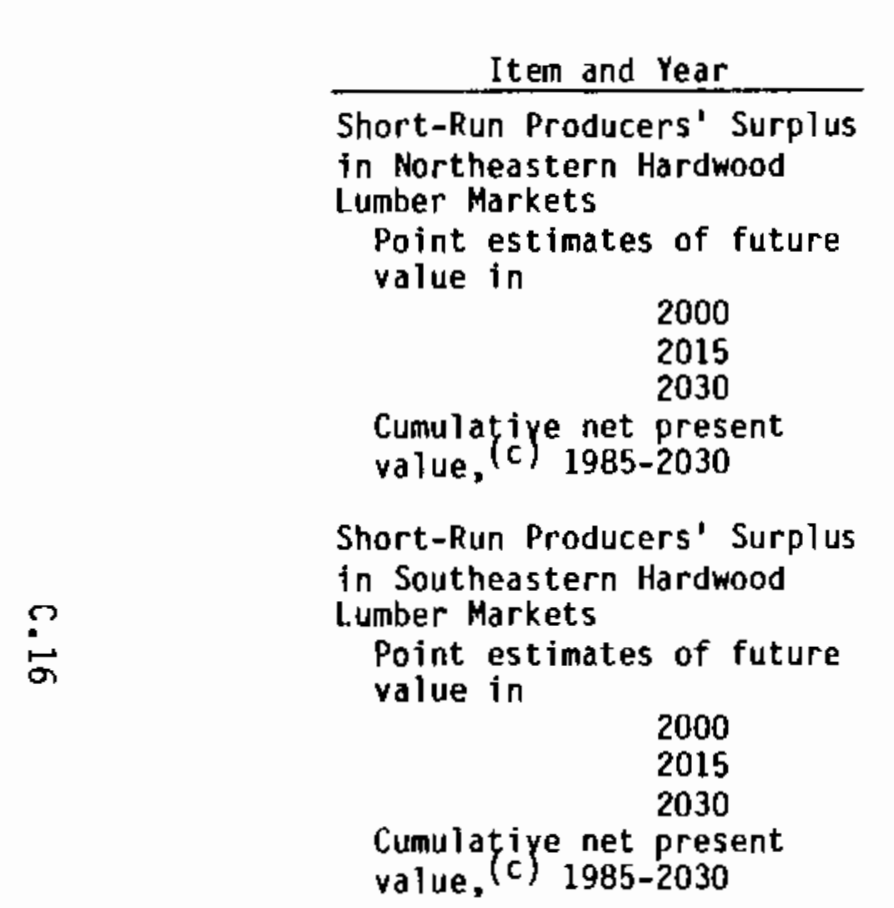

Unit of
Measurement

1984 dollars

mber Markets

Point estimates of future

value in

$$
\begin{aligned}
& 2000 \\
& 2015 \\
& 2030
\end{aligned}
$$

Cumulatipe net present

Hardwood

Point estimates of future

value in

$$
2015
$$

Cumulatiye net present

value, (c) 1985-2030

Billion

1984 dollars 8ase

Case

Reduced Growth Scenarios
Case 1 Case? Case 3 Case 4

$\begin{array}{lllll}0.66 & 0.65 & 0.66 & 0.65 & 0.67 \\ 0.94 & 0.91 & 0.92 & 0.91 & 0.96 \\ 1.34 & 1.25 & 1.29 & 1.26 & 1.36 \\ 7.82 & 7.65 & 7.71 & 7.65 & 7.88\end{array}$

$\begin{array}{rrrrr}0.90 & 0.90 & 0.88 & 0.90 & 0.88 \\ 1.23 & 1.24 & 1.17 & 1.24 & 1.16 \\ 1.61 & 1.63 & 1.48 & 1.63 & 1.46 \\ 10.34 & 10.43 & 10.11 & 10.43 & 10.06\end{array}$


TABLE C.1. Simulated Effects of Various Scenarios on Growing Stock Inventories, Harvests, Stumpage Prices, Lumber and Plywood Production, Lumber and Plywood Consumption, the Wholesale Price Indices of Lumber and Plywood, and Economic Surpluses

Item and Year

\begin{tabular}{l} 
Item and Year \\
\hline Short-Run Producers' Surp \\
in Eastern Hardwood Lumber \\
Markets \\
Point estimates of future \\
value in \\
2000 \\
2015 \\
2030 \\
Cumulatiye net present \\
value, (c) 1985-2030
\end{tabular}

Economic Profit (e) in

Northeastern Softwood Lumber and Plywood Markets

Point estimates of future

value in

2000

2030

Cumulatiye net present

value, $(c)$ 1985-2030

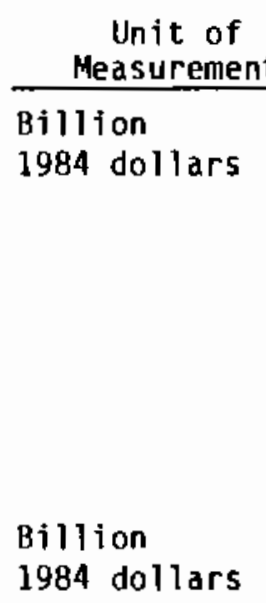

Unit of

Billion

1984 dollars

4.84

3.47

4.84

3.46

4.82

3.47

6.41

6.47

3.46

6.49

40.34

40.28

40.34

6.43

40.36

$\begin{array}{rrrrr}-0.12 & -0.12 & -0.11 & -0.12 & -0.11 \\ -0.04 & -0.03 & 0.01 & -0.04 & 0.00 \\ 0.01 & 0.00 & 0.07 & 0.00 & 0.05 \\ -0.81 & -0.81 & -0.73 & -0.81 & -0.73\end{array}$


TABLE C.1. Simulated Effects of Various Scenarios on Growing Stock Inventories, Harvests, Stumpage Prices, Lumber and Plywood Production, Lumber and Plywood Consumption, the Wholesale Price Indices of Lumber and Plywood, and Economic Surpluses

Unit of

Item and Year

Economic Profit (e) in

Southeastern Softwood Lumber and Plywood Markets

Point estimates of future

value in

$$
\begin{aligned}
& 2000 \\
& 2015 \\
& 2030
\end{aligned}
$$

Cumulatiye net present

value, (c) 1985-2030

Economic Profit(e) in

Sof twood Lumber and Plywood

Markets in the Lower 48

States

Point estimates of future

value in

2000

2030

Cumulatiye net present

value, (c) 1985-2030
Measurement

\section{Billion}

1984 dollars

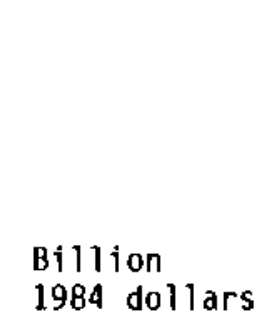

1984 dollars

$\begin{array}{rrrrr}-0.59 & -0.59 & -0.53 & -0.59 & -0.52 \\ 0.03 & 0.05 & 0.19 & 0.03 & 0.19 \\ 0.43 & 0.45 & 0.54 & 0.39 & 0.58 \\ -3.31 & -3.25 & -2.98 & -3.32 & -2.98\end{array}$

$\begin{array}{rrrrr}-3.91 & -3.91 & -3.56 & -3.91 & -3.54 \\ -0.22 & -0.12 & 1.30 & -0.24 & 0.98 \\ 1.81 & 1.77 & 3.30 & 1.64 & 3.46 \\ & & & & \\ -23.36 & -23.34 & -21.09 & -23.35 & -20.79\end{array}$


TABLE C.1. Simulated Effects of Various Scenarios on Growing Stock Inventories, Harvests, Stumpage Prices, Lumber and Plywood Production, Lumber and Plywood Consumption, the Wholesale Price Indices of Lumber and Plywood, and Economic Surpluses

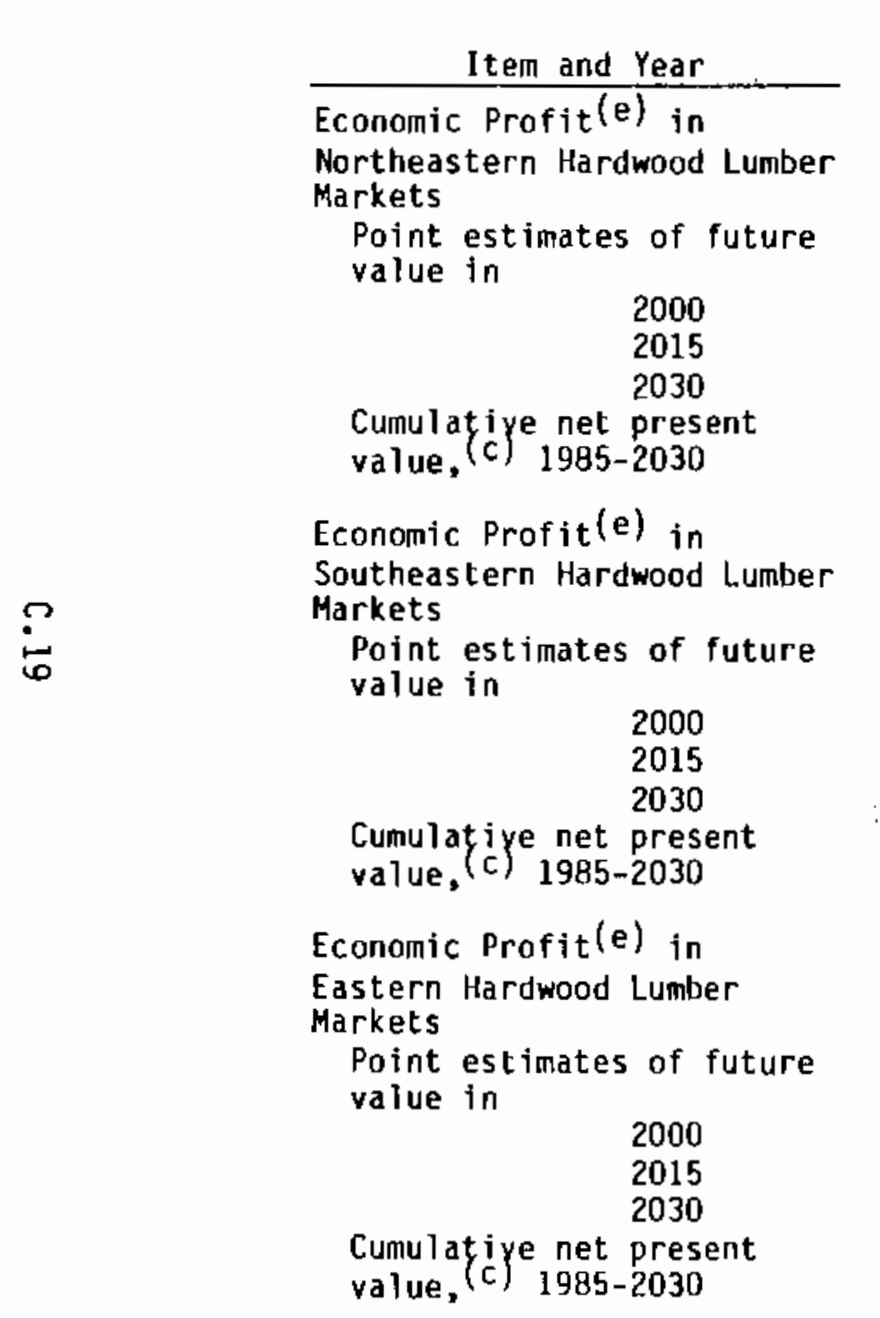

Base

Case

Measurement

Billion

1984 dollars

$\begin{array}{lllll}0.07 & 0.07 & 0.08 & 0.07 & 0.07 \\ 0.24 & 0.23 & 0.24 & 0.23 & 0.24 \\ 0.51 & 0.50 & 0.51 & 0.50 & 0.52 \\ & & & & \\ 1.21 & 1.21 & 1.24 & 1.21 & 1.24\end{array}$

Billition

1984 dollars

(19) dollars

0.31

0.65

0.10

0.31

0.10

0.31

0.10

0.66

0.65

0.66

0.10

1.58

1.60

1.60

1.60

0.64

Billian

1984 dollars

$\begin{array}{lllll}0.39 & 0.39 & 0.40 & 0.39 & 0.40 \\ 1.27 & 1.28 & 1.31 & 1.28 & 1.29 \\ 2.70 & 2.73 & 2.78 & 2.73 & 2.75 \\ 6.47 & 6.53 & 6.66 & 6.53 & 6.60\end{array}$


TABLE C.1. Simulated Effects of Various Scenarios on Growing Stock Inventories, Harvests, Stumpage Prices, Lumber and Plywood Production, Lumber and Plywood Consumption, the Wholesale Price Indices of Lumber and Plywood, and Economic Surpluses

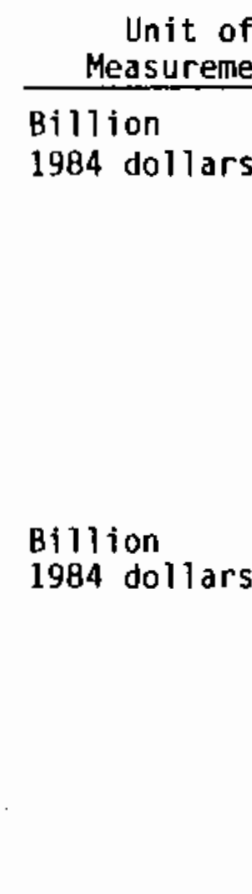

Cumulatjye net present

value, (c) 1985-2030

\section{in \\ Northeastern Softwood and \\ Point estimates of future \\ values in

$$
2015
$$$$
2000
$$ \\ Cumulatije net present \\ value, (c) 1985-2030}

Producers' Surplus in

Southeastern Softwood and

Hardwood Stumpage Markets

Point estimates of future

2000

2015

Base

Case

\author{
value, (c) $1985-2030$
}


TABLE C.1. Simulated Effects of Various Scenarios on Growing Stock Inventories, Harvests, Stumpage Prices, Lumber and Plywood Production, Lumber and Plywood Consumption, the Wholesale Price Indices of Lumber and Plywood, and Economic Surpluses

\begin{tabular}{l} 
Item and Year \\
\hline Producers' Surplus in \\
Softwood and Hardwood \\
Stumpage Markets in the \\
Lower 48 States \\
Point est inates of future \\
values in 2000 \\
2015 \\
2030 \\
Cumulati iye net present \\
value, (c) 1985-2030 \\
Future Value of the Softwood \\
and Hardwood Growing Stock \\
Inventory Remaining in 2030 \\
Northeast \\
Southeast \\
Lower 48 States
\end{tabular}

Unit of

\begin{tabular}{l} 
Measurement \\
\hline Billion \\
1984 dollars
\end{tabular}

1984 dollars
Base

Case

Case

4.43
6.29
8.11

49.27

Billion

1984 dollars
Reduced Growth Scenarios

Case 1. Case 2 Case 3 Case 4

4.54

6.32

B. 31

4.44

6.29

8.22

4.53

6.31

8. 25

50.17

49.45

8. 30

49.41

50.17

50.10

77.71 124.69 437.02
79.95

95.42

429.52

77.51

126.48

440.39
78.18

96.38 
TABLE C.1. Simulated Effects of Various Scenarios on Growing Stock Inventories, Harvests, Stumpage Prices, Lumber and Plywood Production, Lumber and Plywood Consumption, the Wholesale Price Indices of Lumber and Plywood, and Economic Surpluses

Item and Year

1990

2000

2010

2020

2030

Sof twood Inventory Southeast

1990

2000

2010

2020

2030

in

West
Unit of

Softwood Inventory Northeast

$\frac{\text { Measurement }}{\text { Billion cubic feet }}$

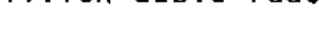

1990

2000

2010

2020

2030

Softwood Inventory Lower 48 States

1990
2000
2010
2020
2030

Hardwood Inventory Northeast

1990
2000
2010
2020
2030

Billion cubic feet

Billion cubic feet

Billion Cubic feet

Billion cubic feet
Reduced Growth Scenarios

\begin{tabular}{llllll} 
Case 5 & Case 6 & Case 7 & Case 8 & Case 9 \\
\cline { 5 - 6 } & & & & & \\
34.88 & 34.08 & 33.29 & 36.48 & 34.08 \\
37.67 & 36.37 & 35.05 & 40.21 & 36.37 \\
38.83 & 37.16 & 35.44 & 42.01 & 37.17 \\
38.66 & 36.71 & 34.69 & 42.26 & 36.73 \\
37.47 & 35.27 & 32.98 & 41.38 & 35.30
\end{tabular}

50.49

52.06

50.30

45.94

40.91

48.15

47.90
44.78

40.20

34.86

45.87

44.00

40.00

34.71

28. 30

55.21

60.05

61.28

59.59

56.54

48.15

47.93

44.80

40.26

71.55

71.50

71.50

71.59

34.97

70.34

70.24

69.38

66.89

65.69

68.51

65.61

62.71

70.66

69.86

63. 04

62.53

60.06

67.97

66.26

71.50

70.24

68.45

65.57

62.47

$\begin{array}{lllll}219.19 & 215.98 & 212.91 & 225.60 & 215.98 \\ 226.00 & 220.30 & 213.73 & 237.11 & 220.32 \\ 222.53 & 214.04 & 204.15 & 238.23 & 214.04 \\ 208.69 & 198.97 & 185.38 & 229.80 & 199.05 \\ 191.27 & 179.13 & 163.23 & 216.92 & 179.26\end{array}$

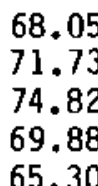

66.84

69.76

69.32

66.33

62.04

65.61

66.77

70.53

67.74

66.70

63.25

58.03

69.44

68.62

65.19

60.37

77.14

75.50

65.30

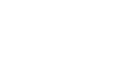


TABLE C.1. Simulated Effects of Various Scenarios on Growing Stock Inventories, Harvests, Stumpage Prices, Lumber and Plywood Production, Lumber and Plywood Consumption, the Wholesale Price Indices of Lumber and Plywood, and Economic Surpluses

Unit of

Item and Year

Hardwood Inventory Southeast

1990

2000

2010

2020

2030

Hardwood Inventory East

1990

2000

2010

2020

2030

Sof twood Harvest Northeast

1990

2000

2010

2020

2030

Softwood Harvest Southeast

1990

2000

2010

2020

2030

Softwood Harvest West

1990

2000

2010

2020

2030

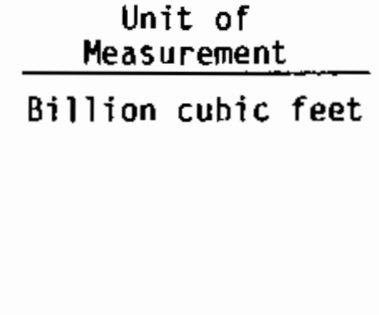

8illion cubic feet

$\begin{array}{lllll}242.93 & 240.27 & 237.60 & 240.30 & 248.28 \\ 258.23 & 253.48 & 248.69 & 253.69 & 266.30 \\ 263.10 & 253.50 & 246.67 & 254.23 & 271.79 \\ 253.01 & 243.84 & 234.04 & 245.49 & 265.81 \\ 241.91 & 231.53 & 220.15 & 234.37 & 256.73\end{array}$

Billion cubic feet

$\begin{array}{ll}0.56 & 0.56 \\ 0.69 & 0.68 \\ 0.82 & 0.81 \\ 0.94 & 0.92 \\ 1.02 & 1.01\end{array}$

\subsection{5}

0.67

0.79

0.90

0.57

0.71

0.85

0.97

1.06

0.56

0.68

0.99

0.80

0.92

Billion cubic feet

2.34
2.64
2.93
2.98
2.92

2.32

2.29

2.50

2.75

2.76

2.69

2.60
2.58

2.40

2.74

3.08

3.22

3.24

2.32

2.59

2.74

2.75

Billion cubic feet

$\begin{array}{ll}4.34 & 4.36 \\ 4.17 & 4.16 \\ 4.43 & 4.39 \\ 4.55 & 4.55 \\ 4.57 & 4.63\end{array}$

4.35

4.26

4.39

4.57

4.32

2.70

4.55
4.63

4.65

4.13

4.36

4.45

4. 36

4.16

4.37 
TABLE C.1. Simulated Effects of Various Scenarios on Growing Stock Inventories, Harvests, Stumpage Prices, Lumber and Plywood Production, Lumber and Plywood Consumption, the Wholesale Price Indices of Lumber and Plywood, and Economic Surpluses

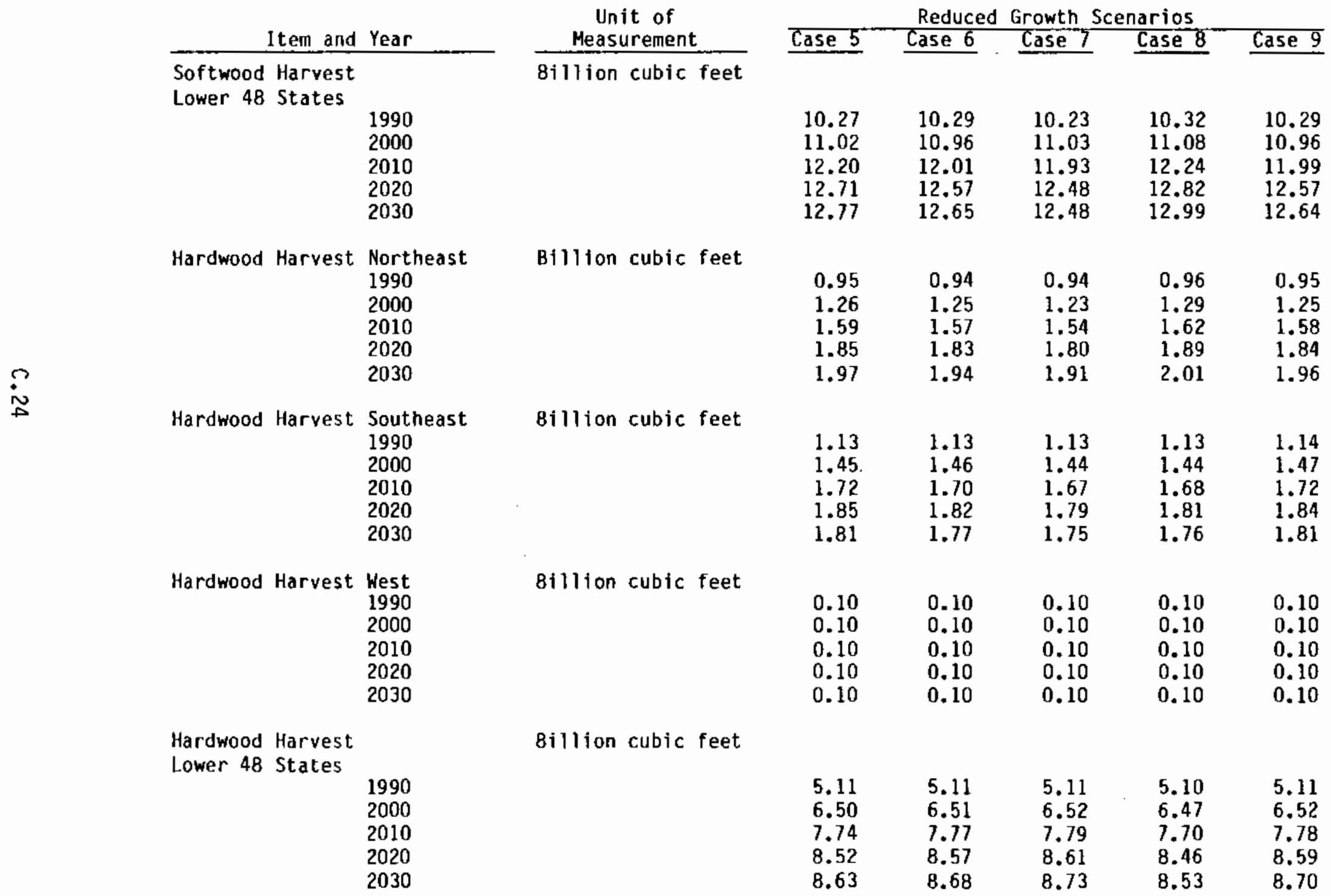


TABLE C.1. Simulated Effects of Various Scenarios on Growing Stock Inventories, Harvests, Stumpage Prices, Lumber and Plywood Production, Lumber and Plywood Consumption, the Wholesale Price Indices of Lumber and Plywood, and Economic Surpluses

Unit of

Item and Year

\begin{tabular}{ll}
\hline Softwood Stumpage Price(a) \\
Northeast & 1990 \\
& 2000 \\
& 2010 \\
& 2020 \\
& 2030
\end{tabular}

Softwood Stumpage Price(b) Southeast

1990

2000

2010

2020

2030

Softwood Stumpage Price(a)

Pacific Northwest West

1990

2000

2010

2020

2030

Hardwood Stumpage Price(b) Northeast

$$
\begin{aligned}
& 1990 \\
& 2000 \\
& 2010 \\
& 2020 \\
& 2030
\end{aligned}
$$

Hardwood Stumpage Price(b) Southeast

$$
\begin{aligned}
& 1990 \\
& 2000 \\
& 2010 \\
& 2020 \\
& 2030
\end{aligned}
$$

\section{7 \\ 0ollars per \\ board feet, \\ Scribner log \\ rule}

1967

Dollars per

board feet,

Scribner log

rule

1967

Dollars per

thous and

board feet,

Scribner log

rule

1967

Dollars per

thous and

board feet,

Scribner log

rule

1967

Dollars per

thousand

board feet,

Scribner log

rule
Reduced Growth Scenarios

Case 5 Case 6 Case 7 Case 8 Case 9

$\begin{array}{lllll}19.48 & 20.03 & 20.59 & 18.39 & 20.01 \\ 28.01 & 28.80 & 29.60 & 26.52 & 28.76 \\ 39.11 & 40.11 & 44.13 & 37.34 & 40.02 \\ 50.90 & 52.11 & 53.39 & 48.85 & 51.95 \\ 61.30 & 62.69 & 64.17 & 59.11 & 62.43\end{array}$

76.86

82.24

102.86

121.00

133.36

80.12

84.57

104.42

122.92

138.77

81.68

89.78

110.48

129.71

148.87

72.47

76.94

95.33

108.97

120.20

80.11

84.59

103.73

123.05

138.69

$\begin{array}{rrrrr}75.84 & 76.44 & 76.69 & 75.04 & 76.44 \\ 64.52 & 62.83 & 71.87 & 60.03 & 62.83 \\ 85.68 & 83.55 & 89.06 & 78.49 & 82.91 \\ 103.27 & 103.47 & 110.52 & 91.69 & 103.66 \\ 116.80 & 120.09 & 128.33 & 103.29 & 120.08\end{array}$

26.21

26.57

29.36

33.96

40.89

27.57

28.98

32.99

39.22

31.10

36.44

44.41

48.45

26.92

27.95

31.59

37.38

46.03

24.88

24.22

25.88

29.08

34.09

18.89

17.36

19.50

20.12

19.49

17.71

17.26

18.43

19.53

19.49
18.40

17.71
15.44

17.51

18.82

20.42

18.69

14.62

19.17

21.88

21.77

19.34

21.48

14.12 
TABLE C.1. Simulated Effects of Various Scenarios on Growing Stock Inventories, Harvests, Stumpage Prices, Lumber and Plywood Production, Lumber and Plywood Consumption, the Wholesale Price Indices of Lumber and Plywood, and Economic Surpluses

\begin{tabular}{|c|c|c|c|c|c|c|c|}
\hline Item a & and Year & $\begin{array}{c}\text { Unit of } \\
\text { Measurement }\end{array}$ & Case 5 & $\begin{array}{l}\text { Reduce } \\
\text { Case } 6\end{array}$ & $\begin{array}{l}\text { Growth } \\
\text { Case } 7\end{array}$ & $\frac{\text { narios }}{\text { Case } 8}$ & Case 9 \\
\hline $\begin{array}{l}\text { Total Lumber } \\
\text { Northeast }\end{array}$ & $\begin{array}{c}\text { Production } \\
\begin{array}{c}1990 \\
2000 \\
2010 \\
2020 \\
2030\end{array}\end{array}$ & $\begin{array}{l}\text { Billion } \\
\text { board feet, } \\
\text { lumber taliy }\end{array}$ & $\begin{array}{l}2.45 \\
2.68 \\
2.91 \\
3.12 \\
3.35\end{array}$ & $\begin{array}{l}2.45 \\
2.67 \\
2.89 \\
3.09 \\
3.31\end{array}$ & $\begin{array}{l}2.44 \\
2.66 \\
2.87 \\
3.06 \\
3.26\end{array}$ & $\begin{array}{l}2.47 \\
2.67 \\
2.88 \\
3.07 \\
3.28\end{array}$ & $\begin{array}{l}2.47 \\
2.71 \\
2.95 \\
3.18 \\
3.43\end{array}$ \\
\hline $\begin{array}{l}\text { Total Lumber } \\
\text { Southeast }\end{array}$ & $\begin{array}{c}\text { Production } \\
\begin{array}{c}1990 \\
2000 \\
2010 \\
2020 \\
2030\end{array}\end{array}$ & $\begin{array}{l}\text { Billion } \\
\text { board feet, } \\
\text { lumber tally }\end{array}$ & $\begin{array}{l}7.03 \\
7.79 \\
8.89 \\
9.47 \\
9.55\end{array}$ & $\begin{array}{l}6.92 \\
7.40 \\
8.05 \\
8.43 \\
8.55\end{array}$ & $\begin{array}{l}6.77 \\
7.11 \\
7.58 \\
7.76 \\
7.80\end{array}$ & $\begin{array}{r}7.26 \\
8.43 \\
10.05 \\
11.20 \\
11.97\end{array}$ & $\begin{array}{l}6.96 \\
7.47 \\
8.13 \\
8.60 \\
8.76\end{array}$ \\
\hline $\begin{array}{l}\text { Total Lumber } \\
\text { West }\end{array}$ & $\begin{array}{c}\text { Production } \\
\qquad \begin{array}{c}1990 \\
2000 \\
2010 \\
2020 \\
2030\end{array}\end{array}$ & $\begin{array}{l}8 \text { illion } \\
\text { board feet, } \\
\text { lumber taliy }\end{array}$ & $\begin{array}{l}19.55 \\
18.98 \\
20.75 \\
21.58 \\
21.64\end{array}$ & $\begin{array}{l}19.71 \\
18.86 \\
20.46 \\
21.54 \\
22.06\end{array}$ & $\begin{array}{l}19.64 \\
19.72 \\
20.65 \\
21.92 \\
22.34\end{array}$ & $\begin{array}{l}19.47 \\
18.70 \\
20.02 \\
20.51 \\
20.71\end{array}$ & $\begin{array}{l}19.71 \\
18.86 \\
20.39 \\
21.56 \\
22.08\end{array}$ \\
\hline $\begin{array}{l}\text { Total Lumber } \\
\text { Lower } 48 \text { Stat }\end{array}$ & $\begin{array}{l}\text { Production } \\
\begin{array}{l}\text { Pes } \\
1990 \\
2000 \\
2010 \\
2020 \\
2030\end{array}\end{array}$ & $\begin{array}{l}8111 \text { ion } \\
\text { board feet, } \\
\text { lumber taliy }\end{array}$ & $\begin{array}{l}41.00 \\
42.98 \\
47.87 \\
50.16 \\
50.44\end{array}$ & $\begin{array}{l}41.10 \\
42.51 \\
46.55 \\
48.73 \\
49.46\end{array}$ & $\begin{array}{l}40.82 \\
43.16 \\
46.11 \\
48.15 \\
48.29\end{array}$ & $\begin{array}{l}41.15 \\
43.33 \\
48.07 \\
50.60 \\
51.85\end{array}$ & $\begin{array}{l}41.15 \\
42.56 \\
46.51 \\
48.89 \\
49.63\end{array}$ \\
\hline $\begin{array}{l}\text { Softwood Lumbe } \\
\text { from Canada }\end{array}$ & $\begin{array}{l} \\
1990 \\
2000 \\
2010 \\
2020 \\
2030\end{array}$ & $\begin{array}{l}\text { Billion } \\
\text { board feet, } \\
\text { lumber tally }\end{array}$ & $\begin{array}{r}12.88 \\
10.98 \\
10.21 \\
9.89 \\
10.41\end{array}$ & $\begin{array}{l}12.45 \\
10.82 \\
11.30 \\
11.27 \\
10.80\end{array}$ & $\begin{array}{r}12.91 \\
9.41 \\
11.68 \\
11.52 \\
11.24\end{array}$ & $\begin{array}{r}12.83 \\
10.87 \\
11.08 \\
10.40 \\
9.64\end{array}$ & $\begin{array}{l}12.45 \\
10.82 \\
11.50 \\
11.26 \\
10.81\end{array}$ \\
\hline
\end{tabular}


TABLE C.1. Simulated Effects of Various Scenarios on Growing Stock Inventories, Harvests, Stumpage Prices, Lumber and Plywood Production, Lumber and Plywood Consumption, the Wholesale Price Indices of Lumber and Plywood, and Economic Surpluses

Item and Year

Soft wood Lumber Consumption Lower 48 States

1990
2000
2010
2020
2030

2030

Hardwood Lumber Consumption Lower 48 States

1990
2000
2010
2020

$\stackrel{n}{i}$

\begin{tabular}{|c|c|c|c|c|c|}
\hline \multirow{2}{*}{$\begin{array}{c}\text { Unit of } \\
\text { Measurement }\end{array}$} & \multicolumn{5}{|c|}{ Reduced Growth } \\
\hline & Case 5 & Case 6 & Case 7 & Case 8 & Case 9 \\
\hline $\begin{array}{l}\text { Billion } \\
\text { board feet, } \\
\text { lumber taliy }\end{array}$ & $\begin{array}{l}42.80 \\
41.90 \\
45.23 \\
46.44 \\
46.55\end{array}$ & $\begin{array}{l}42.52 \\
41.42 \\
45.13 \\
46.42 \\
46.06\end{array}$ & $\begin{array}{l}42.70 \\
40.73 \\
45.05 \\
46.15 \\
45.51\end{array}$ & $\begin{array}{l}42.88 \\
42.14 \\
46.29 \\
47.44 \\
47.26\end{array}$ & $\begin{array}{l}42.52 \\
41.42 \\
45.23 \\
46.42 \\
46.05\end{array}$ \\
\hline $\begin{array}{l}\text { Billion } \\
\text { board feet, } \\
\text { lumber tally }\end{array}$ & $\begin{array}{r}9.01 \\
9.97 \\
10.81 \\
11.41 \\
12.20\end{array}$ & $\begin{array}{r}9.00 \\
9.95 \\
10.77 \\
11.35 \\
12.10\end{array}$ & $\begin{array}{r}8.98 \\
9.93 \\
10.73 \\
11.28 \\
11.98\end{array}$ & $\begin{array}{r}9.00 \\
9.95 \\
10.78 \\
11.36 \\
12.13\end{array}$ & $\begin{array}{r}9.03 \\
10.02 \\
10.87 \\
11.49 \\
12.30\end{array}$ \\
\hline $\begin{array}{l}\text { Index of } \\
\text { price per } \\
\text { thousand } \\
\text { board feet, } \\
\text { Scribner } \\
\log \text { rule, } \\
1967=100.00\end{array}$ & $\begin{array}{l}167.55 \\
200.10 \\
217.62 \\
226.94 \\
231.98\end{array}$ & $\begin{array}{l}171.82 \\
206.29 \\
219.26 \\
227.56 \\
239.07\end{array}$ & $\begin{array}{l}168.74 \\
216.71 \\
220.28 \\
231.47 \\
247.70\end{array}$ & $\begin{array}{l}166.42 \\
196.88 \\
205.19 \\
213.96 \\
220.09\end{array}$ & $\begin{array}{l}171.82 \\
206.30 \\
217.74 \\
227.60 \\
238.23\end{array}$ \\
\hline $\begin{array}{l}\text { Index of } \\
\text { price per } \\
\text { thousand } \\
\text { board feet, } \\
\text { Scribner } \\
\text { log rule, } \\
1967=100.00\end{array}$ & $\begin{array}{l}117.22 \\
125.90 \\
137.72 \\
150.44 \\
166.82\end{array}$ & $\begin{array}{l}117.40 \\
126.24 \\
138.23 \\
151.21 \\
167.92\end{array}$ & $\begin{array}{l}117.59 \\
126.66 \\
138.80 \\
152.08 \\
169.18\end{array}$ & $\begin{array}{l}117.40 \\
126.24 \\
138.17 \\
151.06 \\
167.58\end{array}$ & $\begin{array}{l}116.86 \\
125.28 \\
136.87 \\
149.42 \\
165.62\end{array}$ \\
\hline
\end{tabular}

Softwood Lumber Wholesale Price Index

1990
2000
2010
2020
2030

Hardwood Lumber Wholesale Price Index
Reduced Growth Scenarios 
TABLE C.1. Simulated Effects of Various Scenarios on Growing Stock Inventories, Harvests, Stumpage Prices, Lumber and Plywood Production, Lumber and Plywood Consumption, the Wholesale Price Indices of Lumber and Plywood, and Economic Surpluses

Unit of

Item and Year

Softwood Plywood Production Northeast

1990
2000
2010
2020
2030

Softwood Plywood Production Southeast

$$
\begin{aligned}
& 1990 \\
& 2000 \\
& 2010 \\
& 2020 \\
& 2030
\end{aligned}
$$

Softwood Plywood Production Lower 48 States

2000

2010

2020

2030 Billion

square feet,

3/8-inch basis

$\begin{array}{ll}0.07 & 0.07 \\ 0.08 & 0.08 \\ 0.09 & 0.09 \\ 0.10 & 0.10 \\ 0.11 & 0.11\end{array}$

Billion

square feet,

3/8-inch basis

$\begin{array}{ll}3.13 & 3.05 \\ 3.14 & 2.92 \\ 3.10 & 3.04 \\ 3.05 & 3.04 \\ 3.08 & 3.02\end{array}$

Billion

square feet,

3/8-inch basis
Reduced Growth Scenarios

Case 5 Case 6 Case 7 Case 8 Case 9

0.07

0.07

0.07

0.08

0.09

0.08

0.08

0.10

0.09

0.09

0.11

0.11

0.10

0.11

2.93

3.35

3.06

2. 85

2.91

3.54

2.93

2.95

2. 91

3.69

3.52

3.05

3.04

3.03

$\begin{array}{lllll}19.71 & 19.67 & 19.57 & 19.86 & 19.67 \\ 20.46 & 20.31 & 19.93 & 20.63 & 20.32 \\ 21.92 & 21.78 & 21.36 & 22.33 & 21.78 \\ 22.58 & 22.57 & 22.16 & 23.43 & 22.57 \\ 23.08 & 22.84 & 22.32 & 23.89 & 22.84\end{array}$


TABLE C.1. Simulated Effects of Various Scenarios on Growing Stock Inventories, Harvests, Stumpage Prices, Lumber and Plywood Production, Lumber and Plywood Consumption, the Wholesale Price Indices of Lumber and Plywood, and Economic Surpluses

Item and Year

Softwood Plywood Consumption Lower 48 States

1990

2000

2010

2020

2030

Softwood Plywood Wholesale Price Index
Unft of Measurement

Billion

square feet,

3/8-inch basis

19.49

20.94

1.50

21.99

Index of price per thousand square feet, $3 / 8$-inch basis,

$1967=100.00$
Reduced Growth Scenarios

$\begin{array}{llllll}\text { Case 5 } & & \text { Case 6 } & \text { Case 7 } & \text { Case 8 } & \text { Case 9 } \\ & & & & & \\ & & & & & \\ 18.80 & 18.75 & 18.66 & 18.95 & 18.75 \\ 19.49 & 19.33 & 18.96 & 19.65 & 19.34 \\ 20.94 & 20.80 & 20.37 & 21.35 & 20.78 \\ 21.50 & 21.49 & 21.08 & 22.36 & 21.49 \\ 21.99 & 21.76 & 21.24 & 22.80 & 21.77\end{array}$


TABLE C.1. Simulated Effects of Various Scenarios on Growing Stock Inventories, Harvests, Stumpage Prices, Lumber and Plywood Production, Lumber and Plywood Consumption, the Wholesale Price Indices of Lumber and Plywood, and Economic Surpluses

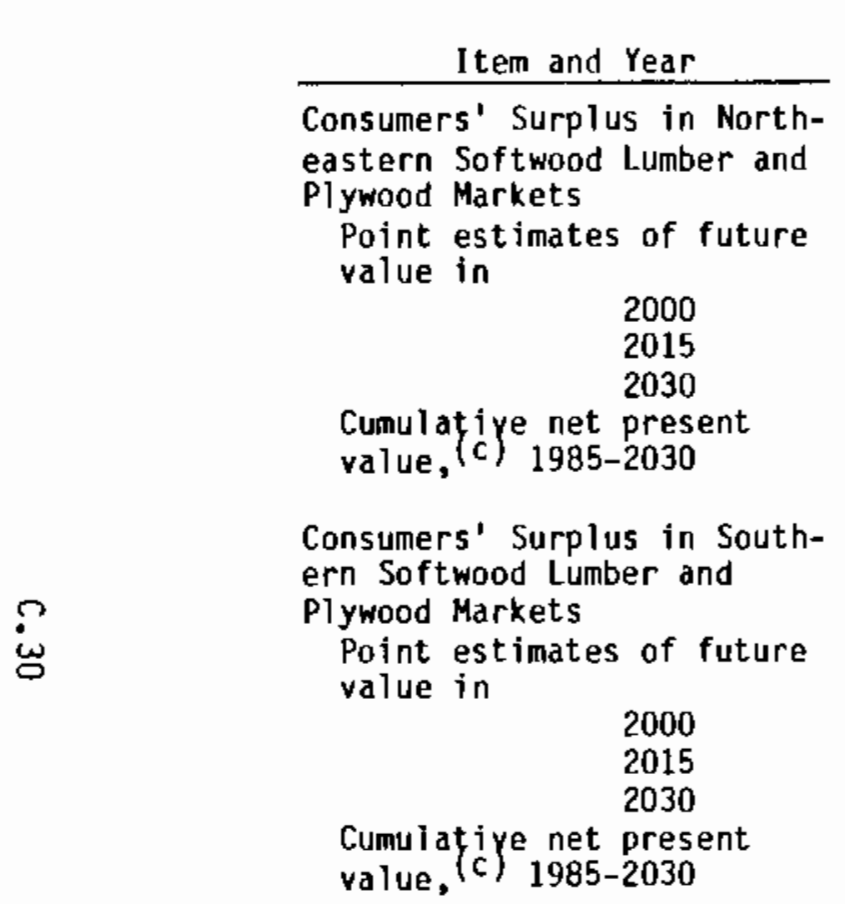

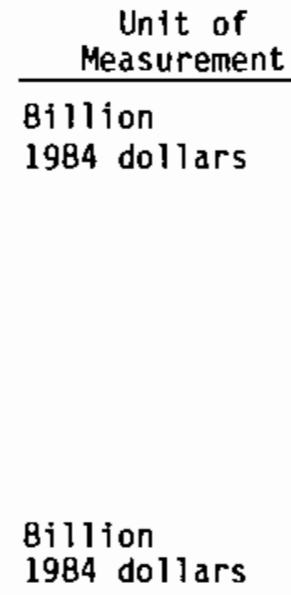

Unit of Measurement Billion 1984 dollars

Billion

1984 dollars Plyood Markets

Point estimates of future value in

value, (c) 1985-2030
Reduced Growth Scenarios

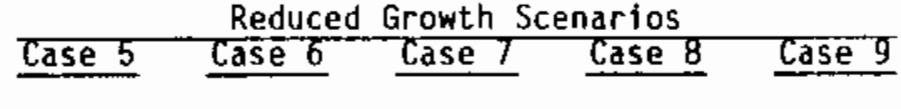

$\begin{array}{rrrrr}3.19 & 3.14 & 3.17 & 3.21 & 3.14 \\ 3.74 & 3.68 & 3.63 & 3.88 & 3.71 \\ 4.55 & 4.46 & 4.31 & 4.76 & 4.46 \\ & & & & \\ 34.49 & 34.24 & 33.88 & 34.92 & 34.24\end{array}$

$\begin{array}{rrrrr}9.47 & 9.34 & 9.42 & 9.52 & 9.34 \\ 10.65 & 10.61 & 10.51 & 11.18 & 10.63 \\ 12.54 & 12.31 & 11.91 & 13.10 & 12.27 \\ 101.79 & 101.34 & 100.36 & 102.78 & 101.32\end{array}$


TABLE C.1. Simulated Effects of Various Scenarios on Growing Stock Inventories, Harvests, Stumpage Prices, Lumber and Plywood Production, Lumber and Plywood Consumption, the Wholesale Price Indices of Lumber and Plywood, and Economic Surpluses

Unit of

Item and Year

Consuners' Surplus in Soft-

wood Lumber and PIywood

Markets in the Lower 48

States

Point estimates of future

value in

2000

2015

2030

Cumulatiye net present

value, $(c)$ 1985-2030

Consumers' Surpius in Hardwood Lumber Markets in the Lower 48 States

Point estimates of future value in

2000

2030

Cumulatiye net present

value, (c) 1985-2030

1984 dollars

Billion

1984 dollars

\section{Measurement \\ Billion}

ase

\section{Case}

ase

Case 1

Case

Case 8 Case 9

33.43

37.76

44.79

33.04

37.56

33.24
37.28

43.87

42.76

33.61

39.45

46.35

33.04

359.45

357.86

354.41

362.59

43.87

$\begin{array}{rrrrr}3.03 & 3.03 & 3.02 & 3.03 & 3.05 \\ 3.59 & 3.57 & 3.54 & 3.57 & 3.64 \\ 3.80 & 3.74 & 3.67 & 3.76 & 3.87 \\ & & & & \\ 33.46 & 33.34 & 33.20 & 33.34 & 33.68\end{array}$


IABLE C.1. Simulated Effects of Various Scenarios on Growing Stock Inventories, Harvests, Stumpage Prices, Lumber and Plywood Production, Lumber and Plywood Consumption, the Wholesale Price Indices of Lumber and Plywood, and Economic Surpluses
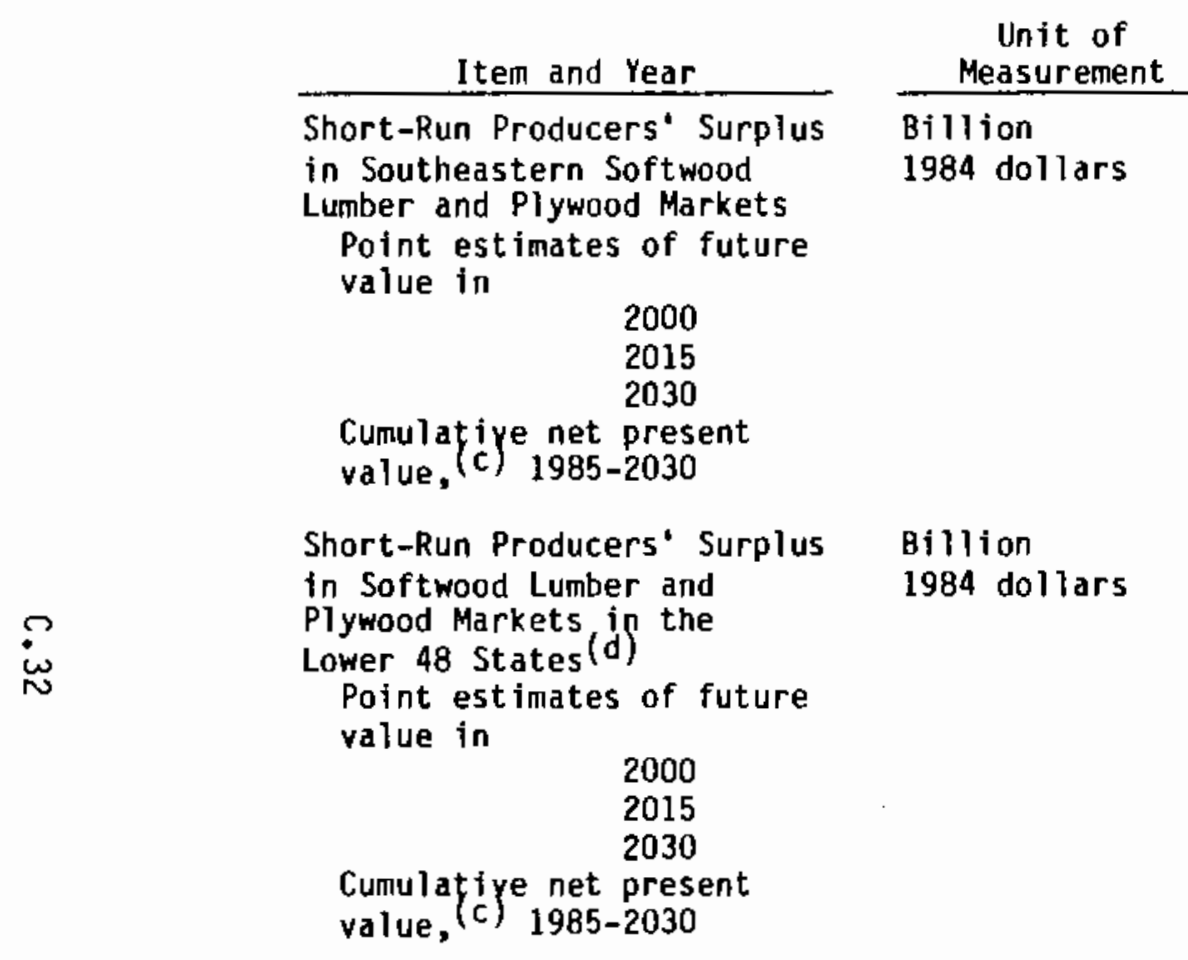
TABLE C.1. Simulated Effects of Various Scenarios on Growing Stock Inventories, Harvests, Stumpage Prices, Lumber and Plywood Production, Lumber and Plywood Consumption, the Wholesale Price Indices of Lumber and Plywood, and Economic Surpluses

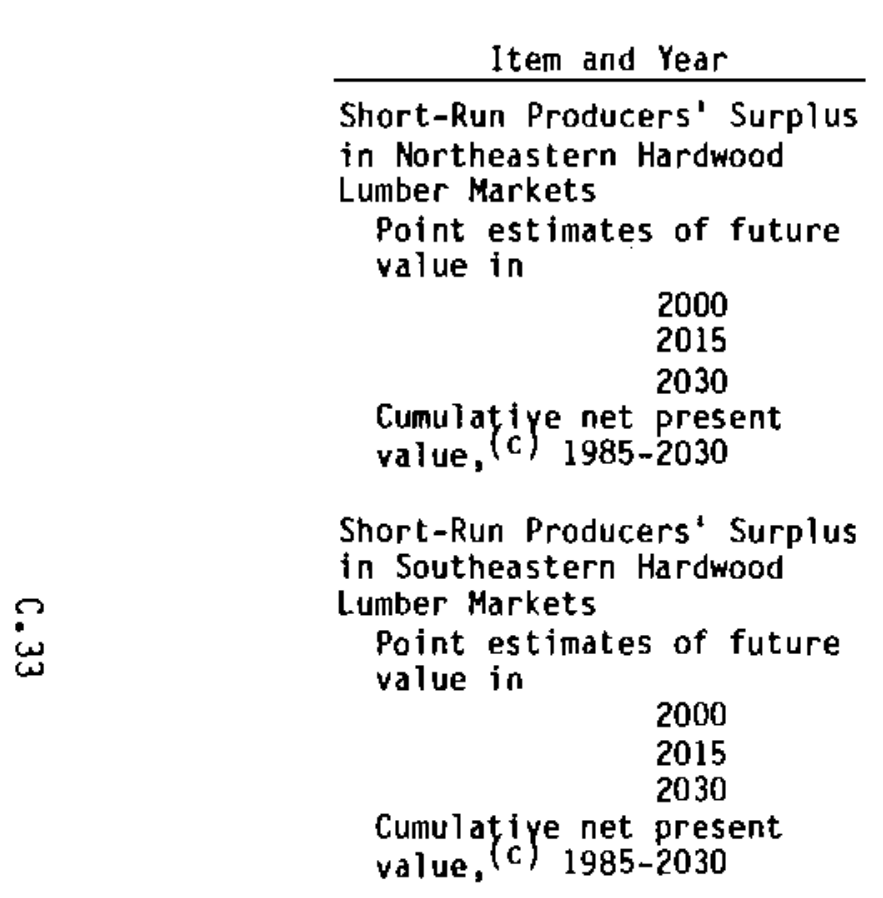

Reduced Growth Scenarios

Unit of
Measurement

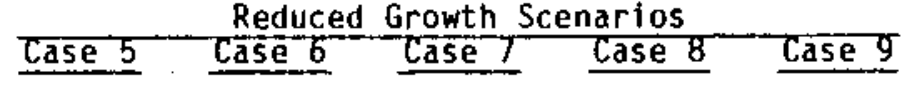

Case 9

Billion

1984 dollars

umber Markets

Point estimates of future

value in

$\begin{array}{lllll}0.66 & 0.66 & 0.66 & 0.66 & 0.66 \\ 0.93 & 0.92 & 0.91 & 0.92 & 0.95 \\ 1.30 & 1.28 & 1.26 & 1.26 & 1.35 \\ 7.75 & 7.71 & 7.67 & 7.69 & 7.83\end{array}$

Billion

1984 dollars

umber Markets

Point estimates of future

value in

$$
2015
$$

value, (c) 1985-2030

$\begin{array}{rrrrr}0.89 & 0.88 & 0.88 & 0.88 & 0.90 \\ 1.19 & 1.17 & 1.15 & 1.17 & 1.22 \\ 1.52 & 1.48 & 1.44 & 1.48 & 1.61 \\ 10.20 & 10.11 & 10.02 & 10.11 & 10.37\end{array}$


TABLE C.1. Simulated Effects of Various Scenarios on Growing Stock Inventories, Harvests, Stumpage Prices, Lumber and Plywood Production, Lumber and Plywood Consumption, the Wholesale Price Indices of Lumber and Plywood, and Economic Surpluses

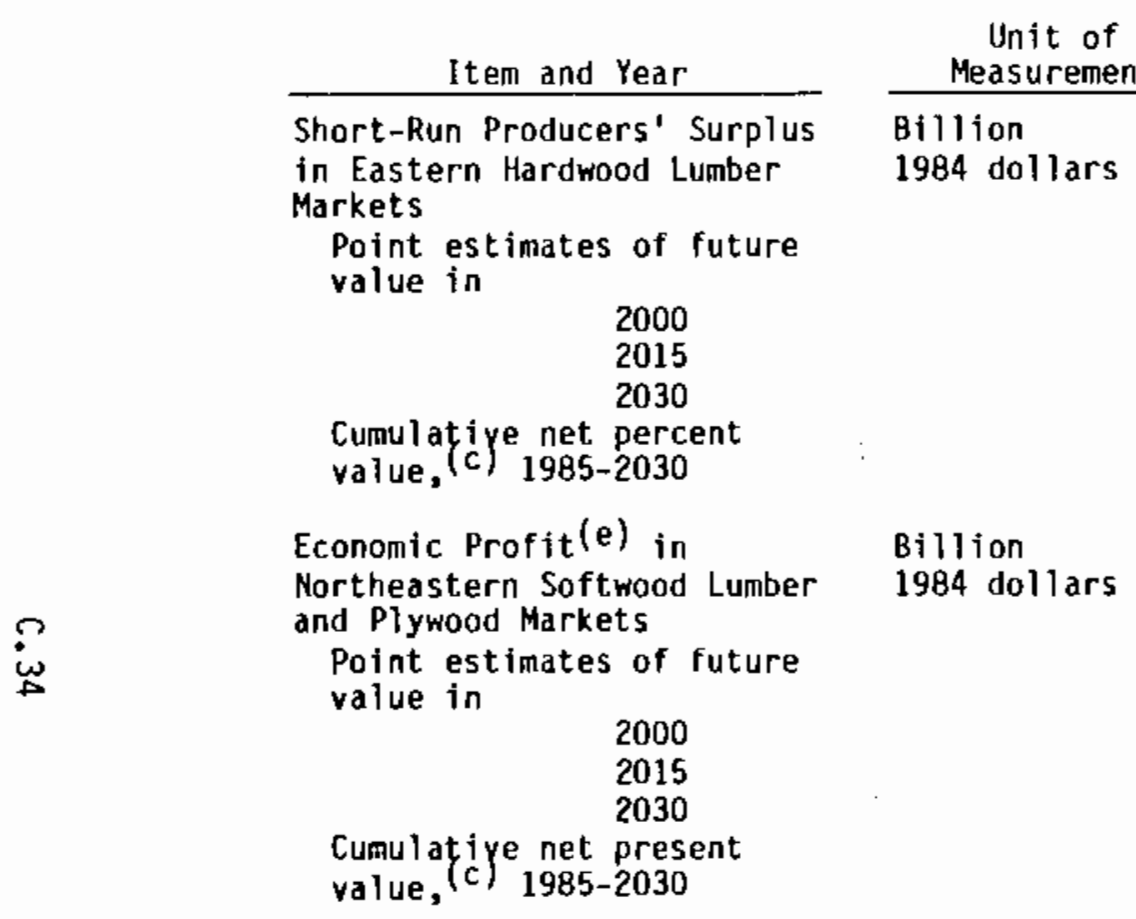

\begin{tabular}{|c|c|}
\hline Item and Year & Measuremer \\
\hline $\begin{array}{l}\text { Short-Run Producers' Surplus } \\
\text { in Eastern Hardwood Lumber } \\
\text { Markets }\end{array}$ & $\begin{array}{l}\text { Billion } \\
1984 \text { dollars }\end{array}$ \\
\hline $\begin{array}{l}\text { Point estimates of future } \\
\text { value in }\end{array}$ & \\
\hline $\begin{array}{l}2000 \\
2015 \\
2030\end{array}$ & \\
\hline $\begin{array}{l}\text { Cumulatice net percent } \\
\text { value, } \\
\text { c) }\end{array}$ & \\
\hline $\begin{array}{l}\text { Economic Profit (e) in } \\
\text { Northeastern Softwood Lumber } \\
\text { and Plywood Markets }\end{array}$ & $\begin{array}{l}\text { Billion } \\
1984 \text { dollars }\end{array}$ \\
\hline $\begin{array}{l}\text { Point estimates of future } \\
\text { value in }\end{array}$ & \\
\hline $\begin{array}{l}2000 \\
2015 \\
2030\end{array}$ & \\
\hline $\begin{array}{l}\text { Cumulatiye net present } \\
\text { value, }\end{array}$ & \\
\hline
\end{tabular}

$\begin{array}{rrrrr}3.46 & 3.46 & 3.46 & 3.46 & 3.47 \\ 4.83 & 4.82 & 4.81 & 4.82 & 4.84 \\ 6.44 & 6.41 & 6.36 & 6.42 & 6.48 \\ 40.31 & 40.28 & 40.24 & 40.28 & 40.36\end{array}$

$\begin{array}{rrrrr}-0.12 & -0.11 & -0.11 & -0.12 & -0.11 \\ -0.01 & 0.00 & 0.01 & -0.03 & 0.00 \\ 0.03 & 0.05 & 0.08 & 0.00 & 0.05 \\ -0.76 & -0.73 & -0.66 & -0.81 & -0.73\end{array}$


TABLE C.1. Simulated Effects of Various Scenarios on Growing Stock Inventories, Harvests, Stumpage Prices, Lumber and Plywood Production, Lumber and Plywood Consumption, the Wholesale Price Indices of Lumber and Plywood, and Economic Surpluses

\begin{tabular}{l} 
Item and Year \\
\hline Economic Profit (e) in \\
Southeastern Softwood Lumber \\
and Plywood Markets \\
Point estimates of future \\
value in \\
$\qquad 2000$ \\
2015 \\
Cumulatiye net present \\
value, (c) 1985-2030 \\
Economic Profit(e) in \\
Softwood Lumber and Plywood \\
Markets in the Lower 48 \\
States \\
Point estimates of future \\
value in $\quad 2000$ \\
Cumulatiye net present \\
value, (c) 1985-2030
\end{tabular}

Reduced Growth Scenarios

\begin{tabular}{|c|c|c|c|c|c|}
\hline \multirow{2}{*}{ Measurement } & \\
\hline & Case 5 & Case 6 & Case 7 & Case 8 & Case 9 \\
\hline \multicolumn{6}{|l|}{$\begin{array}{l}8 \text { illion } \\
1984 \text { dollars }\end{array}$} \\
\hline & $\begin{array}{r}-0.58 \\
0.19 \\
0.54\end{array}$ & $\begin{array}{r}-0.51 \\
0.19 \\
0.59\end{array}$ & $\begin{array}{r}-0.55 \\
0.21 \\
0.67\end{array}$ & $\begin{array}{r}-0.59 \\
0.03 \\
0.38\end{array}$ & $\begin{array}{r}-0.51 \\
0.17 \\
0.57\end{array}$ \\
\hline & -3.08 & -2.58 & -2.51 & -3.32 & -2.89 \\
\hline \multicolumn{6}{|l|}{$\begin{array}{l}\text { Billion } \\
1984 \text { dollars }\end{array}$} \\
\hline & $\begin{array}{r}-3.83 \\
0.91 \\
2.86\end{array}$ & $\begin{array}{r}-3.50 \\
1.04 \\
3.55\end{array}$ & $\begin{array}{r}-3.75 \\
1.08 \\
4.31\end{array}$ & $\begin{array}{r}-3.91 \\
-0.18 \\
1.66\end{array}$ & $\begin{array}{r}-3.50 \\
0.91 \\
3.47\end{array}$ \\
\hline & -21.35 & -20.57 & -18.37 & -23.37 & -20.55 \\
\hline
\end{tabular}


TABLE C.1. Simulated Effects of Various Scenarios on Growing Stock Inventories, Harvests, Stumpage Prices, Lumber and Plywood Production, Lumber and Plywood Consumption, the Wholesale Price Indices of Lumber and Plywood, and Economic Surpluses

Unit of

\begin{tabular}{l} 
Measurement \\
\hline Billion \\
1984 dollars
\end{tabular}

1984 dollars

Economic Profit (e) in
Northeastern Hardwood Lumber

Markets

Point estimates of future

value in

$$
\begin{aligned}
& 2000 \\
& 2015 \\
& 2030
\end{aligned}
$$

Cumulatiye net present value, (c) 1985-2030

\section{Economic Profit(e) in Southeastern Hardwood Lumber Markets \\ Point estimates of future
value in}

2000

2015

2030

Cumulatiye net present

value, (c) 1985-2030

Economic Profit(e) in

Eastern Hardwood Lumber Markets

Point estimates of future value in

$$
\begin{aligned}
& 2000 \\
& 2015
\end{aligned}
$$$$
2030
$$

Cumulatiye net present

value, (c) 1985-2030

Billion

1984 dollars

Billion

1984 dollars
Reduced Growth Scenarios

Reduced Growth Scenarios
Cáse 5 Case 6 Case ? Case 8 Case 9

$\begin{array}{lllll}0.07 & 0.08 & 0.08 & 0.08 & 0.07 \\ 0.24 & 0.24 & 0.24 & 0.24 & 0.24 \\ 0.51 & 0.51 & 0.52 & 0.51 & 0.51 \\ & & & & \\ 1.23 & 1.24 & 1.25 & 1.24 & 1.21\end{array}$

$\begin{array}{lllll}0.10 & 0.10 & 0.10 & 0.10 & 0.09 \\ 0.31 & 0.31 & 0.31 & 0.31 & 0.31 \\ 0.65 & 0.65 & 0.65 & 0.65 & 0.66 \\ & & & & \\ 1.59 & 1.60 & 1.61 & 1.60 & 1.58\end{array}$

$\begin{array}{lllll}0.39 & 0.40 & 0.40 & 0.40 & 0.39 \\ 1.29 & 1.31 & 1.33 & 1.31 & 1.27 \\ 2.74 & 2.78 & 2.82 & 2.76 & 2.71 \\ 6.60 & 6.67 & 6.74 & 6.66 & 6.48\end{array}$


TABLE C.1. Simulated Effects of Various Scenarios on Growing Stock Inventories, Harvests, Stumpage Prices, Lumber and Plywood Production, Lumber and Plywood Consumption, the Wholesale Price Indices of Lumber and Plywood, and Econoric Surpluses

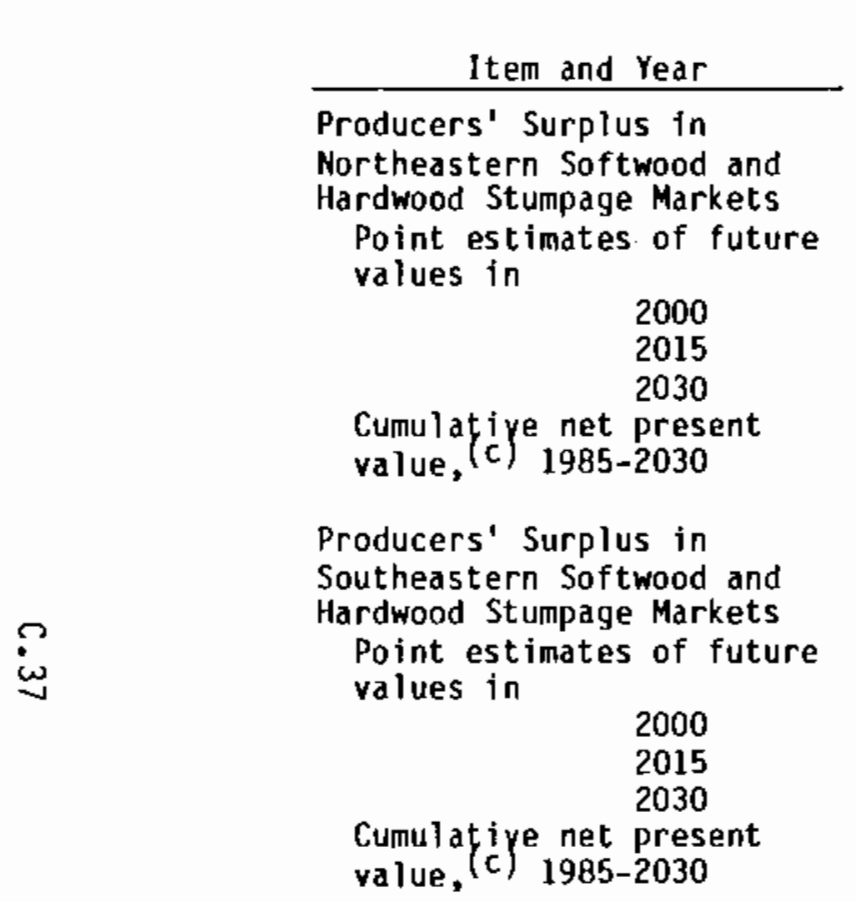

Reduced Growth Scenarios

\begin{tabular}{l} 
Measurement \\
\hline Billion \\
1984 dollars
\end{tabular}

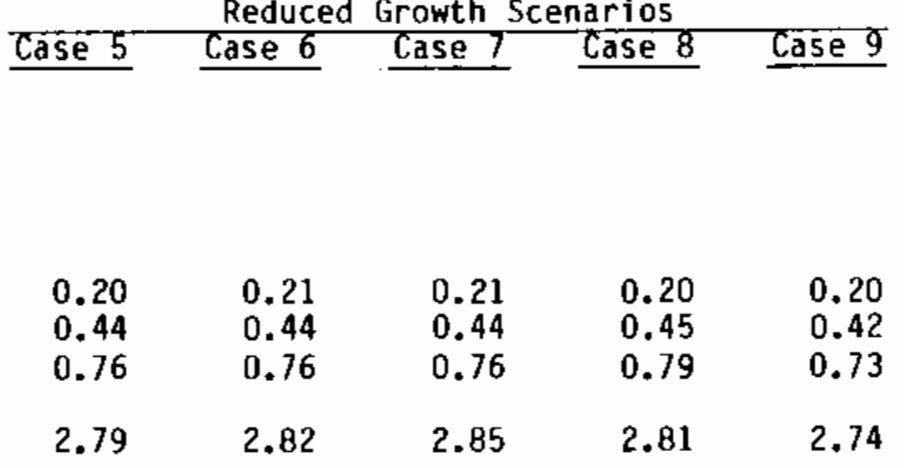

Billion

1984 dollars

$\begin{array}{rrrrr}0.93 & 0.94 & 0.92 & 0.95 & 0.93 \\ 1.40 & 1.26 & 1.34 & 1.61 & 1.24 \\ 1.70 & 1.54 & 1.44 & 2.19 & 1.51 \\ 10.21 & 10.04 & 9.90 & 10.80 & 9.96\end{array}$


TABLE C.1. Simulated Effects of Various Scenarios on Growing Stock Inventories, Harvests, Stumpage Prices, Lumber and Plywood Production, Lumber and Plywood Consumption, the Wholesale Price Indices of Lumber and Plywood, and Economic Surpluses

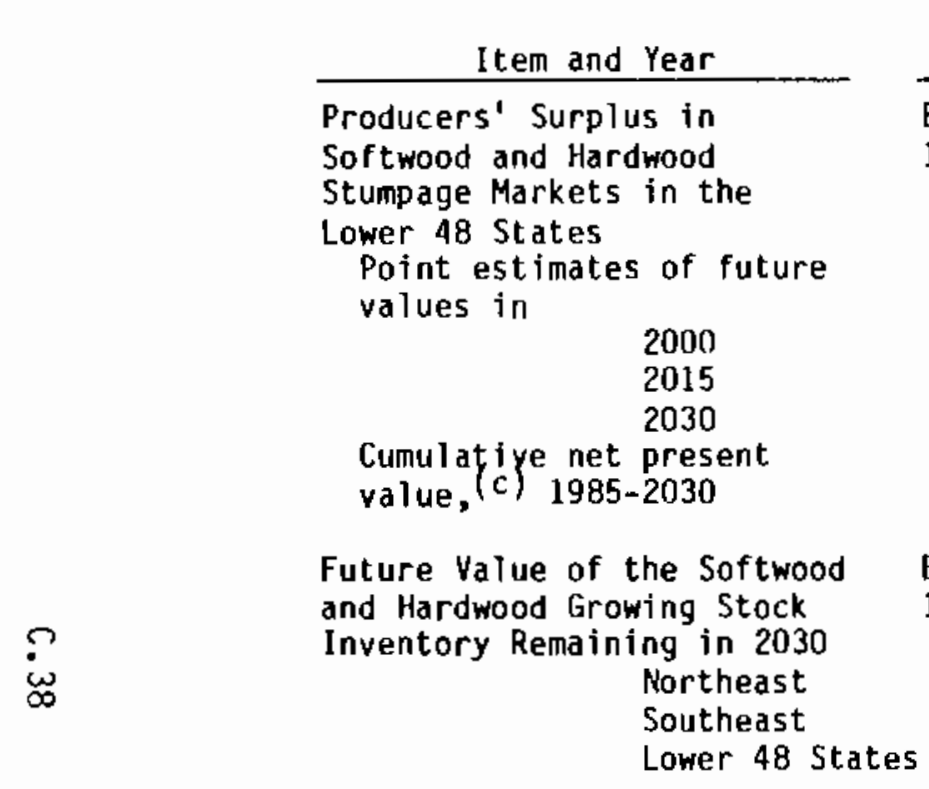

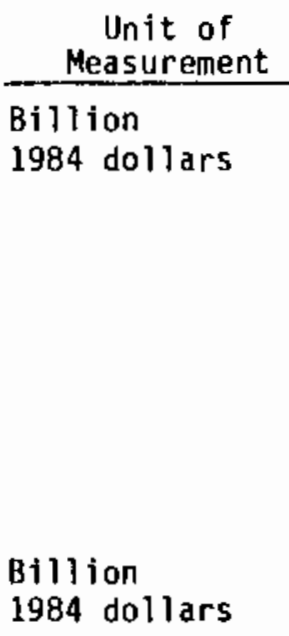

Unit of Measurement

Billion

1984 dollars

Billion

1984 dollars

Point estimates of future

values in

$$
2000
$$

Cumulatiye net present

Future Value of the Softwood and Hardwood Growing Stock

Lower 48 States
Reduced Growth Scenarios

Reduced Growth Scenarios
Case 5 Case- 6 Case I Case 8 Case 9

$\begin{array}{rrrrr}4.47 & 4.54 & 4.50 & 4.44 & 4.52 \\ 6.45 & 6.26 & 7.36 & 6.34 & 6.20 \\ 8.22 & 8.37 & 8.45 & 8.37 & 8.28 \\ 49.91 & 50.44 & 51.63 & 49.50 & 50.20\end{array}$

$\begin{array}{rrrrr}78.07 & 78.01 & 77.34 & 82.16 & 73.52 \\ 105.35 & 96.22 & 86.78 & 127.69 & 93.91 \\ 436.34 & 430.96 & 423.52 & 447.44 & 421.57\end{array}$


TABLE C.2. Simulated Effects of Various Scenarios on Growing Stock Inventories, Harvests, Stumpage Prices, Lumber and Plywood Production, Lumber and Plywood Consumption, the Wholesale Price Indices of Lumber and Plywood, and Economic Surpluses

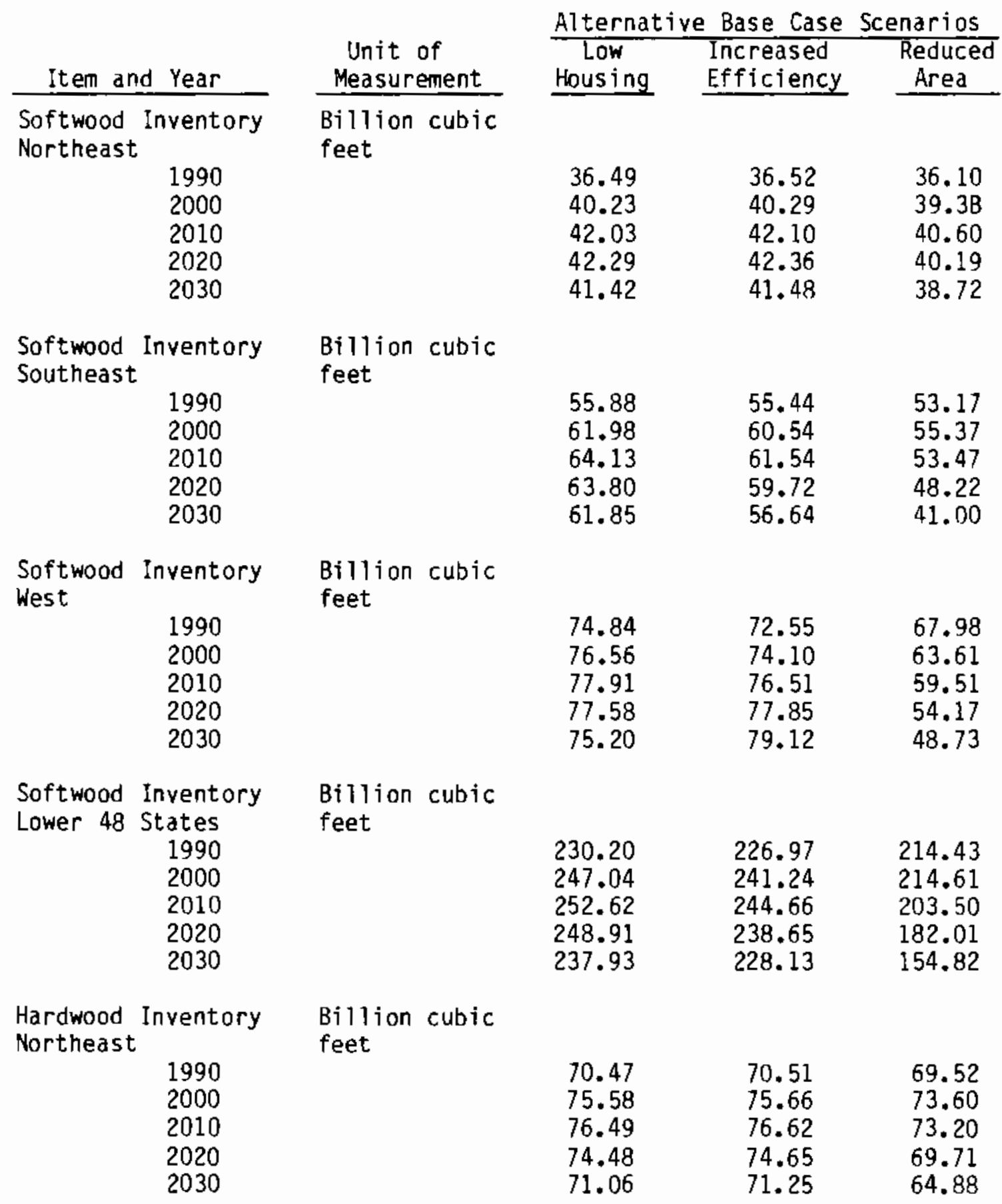


TABLE C.2. Simulated Effects of Various Scenarios on Growing Stock Inventories, Harvests, Stumpage Prices, Lumber and Plywood Production, Lumber and Plywood Consumption, the Wholesale Price Indices of Lumber and Plywood, and Economic Surpluses

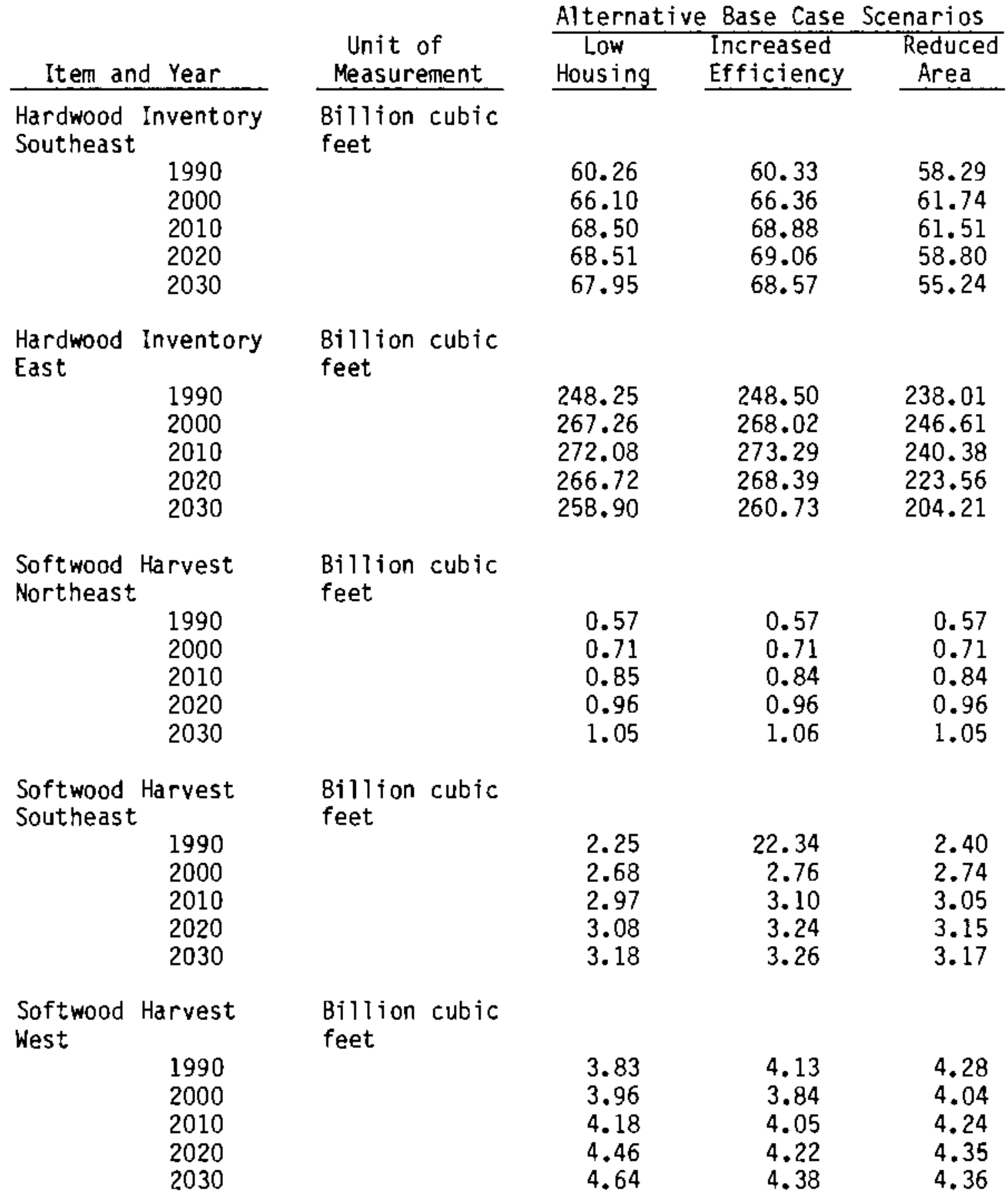


TABLE C.2. Simulated Effects of Various Scenarios on Growing Stock Inventories, Harvests, Stumpage Prices, Lumber and Plywood Production, Lumber and Plywood Consumption, the Wholesale Price Indices of Lumber and Plywood, and Economic Surpluses

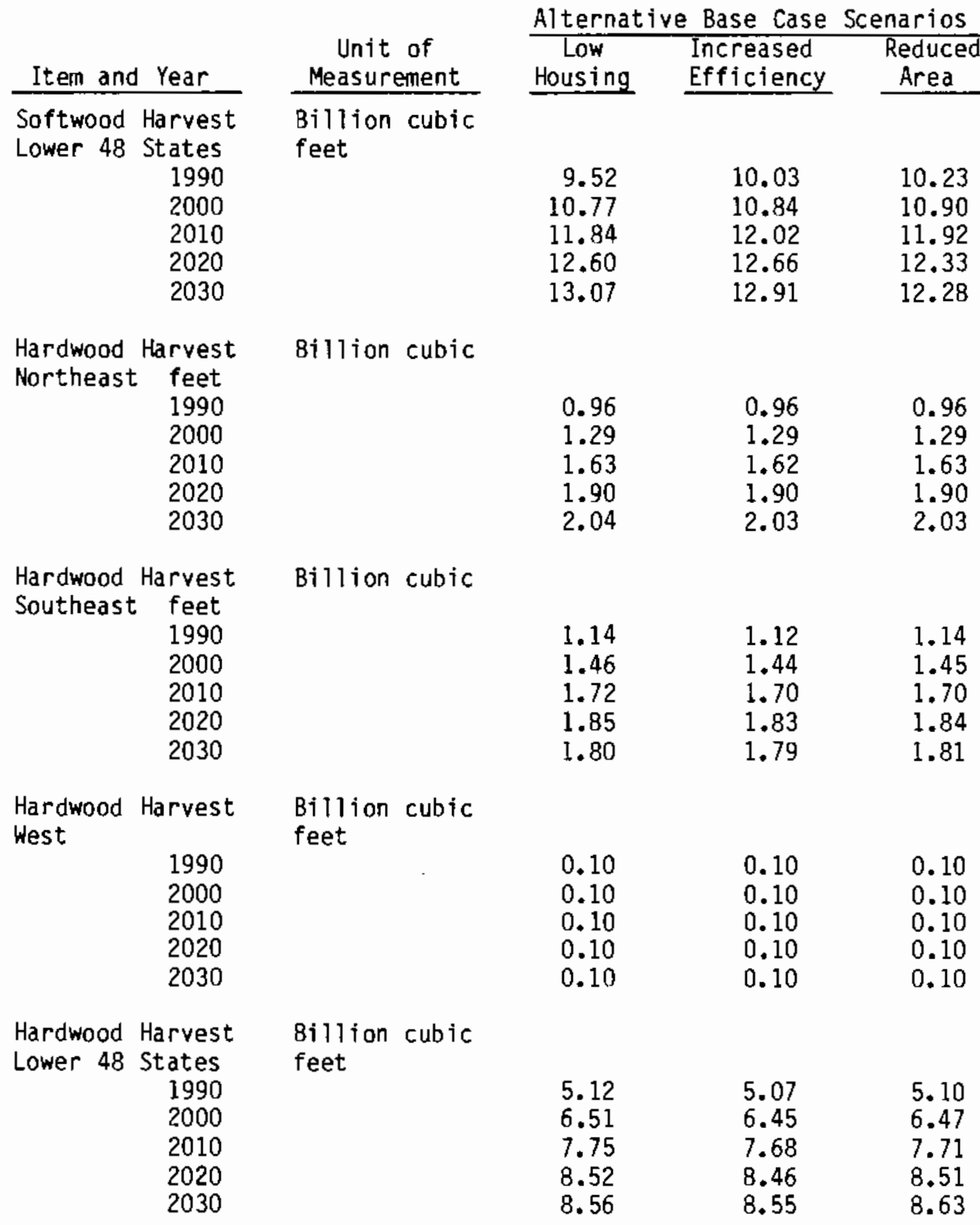


TABLE C.2. Simulated Effects of Various Scenarios on Growing Stock Inventories, Harvests, Stumpage Prices, Lumber and Plywood Production, Lumber and Plywood Consumption, the Wholesale Price Indices of Lumber and Plywood, and Economic Surpluses

\begin{tabular}{|c|c|c|c|c|}
\hline Item and Year & $\begin{array}{c}\text { Unit of } \\
\text { Measurement }\end{array}$ & $\begin{array}{l}\text { Alternat } \\
\text { Low } \\
\text { Housing }\end{array}$ & $\begin{array}{l}\text { Ie Base Case } \\
\text { Increased } \\
\text { Efficiency }\end{array}$ & $\begin{array}{c}\text { Scenarios } \\
\text { Reduced } \\
\text { Area } \\
\end{array}$ \\
\hline $\begin{array}{l}\text { Softwood Stumpage Price } \\
\text { Northeast } \\
\\
1990 \\
2000 \\
2010 \\
2020 \\
2030\end{array}$ & $\begin{array}{l}1967 \\
\text { Dollars per } \\
\text { thousand } \\
\text { board feet, } \\
\text { Scribner log } \\
\text { rule }\end{array}$ & $\begin{array}{l}18.36 \\
26.46 \\
37.23 \\
48.66 \\
58.78\end{array}$ & $\begin{array}{l}17.95 \\
26.01 \\
36.86 \\
48.46 \\
58.79\end{array}$ & $\begin{array}{l}18.87 \\
27.59 \\
39.15 \\
51.45 \\
62.49\end{array}$ \\
\hline $\begin{array}{l}\text { Softwood Stumpage Price } \\
\text { Southeast } \\
\qquad \begin{array}{l}1990 \\
2000 \\
2010 \\
2020 \\
2030\end{array}\end{array}$ & $\begin{array}{l}1967 \\
\text { Dollars per } \\
\text { thousand } \\
\text { board feet, } \\
\text { Scribner log } \\
\text { rule }\end{array}$ & $\begin{array}{l}51.18 \\
61.61 \\
68.52 \\
75.01 \\
92.10\end{array}$ & $\begin{array}{l}63.91 \\
63.35 \\
75.47 \\
85.29 \\
94.68\end{array}$ & $\begin{array}{r}76.55 \\
87.61 \\
112.24 \\
133.77 \\
162.15\end{array}$ \\
\hline $\begin{array}{c}\text { Softwood Stumpage Price(a) } \\
\text { Pacific Northwest West } \\
1990 \\
2000 \\
2010 \\
2020 \\
2030\end{array}$ & $\begin{array}{l}1967 \\
\text { Dollars per } \\
\text { thousand } \\
\text { board feet, } \\
\text { Scribner log } \\
\text { rule }\end{array}$ & $\begin{array}{l}41.47 \\
43.29 \\
48.32 \\
65.61 \\
75.63\end{array}$ & $\begin{array}{l}64.39 \\
35.53 \\
47.11 \\
57.20 \\
58.89\end{array}$ & $\begin{array}{r}82.29 \\
72.46 \\
99.69 \\
125.21 \\
144.94\end{array}$ \\
\hline 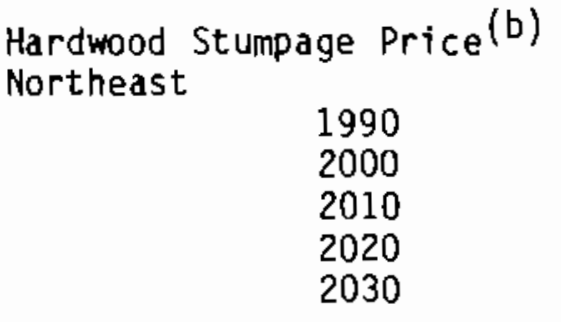 & $\begin{array}{l}1967 \\
\text { Dollars per } \\
\text { thousand } \\
\text { board feet, } \\
\text { Scribner log } \\
\text { rule }\end{array}$ & $\begin{array}{l}24.92 \\
24.40 \\
26.29 \\
29.79 \\
35.23\end{array}$ & $\begin{array}{l}22.18 \\
19.87 \\
20.62 \\
23.43 \\
28.66\end{array}$ & $\begin{array}{l}25.67 \\
25.86 \\
28.78 \\
33.84 \\
41.54\end{array}$ \\
\hline $\begin{array}{l}\text { Hardwood Stumpage Price (b) } \\
\text { Southeast } \\
\qquad \begin{array}{l}1990 \\
2000 \\
2010 \\
2020 \\
2030\end{array}\end{array}$ & $\begin{array}{l}1967 \\
\text { Dollars per } \\
\text { thousand } \\
\text { board feet, } \\
\text { Scribner log } \\
\text { rule }\end{array}$ & $\begin{array}{l}17.72 \\
15.45 \\
14.59 \\
14.09 \\
14.80\end{array}$ & $\begin{array}{r}14.91 \\
10.96 \\
9.30 \\
8.51 \\
9.44\end{array}$ & $\begin{array}{l}18.85 \\
17.66 \\
18.11 \\
19.29 \\
22.43\end{array}$ \\
\hline
\end{tabular}


TABLE C.2. Simulated Effects of Various Scenarios on Growing Stock Inventories, Harvests, Stumpage Prices, Lumber and Plywood Production, Lumber and Plywood Consumption, the Wholesale Price Indices of Lumber and Plywood, and Economic Surpluses

\begin{tabular}{|c|c|c|c|c|c|}
\hline \multicolumn{2}{|c|}{ Item and Year } & $\begin{array}{c}\text { Unit of } \\
\text { Measurement }\end{array}$ & $\begin{array}{l}\text { Alternat } \\
\text { Low } \\
\text { Housing } \\
\end{array}$ & $\begin{array}{l}\text { ve Base Case } \\
\text { Increased } \\
\text { Efficiency }\end{array}$ & $\begin{array}{c}\text { Scenarios } \\
\text { Reduced } \\
\text { Area } \\
\end{array}$ \\
\hline $\begin{array}{l}\text { Total Lumber } \\
\text { Northeast }\end{array}$ & $\begin{array}{l}\text { Production } \\
\\
1990 \\
2000 \\
2010 \\
2020 \\
2030\end{array}$ & $\begin{array}{l}\text { Billion } \\
\text { board feet, } \\
\text { lumber tally }\end{array}$ & $\begin{array}{l}2.47 \\
2.71 \\
2.94 \\
3.16 \\
3.41\end{array}$ & $\begin{array}{l}2.48 \\
2.73 \\
2.97 \\
3.21 \\
3.46\end{array}$ & $\begin{array}{l}2.47 \\
2.72 \\
2.96 \\
3.18 \\
3.43\end{array}$ \\
\hline $\begin{array}{l}\text { Total Lumber } \\
\text { Southeast }\end{array}$ & $\begin{array}{l}\text { Production } \\
\qquad \begin{array}{l}1990 \\
2000 \\
2010 \\
2020 \\
2030\end{array}\end{array}$ & $\begin{array}{l}\text { Billion } \\
\text { board feet, } \\
\text { lumber tally }\end{array}$ & $\begin{array}{r}6.59 \\
8.17 \\
9.37 \\
10.23 \\
11.52\end{array}$ & $\begin{array}{r}7.36 \\
8.76 \\
10.45 \\
11.47 \\
12.11\end{array}$ & $\begin{array}{r}7.29 \\
8.54 \\
10.03 \\
10.89 \\
11.60\end{array}$ \\
\hline $\begin{array}{l}\text { Total Lumber } \\
\text { West }\end{array}$ & $\begin{array}{l}\text { Production } \\
\qquad \begin{array}{l}1990 \\
2000 \\
2010 \\
2020 \\
2030\end{array}\end{array}$ & $\begin{array}{l}\text { Billion } \\
\text { board feet, } \\
\text { lumber taliy }\end{array}$ & $\begin{array}{l}16.20 \\
17.53 \\
18.82 \\
21.11 \\
22.97\end{array}$ & $\begin{array}{l}19.71 \\
1 B .44 \\
20.07 \\
21.75 \\
22.86\end{array}$ & $\begin{array}{l}19.28 \\
18.06 \\
19.34 \\
19.83 \\
19.60\end{array}$ \\
\hline $\begin{array}{l}\text { Total Lumber } \\
\text { Lower } 48 \text { Stat }\end{array}$ & $\begin{array}{l}\text { Production } \\
\text { es } \\
1990 \\
2000 \\
2010 \\
2020 \\
2030\end{array}$ & $\begin{array}{l}\text { Billion } \\
\text { board feet, } \\
\text { lumber talliy }\end{array}$ & $\begin{array}{l}36.46 \\
41.21 \\
45.33 \\
49.22 \\
53.24\end{array}$ & $\begin{array}{l}41.65 \\
43.73 \\
48.99 \\
52.14 \\
54.02\end{array}$ & $\begin{array}{l}40.70 \\
41.97 \\
45.70 \\
46.63 \\
46.06\end{array}$ \\
\hline $\begin{array}{l}\text { Softwood Lumbe } \\
\text { from Canada }\end{array}$ & $\begin{array}{l}\text { er Imports } \\
1990 \\
2000 \\
2010 \\
2020 \\
2030\end{array}$ & $\begin{array}{l}\text { Billion } \\
\text { board feet, } \\
\text { lumber tally }\end{array}$ & $\begin{array}{r}11.13 \\
7.64 \\
5.86 \\
4.12 \\
2.15\end{array}$ & $\begin{array}{l}13.44 \\
11.99 \\
12.23 \\
11.62 \\
10.24\end{array}$ & $\begin{array}{l}12.99 \\
11.52 \\
11.67 \\
12.01 \\
11.97\end{array}$ \\
\hline
\end{tabular}


TABLE C.2. Simulated Effects of Various Scenarios on Growing Stock Inventories, Harvests, Stumpage Prices, Lumber and Plywood Production, Lumber and Plywood Consumption, the Wholesale Price Indices of Lumber and Plywood, and Economic Surpluses

\begin{tabular}{|c|c|c|c|c|c|}
\hline \multirow{2}{*}{\multicolumn{2}{|c|}{ Item and Year }} & \multirow{2}{*}{$\begin{array}{l}\text { Unit of } \\
\text { Measurement } \\
\text { Billion } \\
\text { board feet, }\end{array}$} & \multicolumn{2}{|c|}{ Alternative Base Case } & \multirow{2}{*}{$\begin{array}{c}\text { Scenarios } \\
\text { Reduced } \\
\text { Area } \\
\end{array}$} \\
\hline & & & $\begin{array}{l}\text { Low } \\
\text { Housing }\end{array}$ & $\begin{array}{l}\text { Increased } \\
\text { Efficiency }\end{array}$ & \\
\hline $\begin{array}{l}\text { Softwood Lumber } \\
\text { Lower } 48 \text { States }\end{array}$ & $\begin{array}{l}\text { Consumption } \\
1990 \\
2000 \\
2010 \\
2020 \\
2030\end{array}$ & $\begin{array}{l}\text { Billion } \\
\text { board feet, } \\
\text { lumber tally }\end{array}$ & $\begin{array}{l}36.59 \\
36.84 \\
38.41 \\
39.87 \\
41.13\end{array}$ & $\begin{array}{l}43.95 \\
43.43 \\
48.02 \\
49.65 \\
49.44\end{array}$ & $\begin{array}{l}42.64 \\
41.54 \\
44.76 \\
45.50 \\
44.30\end{array}$ \\
\hline $\begin{array}{l}\text { Hardwood Lumber } \\
\text { Lower } 48 \text { States }\end{array}$ & $\begin{array}{l}\text { Consumption } \\
1990 \\
2000 \\
2010 \\
2020 \\
2030\end{array}$ & $\begin{array}{l}\text { Billion } \\
\text { board feet, } \\
\text { lumber taliy }\end{array}$ & $\begin{array}{r}9.03 \\
10.02 \\
10.87 \\
11.49 \\
12.32\end{array}$ & $\begin{array}{r}9.14 \\
10.21 \\
11.14 \\
11.80 \\
12.65\end{array}$ & $\begin{array}{r}8.96 \\
9.87 \\
10.62 \\
11.09 \\
11.67\end{array}$ \\
\hline $\begin{array}{l}\text { Softwood Lumber } \\
\text { Price Index }\end{array}$ & $\begin{array}{l}\text { Wholesale } \\
1990 \\
2000 \\
2010 \\
2020 \\
2030\end{array}$ & $\begin{array}{l}\text { Index of } \\
\text { price per } \\
\text { thousand } \\
\text { board feet, } \\
\text { Scribner } \\
\text { log rule, } \\
1967=100.00\end{array}$ & $\begin{array}{l}158.65 \\
178.07 \\
185.45 \\
198.35 \\
212.31\end{array}$ & $\begin{array}{l}152.01 \\
178.11 \\
180.46 \\
182.51 \\
187.07\end{array}$ & $\begin{array}{l}170.35 \\
204.02 \\
226.38 \\
247.65 \\
266.61\end{array}$ \\
\hline $\begin{array}{l}\text { Hardwood Lumber } \\
\text { Price Index }\end{array}$ & $\begin{array}{l}\text { Wholesale } \\
1990 \\
2000 \\
2010 \\
2020 \\
2030\end{array}$ & $\begin{array}{l}\text { Index of } \\
\text { price per } \\
\text { thousand } \\
\text { board feet, } \\
\text { Scribner } \\
\text { log rule, } \\
1967=100.00\end{array}$ & $\begin{array}{l}116.87 \\
125.31 \\
136.90 \\
149.38 \\
165.42\end{array}$ & $\begin{array}{l}115.08 \\
122.36 \\
133.22 \\
145.52 \\
161.71\end{array}$ & $\begin{array}{l}117.97 \\
127.46 \\
140.2 B \\
154.41 \\
172.70\end{array}$ \\
\hline
\end{tabular}


TABLE C.2. Simulated Effects of Various Scenarios on Growing Stock Inventories, Harvests, Stumpage Prices, Lumber and Plywood Production, Lumber and Plywood Consumption, the Wholesale Price Indices of Lumber and Plywood, and Economic Surpluses

\begin{tabular}{|c|c|c|c|c|}
\hline \multirow{2}{*}{ Item and Year } & \multirow[b]{2}{*}{$\begin{array}{c}\text { Unit of } \\
\text { Measurement } \\
\end{array}$} & \multicolumn{3}{|c|}{ Alternative Base Case Scenarios } \\
\hline & & $\begin{array}{c}\text { Low } \\
\text { Housing }\end{array}$ & $\begin{array}{l}\text { Increased } \\
\text { Efficiency }\end{array}$ & $\begin{array}{l}\text { Reduced } \\
\text { Area } \\
\end{array}$ \\
\hline $\begin{array}{l}\text { Softwood Plywood Production } \\
\text { Northeast } \\
\qquad \begin{array}{l}1990 \\
2000 \\
2010 \\
2020 \\
2030\end{array}\end{array}$ & $\begin{array}{l}\text { Billion } \\
\text { square feet, } \\
3 / 8-i n c h \\
\text { basis }\end{array}$ & $\begin{array}{l}0.07 \\
0.08 \\
0.09 \\
0.10 \\
0.11\end{array}$ & $\begin{array}{l}0.07 \\
0.08 \\
0.09 \\
0.10 \\
0.11\end{array}$ & $\begin{array}{l}0.07 \\
0.08 \\
0.09 \\
0.10 \\
0.11\end{array}$ \\
\hline $\begin{array}{l}\text { Softwood Plywood Production } \\
\text { Southeast } \\
\qquad \begin{array}{l}1990 \\
2000 \\
2010 \\
2020 \\
2030\end{array}\end{array}$ & $\begin{array}{l}\text { Billion } \\
\text { square feet, } \\
3 / 8-i \text { nch } \\
\text { basis }\end{array}$ & $\begin{array}{l}2.76 \\
3.08 \\
3.16 \\
3.34 \\
3.44\end{array}$ & $\begin{array}{l}3.46 \\
3.82 \\
4.05 \\
4.19 \\
3.95\end{array}$ & $\begin{array}{l}3.34 \\
3.44 \\
3.47 \\
3.27 \\
2.93\end{array}$ \\
\hline $\begin{array}{l}\text { Softwood Plywood Production } \\
\text { Lower } 48 \text { States } \\
\qquad \begin{aligned} 1990 \\
2000 \\
2010 \\
2020 \\
2030\end{aligned}\end{array}$ & $\begin{array}{l}\text { Billion } \\
\text { square feet, } \\
3 / 8-\text { inch } \\
\text { basis }\end{array}$ & $\begin{array}{l}17.92 \\
19.03 \\
20.11 \\
21.43 \\
22.48\end{array}$ & $\begin{array}{l}20.45 \\
21.82 \\
23.94 \\
25.42 \\
26.01\end{array}$ & $\begin{array}{l}19.54 \\
20.03 \\
21.17 \\
21.68 \\
21.55\end{array}$ \\
\hline $\begin{array}{l}\text { Softwood Plywood Consumption } \\
\text { Lower } 48 \text { States } \\
\qquad \begin{array}{l}1990 \\
2000 \\
2010 \\
2020 \\
2030\end{array}\end{array}$ & $\begin{array}{l}\text { Billion } \\
\text { square feet, } \\
3 / 8-i n c h \\
\text { basis }\end{array}$ & $\begin{array}{l}17.04 \\
18.05 \\
19.12 \\
20.35 \\
21.39\end{array}$ & $\begin{array}{l}19.53 \\
20.85 \\
22.94 \\
24.33 \\
24.94\end{array}$ & $\begin{array}{l}18.64 \\
19.06 \\
20.19 \\
20.60 \\
20.47\end{array}$ \\
\hline $\begin{array}{l}\text { Softwood Plywood Wholesale } \\
\text { Price Index }\end{array}$ & $\begin{array}{l}\text { Index of } \\
\text { price per }\end{array}$ & & & \\
\hline $\begin{array}{l}1990 \\
2000 \\
2010 \\
2020 \\
2030\end{array}$ & $\begin{array}{l}\text { thousand } \\
\text { square feet, } \\
3 / 8 \text {-inch } \\
\text { basis, } \\
1967=100.00\end{array}$ & $\begin{array}{l}159.09 \\
166.25 \\
172.24 \\
181.81 \\
191.08\end{array}$ & $\begin{array}{l}164.43 \\
164.08 \\
172.06 \\
177.02 \\
182.29\end{array}$ & $\begin{array}{l}174.37 \\
186.24 \\
205.47 \\
222.12 \\
235.42\end{array}$ \\
\hline
\end{tabular}


TABLE C.2. Simulated Effects of Various Scenarios on Growing Stock Inventories, Harvests, Stumpage Prices, Lumber and Plywood Production, Lumber and Plywood Consumption, the Wholesale Price Indices of Lumber and Plywood, and Economic Surpluses

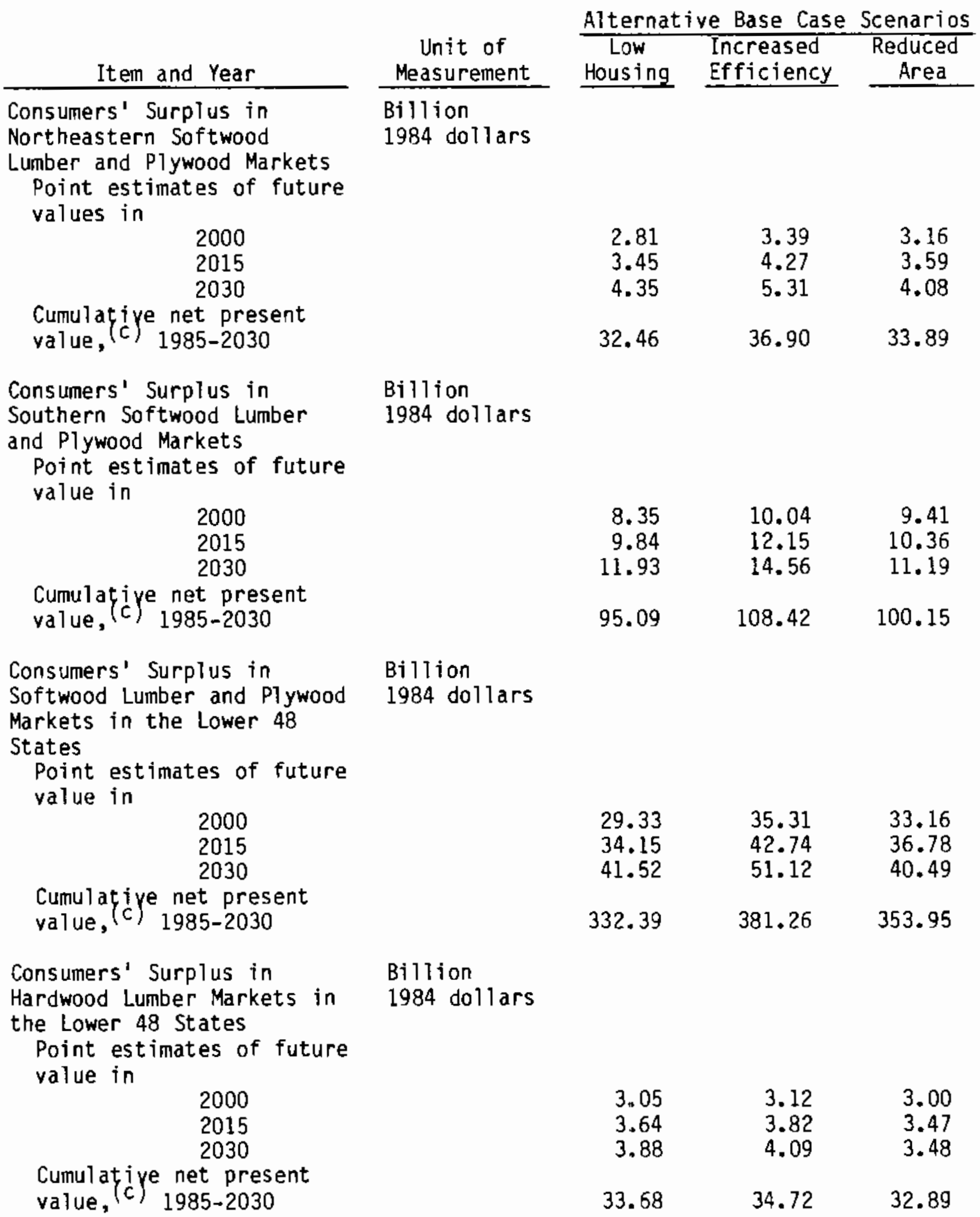


TABLE C.2. Simulated Effects of Various Scenarios on Growing Stock Inventories, Harvests, Stumpage Prices, Lumber and Plywood Production, Lumber and Plywood Consumption, the Wholesale Price Indices of Lumber and Plywood, and Economic Surpluses

\begin{tabular}{|c|c|c|c|c|}
\hline & & Alternat & ve Base Case & $\frac{\text { Scenarios }}{\text { Reduced }}$ \\
\hline Item and Year & $\begin{array}{l}\text { Unit of } \\
\text { Measurement }\end{array}$ & $\begin{array}{l}\text { Low } \\
\text { Housing }\end{array}$ & $\begin{array}{l}\text { Increased } \\
\text { Efficiency }\end{array}$ & $\begin{array}{l}\text { Reduced } \\
\text { Area } \\
\end{array}$ \\
\hline $\begin{array}{l}\text { Short-Run Producers' } \\
\text { Surplus in Southeastern } \\
\text { Softwood Lumber and Plywood } \\
\text { Markets } \\
\text { Point estimates of future } \\
\text { value in }\end{array}$ & $\begin{array}{l}\text { Billion } \\
1984 \text { dollars }\end{array}$ & & & \\
\hline $\begin{array}{l}2000 \\
2015 \\
2030\end{array}$ & & $\begin{array}{l}2.38 \\
3.90 \\
5.40\end{array}$ & $\begin{array}{l}2.86 \\
4.66 \\
5.46\end{array}$ & $\begin{array}{l}3.02 \\
5.10 \\
6.48\end{array}$ \\
\hline $\begin{array}{l}\text { Cumulatije net present } \\
\text { value, }(c)_{1985-2030}\end{array}$ & & 28.80 & 35.17 & 37.06 \\
\hline $\begin{array}{l}\text { Short-Run Producers' } \\
\text { Surplus in Softwood Lumber } \\
\text { and Plywood Markets in the } \\
\text { Lower } 48 \text { States } \\
\text { Point estimates of future } \\
\text { value in }\end{array}$ & $\begin{array}{l}\text { Billion } \\
1984 \text { dollars }\end{array}$ & & & \\
\hline $\begin{array}{r}2000 \\
2015 \\
2030 \\
\end{array}$ & & $\begin{array}{l}13.34 \\
18.76 \\
24.83\end{array}$ & $\begin{array}{l}15.79 \\
21.25 \\
24.12\end{array}$ & $\begin{array}{l}16.44 \\
22.52 \\
24.93\end{array}$ \\
\hline $\begin{array}{l}\text { Cumulaticiye net present } \\
\text { value,(c), } \\
1985-2030\end{array}$ & & 154.78 & 188.22 & 193.94 \\
\hline $\begin{array}{l}\text { Short-Run Producers' } \\
\text { Surplus in Northeastern } \\
\text { Hardwood Lumber Markets } \\
\text { Point estimates of future } \\
\text { value in }\end{array}$ & $\begin{array}{l}\text { Billion } \\
1984 \text { dollars }\end{array}$ & & & \\
\hline $\begin{array}{r}2000 \\
2015 \\
2030 \\
\end{array}$ & & $\begin{array}{l}0.66 \\
0.94 \\
1.34\end{array}$ & $\begin{array}{l}0.66 \\
0.94 \\
1.34\end{array}$ & $\begin{array}{l}0.67 \\
0.97 \\
1.40\end{array}$ \\
\hline $\begin{array}{l}\text { Cumulatije net present } \\
\text { value, }(c) \\
1985-2030\end{array}$ & & 7.82 & 7.80 & 7.96 \\
\hline $\begin{array}{l}\text { Short-Run Producers' } \\
\text { Surplus in Southeastern } \\
\text { Hardwood Lumber Markets } \\
\text { Point estimates of future } \\
\text { value in }\end{array}$ & $\begin{array}{l}8 \text { illion } \\
1984 \text { dollars }\end{array}$ & & & \\
\hline $\begin{array}{r}2000 \\
2015 \\
2030 \\
\end{array}$ & & $\begin{array}{l}0.90 \\
1.23 \\
1.61\end{array}$ & $\begin{array}{l}0.90 \\
1.24 \\
1.63\end{array}$ & $\begin{array}{l}0.90 \\
1.26 \\
1.67\end{array}$ \\
\hline $\begin{array}{l}\text { Cumulaticye net present } \\
\text { value, }(c) \\
1985-2030\end{array}$ & & 10.38 & 10.44 & 10.51 \\
\hline & & & & \\
\hline
\end{tabular}


TABLE C.2. Simulated Effects of Various Scenarios on Growing Stock

Inventories, Harvests, Stumpage Prices, Lumber and

Plywood Production, Lumber and Prywood Consumption, the Wholesale Price Indices of Lumber and Plywood, and Economic Surpluses

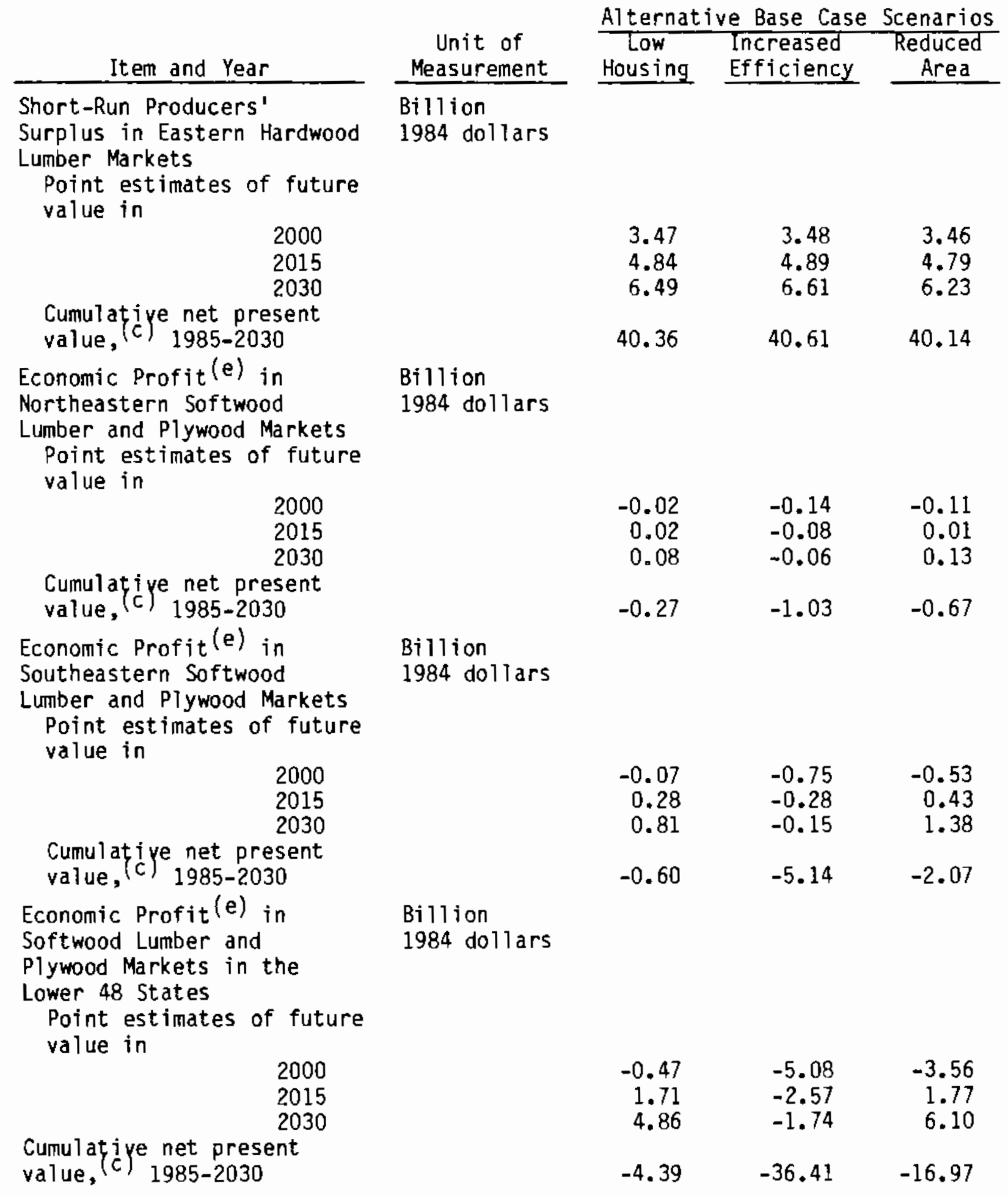


TABLE C.2. Simulated Effects of Various Scenarios on Growing Stock Inventories, Harvests, Stumpage Prices, Lumber and Plywood Production, Lumber and Plywood Consumption, the Wholesale Price Indices of Lumber and Plywood, and Economic Surpluses 
TABLE C.2. Simulated Effects of Various Scenarios on Growing Stock Inventories, Harvests, Stumpage Prices, Lumber and Plywood Production, Lumber and Plywood Consumption, the Wholesale Price Indices of Lumber and PTywood, and Economic Surpluses

\begin{tabular}{|c|c|c|c|c|}
\hline Item and Year & $\begin{array}{l}\text { Unit of } \\
\text { Measurement }\end{array}$ & $\begin{array}{l}\frac{\text { Alternat }}{\text { Low }} \\
\text { Housing }\end{array}$ & $\begin{array}{l}\text { ve Base Case } \\
\text { Increased } \\
\text { Efficiency } \\
\end{array}$ & $\begin{array}{l}\frac{\text { Scenarios }}{\text { Reduced }} \\
\text { Area } \\
\end{array}$ \\
\hline $\begin{array}{l}\text { Producers' Surplus in } \\
\text { Southeastern Softwood and } \\
\text { Hardwood Stumpage Markets } \\
\text { Point estimates of future } \\
\text { value in }\end{array}$ & $\begin{array}{l}\text { Billion } \\
1984 \text { dollars }\end{array}$ & & & \\
\hline $\begin{array}{r}2000 \\
2015 \\
2030\end{array}$ & & $\begin{array}{l}0.63 \\
1.12 \\
1.70\end{array}$ & $\begin{array}{l}0.80 \\
1.17 \\
1.54\end{array}$ & $\begin{array}{l}0.99 \\
1.77 \\
2.47\end{array}$ \\
\hline $\begin{array}{l}\text { Cumulatije net present } \\
\text { value, }\end{array}$ & & 7.98 & 8.62 & 11.49 \\
\hline $\begin{array}{l}\text { Producers' Surplus in } \\
\text { Softwood and Hardwood } \\
\text { St umpage Markets in the } \\
\text { Lower } 48 \text { States } \\
\text { Point estimates of future } \\
\text { values in }\end{array}$ & $\begin{array}{l}\text { Billion } \\
1984 \text { dollars }\end{array}$ & & & \\
\hline $\begin{array}{r}2000 \\
2015 \\
2030\end{array}$ & & $\begin{array}{l}2.86 \\
4.49 \\
6.82\end{array}$ & $\begin{array}{l}3.72 \\
4.44 \\
5.81\end{array}$ & $\begin{array}{l}4.63 \\
6.72 \\
8.77\end{array}$ \\
\hline $\begin{array}{l}\text { Cumulatijye net present } \\
\text { value, }(c){ }_{1985-2030}\end{array}$ & & 35.09 & 39.08 & 51.83 \\
\hline $\begin{array}{l}\text { Future value of the } \\
\text { Softwood and Hardwood } \\
\text { Growing Stock Inventory } \\
\text { Remaining in } 2030\end{array}$ & $\begin{array}{l}\text { Billion } \\
1984 \text { dollars }\end{array}$ & & & \\
\hline $\begin{array}{ll} & \text { Northeast } \\
\text { Southeast } \\
\text { Lower } 48 \text { State }\end{array}$ & & $\begin{array}{r}77.75 \\
107.50 \\
396.56\end{array}$ & $\begin{array}{r}84.89 \\
115.92 \\
394.99\end{array}$ & $\begin{array}{r}80.45 \\
126.46 \\
430.00\end{array}$ \\
\hline
\end{tabular}


Notes

(a) This stumpage price is the average price of sawtimber, pulpwood, and fuelwood stumpage harvested.

(b) This stumpage price is the price of sawtimber harvested.

(c) Discount rate is $10 \%$ per year.

(d) Short-run producers' surplus in softwood lumber and plywood markets in the Northeast and North Central regions are not available.

(e) The estimates of economic profit for any given scenario contain errors. The errors do not, however, affect comparative analyses because the errors cancel out (see Section B.4). 
.

$-$ 


\section{DISTRIBUTION}

No. of

Copies

OFFSITE

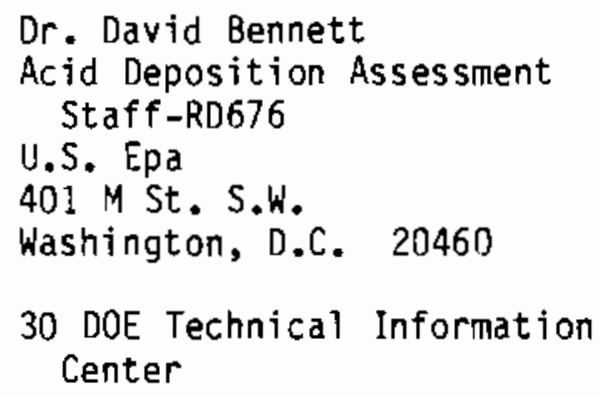

No. of

Copies

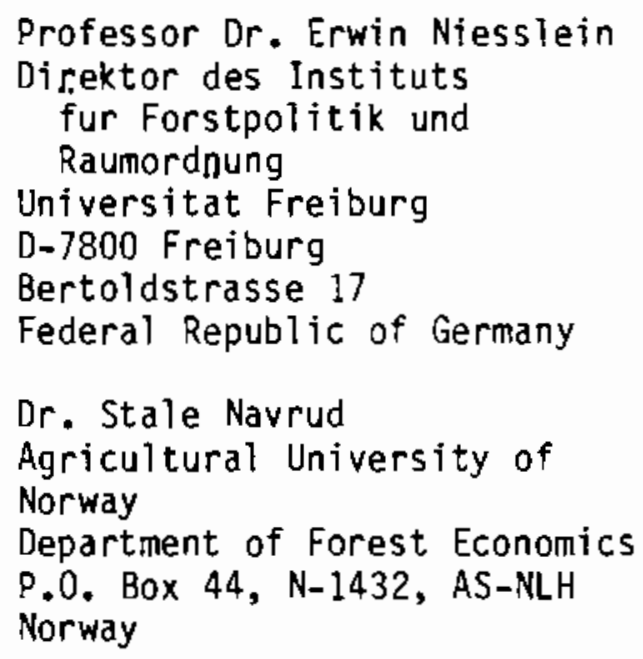


No. of

Copies

ONSITE

OOE-Richland Operations Office

J. J. Sutey

36 Pacific Northwest Laboratory

R. C. Adams

J. M. Call away (5)

J. W. Currie

R. F. Darwin (8)

H. Harly

R. J. Moe

R. J. Nesse (8)

Economics Library (5)

Publishing Coordination MH (2)

Technical Information (5) 